PLINIO RILLO CARRARO

\begin{abstract}
AVALIAÇÃO DA INFLUÊNCIA DE ASPECTOS LOGÍSTICOS, FISCAIS E AMBIENTAIS NO PROJETO DE REDES DE DISTRIBUIÇÃO FISICA
\end{abstract}

\author{
Dissertação apresentada à Escola \\ Politécnica da Universidade de São \\ Paulo para obtenção do Título de \\ Mestre em Engenharia de Sistemas \\ Logísticos
}

São Paulo

2009 
PLINIO RILLO CARRARO

\title{
AVALIAÇÃO DA INFLUÊNCIA DE ASPECTOS LOGÍSTICOS, FISCAIS E AMBIENTAIS NO PROJETO DE REDES DE DISTRIBUIÇÃO FISICA
}

\author{
Dissertação apresentada à Escola \\ Politécnica da Universidade de São \\ Paulo para obtenção do Título de \\ Mestre em Engenharia de Sistemas \\ Logísticos
}

Área de Concentração:

Engenharia de Sistemas Logísticos

Orientador: Prof. Livre-Docente

Hugo Tsugunobu Yoshida Yoshizaki

\section{São Paulo}




\section{DEDICATÓRIA}

À minha família e amigos, pelo apoio e suporte durante as longas horas de trabalho e dedicação. 


\section{AGRADECIMENTOS}

À minha família, pelo apoio e aconselhamento incessante durante todo o período de minha formação.

À Taty, pela ajuda incansável, compreensão e apoio nos momentos difíceis.

Ao professor e orientador Hugo Yoshizaki, pelos ensinamentos, dedicação e paciência durante os três anos de mestrado.

Ao professor Nicolau Gualda, pela oportunidade, apoio e dedicação durante a elaboração desta dissertação.

Ao Luiz Freitas, pela ajuda no processo de modelagem em GAMS e pelas habilidades em Excel que tornaram o processo de análise de cenários muito mais veloz e precisa.

Ao amigo Raphael Cyjon, pela ajuda na coleta e devolução de livros utilizados como referência ao longo desta dissertação.

A todos os amigos pelo apoio e compreensão durante os árduos finais de semana de trabalho e dedicação.

Aos meus chefes, que me apoiaram durante o programa e permitiram a minha presença em sala de aula.

A todos que direta ou indiretamente colaboraram com a elaboração desta dissertação. 


\section{RESUMO}

Este estudo tem como objetivo analisar os trade-offs existentes entre os custos logísticos, os incentivos fiscais baseados no ICMS e o custo da neutralização das emissões de carbono geradas nos problemas de localização de Fábricas e Centros de Distribuição.

Para isso, elaborou-se um modelo de programação linear inteira mista (PLIM) em GAMS, capaz de determinar o menor custo total de um problema, através da otimização de sua função objetivo composta pelos custos fixos e variáveis dos centros de distribuição e fábricas, custos de transporte (frete de transferência e distribuição), benefícios fiscais e custos ambientais. O modelo foi elaborado de modo a possuir flexibilidade suficiente para simular os diversos cenários que se fizeram necessários durante as análises.

Utilizando-se deste modelo, foram avaliados diversos cenários com base em dados reais de uma empresa de bens de consumo não duráveis. Alguns desses cenários estudados mostraram algumas distorções causadas pela existência de incentivos fiscais em alguns Estados brasileiros, mostrando como a guerra fiscal no País pode influenciar decisões estratégicas de negócio.

A partir dos resultados obtidos, concluiu-se que o benefício fiscal associado ao crédito presumido de ICMS tem impacto significativo nas decisões de localização, reduzindo de forma relevante os custos totais.

Já os custos ambientais, relacionados a neutralização das emissões de carbono, apesar de serem importantes nas decisões de empresas social e ambientalmente responsáveis, possuem peso econômico desprezível e não alteram o resultado da análise. Isso mostra que a política fiscal brasileira gera um aumento da emissão de poluentes na atmosfera e um aumento do desgaste e do fluxo de veículos de transporte pelas rodovias do País.

Palavras Chave: Logística, Projeto de Rede, Impostos, ICMS, Carbono. 


\begin{abstract}
The main object of this work piece is to analyze existing trade-offs among logistic costs, tax incentives based on ICMS and carbon emission volume variations, to be able to define how these factors influence the network localization of Plants and Distribution Centers.
\end{abstract}

To achieve this objective, a Mixed Integer Linear Programming model was developed in GAMS. The model is able to determine the minimum total cost for a given problem through the optimization of a specific objective function. The components of the objective function are: storage costs, transportation costs (transference and distribution freights), operational fixed costs and tax incentives. The model was designed to have enough flexibility to simulate multiple scenarios required to carry out the analysis.

Several logistics configurations were examined using this model. All of the scenarios were established based on real data provided by a consumer goods industry. Nevertheless, some of the studied network configurations are distortions caused by existing tax incentives in some Brazilian states, showing how the "fiscal war" can influence strategic business decisions.

Based on the results, one concludes that the tax benefits associated to the ICMS discounts applied in some Brazilian states actually have significant impact in the location decisions because it cuts down a relevant portion of the operational costs, whereas the carbon credits do not change the chosen network configuration, once it has shown a limited potential for financial benefit.

The carbon emissions reduction is, in the other hand, an important aspect of the decisions making in social and environmental responsible companies as it can modify the image of the institution and the way it is perceived by the market.

Key words: Logistics. Supply Chain. Network Modeling. Taxes. ICMS. Carbon 


\section{LISTA DE FIGURAS}

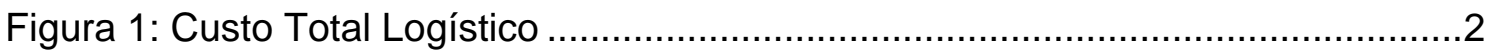

Figura 2: Composição do Custo Logístico no Brasil e nos Estados Unidos ..................

Figura 3: Representação de uma Cadeia de Suprimentos.........................................

Figura 4: Impacto da Introdução de um Estágio na Cadeia de Suprimentos ................8

Figura 5: Planejamento Logístico Hierárquico para Tomada de Decisão .....................9

Figura 6: Estrutura de Créditos e Débitos de ICMS …….......................................16

Figura 7: Fluxo da Cadeia com ICMS (SP-SP-RS) ……….................................16

Figura 8: Fluxo da Cadeia com ICMS (SP-PR-RS) ...............................................17

Figura 9: Posicionamento dos Países sobre o Protocolo de Kyoto.............................28

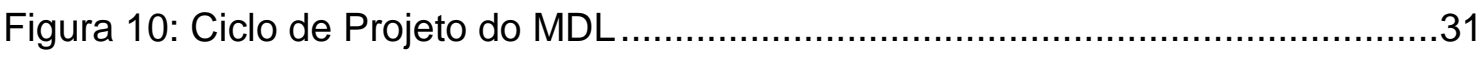

Figura 11: Situação dos Projetos do MDL no Brasil em 2008 ...................................31

Figura 12: Preços de Projetos em 05/06 (Dólar por Tonelada de $\mathrm{CO}_{2} \mathrm{e}$ ) ...................34

Figura 13: Entidades Associadas à Bolsa do Clima de Chicago (CCX).....................35

Figura 14: Acompanhamento das Cotações de CFI para 2008 ...................................36

Figura 15: Acompanhamento das Cotações de CFI para 2009 ..................................36

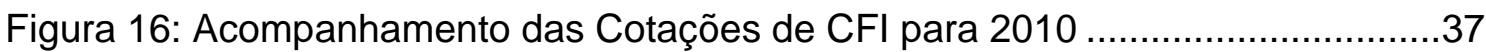

Figura 17: Volume Anual de Transações no Mercado de Certificação de Projetos...38

Figura 18: Compradores no Mercado Primário de Certificação de Projetos ................39

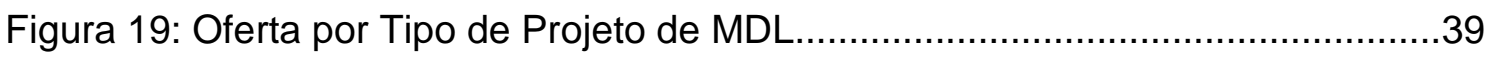

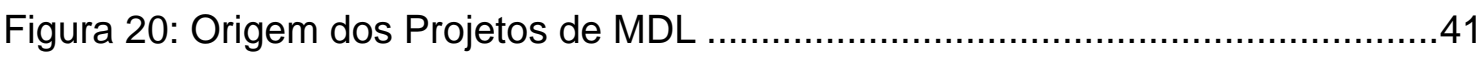

Figura 21: Distribuição dos Locais Candidatos para Abertura de Fábricas ...............60

Figura 22: Distribuição dos Locais Candidatos para Abertura de CDs ......................61

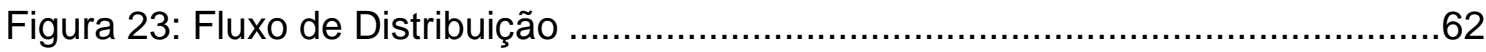

Figura 24: Distribuição da Demanda do Produto GO ……………………….........64

Figura 25: Distribuição da Demanda do Produto MG ..............................................64

Figura 26: Distribuição da Demanda do Produto SP ...............................................64

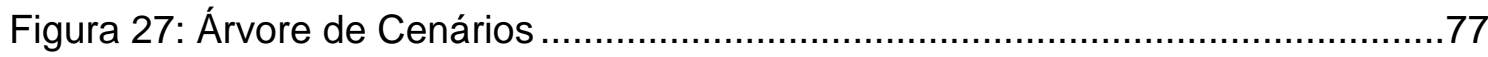

Figura 28: Custo Total do Cenário Base............................................................

Figura 29: Comparação de Custos entre Cenários 1 e Cenário Silva (2007) .............80

Figura 30: Fluxo de Distribuição do Cenário 1 .....................................................

Figura 31: Custo Total do Cenário 1 vs. Cenário Fiscal GO .....................................83 
Figura 32: Fluxo de Distribuição do Cenário Fiscal GO .............................................84

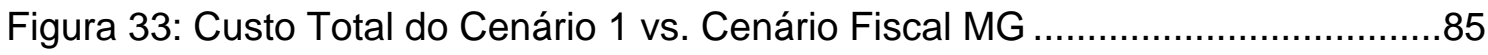

Figura 34: Fluxo de Distribuição do Cenário Fiscal MG ..........................................

Figura 35: Custo Total do Cenário 1 vs. Cenário Fiscal GO e MG ……...................87

Figura 36: Fluxo de Distribuição do Cenário Fiscal Simultâneo ................................88

Figura 37: Custo Total dos Cenários com Benefício Fiscal ......................................

Figura 38: Comparativo de Custo Total dos Cenários com Benefício Fiscal .............89

Figura 39: Comparativo de Custo Logístico dos Cenários com Benefício Fiscal.......90

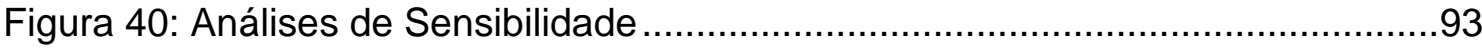

Figura 41: Variação do Fluxo de Distribuição - Análise de Variação na Margem .....97

Figura 42: Variação do Fluxo de Distribuição - Análise do Preço do Carbono .......100

Figura 43: Fluxo de Distribuição do Cenário com Matéria-Prima maior que 20\% ...103

Figura 44: Fluxo de Distribuição do Cenário com Nível de Serviço "AAA"...............106

Figura 45: Fluxo de Distribuição do Cenário com Nível de Serviço "AAA" + "AA" ...107

Figura 46: Custo Total dos Cenários com Restrição de Nível de Serviço.................108

Figura 47: Custo Total e Benefício Fiscal com Restrição de Nível de Serviço ........108

Figura 48: Custo Total e Benefício Fiscal do Cenário 4: Final ................................110 


\section{LISTA DE TABELAS}

Tabela 1: Comparativo de Cenários sob a Ótica Fiscal ..........................................18

Tabela 2: Comparativo dos Resultados Consolidados ...........................................19

Tabela 3: Créditos de Carbono por Tonelada de GEE Reduzida .............................29

Tabela 4: Mercado de Carbono, Valores e Volumes 2006 e 2007............................32

Tabela 5: Estimativa de Participação de Brasil no Mercado de MDL...........................41

Tabela 6: Participação de Brasil no Mercado de MDL em 2007 .................................41

Tabela 7: Síntese da Situação de MDL no Brasil em 2008 ....................................42

Tabela 8: Quadro Comparativo (Modelo de Silva (2007) vs. Modelo Desenvolvido).48

Tabela 9: Relação dos Locais Candidatos para Abertura de Fábricas .......................60

Tabela 10: Relação dos Locais Candidatos para Abertura de CDs ..........................61

Tabela 11: Lista dos Produtos Agrupados de Acordo com seu Processo Produtivo .63

Tabela 12: Parâmetros de Custo, Preço e Margem de Venda dos Produtos .............63

Tabela 13: Demanda dos Produtos (em toneladas) ................................................63

Tabela 14: Capacidade de Cada um dos Níveis de Fábrica ......................................65

Tabela 15: Capacidade de Cada um dos Níveis dos Centros de Distribuição............65

Tabela 16: Custo Variável nas Fábricas .............................................................6

Tabela 17: Custo Variável nos Centros de Distribuição …………………………....68

Tabela 18: Dias de Estoque presentes nas Fábricas ..............................................69

Tabela 19: Dias de Estoque presentes nos Centros de Distribuição .........................69

Tabela 20: Detalhamento dos Veículos de Transporte ...........................................72

Tabela 21: Fluxo de Transferência no Cenário 1 (em toneladas) ………………......79

Tabela 22: Fluxo de Transferência no Modelo de Silva (2007) (em toneladas)..........80

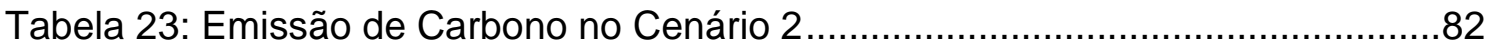

Tabela 24: Fluxo de Transferência no Cenário Fiscal MG (em toneladas) .................84

Tabela 25: Fluxo de Transferência no Cenário Fiscal GO (em toneladas) .................85

Tabela 26: Fluxo de Transferência no Cenário Fiscal MG e GO (em toneladas) ......87

Tabela 27: Quadro resumo dos cenários analisados ................................................

Tabela 28: Quadro Resumo dos Preços de Transferência Utilizados na Análise......94

Tabela 29: Quadro Resumo dos Preços de Venda Utilizados na Análise ..................94

Tabela 30: Resumo da Análise de Sensibilidade dos Preços. (em R\$ milhões) .......95

Tabela 31: Resumo dos Preços de Venda Utilizados na Análise de Margem ............96 
Tabela 32: Resumo dos Custos Totais - Análise de Margem. (em R \$ milhões)........97

Tabela 33: Resumo das Configurações Logísticas - Análise de Margem ...................98

Tabela 34: Resumo da Análise dos Preços do Carbono. (em $\mathrm{R} \$$ milhões) .................99

Tabela 35: Fluxo de Transferência no Cenário 1 - Análise de Preço do Carbono ....99

Tabela 36: Resumo dos Custos (Variação do Percentual de Fornecimento) ...........101

Tabela 37: Fluxo de Transferência (Variação do Percentual de Fornecimento) ......102

Tabela 38: Quadro Resumo dos Custos (Variação da Demanda) ...........................104

Tabela 39: Fluxo de Transferência (Variação da Demanda)......................................104

Tabela 40: Fluxo de Transferência (Nível de Serviço "AAA") ...................................105

Tabela 41: Fluxo de Transferência (Nível de Serviço "AAA" + "AA") .........................106

Tabela 42: Comparativo das Emissão de $\mathrm{CO}_{2}$ entre Cenário 1 e 4 .......................111 


\section{SUMÁRIO}

1 INTRODUÇÃO

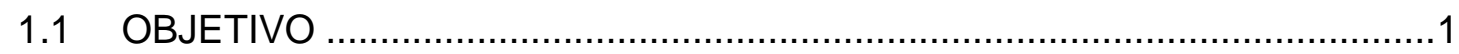

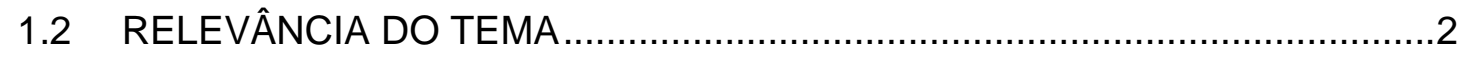

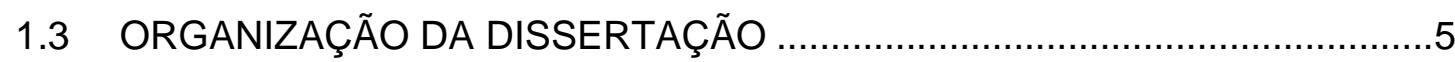

2 REVISÃO DA LITERATURA E CONCEITOS IMPORTANTES ..........................6

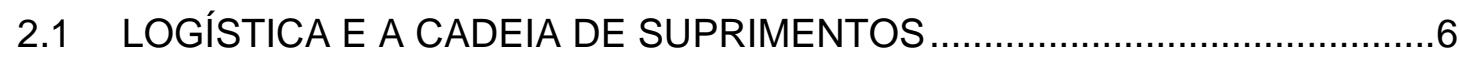

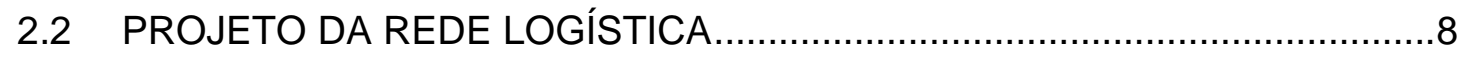

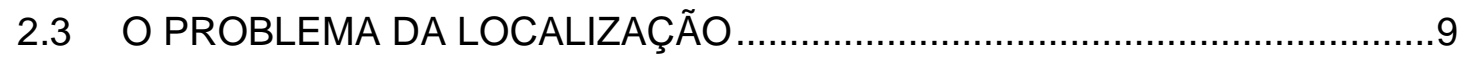

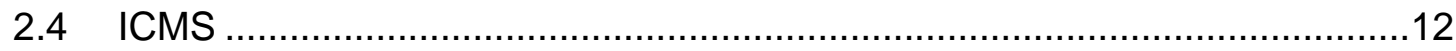

2.4.1 Incidência do ICMS ……….........................................................

2.4.2 Estrutura de Alíquotas ....................................................................14

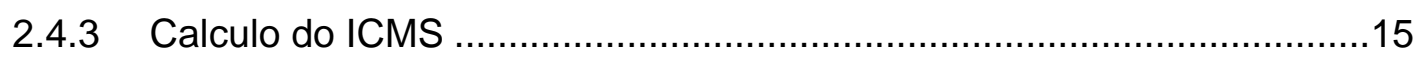

2.4.4 Impacto do ICMS nas redes de distribuição ........................................19

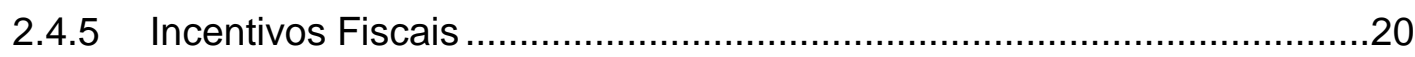

2.5 PROBLEMAS DE LOCALIZAÇÃO CONSIDERANDO IMPACTO FISCAL ..21

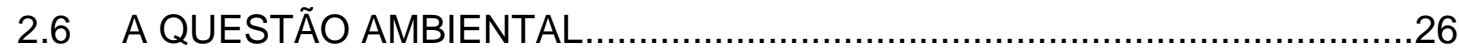

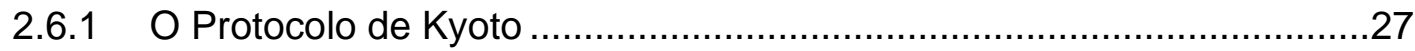

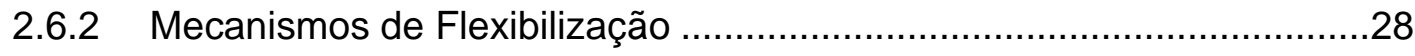

2.6.3 O Mercado de Carbono ....................................................................

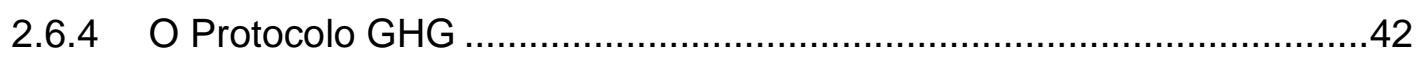

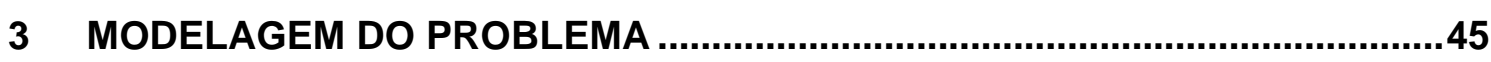

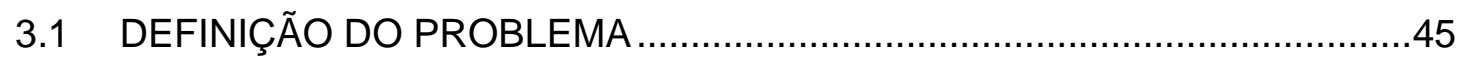

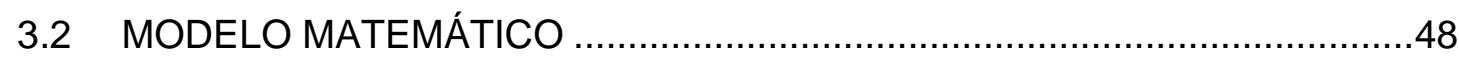

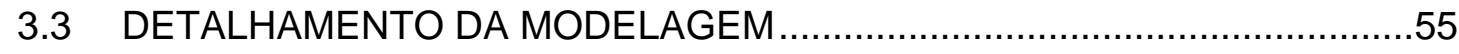

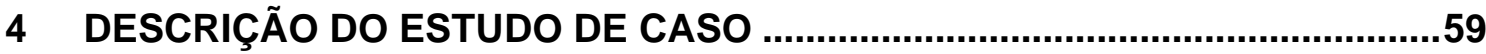

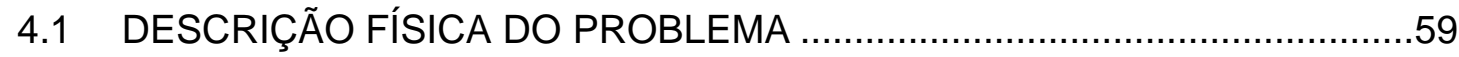

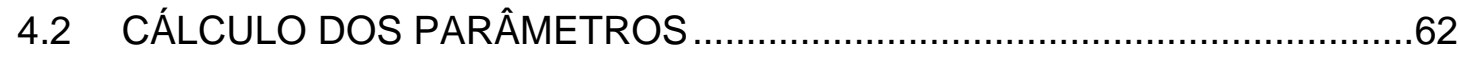

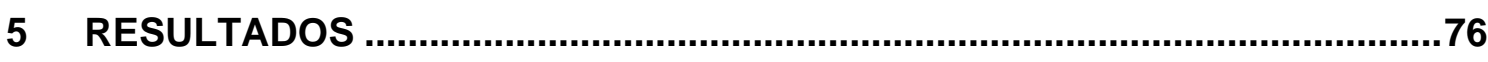

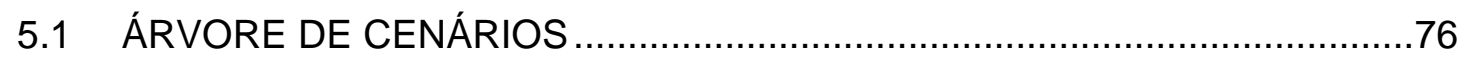

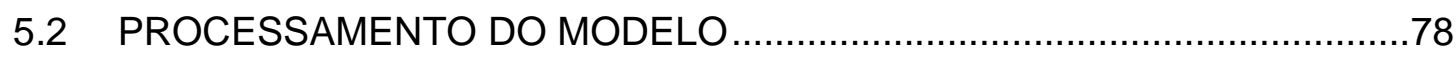

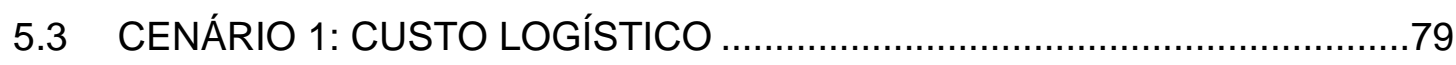




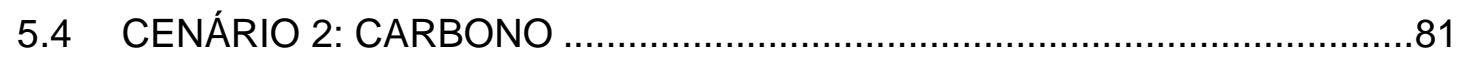

5.5 CENÁRIO 3.1: BENEFÍCIO FISCAL SOMENTE EM GO ……...................82

5.6 CENÁRIO 3.2: BENEFÍCIO FISCAL SOMENTE EM MG ………................84

5.7 CENÁRIO 3.3: BENEFÍCIO FISCAL SIMULTÂNEO EM GO E MG .............86

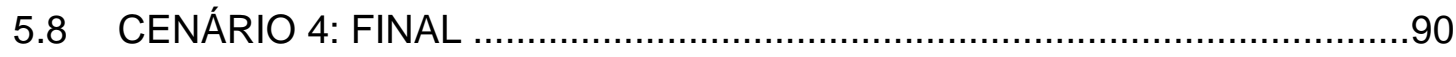

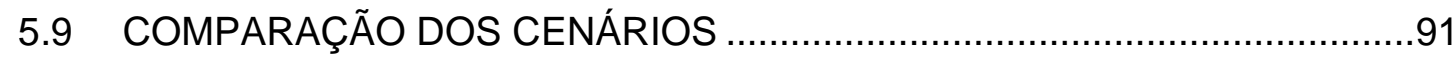

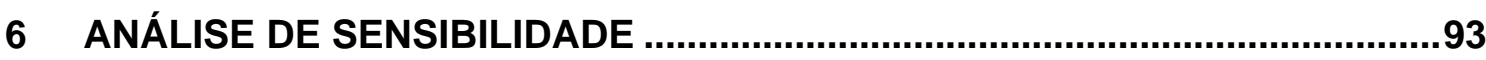

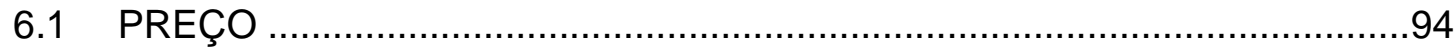

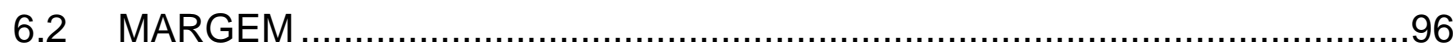

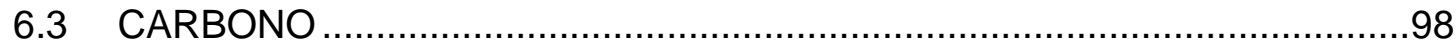

6.4 FORNECIMENTO DE MATÉRIA-PRIMA …...............................................100

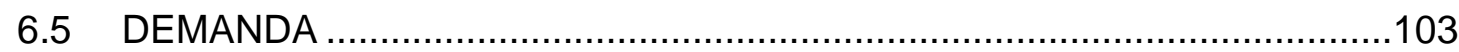

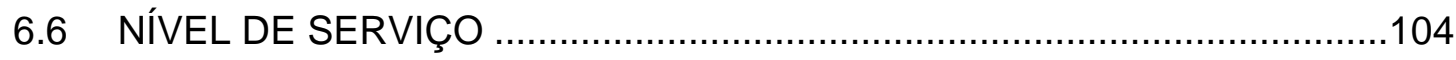

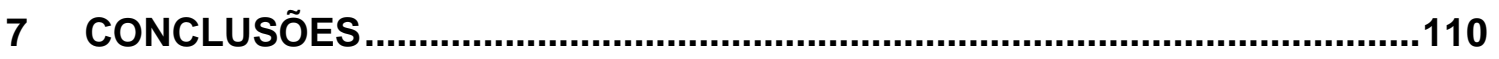




\section{INTRODUÇÃO}

O primeiro capítulo apresenta os objetivos do trabalho realizado, mostra a importância do tema em análise e explica a estrutura da dissertação.

\subsection{OBJETIVO}

Dois são os objetivos principais desta dissertação:

1. Avaliar o impacto dos benefícios fiscais na estratégia de localização de fábricas e centros de distribuição;

2. Verificar as alterações causadas nos cenários, pelo acréscimo de uma variável ambiental aos critérios de decisão.

Para atingir o primeiro objetivo, foi criado um modelo matemático que incorpora os trade-offs existentes na otimização logística e as políticas brasileiras de incentivo fiscal. O incentivo fiscal em análise é baseado no crédito presumido de ICMS, que é um percentual aplicado sobre o valor base das notas fiscais de venda.

O fator determinante para se chegar a uma conclusão definitiva sobre os impactos causados pelos incentivos fiscais ao projeto de malha é a adequação dos parâmetros do modelo (custos, distâncias, demandas, etc.) para a realidade dos negócios, utilizando-se dos mecanismos de estudo de caso. Nesta dissertação foi estudado o caso do projeto de rede para uma empresa de bens de consumo não duráveis, com atuação em todo o território nacional.

Por fim, acrescenta-se uma variável de decisão relativa ao custo de neutralização das emissões de carbono no modelo formulado e, assim, permite-se avaliar a questão ambiental na otimização da malha logística. Pretende-se, com isso, tornar o modelo mais aderente à realidade empresarial atual, que está cada vez mais consciente e atenta aos seus impactos sobre o meio-ambiente.

Desta forma, através de um modelo matemático adequado, pode-se avaliar o impacto de aspectos fiscais e ambientais nos projetos de rede conduzidos para empresas brasileiras. 


\subsection{RELEVÂNCIA DO TEMA}

Segundo Meirim (2006), as empresas brasileiras vivem atualmente um momento extremamente desafiador, caracterizado pela busca por maior competitividade, maior rentabilidade, melhor oferta de produtos e serviços e melhor posicionamento frente a seus concorrentes.

Segundo Hamad (2006), a competição não acontece mais entre produtos e empresas e, sim, entre cadeias de suprimento, sendo elas as verdadeiras responsáveis por grande parte do sucesso de uma empresa.

$\mathrm{Na}$ literatura tradicional (Novaes, 2004, p. 213 - 220), a composição do custo total logístico se dá através da soma dos custos de Estoque, Armazenagem, Compra e Transporte. Pode-se representar graficamente o custo total na soma das curvas apresentadas na Figura 1, onde se observa que o impacto fiscal é tipicamente desconsiderado na definição do custo mínimo (ponto de inflexão do custo total).

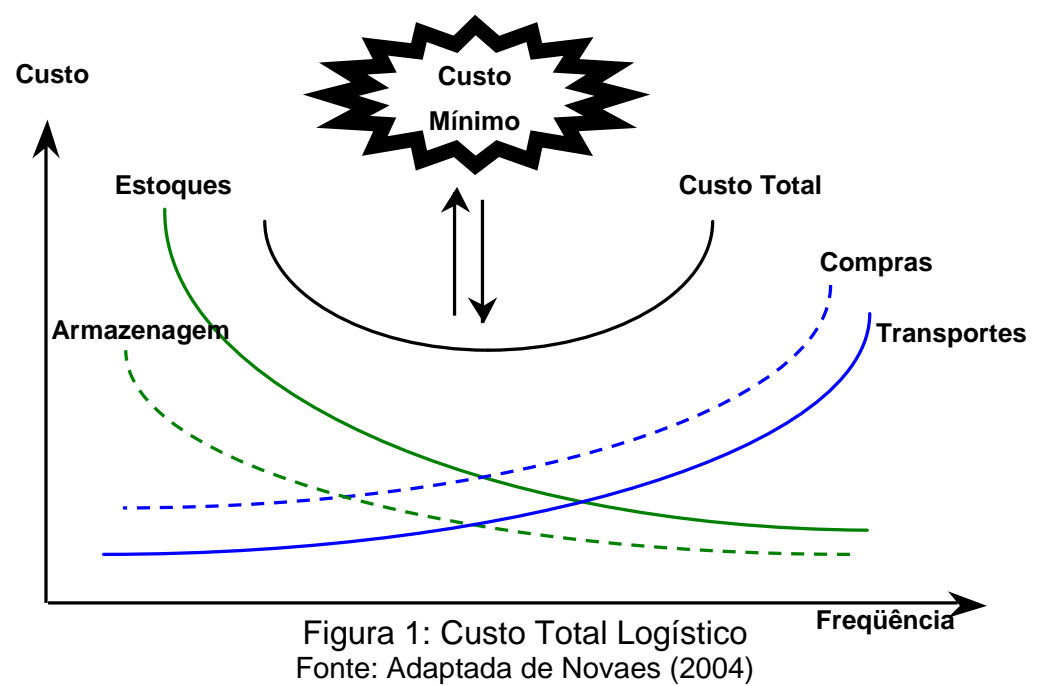

Segundo estudo da COPPEAD (Lima, M. P., 2006), a composição de todos os componentes de custos logísticos do Brasil, em 2004, chega a um total de R\$222 bilhões, o equivalente a $12,6 \%$ do PIB. Nos Estados Unidos, os custos logísticos (domésticos) equivalem a apenas $8,26 \%$ do PIB. Entre os componentes de custo, o de estoque é relativamente o que apresenta a maior diferença na comparação: 3,9\% no Brasil contra 2,1\% nos EUA. A outra parte da diferença é relativa ao custo de 
transporte: 5,0\% e 7,5\%, respectivamente. A Figura 2 apresenta o gráfico com esta comparação.

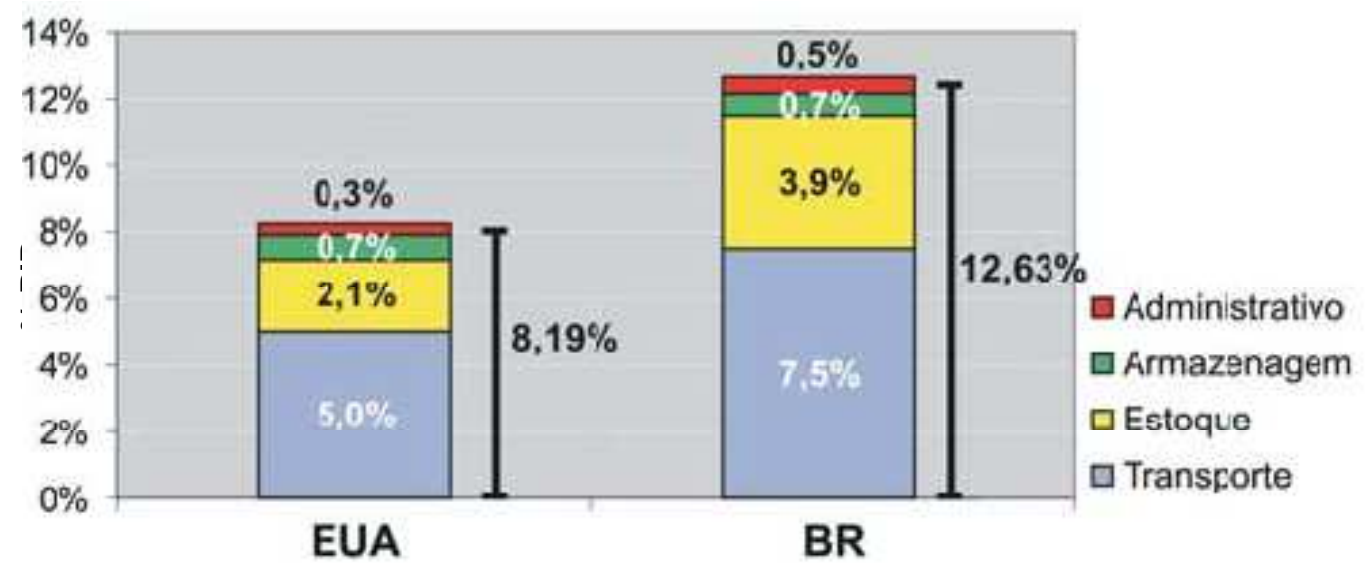

Figura 2: Composição do Custo Logístico no Brasil e nos Estados Unidos Fonte: COPPEAD (Lima, M. P., 2006)

Ainda segundo estudo da COPPEAD (Lima, M. P., 2006), devido à alta relevância das componentes de estoque e de transporte nos custos de disponibilização de produtos de uma indústria no seu mercado consumidor, a decisão da quantidade e localização dos seus principais pontos de infra-estrutura (fábricas, centros de distribuição, pontos de apoio, etc.) é estratégica. Além de estar diretamente relacionada à rentabilidade da operação, esta decisão será também fator determinante do nível de serviço que se pretende oferecer aos clientes.

O conceito fundamental da logística trata do entendimento do custo logístico total da empresa na busca pelo equilíbrio operacional, através da otimização conjunta dos componentes de custo. O cenário tributário e fiscal brasileiro acrescenta um componente adicional ao custo logístico total, que é o conjunto de impostos e incentivos fiscais incidentes nas transações interestaduais de compra e venda.

A carência de informações mais detalhadas sobre os custos logísticos e tributários no Brasil torna frequente a utilização de modelos matemáticos simplificados. $O$ grande problema é que esses modelos não representam necessariamente a nossa atual realidade, tornando difícil a comparação deste modelo com as decisões de gestão tomadas por diversas empresas. A parcela de custo tributário vem sendo analisada por diversos autores brasileiros como Yoshizaki (2002) e Silva (2007) e 
incorporada à decisão dos empresários sobre o modelo de distribuição de suas empresas. Ainda que não exista muita literatura relacionada ao tema ou que as decisões de localização não sejam apenas relacionadas ao planejamento fiscal, diversas empresas já abriram, fecharam e transferiram de lugar suas Fábricas e Centros de Distribuição, além de mudarem completamente seus fluxos de transporte, levando em consideração os benefícios fiscais que poderiam capturar (Amaral,2004).

Apesar da Reforma Tributária proposta pelo Governo Federal estar em andamento, a mesma ainda deve demorar para ser aprovada e implantada, o que, por si só, já daria motivos para aprofundarmos o estudo fiscal relacionado à localização. Além disso, especula-se que os benefícios fiscais não serão completamente eliminados após a reforma tributária devido à existência de grandes diferenças econômicas no país, que impõem a alguns estados a necessidade de oferecer benefícios fiscais para atrair empresas e, consequentemente, gerar empregos e fomentar a economia local. Existe ainda a pressão de grandes corporações que já se estabeleceram em locais onde existe a incidência de benefícios fiscais e que, com uma mudança nesse cenário, tenderiam a abandonar suas instalações e se mover para estados mais competitivos e/ou mais próximos de sua demanda. Esta movimentação traria péssimas conseqüências à sociedade local, que teria sua economia fortemente afetada (Netto, 2003).

Além da influência dos benefícios fiscais, os fatores relacionados ao desenvolvimento sustentável tem sido pauta de discussões governamentais sobre maneiras de incentivar o crescimento econômico de locais mais distantes dos principais centros. O tema da mudança do clima e suas consequências nas atividades econômicas ocupam um espaço cada vez maior nas preocupações das sociedades. Por isso, um dos fatores de destaque na busca de um desenvolvimento sustentável é a redução da emissão de gases poluentes, especialmente aqueles ligados ao efeito estufa $\left(\mathrm{CO}_{2}, \mathrm{CH}_{4}, \mathrm{~N}_{2} \mathrm{O}, \mathrm{SF}_{6}, \mathrm{HFCs}\right.$ e PFCs), denominados GEE pelas Nações Unidas (UNFCC, 2001a).

Este estudo mostra a sua importância ao incorporar novas variáveis de custo e de impacto ambienteal num modelo matemático capaz de suportar a definição de estratégias logísticas das empresas. 


\subsection{ORGANIZAÇÃO DA DISSERTAÇÃO}

A dissertação de mestrado aqui apresentada está organizada em sete capítulos:

- Capítulo 1 - Introdução: Definição dos objetivos do trabalho, discussão sobre a importância do tema e apresentação da organização desta dissertação de mestrado.

- Capítulo 2 - Revisão da Literatura e Conceitos Importantes: Pesquisa realizada para suportar toda análise e modelagem posterior. Neste capítulo são apresentados os principais dados e conceitos aplicados nesta dissertação, além de alguns dos trabalhos e modelos já elaborados sobre o tema.

- Capítulo 3 - Modelagem do Problema: Descrição detalhada do modelo conceitual e matemático elaborado, definição da função objetivo, das restrições, das variáveis e dos parâmetros, além das premissas assumidas e especificidades da modelagem.

- Capítulo 4 - Descrição do Estudo de Caso: Detalhamento das características e parâmetros do estudo de caso, assim como das bases de dados utilizadas para composição dos custos envolvidos no modelo.

- Capítulo 5 - Resultados: Apresentação dos resultados obtidos em cada um dos cenários simulados, comparação e discussão sobre a composição dos resultados, considerando as principais variáveis de decisão.

- Capítulo 6 - Análise de Sensibilidade: Verificação do comportamento do modelo alterando-se forçosamente algumas das principais variáveis e parâmetros, de modo a determinar a coerência dos resultados obtidos.

- Capítulo 7 - Conclusões: Argumentação das conclusões obtidas com base no estudo realizado até o momento e apresentação de recomendações para estudos futuros relacionados ao tema dessa dissertação. 


\section{REVISÃO DA LITERATURA E CONCEITOS IMPORTANTES}

A revisão bibliográfica aborda e discute temas relevantes a esta dissertação: logística e cadeia de suprimentos, projetos de rede, problemas de localização, estrutura e cálculo do ICMS, problemas de localização considerando impacto fiscal e a questão ambiental relacionada aos gases do efeito estufa.

\subsection{LOGÍSTICA E A CADEIA DE SUPRIMENTOS}

A logística pode ser conceituada adotando-se diversas definições literárias. $\mathrm{Na}$ interpretação de Novaes (2004, p. 35), a definição de logística é bastante clara e objetiva:

"Logística é o processo de planejar, implementar e controlar de maneira eficiente o fluxo e a armazenagem de produtos, bem como os serviços e as informações associados, cobrindo desde o ponto de origem até o ponto de consumo, com o objetivo de atender aos requisitos do consumidor".

O importante desta definição é notar que a logística abrange não só a estrutura física que permite movimentar produtos e serviços, mas também todas as ações e decisões que a permeiam. Outro ponto relevante é que a logística tem como objetivo viabilizar o negócio de uma empresa, fazendo com que a sua oferta esteja disponível para o consumidor final.

Sendo assim, entende-se logística como a forma de conectar a empresa ao seu consumidor. Resta entender o que é a Cadeia de Suprimentos e como estes dois conceitos estão interligados. Chopra (2003, p. 3) define Cadeia de Suprimentos dizendo:

"Uma cadeia de suprimento engloba todos os estágios envolvidos, direta ou indiretamente, no atendimento de um pedido a um cliente. A cadeia de suprimentos não inclui apenas fabricantes e fornecedores, mas também transportadoras, depósitos, varejistas e os próprios clientes."

Com base nestas definições, verifica-se que a Cadeia de Suprimentos pode ser considerada como o conjunto de entidades ligadas à disponibilização ao mercado de um produto ou serviço e a Logística como a ferramenta que assegura o abastecimento de cada elo. 
Para ilustrar melhor este conceito, utiliza-se o modelo esquemático da Figura 3, adaptado de Shapiro (2001, p. 6), onde uma cadeia de suprimentos é representada por nós e arcos. Os nós representam as fábricas e centros de distribuição (ou estágios, segundo Chopra) e os arcos representam as conexões diretas de transportes permitidas na operação. A capacidade de fazer esta rede se conectar e garantir o fluxo de produtos por cada ponto da cadeia é responsabilidade da logística.

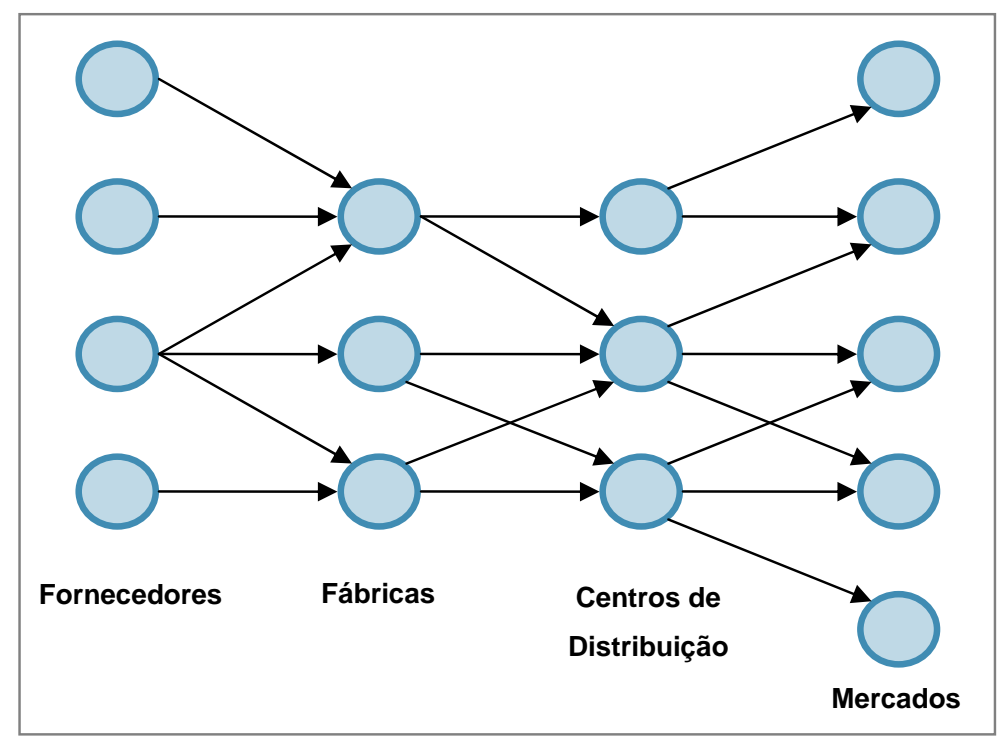

Figura 3: Representação de uma Cadeia de Suprimentos Fonte: Adaptado de Shapiro (2001)

A análise da cadeia de suprimentos pode ser tão complexa quanto maior a quantidade de elos, de tipos de instalações e pela combinação potencial de conexões entre estes elos (modais de transporte e rotas de atendimento da demanda, por exemplo). Tipicamente, são feitas distinções entre as instalações do tipo fábrica, que são capazes de consolidar materiais e transformá-los em um novo produto e centros de distribuição ou armazéns, que são onde estes produtos são recebidos, organizados, guardados, separados na preparação do pedido e finalmente despachados (Shapiro, 2001).

Na Figura 4, Slack (1996, p.420), mostra que a inserção de armazéns na cadeia de suprimentos pode simplificar as operações de distribuição e reduzir drasticamente o número de conexões existentes entre os elos. 


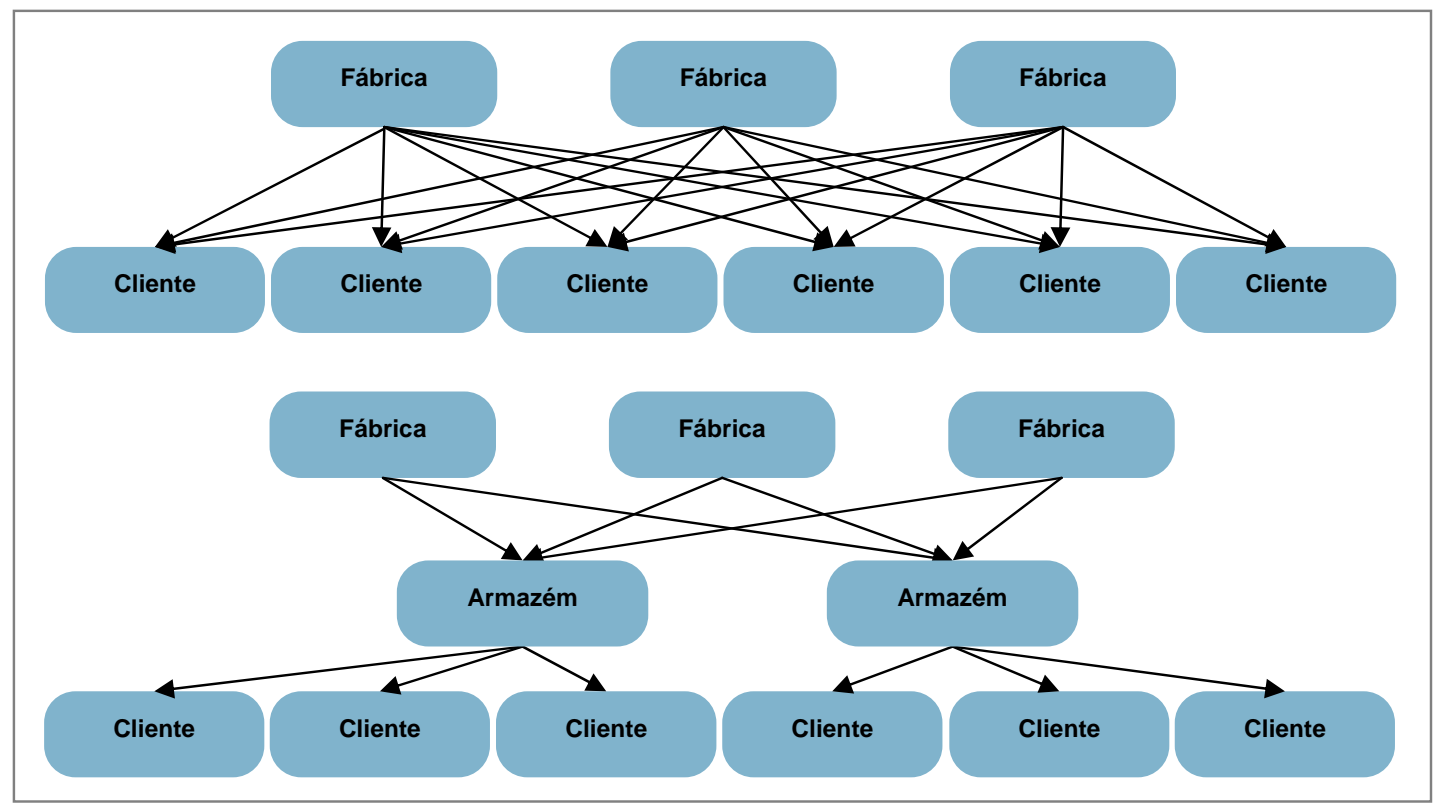

Figura 4: Impacto da Introdução de um Estágio na Cadeia de Suprimentos Fonte: Adaptado de Slack (1996, p.420)

A seguir analisa-se em mais detalhe o tema dos projetos de rede e em especial o problema da localização dentro da realização de um projeto.

\subsection{PROJETO DA REDE LOGÍSTICA}

Segundo Ballou (2006), a modificação ou a aquisição de uma instalação é, em sua maioria, um projeto de alto custo e deve ser colocado em prática no tempo certo, para acompanhar o crescimento projetado da empresa e suportar a demanda dos clientes. Antes de criar um novo elo em sua cadeia de suprimentos, uma empresa deve identificar quais são os locais candidatos, determinar as especificações de capacidade (que pode já ter um aumento previsto para o período de uso da instalação) e provisionar capital para o investimento necessário.

Por normalmente apresentarem um alto custo de realização, os projetos de rede são colocados no topo do processo de hierarquização do planejamento logístico e, por suportarem decisões de longo prazo, estes projetos são bastante diferentes de outros problemas de planejamento logístico. Diferenciam-se tanto pela baixa frequência com que são realizados, quanto pelo alto grau de agregação da 
informação usada no processo de planejamento, como pode ser observado na Figura 5, adaptada de Ballou (2006, p.507).

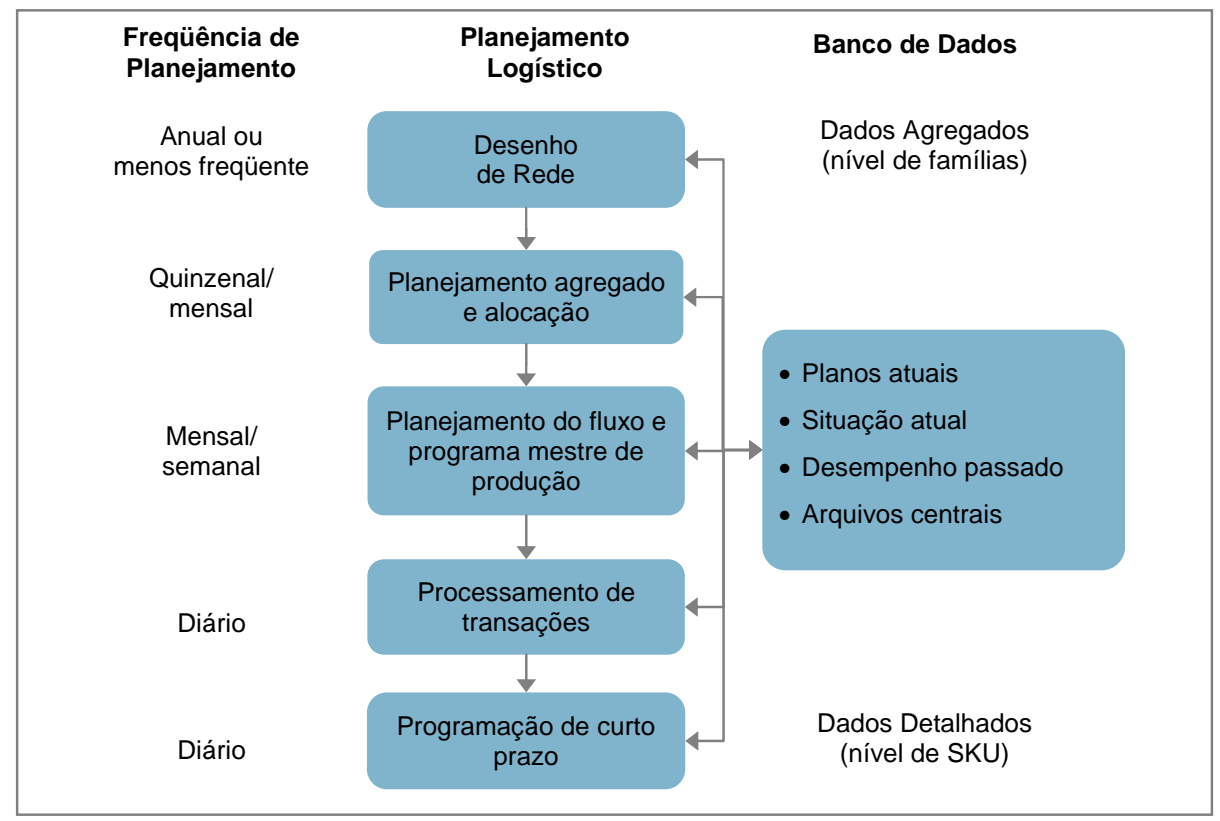

Figura 5: Planejamento Logístico Hierárquico para Tomada de Decisão Fonte: Adaptado de Ballou (2006, p.507)

Ainda segundo Ballou (2006), o problema da localização e da quantidade de instalações a serem operadas pela empresa, são os principais resultados a serem atingidos em projetos de rede. Para tanto, são desenvolvidos modelos matemáticos que simulam e otimizam os fluxos da rede, permitindo calcular os melhores cenários com base no objetivo de minimizar custos ou de maximizar receita.

\subsection{O PROBLEMA DA LOCALIZAÇÃO}

De acordo com Ballou (2006), a teoria de localização data do início do século XIX e foi iniciada por economistas rurais e geógrafos regionais que tinham como objetivo reduzir a distância percorrida entre armazéns e seus cliente. Atualmente existem diversos trabalhos associados ao tema que refletem sua evolução, como: Brandeau; Chiu (1989), Crainic; Laporte (1996), Owen; Daskin (1998), Martos (2000, Cap.3), Yoshizaki (2002), Vallim (2004), Klose; Drexl (2005), Hamad (2006) e Silva (2007). 
Segundo Vallim (2004), a utilização de modelos de Programação Linear Inteira Mista (PLIM) ainda corresponde à maioria dos modelos criados para localização de instalações, apesar da complexidade computacional associada. Porém, o autor estima que essa participação dos modelos de PLIM esteja diminuindo devido ao recente crescimento e aprimoramento de pesquisas relacionadas a heurística e metaheuristica, entre as quais podemos citar: colônia de formigas, busca tabu e redes neurais, o que permite solucionar modelos de maior complexidade (porte).

Hamad (2006) afirma que o problema da localização é e sempre será um dos desafios mais complexos na arte de gerenciamento de uma cadeia de suprimentos. Comenta ainda que o acréscimo de variáves aumenta a complexidade computacional do modelo e o torna difícil de ser solucionado sem a aplicação de métodos adequados.

Owen; Daskin (1998), declararam que diversas funções objetivo e formulações foram criadas nos últimos anos para tornar o problema da localização mais simples de ser solucionado. Entretanto, os modelos formulados são muito complicados de serem otimizados e são, em sua maioria, classificados como de difícil solução (NP-Hard).

Ainda segundo Owen; Daskin (1998), a dificuldade de se alcançar uma solução faz com que a maioria desses problemas sejam modelados de maneira determinística, não sendo capazes de representar as incertezas inerentes às decisões estratégicas do mundo real.

Analisando as recomendações de Ballou (2006) e Shapiro (2001), observa-se que o estudo da localização deve incluir os seguintes componentes de custo:

- Custo de aquisição de matéria-prima e outros componentes

- Custo de investimento dos "sites" e localizações definidas

- Custos de produção (diretos e indiretos)

- Custos de estocagem e manuseio nos armazéns (centros de distribuição)

- Custos fixos das instalações (fábricas e armazéns)

- Custos de manutenção do estoque

- Custos de processamento dos pedidos (de estoque e de clientes)

- Custos de transporte entre sites 
Slack (1996), considera que devido ao fato da gestão da cadeia de suprimentos contemplar todos os estágios do fluxo de materiais e informações, o mesmo deve considerar o cliente como o único que tem a moeda "real" em toda a cadeia, pois é o cliente quem dispara uma compra e faz com que toda a cadeia se movimente. Em linha com este conceito, Shapiro (2001) também ressalta que muitos modelos e empresas, ao fazerem a análise de suas cadeias de distribuição, levam em consideração aspectos como o nível de serviço prestado e a qualidade dos seus produtos. É bem verdade que se cria, no entanto, mais um trade-off que deve ser considerado e mais um ponto que deve ser balanceado pelos modelos: quanto maior o nível de serviço que se espera oferecer, tão maior será o custo associado à disponibilidade de produtos no mercado.

Um tipo de dado, tem impacto especialmente sensível na modelagem: o conjunto de distâncias entre os locais candidatos para instalação dos elos da cadeia e entre estes elos e o mercado consumidor. Na maioria dos problemas práticos de localização que envolvem áreas geográficas de amplidão significativa, as aproximações de distância por rodovias são razoáveis, uma vez que a resposta esperada será a região onde deve-se instalar uma nova localidade. Nos casos em que se analisa um problema de localização de malhas em áreas pequenas, todas as estimativas (principalmente aquelas ligadas às distâncias) devem utilizar dados reais, uma vez que pequenas distorções nos dados de entrada irão fatalmente gerar resultados poucos confiáveis (Ballou, 2006 p. 434-466).

As medições de distância envolvidas em problemas de localização de são um elemento importante na formulação de modelos analíticos. Estas medições podem ser divididas em três categorias (Tompkins, 1996, p. 534-535):

- Distâncias Lineares: medidas ao longo de caminhos ortogonais, ou perpendiculares.

- Distâncias Euclidianas: medidas ao longo de uma linha reta entre dois pontos.

- Distâncias Reais: medidas ao longo do percurso de rodovia real entre dois pontos. 
Outro tipo de dado importante para que o resultado final dos estudos de localização reflita a realidade é a estimativa da demanda. Segundo Ballou (2006 p. 434-466), faz pouco sentido planejar uma rede de distribuição com base em dados de demandas passadas ou atuais, uma vez que as instalações estão sendo planejadas para operar por um prazo relativamente longo e que mudanças de infra-estrutura dificilmente ocorrem com frequência. Daskin e Owen (1998) complementam:

\begin{abstract}
"[as decisões de localização] são necessariamente decisões de longo prazo tomadas pelas empresas, por isso tais decisões não devem ser tomadas com base em fatores momentâneos e relacionados a operação atual, mas sim com base no estudo de longo prazo da empresa levando em consideração fatores como crescimento e migração da população, tendências de mercado, concorrência, infra-estrutura da região, entre outros."
\end{abstract}

O problema da localização pode ser resolvido em diversos níveis de detalhe. Neste estudo, será tratado o problema da macro-localização de instalações resultando na recomendação, por exemplo, da abertura de um novo centro de distribuição em uma determinada região, tal como a Grande São Paulo, as cercanias de Belo Horizonte, etc. Um outro estudo de micro-localização poderia tratar do detalhamento refinado da localização desta instalação, resultando na recomendação de que tal centro seja localizado próximo ao Rodoanel, devido à proximidade com as principais rodovias e às restrições de tráfego existentes na cidade de São Paulo.

Tentar alcançar a micro-localização sem realização de um trabalho preliminar de localização torna a modelagem muito mais complexa, sendo necessária uma base de dados ainda mais refinada e um maior número de potenciais localizações para cobrir toda a abrangência da análise. Por isso, uma boa seqüência de trabalho para estudos de localização é que, uma vez definida a macro-localização de determinada instalação, se inicie o trabalho de micro localizá-la.

\title{
2.4 ICMS
}

O ICMS (Imposto Sobre Circulação de Mercadorias e Prestação de Serviços) é um tributo estadual cobrado sobre as operações relativas à circulação de mercadorias e sobre prestações de serviços de transporte interestadual, intermunicipal e de comunicação. 
Ribeiro (1999) elabora um quadro onde são apresentados os diversos tributos incidentes sobre as operações logísticas, desde os fornecedores até os clientes finais. Através desse quadro é possível observar que o ICMS é o imposto que incide sobre todas as operações logísticas, mostrando assim a importância do ICMS no estudo de localização de instalações em malhas logísticas de distribuição.

Sendo assim, toda a malha logística de transporte de materiais no Brasil está sujeita à incidência do ICMS em suas transações de transferência e venda de produto. Melo (2006) dedica cerca de cem páginas do seu livro para detalhar os fatores geradores de ICMS em relação a operações de circulação de mercadorias.

De acordo com o guia do Portal Tributário (www.portaltributario.com.br), pode-se citar alguns dos fatores geradores do ICMS:

- Saída de mercadoria de estabelecimento de contribuinte, ainda que para outro estabelecimento do mesmo titular;

- Transferência a terceiro de mercadoria depositada em armazém geral ou em depósito fechado no próprio Estado;

- Transferência de propriedade de mercadoria, ou de título que a represente, quando a mercadoria não tiver transitado pelo estabelecimento do transmitente;

- Início da prestação de serviços de transporte interestadual e intermunicipal, de qualquer natureza;

- Ato final do transporte iniciado no exterior;

- Fornecimento de mercadoria com prestação de serviços:

- Utilização, por contribuinte, de serviço cuja prestação se tenha iniciado em outro Estado e não esteja vinculada à operação ou prestação subsequente. 


\subsubsection{Incidência do ICMS}

Segundo o guia do Portal Tributário (www.portaltributario.com.br), o ICMS incide sobre:

- Operações relativas à circulação de mercadorias;

- Prestações de serviços de transporte interestadual e intermunicipal, por qualquer via, de pessoas, bens, mercadorias ou valores;

- Fornecimento de mercadorias com prestação de serviços não compreendidos na competência tributária dos Municípios;

- Fornecimento de mercadorias com prestação de serviços sujeitos ao imposto sobre serviços, de competência dos Municípios, quando a lei complementar aplicável sujeitar à incidência do imposto estadual.

\subsubsection{Estrutura de Alíquotas}

Segundo Melo (2006), o ICMS é um imposto não-cumulativo, compensando-se o que for devido em cada operação relativa à circulação de mercadorias ou prestação de serviços, onde, dependendo dos valores dos produtos e dos estados de origem e destino, gera-se créditos ou débitos de ICMS para determinada operação.

A estrutura de alíquotas do ICMS é diferenciada em função da origem e destino da circulação de mercadorias. Isso se deve a política do governo de favorecer aos estados importadores na compra de mercadorias de estados exportadores. A tabela completa de alíquotas de ICMS pode ser observada no Anexo A deste trabalho (Regulamentação Constitucional prevista na Lei Complementar 87/1996, alterada posteriormente pelas Leis Complementares 92/97, 99/99, 102/2000 e 114/2002).

De maneira resumida, pode-se dizer que a alíquota padrão entre os estados brasileiros comporta-se da seguinte maneira:

- Tributação para as transações intra-estaduais:

- $19 \%$ é aplicado no Estado do Rio de Janeiro devido ao Fundo de Combate à Pobreza;

- $18 \%$ nos Estados do Paraná, São Paulo e Minas Gerais;

- $17 \%$ demais estados; 
- Tributação para transações interestaduais:

- 7\% para as transações com origem em São Paulo ou Minas Gerais e destino nos estados do Norte, Nordeste, Centro-Oeste e para o Espírito Santo;

- $8 \%$ para as transações descritas acima, mas com origem no Estado do Rio de Janeiro

- $12 \%$ nas demais transações com origem em São Paulo e Minas Gerais

- $13 \%$ nas demais transações com origem no Rio de Janeiro

\subsubsection{Calculo do ICMS}

Segue abaixo um exemplo do modelo de cálculo do tributo do ICMS, citado por Amaral e Olenike (2003), para um produto fictício com valor de $\mathrm{R} \$ 350,00$ e alíquota de ICMS de $18 \%$, referente a uma operação de venda de um bem de consumo durável dentro do Estado de SP.

$$
\text { ICMS }=\left[\frac{\text { Valor do Produto }}{(1-\text { Aliquota })}-\text { Valor do Produto }\right]=\left[\frac{350}{(1-0,18)}-350\right]=76,83
$$

No cálculo realizado observa-se que, apesar de a alíquota de ICMS ser de $18 \%$, o percentual de tributo sobre o valor do produto é de aproximadamente $22 \%[R \$ 76,83$ / $\mathrm{R} \$ 350,00]$.

Como citado anteriormente, o ICMS é um imposto não-cumulativo baseado na estrutura de débitos e créditos. No exemplo anterior, o estabelecimento de origem gerará um débito de ICMS no valor de $\mathrm{R} \$ 76,83$ e o estabelecimento de destino terá um crédito de ICMS no mesmo valor, como ilustrado na Figura 6. 


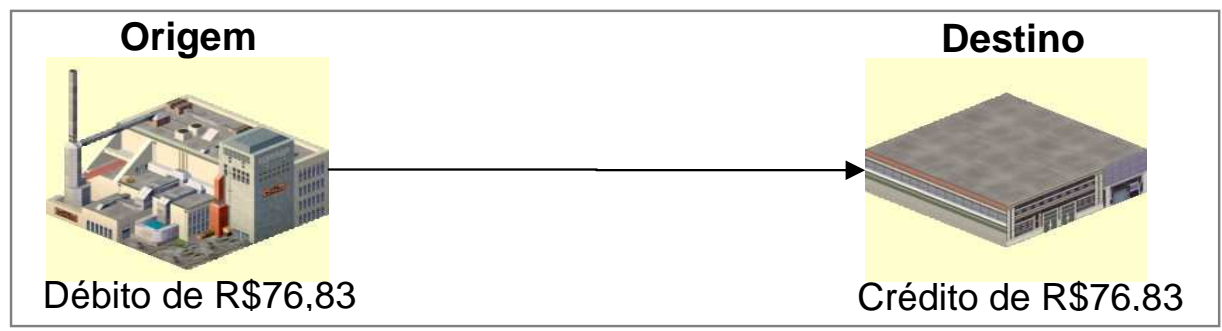

Figura 6: Estrutura de Créditos e Débitos de ICMS Fonte: Adaptada de Silva (2007)

Para melhor ilustrar a estrutura de débitos e créditos, consideremos que o exemplo anterior representa a circulação de produtos da fábrica para o centro de distribuição e que o mesmo fará uma venda dessa mercadoria no Estado do Rio Grande do Sul. A Figura 7 ilustra detalhadamente esta operação.

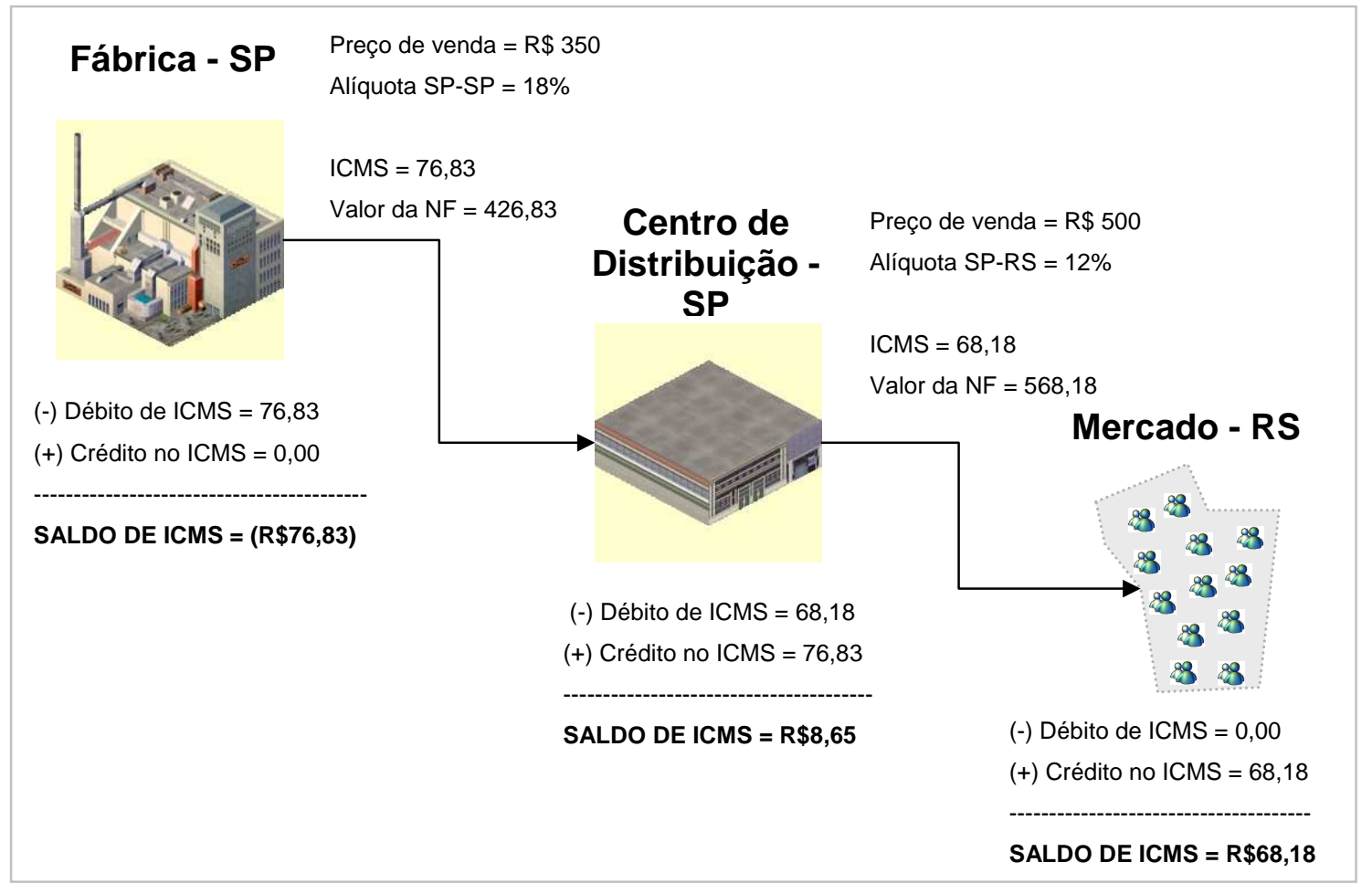

Figura 7: Fluxo da Cadeia com ICMS (SP-SP-RS)

Fonte: Adaptada de Silva (2007)

Através deste exemplo, pode-se observar a formação de débitos e créditos de ICMS ao longo da cadeia de distribuição. Devido ao fato do imposto ser cobrado em cada movimentação na cadeia, o total de imposto repassado representa boa parte do custo do produto. 
Voltando ao exemplo apresentado na Figura 7, mas alterando-se somente a localização do centro de distribuição para o Estado do Paraná, sem alteração dos preços de venda do produto, pode-se observar que acontece uma mudança significativa nos débitos e créditos de ICMS gerados em cada elo da cadeia de distribuição.

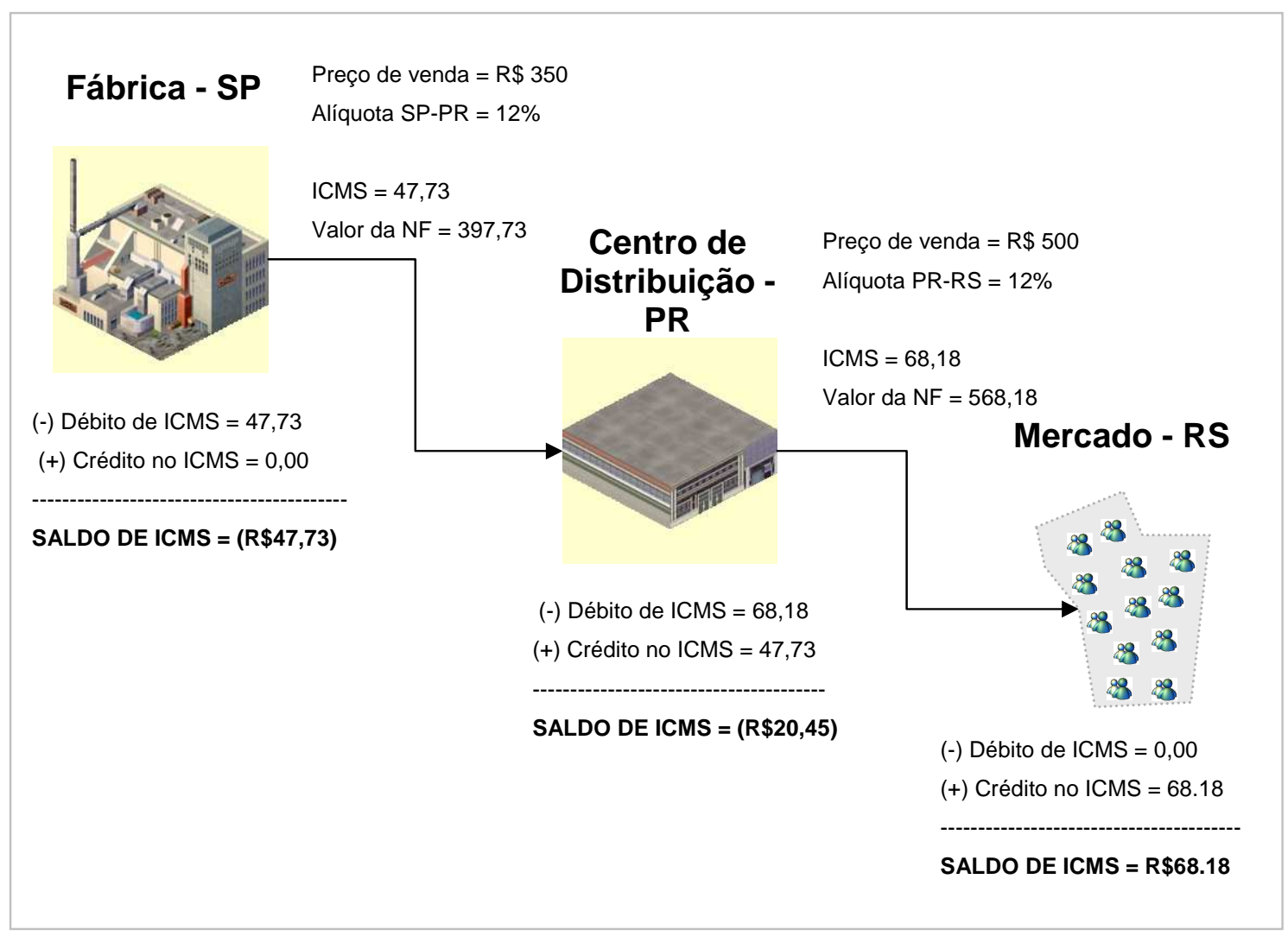

Figura 8: Fluxo da Cadeia com ICMS (SP-PR-RS)

Fonte: Adaptada de Silva (2007)

Nesse exemplo, pode-se observar que o centro de distribuição passa a ter um débito de ICMS de $R \$ 20,45$ e não mais o crédito de $R \$ 8,65$ apresentado no exemplo onde o CD estava localizado em São Paulo.

Com base nestes dois resultados, concluir-se-ia erroneamente que a localização do centro de distribuição tem impacto significativo no custo total da cadeia e no total de débitos e créditos de ICMS gerados em cada elo da cadeia. No entanto, isto não é real e, para permitir que se chegue à conclusão correta sobre o impacto do ICMS no custo total, será conduzida uma nova avaliação de cenários. A seguir, discute-se a 
análise apresentada por Silva (2007), que está estruturada sob a ótica fiscal e que não considera os custos logísticos.

Inicia-se a análise comparando os dois casos utilizados até o momento (Fábrica em SP e Cliente em RS, com o CD em SP no cenário 1, ou o CD em PR no cenário 2) com um terceiro caso onde o CD fica localizado no Estado do Rio Grande do Sul.

\begin{tabular}{l|r|r|r|}
\cline { 2 - 4 } & \multicolumn{1}{|c|}{ Cenário 1 } & Cenário 2 & Cenário 3 \\
SP - SP - RS & SP - PR - RS & SP - RS - RS \\
\hline Passo 1 - Compra de Matéria-Prima pela fabrica & $18 \%$ & $18 \%$ & $18 \%$ \\
Aliquota & 150,00 & 150,00 & 150,00 \\
& 182,93 & 182,93 & 182,93 \\
Valor do Produto & $-32,93$ & $-32,93$ & $-32,93$ \\
Valor da Nota & 32,93 & 32,93 & 32,93 \\
Débito Fornecedor & & & \\
Crédito Fabrica & $18 \%$ & $12 \%$ & $12 \%$ \\
Passo 2 - Transferencia do produto manufaturado para o centro de distribuição & \\
Aliquota & 350,00 & 350,00 & 350,00 \\
Valor do Produto & 426,83 & 397,73 & 397,73 \\
Valor da Nota & $-76,83$ & $-47,73$ & $-47,73$ \\
Débito Fabrica & 76,83 & 47,73 & 47,73 \\
Crédito Centro de Distribuição & & \\
Passo 3 - Venda do centro de distribuição ao cliente & $12 \%$ & $12 \%$ & $18 \%$ \\
Aliquota & 500,00 & 500,00 & 500,00 \\
Valor do Produto & 568,18 & 568,18 & 609,76 \\
Valor da Nota & $-68,18$ & $-68,18$ & $-109,76$ \\
\hline
\end{tabular}

Tabela 1: Comparativo de Cenários sob a Ótica Fiscal Fonte: Adaptada de Silva (2007)

A partir dos créditos e débitos gerados por cada operação apresentada na Tabela 1, foi calculado o fluxo de caixa e o resultado final das operações para a indústria e para o centro de distribuição, considerando-se que são empresas diferentes que realizam cada uma das operações. (Tabela 2 ). 


\begin{tabular}{|c|c|c|c|}
\hline & $\begin{array}{c}\text { Cenário } 1 \\
S P \text { - SP - RS }\end{array}$ & $\begin{array}{c}\text { Cenário } 2 \\
S P \text { - PR - RS }\end{array}$ & $\begin{array}{c}\text { Cenário } 3 \\
S P \text { - RS - RS }\end{array}$ \\
\hline \multicolumn{4}{|l|}{ FABRICA } \\
\hline \multicolumn{4}{|l|}{ Fluxos Positivos } \\
\hline Crédito Compra de Matéria-Prima & 32,93 & 32,93 & 32,93 \\
\hline Recebimento pela venda ao CD & 426,83 & 397,73 & 397,73 \\
\hline \multicolumn{4}{|l|}{ Fluxos Negativos } \\
\hline Débito da transferencia ao CD & $-76,83$ & $-47,73$ & $-47,73$ \\
\hline Pagamento de matéria-prima & $-182,93$ & $-182,93$ & $-182,93$ \\
\hline Balanço ICMS & $-43,90$ & $-14,80$ & $-14,80$ \\
\hline Resultado Final & 200,00 & 200,00 & 200,00 \\
\hline \multicolumn{4}{|l|}{ CD } \\
\hline \multicolumn{4}{|l|}{ Fluxos Positivos } \\
\hline Crédito Compra do Produto & 76,83 & 47,73 & 47,73 \\
\hline Recebimento pela venda ao cliente & 568,18 & 568,18 & 609,76 \\
\hline \multicolumn{4}{|l|}{ Fluxos Negativos } \\
\hline Débito da transferencia ao CD & $-68,18$ & $-68,18$ & $-109,76$ \\
\hline Pagamento a fabrica & $-426,83$ & $-397,73$ & $-397,73$ \\
\hline Balanço ICMS & 8,65 & $-20,45$ & $-62,03$ \\
\hline Resultado Final & 150,00 & 150,00 & 150,00 \\
\hline
\end{tabular}

Tabela 2: Comparativo dos Resultados Consolidados Fonte: Adaptada de Silva (2007)

A partir dos resultados apresentados, pode-se observar que o resultado final da fábrica e do centro de distribuição não sofre alteração com a mudança de localização do centro de distribuição. O resultado final em cada um dos elos da cadeia permanece sempre o mesmo, o que varia é somente o balanço de ICMS.

Mostrou-se então que diferentes localizações para o centro de distribuição geram balanços de ICMS distintos, mas apresentam o mesmo resultado final para empresa, devido ao princípio da não-cumulatividade.

\subsubsection{Impacto do ICMS nas redes de distribuição}

Assim como alertado por Silva (2007), além da estrutura de créditos e débitos trabalhada anteriormente, onde foi avaliado o impacto do ICMS sobre a rede de distribuição de maneira isolada, existem diversos outros fatores diretamente ligados 
ao ICMS e que podem causar impacto significativo na rede de distribuição das empresas, os quais pode-se citar:

- Sonegação Fiscal: existência de elementos na cadeia que sonegam impostos: fornecedores, indústrias, atacadistas, varejistas, etc;

- Prazo para compensação de Saldo: Compensação do saldo do ICMS devido a realizar-se antes ou depois do recebimento pelas vendas;

- Concessão de benefícios: Incentivos para elementos da rede de distribuição.

A sonegação fiscal foi o tema abordado na tese de livre docência de Yoshizaki (2002), o prazo para compensação do saldo foi estudado no trabalho de Ribeiro (1999) e a concessão de benefícios foi o tema abordado por Silva (2007).

Esta dissertação vai abordar a concessão de benefícios fiscais, inovando ao acrescentar uma variável ambiental para analisar os trade-offs existentes entre os custos logísticos, os incentivos auferidos e o custo de neutralização das emissões de carbono geradas pelo modelo.

\subsubsection{Incentivos Fiscais}

Segundo Netto (2003), existem vários tipos de incentivos fiscais, porém o autor classifica dois deles como sendo os mais importantes:

- Crédito Financeiro: consiste no financiamento subsidiado de parte ou do total dos débitos do ICMS da empresa de modo a prolongar o prazo para quitação dos débitos de ICMS;

- Crédito Presumido: o Estado concede uma redução do montante do imposto devido indicado na NF sem alterar esse montante no documento fiscal, de modo que a redução é efetuada no momento do pagamento do imposto e o comprador recebe o crédito integral indicado na NF.

Ainda segundo Netto (2003), o crédito presumido é mais eficaz que o crédito financeiro na atração de investimentos, uma vez que este mecanismo oferece uma redução real sobre o valor a ser pago dos tributos ao invés de apenas postergar o prazo de pagamento. Para melhor esclarecer o conceito de crédito presumido, toma- 
se como exemplo novamente o cenário apresentado na Figura 11 para realizar o cálculo, assumindo que o incentivo fiscal é de $3 \%$ no centro de distribuição.

- Saldo de ICMS no CD = $(\mathrm{R} \$ 20,45)$

- Incentivo Fiscal $=3 \%$ do preço de venda $=0,03 \times \mathrm{R} \$ 568,18=\mathrm{R} \$ 17,05$

- $\quad$ Valor do imposto a ser pago: $(R \$ 20,45)+R \$ 17,05=(R \$ 3,40)$

Esta dissertação utiliza o conceito de crédito presumido e considera de aqui em diante que o incentivo fiscal sobre o ICMS é um percentual de desconto dado pelo Estado sobre o saldo de ICMS das empresas. Mais adiante, será verificado que a aplicação de descontos nos pagamentos de ICMS efetivamente altera a configuração da malha.

Observa-se que os benefícios fiscais existentes incidem sobre uma grande variedade de produtos. Nesta dissertação foram considerados, para efeito de análise, os incentivos fiscais mais abrangentes e que não possuem regras que os restrinjam a produtos específicos, assim como feito por Silva (2007). Os Estados que oferecem incentivo mais abrangentes são Goiás e Minas Gerais, tal como descrito a seguir:

- Goiás (GO): crédito presumido de $3 \%$ sobre a base de cálculo para estabelecimento de comércio atacadista que destine mercadorias para comercialização, produção ou industrialização;

- Minas Gerais (MG): oferta de crédito de 9\% da base de cálculo para mercadorias remetidas por estabelecimento atacadista ou central de distribuição para comercialização, produção ou industrialização.

\subsection{PROBLEMAS DE LOCALIZAÇÃO CONSIDERANDO IMPACTO FISCAL}

Yoshizaki (2002) foi um dos primeiros a abordar o impacto fiscal, considerando o ICMS como um componente de custo estratégico na determinação de uma rede física de distribuição. O autor considera que o gerenciamento e controle dos custos tributários são fundamentais para a tomada de decisão. Para a realização de sua dissertação, Yoshizaki (2002) partiu do modelo de Geoffrion e Graves e realizou uma 
série de adaptações, de modo a incorporar a variável tributária ao modelo de decisão. As mudanças realizadas pelo autor foram:

- Não restringir o abastecimento entre depósito e mercado;

- Inserir a variável tributária referente ao ICMS na função objetivo;

- Incorporar o conceito de economia de escala na operação de depósito, no que tange custos fixos, amortização de capital, depreciação e mãode-obra direta.

No modelo proposto por Yoshizaki (2002) não existem restrições de nível de serviço, pois o mesmo foi modelado através da distância máxima permitida. Os arcos com distância acima da permitida foram simplesmente eliminados do modelo, ao invés de serem penalizados artificialmente com um valor muito grande na função objetivo, tal como utilizado por Love, Morris e Wesolowsky (1988, p. 202).

Pantalena (2004) voltou a abordar a questão do ICMS através de um estudo que teve como objetivo minimizar os custos de distribuição e de ICMS de uma indústria química, através da criação de um Modelo de Localização de Centros de Distribuição.

Para tal, a autora criou um modelo de programação linear inteira mista (PLIM) em que considerava como componentes da parcela de custos de distribuição: custos fixos e variáveis de armazenagem, custos de frete de transferência e frete de distribuição; e como componentes da parcela de ICMS: os valores a serem pagos tanto na fábrica quanto no centro de distribuição.

Utilizando como base os modelos de Yoshizaki (2002) e Pantalena (2004), Silva (2007) construiu um modelo cujo objetivo era determinar a logística de menor custo total de operação levando em consideração os decréscimos gerados por incentivos fiscais relacionados ao ICMS.

Através de seu estudo, Silva (2007) procurou avaliar os trade-offs existentes entre os custos logísticos de transporte e armazenagem e a redução no saldo de ICMS a pagar, proporcionada pelo benefício fiscal. O modelo desenvolvido por Silva (2007) está detalhado a seguir, pois é o ponto de partida desta dissertação: 


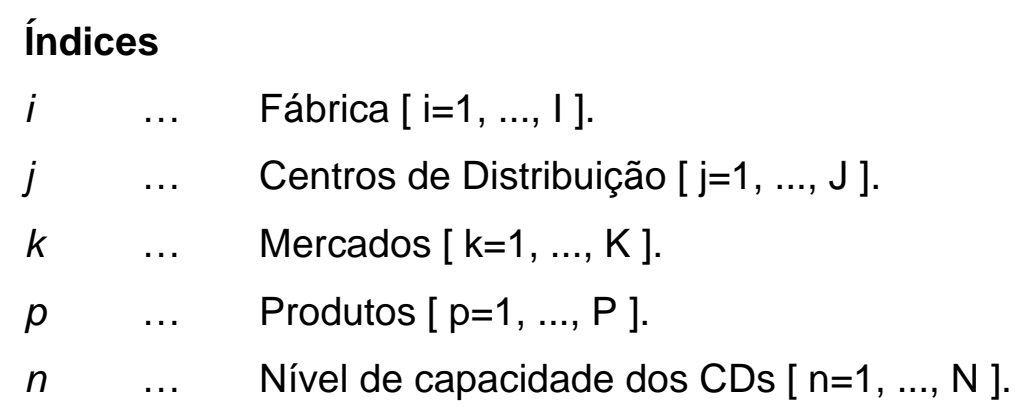

\section{Parâmetros}

Dem $_{p k} \quad \ldots \quad$ Demanda do produto $p$ no mercado $k$ (t/ano);

$\mathrm{CapFab}_{i p} \quad \ldots \quad$ Capacidade da fábrica $i$ para produzir o produto $p$ (t/ano);

${\operatorname{Cap} C D_{j n}} \quad \ldots \quad$ Capacidade do CD $j$ no nível de capacidade $n$ (t/ano);

CTrnsij $\quad \ldots \quad$ Custo do frete de transferência da fábrica i para o $\operatorname{CD} j(\mathrm{R} \$ / \mathrm{t})$;

CDstrjk $\quad \ldots \quad$ Custo do frete de distribuição do $C D j$ para o mercado $k(R \$ / t)$;

Fix $C D_{j n} \quad \ldots \quad$ Custo fixo do $C D j$ com capacidade $n$ ( $\mathrm{R} \$ /$ ano);

$\begin{array}{lll}C v C D_{j} & \ldots & \text { Custo variável de transbordo no } \mathrm{CD} j(\mathrm{R} \$ / \mathrm{t}) ;\end{array}$

$\mathrm{CvF}_{i} \quad \ldots \quad$ Custo variável de transbordo na fábrica $i(\mathrm{R} \$ / \mathrm{t}) ;$

AlíqICMS $_{i j} \quad \ldots \quad$ Alíquota de ICMS correspondente ao arco com origem na fábrica $i$ e destino no CD $j$;

AlíqICMS $_{j k} \quad \ldots \quad$ Alíquota de ICMS correspondente ao arco com origem no CD $j$ e destino no mercado $k$;

AlíqBef $f_{j} \quad \ldots \quad$ Percentual relativo ao crédito presumido fornecido pelo benefício em relação à base de cálculo, no $C D$ j;

$P T_{p} \quad \ldots \quad$ Custo de produção do produto $p$ sem o ICMS, ou seja, o valor utilizado na NF de transferência do produto, sobre o qual incide o ICMS $(\mathrm{R} \$ / \mathrm{t})$;

$\begin{array}{lll}P V_{p} & \ldots & \text { Preço de venda do produto } \mathrm{p} \text { sem o ICMS, ou seja, custo de }\end{array}$ produção + margem, sobre o qual incide o ICMS $(R \$ / t)$;

$F_{\text {MIN }} \quad \ldots \quad$ Constante referente ao fluxo mínimo de operação dos CDs (\%). 


\section{Variáveis}

Trnsijp $_{i j} \quad \ldots \quad$ Quantidade do produto $\mathrm{p}$ transferida da fábrica $i$ para o CD $j$ (t/ano);

$D_{s t r} D_{j k p} \quad \ldots \quad$ Quantidade do produto $\mathrm{p}$ distribuída do CD $j$ para o mercado $k$ (t/ano);

$B F_{j} \quad \ldots \quad$ Ganho auferido com o benefício fiscal com a distribuição a partir do $\mathrm{CD} j(\mathrm{R} \$ / \mathrm{ano})$.

$Z_{j n} \quad \ldots \quad$ Variável binária: assume valor 1 caso o $\mathrm{CD} \mathrm{j}$ com capacidade $\mathrm{n}$ esteja aberto e 0 em caso contrário.

CT $\quad$.. $\quad$ Custo total da operação (R\$/ano).

\section{Função Objetivo}

Minimizar Custo Total (CT)

$C T=\sum_{i} \sum_{j} \sum_{p}\left(\operatorname{Trns}_{i j p} \times C \operatorname{Trns}_{i j}\right) \quad$ / (A) Custo do frete de transferência $i-j$

$+\sum_{j} \sum_{k} \sum_{p}\left(D s t r D_{j k p} \times C D s t r_{j k}\right) \quad /(\mathrm{B})$ Custo do frete de distribuição $j-k$

$+\sum_{j n}\left(Z_{j n} \times F i x C D_{j n}\right) \quad$ / (C) Custo fixo anual do CD $j$

$+\sum_{j} \sum_{k} \sum_{p}\left(D s t r D_{j k p} \times C v C D_{j}\right) \quad$ / (D) Custo de transbordo no CD $j$

$+\sum_{i} \sum_{k} \sum_{p}\left[\left(\operatorname{Trns}_{i j p} \times C v F_{i}\right)\right] \quad /(\mathrm{E})$ Custo de transbordo na fábrica $i$

$-\sum_{j} B F_{j} \quad /(\mathrm{F})$ Ganho fiscal a partir do CD $j$

\section{Restrições}

- Restrição de atendimento da demanda

$$
D^{D e m_{p k}}=\sum_{j} D_{s t r D} D_{j p} \quad \forall k, \forall p
$$

- Restrição de capacidade de operação do CD $j$

$$
\sum_{i} \sum_{p} \operatorname{Trns}_{i j p} \leq \sum_{n}\left(Z_{j n} \times \operatorname{CapCD}_{j n}\right)
$$

- Restrição para haver uma única capacidade de operação no CD $j$

$$
\sum_{n} Z_{j n}=1 \quad \forall j
$$


- Restrição de fluxo mínimo no CD j com capacidade $n$

$$
\sum_{i} \sum_{p} \operatorname{Trns}_{i j p} \geq \sum_{n}\left(Z_{j n} \times F_{M I N} \times \operatorname{CapCD}_{j n}\right) \quad \forall j, \forall n
$$

- Balanço de massa no CD $j$

$$
\sum_{i} \text { Trns }_{i j p}=\sum_{k} D s t r D_{j k p} \quad \forall j, \forall p
$$

- Saldo de ICMS nulo ou positivo no CD $j$

$$
D_{s t r D} D_{j k p} \times \sum_{j}\left\{\left\{\left[\frac{P T_{p}}{\left(1-\text { AliqICMS }_{i j}\right)}-P T_{p}\right]-\left[\frac{P V_{p}}{\left(1-\text { AliqICMS }_{j k}\right)}-P V_{p}\right]\right\}-B F_{j}\right\} \geq 0
$$

$\forall j$

- Binárias

$$
\operatorname{Zjn}\left\{\begin{array}{l}
=1, \text { se o CDj com capacidaden esta operando } \quad \forall j, \forall n \\
=0, \text { em caso contrário }
\end{array}\right.
$$

- Cálculo do ganho auferido com o benefício fiscal

$$
B F_{j}=\sum_{p}\left\{\left[\frac{P V_{p}}{1-\text { AliqBef }_{j}}\right]-P V_{p}\right\}
$$

- Não negatividade

$$
\begin{array}{ll}
\operatorname{Trns}_{i j p} \geq 0 & \forall i, \forall j, \forall p \\
\operatorname{DstrD}_{j k p} \geq 0 & \forall j, \forall k, \forall p \\
B F_{j} \geq 0 & \forall j
\end{array}
$$

O modelo proposto pela autora apresenta diversas restrições que limitam sua capacidade de otimização; por exemplo:

- Considerar a existência de fábricas especializadas (que podem produzir um único produto) impõe, conseqüentemente, a abertura de uma fábrica para cada um dos produtos em análise.

- Não considerar o incentivo fiscal em Estados diferentes do local das fábricas

- Não considerar a oferta simultânea de incentivos em mais de um Estado. 
As restrições descritas acima foram eliminadas do modelo elaborado para esta dissertação. O detalhamento das melhorias serão apresentados no Capítulo 3.

Vale destacar, que o modelo utilizado por Geoffrion e Graves e que serviu de base para os estudos de Yoshizaki (2002), Pantalena (2004) e Silva (2007) é um modelo de Programação Linear Inteira Mista (PLIM) de elevada complexidade computacional. Porém, dada a dimensão dos seus modelos (em termos de número de variáveis inteiras), os autores citados utilizaram ferramentas de otimização (GAMS/CPLEX ou What's Best) para sua resolução, não havendo necessidade de desenvolver e aplicar métodos heurísticos ou metaeuristicas. Dado que a dimensão do modelo desta dissertação é da mesma ordem dos autores citados, também foi adotado a modelagem de PLIM e ferramenta GAMS/CLPEX, entendendo que a mesma será capaz de otimizar o modelo detalhado no capítulo 3 desta dissertação.

\subsection{A QUESTÃO AMBIENTAL}

Esta sessão apresenta como a questão ambiental vem sendo tratada pelos órgãos intenacionais e pelas corporações empresarias. Aborda ainda as regulamentações e metas que estão em vigor para redução da emissão de gases poluentes, com o objetivo de dar suporte para as análises conduzidas nesta dissertação.

Desde a Conferência do Rio em 1992 (ECO-92), a comunidade internacional vem desenhando uma série de regulamentações e diretrizes com o objetivo de atingir "a estabilização da concentração dos gases do efeito estufa (GEE) na atmosfera num nível que impeça uma interferência antrópica perigosa no sistema climático". Exemplo maior destas regulamentações é a "Convenção do Clima", escrita em 2001 por diversos países participantes (partes da convenção) da Organização das Nações Unidas (United Nations Framework Convention on Climate Change, UNFCCC2001a). As Partes da Convenção estabeleceram uma rotina de discussões sobre o problema do efeito estufa e suas possíveis soluções, que gerou nove encontros distintos. No terceiro encontro, realizado em Kyoto em 1997, foi estabelecido um acordo que define metas de redução de emissões de GEE, além de critérios e diretrizes para a utilização de mecanismos de mercado que suportem e/ou viabilizem 
o atingimento de tais metas. (Manual de Capacitação sobre Mudança do Clima, CGEE, 2008)

\subsubsection{O Protocolo de Kyoto}

O Protocolo de Kyoto (UNFCCC-2001b), nome pelo qual o acordo ficou conhecido, determinava que, no período entre 2008 e 2012 (primeiro período de compromisso), os países industrializados deveriam reduzir suas emissões de GEE em pelo menos $5,2 \%$ em relação aos níveis de 1990 . Para muitos países, tais como os membros da União Européia (EU), a redução proposta correspondia a 15\% das emissões esperadas para 2008 (UNFCCC, 2001b).

As metas de Kyoto não são estabelecidas de forma homogênea entre todos os países do mundo, sendo aplicados níveis de redução diferentes para os 38 países que mais emitem gases. A diminuição na emissão de gases estabelecida como meta na União Européia é de cerca 8\%, nos Estados Unidos de 7\%, no Japão 6\%. Nas nações em desenvolvimento (Brasil, México, Argentina, China, Índia, etc.) não existe nenhuma meta de redução (UNFCCC, 2001b).

Para que entrasse em vigor, o protocolo de Kyoto, precisou da ratificação de 55 Partes da Convenção, incluindo especialmente os países desenvolvidos que contabilizavam, pelo menos, $55 \%$ das emissões totais de $\mathrm{CO}_{2}$ em 1990 . Por este motivo, foi só depois que a Rússia o ratificou que o Protocolo de Kyoto entrou em vigor em 16 de fevereiro de 2005. A Figura 9 (Magnoli, 2008) mostra um mapa mundi com a posição dos países com relação ao Protocolo, no ano de 2005. 


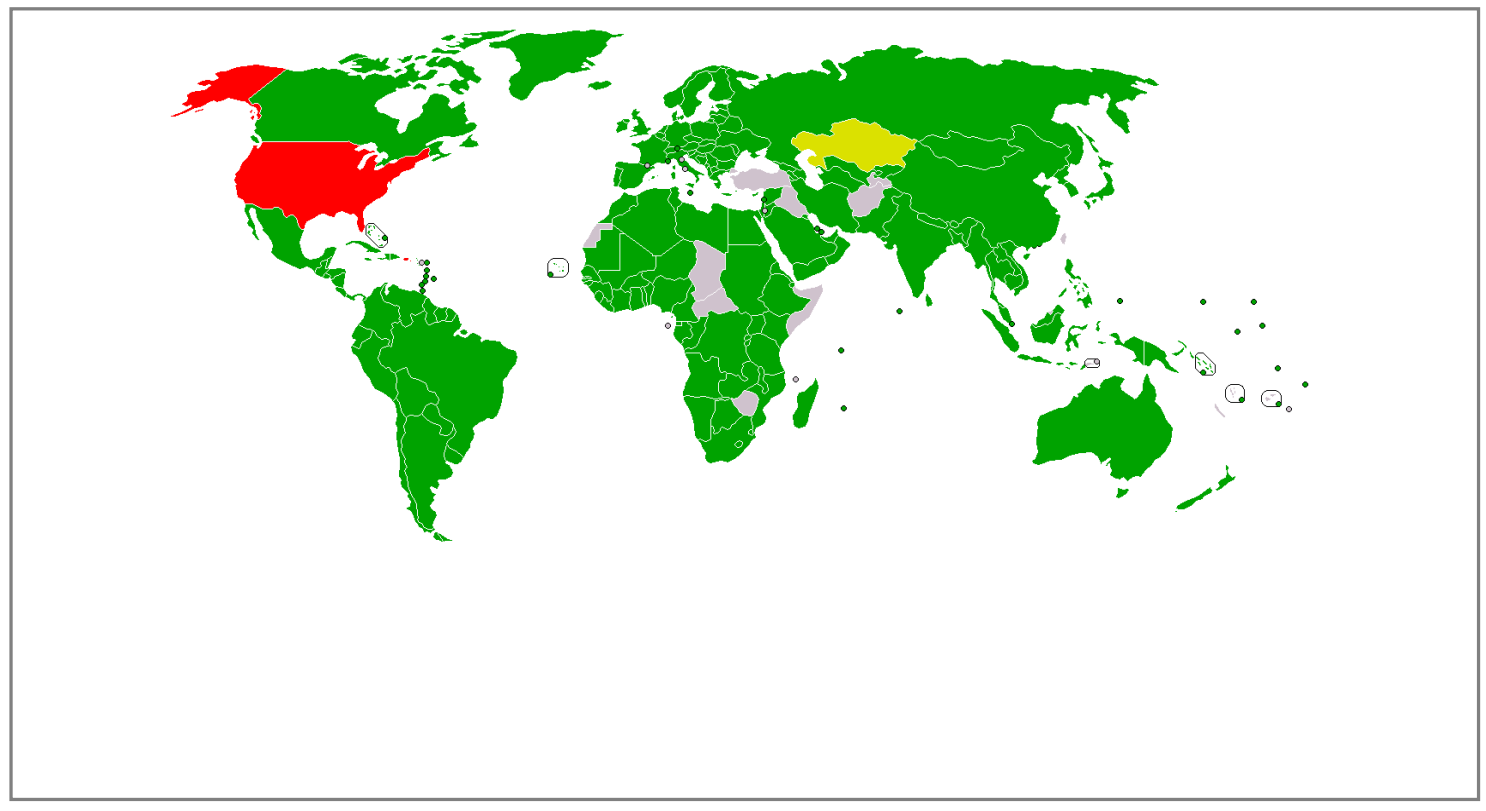

Figura 9: Posicionamento dos Países sobre o Protocolo de Kyoto Fonte: Transcrita de Magnoli (2008)

Diante das metas estabelecidas e da não obrigatoriedade de redução nos países em desenvolvimento, os Estados Unidos (maior emissor de gases do mundo), se desligou do Protocolo em 2001, alegando que a redução iria comprometer o desenvolvimento econômico do país. Porém, no intuito de seguir a tendência mundial, mas não aplicar as metas compulsórias de redução de emissões, os Estados Unidos criaram junto com o Japão, Austrália, Índia, China e Coréia do Sul a Parceria da Ásia Pacífico para Desenvolvimento Limpo e Clima. Esta parceria tem como o objetivo o desenvolvimento de tecnologias energéticas menos poluentes e estabelece regras próprias de restrição de GEE e comercialização de créditos de carbono. Em linhas gerais os países "Non-Kyoto" tendem a seguir as exigências técnicas do Protocolo, apenas não criando uma obrigatoriedade de redução (Magnoli, 2008).

\subsubsection{Mecanismos de Flexibilização}

O Protocolo de Kyoto (UNFCCC, 2001b) trata de maneira combinada os seis principais gases do efeito estufa $\left(\mathrm{CO}_{2}, \mathrm{CH}_{4}, \mathrm{~N}_{2} \mathrm{O}, \mathrm{SF}_{6}, \mathrm{HFC}\right.$ e PFCs), fazendo com que a redução de cada gás seja contabilizada em função da redução total estabelecida na meta e criando taxas de equivalência em $\mathrm{CO}_{2}$ para viabilizar a quantificação dos resultados. A contabilização conjunta parte do princípio de que 
uma tonelada de $\mathrm{CO}_{2}$ corresponde a uma unidade de crédito de carbono, ou seja, que seu potencial de aquecimento global pode ser arbitrariamente estipulado como 1 (um). A partir deste princípio, é estabelecido o conceito de $\mathrm{CO}_{2}$ equivalente que nada mais é que a multiplicação das toneladas emitidas do GEE pelo seu potencial de aquecimento global. O potencial de aquecimento global do gás metano $\left(\mathrm{CH}_{4}\right)$, por exemplo, é 21 vezes maior do que o potencial do $\mathrm{CO}_{2}$, portanto o $\mathrm{CO}_{2}$ equivalente $\left(\mathrm{CO}_{2} \mathrm{e}\right)$ do metano é igual a 21. Assim, cada tonelada de metano reduzida gera 21 créditos de carbono.

\begin{tabular}{|c|c|c|}
\hline & GEE & $\begin{array}{c}\text { Créditos de Carbono por Tonelada } \\
\text { Reduzida }\end{array}$ \\
\hline $\mathrm{CO}_{2}$ & Dióxido de Carbono & 1 \\
\hline $\mathrm{CH}_{4}$ & Metano & 21 \\
\hline $\mathrm{N}_{2} \mathrm{O}$ & Óxido nitroso & 310 \\
\hline HFCs & Hidrofluorcarbonetos & de 140 a 11700 \\
\hline PFCs & Perfluorcarbonetos & de 6500 a 9200 \\
\hline $\mathrm{SF}_{6}$ & Hexafluoreto de enxofre & 23900 \\
\hline
\end{tabular}

O Protocolo criou três mecanismos de flexibilização para ajudar os países desenvolvidos a atingirem suas metas. Dois destes mecanismos são de aplicação exclusiva entre os países desenvolvidos: Implementação Conjunta de projetos (IC) e o Comércio de Emissões (CE). Apenas o Mecanismo de Desenvolvimento Limpo (MDL) se estende também aos países em desenvolvimento (Araujo, 2006).

- Implementação Conjunta (IC) - permite que países desenvolvidos possam financiar projetos de redução das emissões de GEEs em outros países que apresentam metas a cumprir, com o objetivo de facilitar e tornar mais barato para cada país chegar às suas metas;

- Comércio de Emissões (CE) - estabelece um mercado de compra e venda do "direito de emitir gases", ou seja, cria regras para se comercializar créditos de carbono. O CE permite que um país que tenha diminuído as emissões de GEE além de sua meta transfira o excesso de suas reduções para outro país que não tenha alcançado tal condição;

- Mecanismo de Desenvolvimento Limpo (MDL) - semelhante ao IC, mas permite que os créditos de carbono sejam alocados a países desenvolvidos que financiem projetos realizados em países em desenvolvimento; 
O MDL é a alternativa que mais interessa ao Brasil, pois permite que os países industrializados alcancem suas metas de redução ao investir em projetos de redução de emissão realizados em países em desenvolvimento, onde o custo de implantação é seguramente menor. Através do MDL, as empresas que não conseguirem reduzir suas emissões poderão comprar Reduções Certificadas de Emissão (RCE) em países em desenvolvimento e usá-las, com alguma limitação, para cumprir suas obrigações. Estes mecanismos interessam muito às empresas brasileiras, que podem inscrever seus projetos para a certificação e depois comercializar os certificados obtidos. Entre os diversos segmentos que poderão se beneficiar do comércio destes certificados, destaca-se: a geração de energia renovável (hidráulica, eólica, etc.), o uso de bio-combustíveis (álcool, biodiesel, etc.), o aumento da eficiência energética e eficiência em transporte (logística), melhorias e tecnologias industriais (petroquímica, fertilizantes, etc.) e a condução de projetos florestais (Araujo, 2006).

A elaboração de um projeto de MDL deve passar por uma série de fases de validação para chegar à emissão e comprovação das RCEs. O Centro de Gestão e Estudos Estratégicos (CGEE) lançou, em 2008, um manual de capacitação que detalha cada uma das fases e passos para a elaboração e validação dos projetos (Manual de Capacitação sobre Mudança do Clima e Projetos de Mecanismo de Desenvolvimento Limpo). De maneira simplificada, o Ciclo de Projeto MDL pode ser dividido em duas partes. A primeira delas vai desde a submissão (passo 1) até o registro (passo 4) do projeto, sendo que neste período, o proponente do projeto ainda não desenvolve uma atividade de MDL propriamente dita, mas está buscando o reconhecimento da UNFCCC de que a atividade proposta pode reduzir emissões de GEE. Esse reconhecimento é dado no momento do registro do projeto. A segunda parte vai do monitoramento (passo 5) até a emissão das RCE (passo 7) e é conhecida como Ciclo de Verificação. Esse ciclo, teoricamente, nunca acaba, uma vez que se repetirá sempre que o dono do projeto emitir a RCE a que tem direito (CGEE, 2008). 


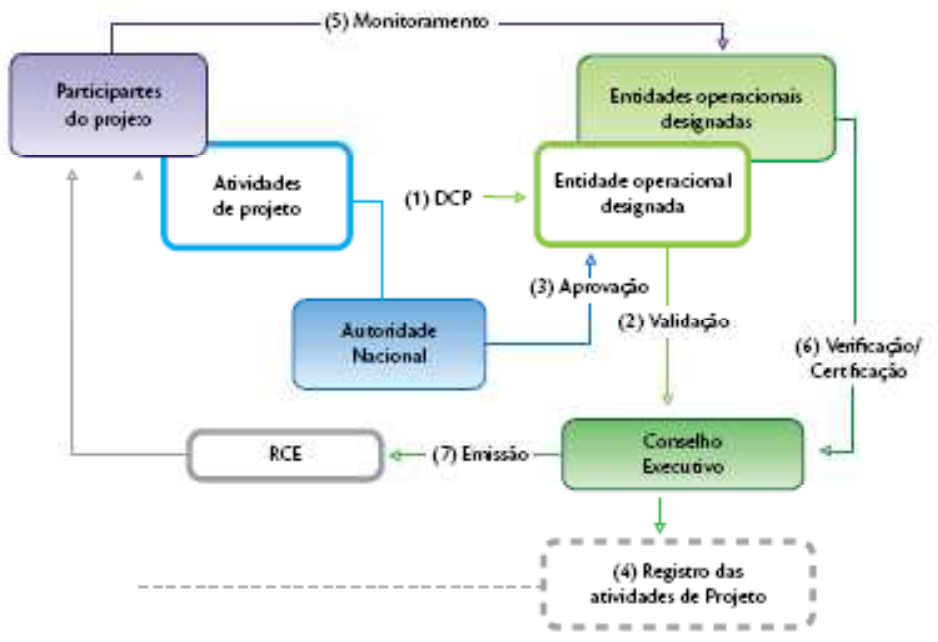

Figura 10: Ciclo de Projeto do MDL

Fonte: Transcrita do Manual de Capacitação sobre Mudança do Clima (CGEE,2008)

Até fevereiro de 2008, o Brasil possuía 198 atividades de projeto de MDL na autoridade nacional designada, sendo que 89\% delas já estavam aprovadas, esperando validação da UNFCCC.

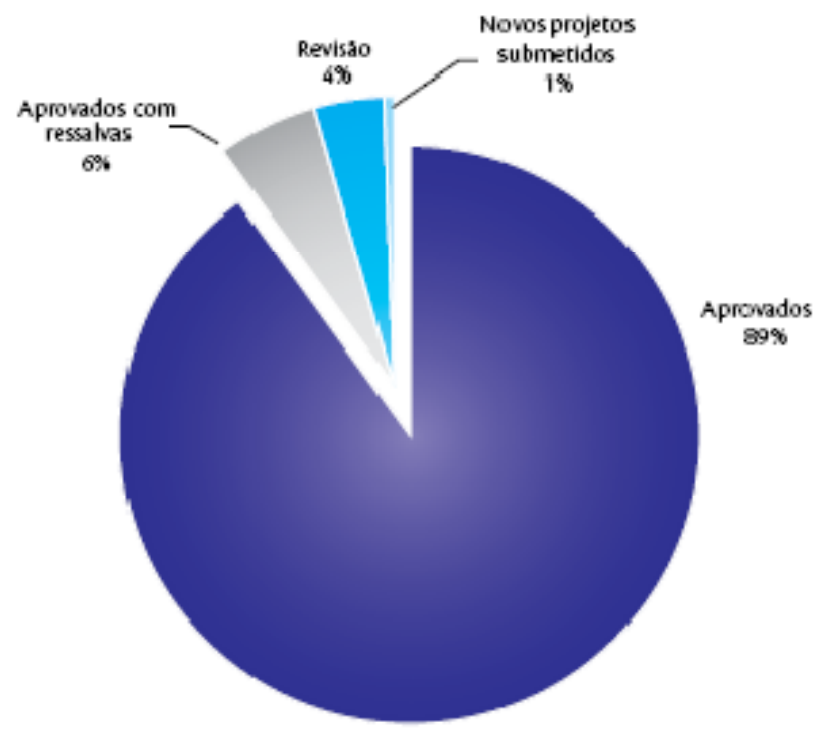

Figura 11: Situação dos Projetos do MDL no Brasil em 2008

Fonte: Transcrita do Manual de Capacitação sobre Mudança do Clima (CGEE,2008)

\subsubsection{O Mercado de Carbono}

Uma vez que Protocolo de Kyoto estabeleceu mecanismos de compra e venda de créditos de carbono ( $\mathrm{CE})$, gerou-se a tendência do carbono se tornar efetivamente 
uma moeda de troca. $1^{\circ}$ de Janeiro de 2008 marcou formalmente 0 início do “primeiro período" de cumprimento das metas do Protocolo e também a Fase 2 do Emission Trading Scheme da União Européia (EU ETS); fatos que impulsionaram o aumento da maturidade necessária nas relações comercias envolvendo créditos de carbono (Araujo, 2006).

Segundo o mais recente estudo do Banco Mundial (Capoor; Ambrosi, 2008), que acompanha a evolução do mercado de carbono desde 2003, o ano de 2007 foi especialmente interessante para as iniciativas de restrição de emissão de gases justamente pela proximidade do início do primeiro período. O mercado de carbono foi avaliado em US\$64 Bilhões, o que demonstra um crescimento de mais de $100 \%$ em relação à valorização do ano anterior e consolida a velocidade com que este mercado vem se estabelecendo (em 2006 o mercado foi avaliado em US\$31 Bilhões e em 2005, eram apenas US\$ 11 Bilhões).

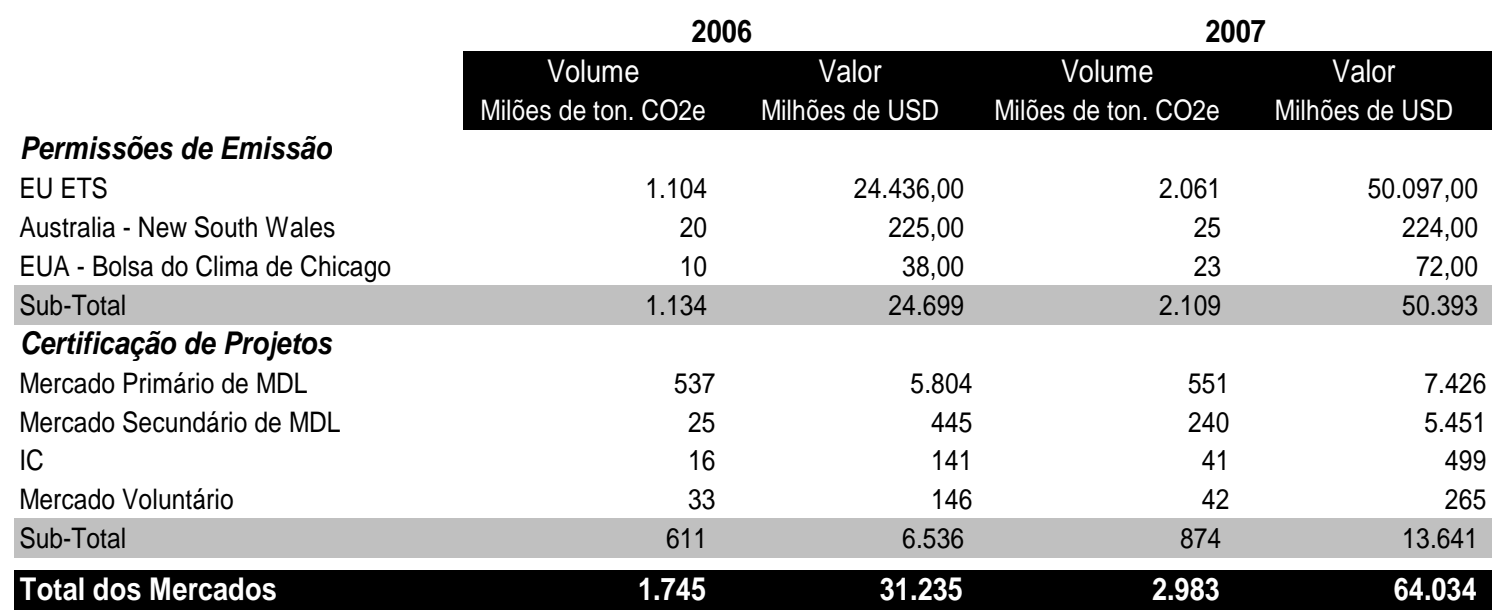

Tabela 4: Mercado de Carbono, Valores e Volumes 2006 e 2007

Fonte: Adaptada de State Trends of Carbon Markets (2008)

\section{Tipos de Mercado}

O mercado de permissões de emissão se caracteriza por fomentar a redução de emissão de GEEs, de forma regulamentada à parte do Protocolo de Kyoto. Este mercado consiste em um sistema de negociação de emissões de GEEs entre empresas e países, onde cada membro possui uma meta de redução que, se for superada, poderá gerar créditos de carbono negociáveis. Nas negociações da Emission Trading Scheme (EU ETS) também são válidos os créditos gerados por 
projetos de IC ou MDL, porém estes projetos já devem estar certificados e não devem ser realizados no território do proponente (European Commission, 2007).

Para que projetos, como os de MDL, possam gerar créditos de carbono, eles precisam antes ser aprovados pela Convenção Quadro das Mudanças Climáticas da ONU. Entretanto, mesmo antes da viabilização de todas as etapas do projeto, uma empresa pode negociar seus certificados futuros para a financiar a aquisição de equipamentos, a execução de obras civis, planejamento de engenharia, etc., nos chamados mercado primário e mercado secundário. A diferença básica entre estes mercados é a existência de um intermediário entre a entidade financiadora e a empresa responsável pelo projeto, com o papel de pré-certificar ou patrocinar os projetos, além de agregar volume de reduções para os casos em que um projeto sozinho não atinja os limites mínimos de negociação (Capoor; Ambrosi, 2008). Os preços praticados neste segmento são menores que no mercado de permissões e variam conforme fatores qualitativos do projeto, tais como (Lecock, 2004):

- Probabilidade de ser certificado

- Tipo e local de implementação

- Credibilidade financeira do patrocinador e a viabilidade econômica do projeto

- Confiabilidade dos métodos de gestão dos recursos (financeiros e o carbono)

- Estruturação do contrato (por exemplo: redução pontual vs. contínua; pagamento antecipado vs. pagamento ao final da comprovação de redução)

- Ano de aplicação da redução

- Custo da verificação e da certificação (quem é o responsável)

- Existência de benefícios adicionais (ambientais ou sociais)

Dados de 2007 (CGEE, 2007) mostram a variação de preços entre diferentes tipos de projeto e confirmam a grande variação de valor existente dependendo da aplicação do projeto, ou seja, se este será usado para um país atender às metas do Protocolo (CER) ou não (ERU) e do risco implícito na certificação (pré CER , CER ou CER Secundário). 


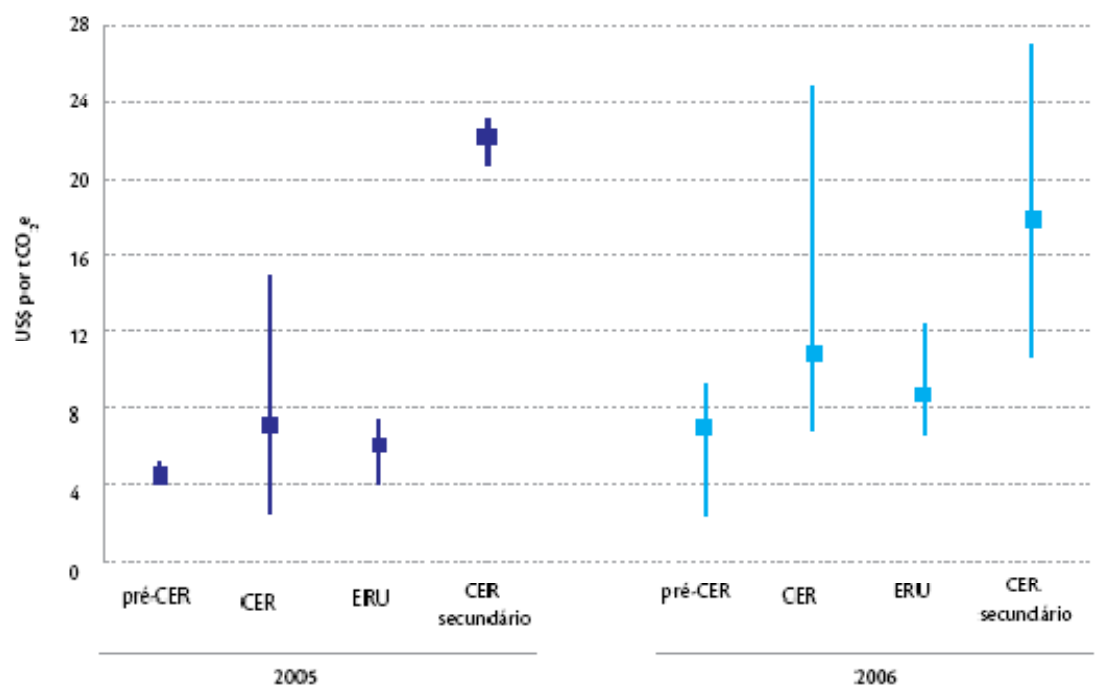

Figura 12: Preços de Projetos em 05/06 (Dólar por Tonelada de $\mathrm{CO}_{2} \mathrm{e}$ ) Fonte: Transcrita de State Trends of Carbon Markets (2008)

Existe ainda o mercado voluntário, onde são negociados certificados chamados de VERs (voluntary emission reductions), sob um modelo comercial mais flexível e regulamentado pelos próprios investidores. A vantagem deste mercado (CGEE, 2007) é que os VERs podem ser obtidos de forma retroativa ao ano de 2003, inclusive, para atividades que foram iniciadas desde janeiro de 1999, ou seja, um projeto que efetivamente reduz emissões de GEE iniciado em 2000 pode negociar os seus VERs até hoje.

\section{As Bolsas do Clima}

Conforme publicado em seu site oficial (www.chicagoclimatex.com), a Bolsa do Clima de Chicago, CCX, foi a primeira Bolsa do mundo a negociar reduções certificadas de emissões de GEE, iniciando suas atividades em outubro de 2003. Seu fundador e CEO é o economista americano Dr. Richard L. Sandor, que foi chamado de "Herói do Planeta" pela revista TIME em 2002 por tê-la fundado. Além da CCX, o grupo controlador abriu duas novas Bolsas, com operações que seguem os mesmo regulamentos e estão localizadas no Canadá (Bolsa do Clima de Montreal - MceX) e na Europa (Bolsa do Clima Européia - ECX).

Também encontra-se disponível no site oficial da CCX a declaração de que as empresas a ela associadas comprometeram-se de maneira espontânea a diminuir 
em 4\% as emissões de GEE, em relação aos níveis emitidos em 1998. Estas empresas representam quase todos os setores da economia, além de entidades governamentais, tal como pode ser visto na Figura 13 (www.chicagoclimatex.com).

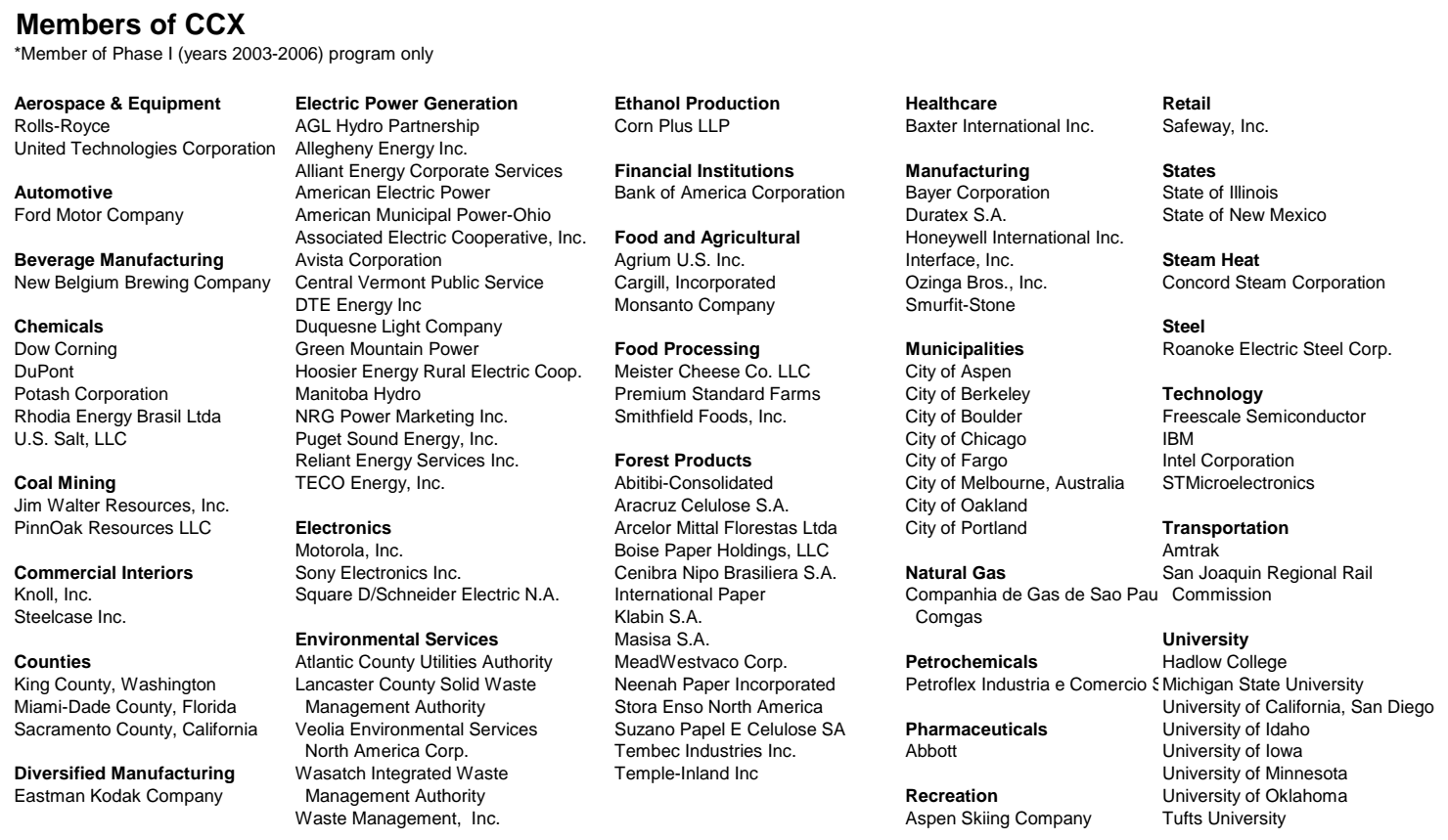

Figura 13: Entidades Associadas à Bolsa do Clima de Chicago (CCX) Fonte: Transcrita de http://www.chicagoclimatex.com

Tanto prestígio em Chicago levou à inauguração, em abril de 2005, da filial européia da Bolsa do Clima (ECX) e desde então, mais de 2 bilhões de toneladas $\mathrm{CO}_{2}$ foram comercializadas nesta nova plataforma, o que representa um valor de mercado equivalente a €24 bilhões (Capoor, Ambrosi, 2008). Lá também se encontram listadas grandes empresas, incluindo companhias globais, tais como: ABN AMRO, Barclays, British Petroleum (BP), Calyon, E.ON UK, Fortis, Goldman Sachs, Morgan Stanley e Shell.

A CCX e suas filiais possuem suas próprias normas para as empresas receberem os créditos devidos à redução de emissões e negociá-los com outras empresas. A commodity negociada na CCX é um contrato futuro, chamado CFI - Instrumento de Financiamento do Carbono - que representa 100 toneladas de $\mathrm{CO}_{2}$ equivalente e que pode ser resultado de uma iniciativa já validada, ou seja, uma permissão de emissão, ou de projetos em avaliação. 
Para cada ano em que as reduções de GEE terão efeito, uma CFI é emitida e negociada. Os preços e volumes das CFls negociadas em Chicago sofreram um aumento nos últimos meses e mostram a tendência de valorização, como se pode verificar nos quadros abaixo (referentes a reduções em 2008, 2009 e 2010 negociadas entre abril de 2006 e janeiro de 2009).

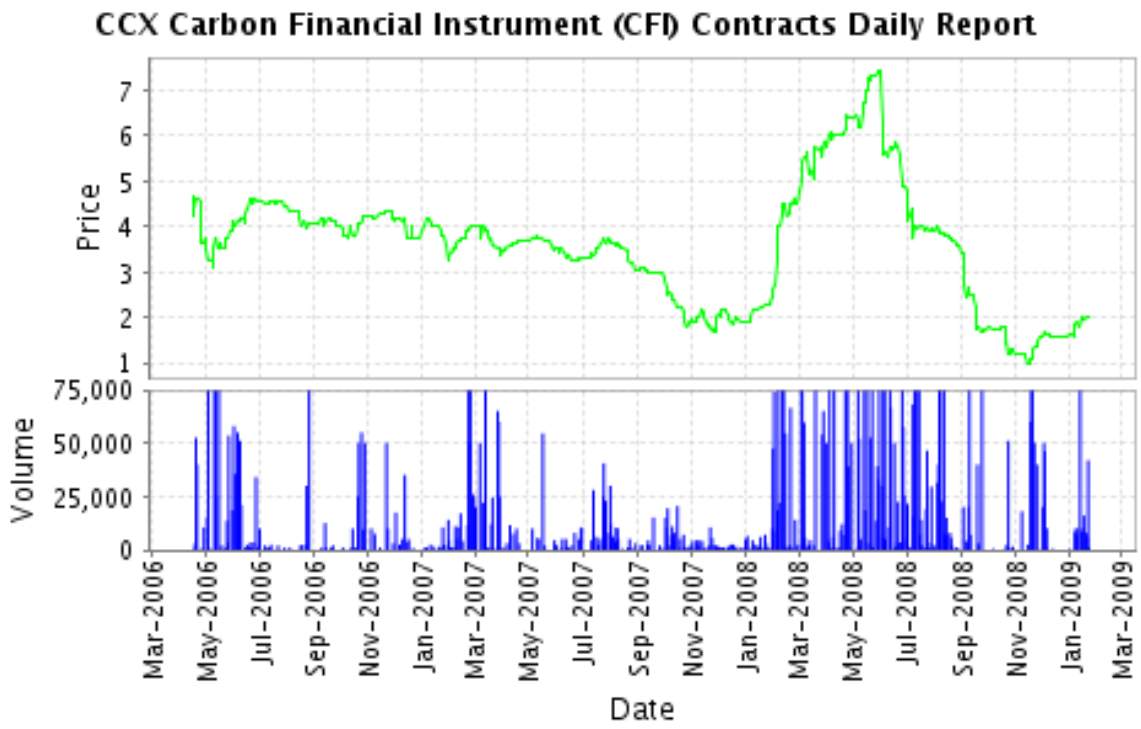

Figura 14: Acompanhamento das Cotações de CFI para 2008

Fonte: Transcrita de http://www.chicagoclimatex.com/ market/data/summary.jsf

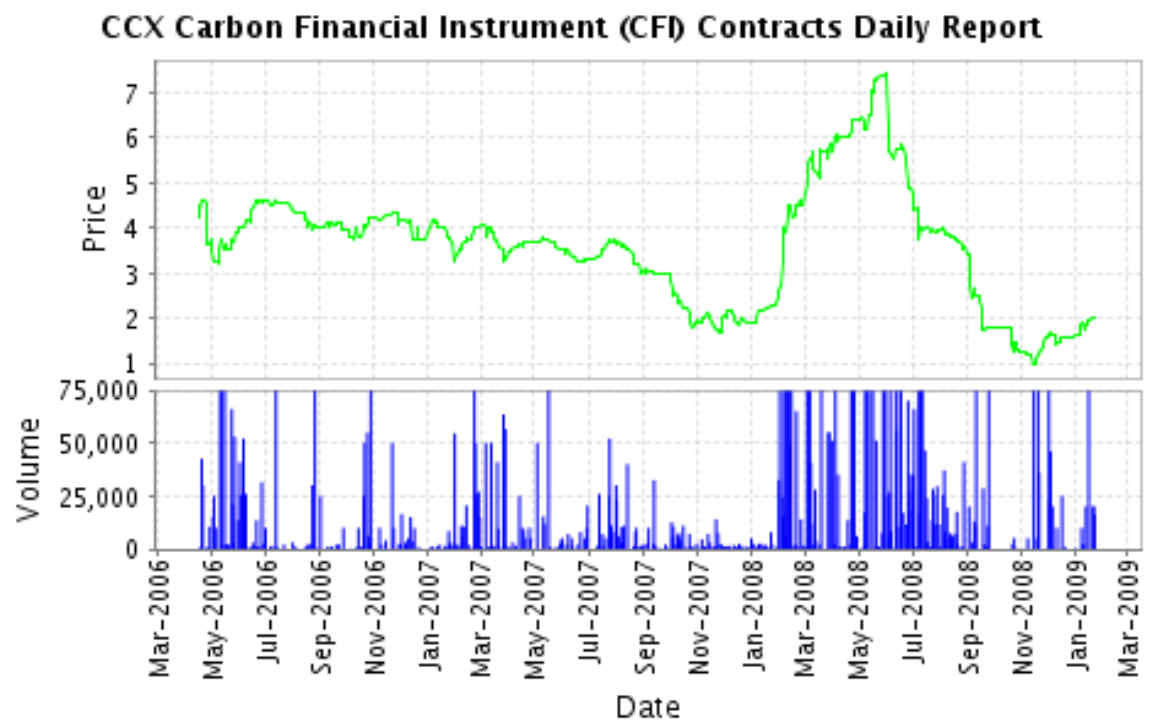

Figura 15: Acompanhamento das Cotações de CFI para 2009

Fonte: Transcrita de http://www.chicagoclimatex.com/ market/data/summary.jsf 


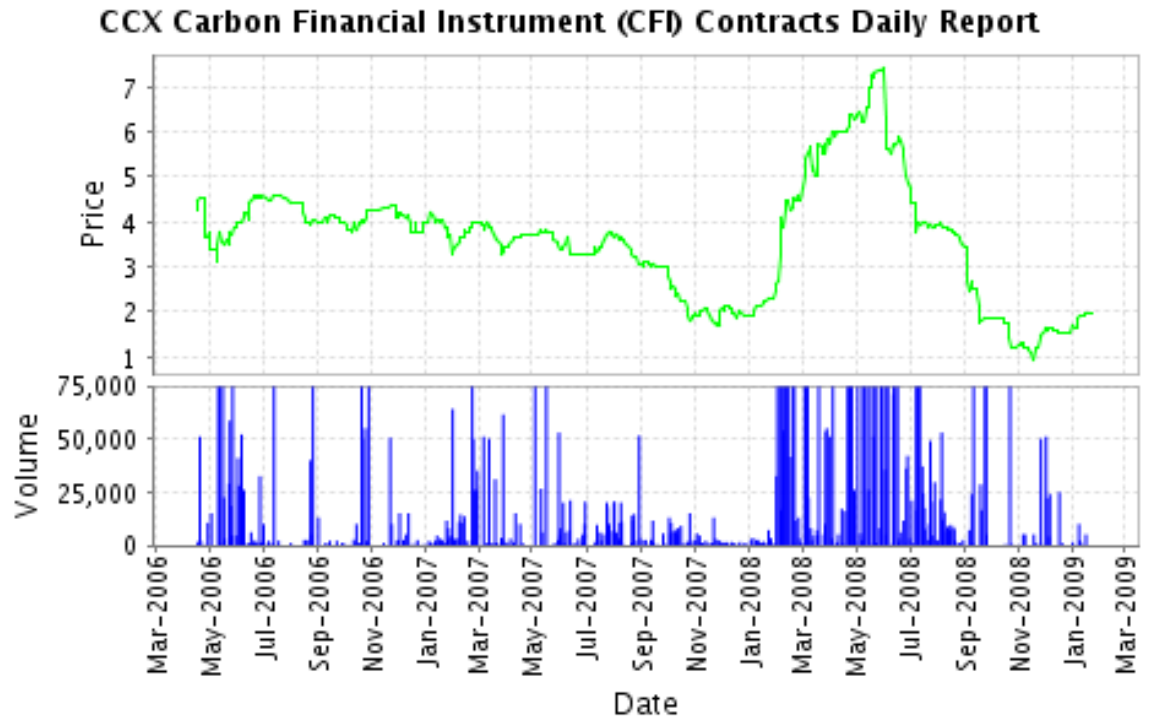

Figura 16: Acompanhamento das Cotações de CFI para 2010

Fonte: Transcrita de http://www.chicagoclimatex.com/ market/data/summary.jsf

Em 2007, a CCX fechou com um volume transacionado recorde de 23 milhões de toneladas de $\mathrm{CO}_{2} \mathrm{e}$, que representam pouco mais do que o dobro do volume de 2006 (CCX Market Report, 2008).

\section{Cenário Atual do Mercado de Certificação de Projetos}

Na CARBON-EXPO 2007, Andrei Marcu, representante da Associação Comercial Internacional das Emissões (IETA), que conta com mais de 100 países associados, descreveu sua visão sobre o estado atual do mercado de carbono:

"O mercado está amadurecendo. Além disso, mudanças significativas nos EUA, na Austrália e no Canadá estão ocorrendo. Mas ainda existem problemas. Nós precisamos assegurar a credibilidade do mercado. Eu caracterizaria o mercado como resiliente, bem sucedido e com um claro potencial de crescimento." (fonte: http://go.worldbank.org/wepkn5kcg0)

O Banco Mundial acompanha a evolução do mercado de carbono desde 2003 e lança anualmente estudos atualizados sobre o estado e as tendências do mercado (State And Trends Of The Carbon Market). Os dados apresentados a seguir tomam como base este estudos, em especial o mais recente (Capoor; Ambrosi, 2008).

O tamanho do mercado de certificação aumentou $70 \%$ em volume de $\mathrm{CO}_{2} \mathrm{e}$ transacionado, porém mais que dobrou em valor (vide Tabela 4), o que indica o 
aumento da concorrência e atividade do mercado. Em 2007, os projetos de MDL representaram a maior parte das transações do mercado (87\% do volume e $91 \%$ do valor transacionado), os projetos de IC e o mercado voluntário dobraram em volume e triplicaram em valor, sendo, no entanto, ainda pouco representativos no total. A Figura 17 mostra a evolução do mercado de certificações (Capoor; Ambrosi, 2008).

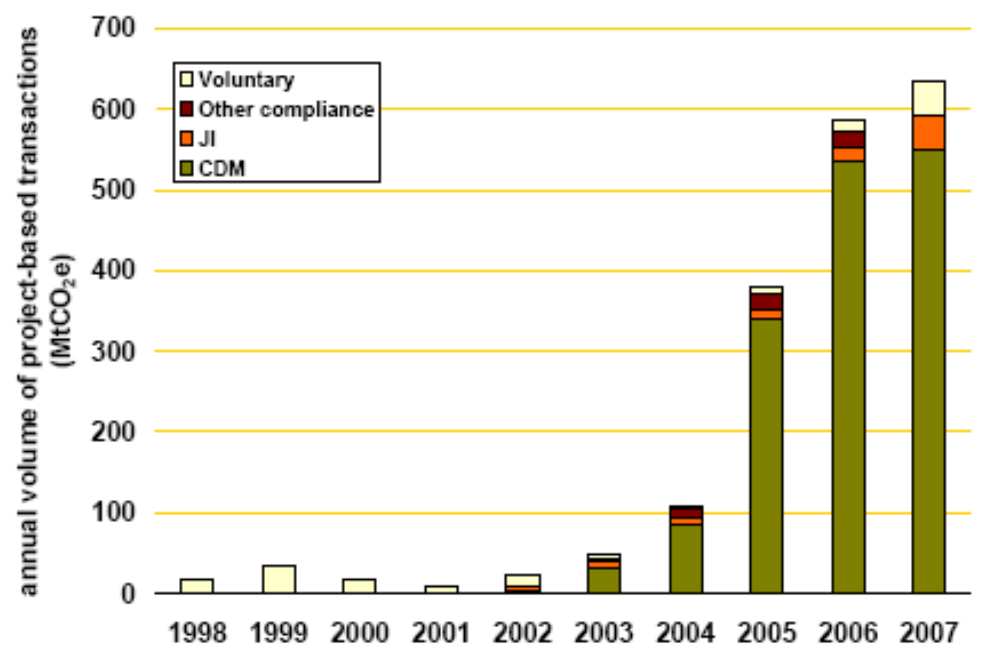

Figura 17: Volume Anual de Transações no Mercado de Certificação de Projetos $\left(^{*}\right) \mathrm{JI}=$ Implantação Conjunta, CDM = Mecanismo de Desenvolvimento Limpo

Fonte: Transcrita de State Trends of Carbon Markets (2008)

Os principais compradores deste mercado são os europeus, que adquiriram $90 \%$ de toda a oferta de certificação de projetos (MDL e IC) entre 2006 e 2007. Entre eles, os ingleses são os maiores compradores, com $59 \%$ de toda a oferta, como se pode ver na Figura 21(Capoor; Ambrosi, 2008). O Reino Unido é considerado hoje o "hub mundial" para o financiamento de projetos ligados à redução de carbono. Diversas empresas inglesas procuram projetos que poderão the colocar numa posição de agregador e revendedor de certificados garantidos no mercado secundário. Interessante notar a característica de investimento deste mercado, uma vez que $79 \%$ das compras foram feitas por empresas privadas. 


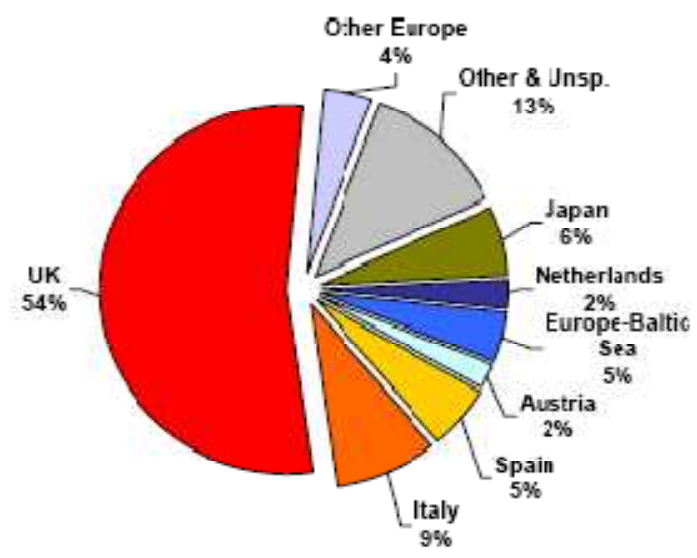

2006

Overall volume $553 \mathrm{MtCO}_{2} \mathrm{e}$

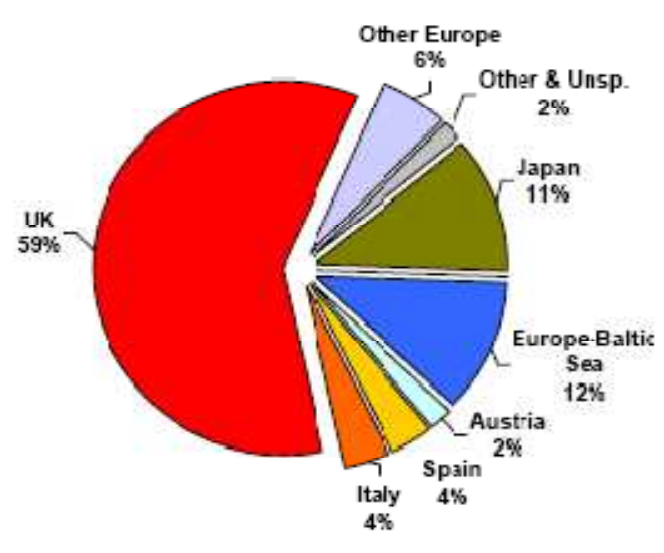

2007

Overall volume $592 \mathrm{MtCO}_{2} \mathrm{e}$

Figura 18: Compradores no Mercado Primário de Certificação de Projetos (*) Percentual do volume comprado, para projetos com duração ate 2012

Fonte: Transcrita de State Trends of Carbon Markets (2008)

A tendência que vem sendo observada desde 2005 é o aumento na condução de projetos que tratam do uso de "energia limpa" (fontes renováveis, troca de combustível e eficiência energética); em 2007 foram negociados $358 \mathrm{MtCO}_{2} \mathrm{e}(64 \%$ do mercado, comparada a apenas 33\% em 2006 e em 14\% em 2005). Os projetos da eficiência energética em grandes indústrias contabilizam a maioria das transações de redução da emissão. A Figura 19 ilustra estes dados (Capoor; Ambrosi, 2008).

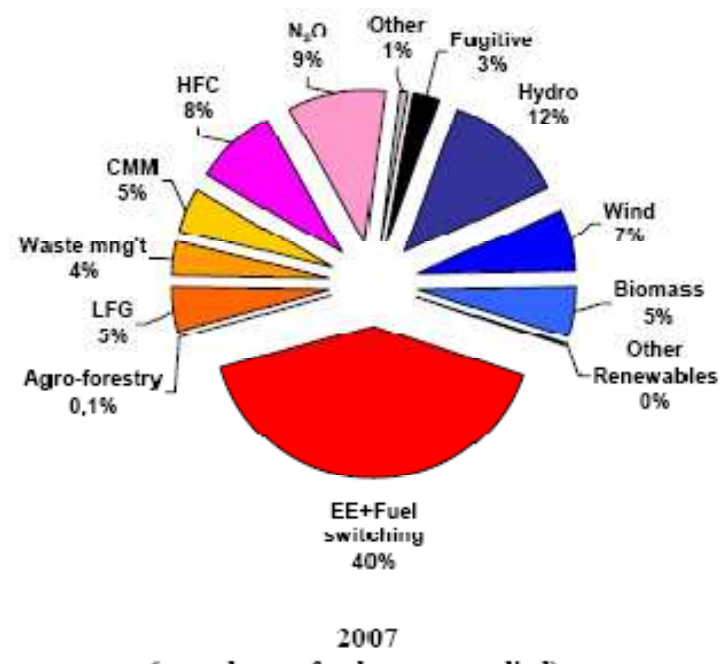

(as a share of volumes supplied)

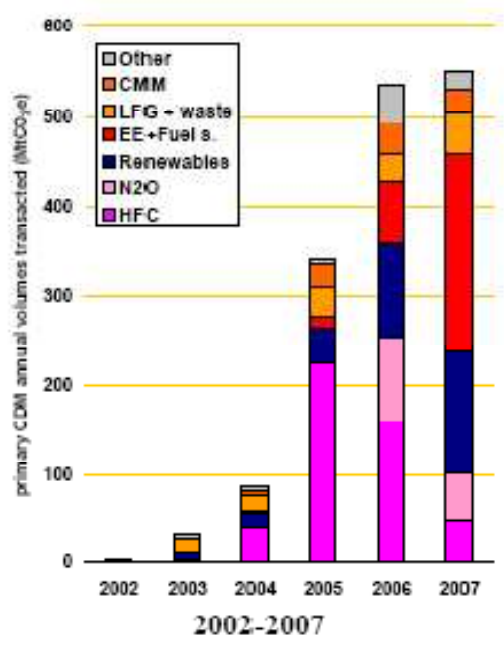

Figura 19: Oferta por Tipo de Projeto de MDL

$\left(^{*}\right)$ Percentual do volume ofertado por cada tipo de projeto, em $\mathrm{MtCO}_{2} \mathrm{e}$

Fonte: Transcrita de State Trends of Carbon Markets (2008) 
Os projetos certificados começam gradualmente a comprovar as reduções planejadas nos seus RCEs e novos investidores tentam tomar estes resultados como base para estimar a eficácia de projetos ainda em análise. Com exceção dos projetos chamados de redução de gás indústrial ( $\mathrm{HFC}$ e $\mathrm{N}_{2} \mathrm{O}$ ), que não só alcançaram como ultrapassaram as expectativas iniciais, outros tipos de projetos estão ainda bastante incipientes para gerar um índice de desconto mais baixo nas avaliações dos projetos devido ao risco de não alcançarem a redução prometida (os índices variam hoje entre $15 \%$ e $50 \%$ do valor do projeto).

Em março 2008, havia 3.188 projetos de MDL em andamento do mercado mundial, dos quais aproximadamente um terço estavam registrados (978), ou no processo do registro (188), os outros dois terços estavam em estágio de validação (2.022). O mercado de certificação de projetos começa, de certa forma, a sofrer com seu próprio sucesso: conseguir a emissão de uma RCE passou a ser cada vez mais demorado, principalmente em função da falta de capacidade das instituições avaliadoras.

A dinâmica do mercado de certificações vem mudando desde meados de 2008; os compradores se tornaram mais cautelosos em resposta a uma combinação de fatores ligados principalmente aos desafios e atrasos inesperados para atingir a certificação e verificação das reduções planejadas e ao aumento dos riscos ligados a concessão de crédito. Além disso, existe uma incerteza sobre o papel e sobre a demanda de projetos de MDL e IC após 2012, quando o primeiro período do protocolo poderá ter levado diversos países às suas reduções acordadas.

A China é o maior fornecedor primário de RCE dada a sua base industrial. Ela consolidou sua posição de principal fornecedor de projetos de redução de carbono, quadruplicando seu número dos projetos de janeiro 2007 a março 2008 e se colocando bem na frente dos outros países, com 53\% do potencial de fornecimento de RCEs até 2012. Brasil e Índia estão em segundo colocados, com 6\% do mercado cada um, seguidos de perto pelos países da África que somam juntos $5 \%$. A Figura 20 ilustra estes dados (Capoor; Ambrosi, 2008). 


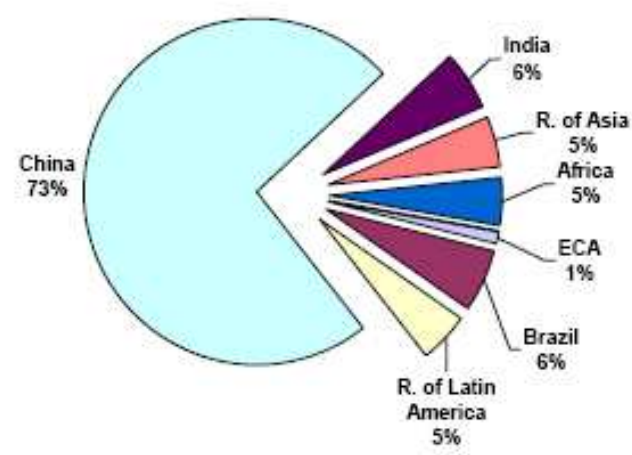

2007

(as a share of volumes supplied)

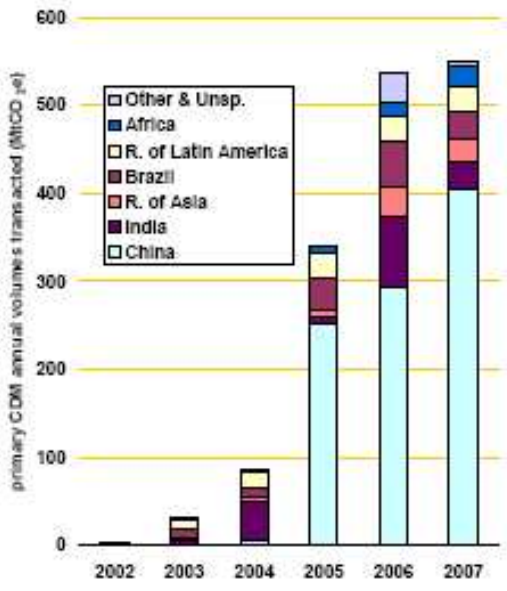

2002-2007

Figura 20: Origem dos Projetos de MDL (*) Percentual do volume ofertado por cada país, em $\mathrm{MtCO}_{2} \mathrm{e}$

Fonte: Transcrita de State Trends of Carbon Markets (2008)

Segundo estudo de 2006 da Embrapa (Tabela 5), a participação do Brasil no mercado de MDL é esperada para ser $25 \%$ do total do mercado de créditos de carbono, podendo gerar uma receita anual de 400 milhões de dólares (Araujo, 2006).

\begin{tabular}{|ll|}
\hline Emissão dos países desenvolvidos em 1990 & 13,7 bilhões de toneladas de $\mathrm{CO}_{2}$ \\
\hline Redução comprometida (5,2\% do total) & 714 milhões de toneladas de $\mathrm{CO}_{2}$ \\
\hline Preço estimado em 2006 (US $\$ 5,63$ por tonelada de $\mathrm{CO}_{2}$ ) & US $\$ 4$ bilhões/ano \\
\hline Estimativa de participação do MDL (40\%) & US $\$ 1,6$ bilhões/ano \\
\hline Expectativa do Brasil no mercado de MDL (25\%) & US $\$ 400$ milhões/ano \\
\hline
\end{tabular}

Tabela 5: Estimativa de Participação de Brasil no Mercado de MDL Fonte: Adaptada de Araujo (2006)

Na Tabela 6, o estudo da Embrapa é atualizado com dados de 2008, verificando-se que o Brasil tem uma receita real de apenas 33 milhões de dólares por ano, 12 vezes menos que a expectativa em 2006.

\begin{tabular}{|ll|}
\hline Emissão dos países desenvolvidos em 1990 & 13,7 bilhões de toneladas de $\mathrm{CO}_{2}$ \\
\hline Redução comprometida (5,2\% do total) & 714 milhões de toneladas de $\mathrm{CO}_{2}$ \\
\hline Preço estimado em 2006 (US $\$ 5,63$ por tonelada de $\mathrm{CO}_{2}$ ) & US $\$ 4$ bilhões/ano \\
\hline Participação do MDL no mercado em 2007 (12,5\%) & US $\$ 550$ milhões/ano \\
\hline Participação do Brasil no mercado de MDL $(6 \%)$ & US $\$ 33$ milhões/ano \\
\hline
\end{tabular}

Tabela 6: Participação de Brasil no Mercado de MDL em 2007

Fonte: Adaptada de Araujo (2006) 
Uma possível explicação para a baixa participação do Brasil no mercado atual de MDL é que, diferentemente da China, uma das características brasileiras no MDL é a diversidade de áreas para o desenvolvimento de atividades de projeto, ao todo, nove escopos setoriais já foram envolvidos. A Tabela 7 mostra que entre os 268 projetos de $\mathrm{MDL}$ desenvolvidos no Brasil, $67 \%$ envolveram atividades que reduzem $\mathrm{CO}_{2}$ e $32 \%$ visam à redução de $\mathrm{CH}_{4}$ (CGEE, 2007). A China, por sua vez, tem se concentrado em projetos de redução de gases indústrias que possuem um potencial de aquecimento global milhares de vezes maior que o $\mathrm{CO}_{2}$ e o $\mathrm{CH}_{4}$ (Capoor, Ambrosi; 2008).

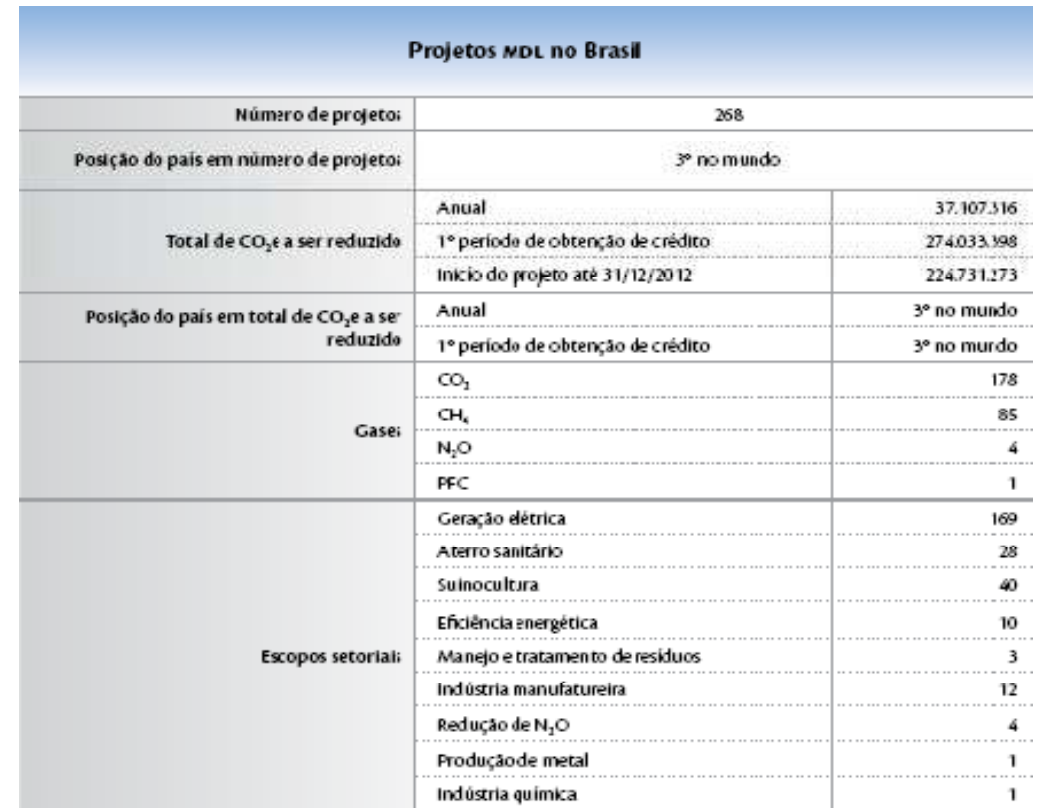

Tabela 7: Síntese da Situação de MDL no Brasil em 2008

Fonte: Transcrita do Manual de Capacitação sobre Mudança do Clima (CGEE,2008)

\subsubsection{O Protocolo GHG}

O Green House Gas Protocol, ou Protocolo GHG, é a mais difundida metodologia internacional de gestão de emissões de gases do efeito estufa, sendo a ferramenta mais utilizada por governantes, líderes sociais e empresários para quantificar e gerenciar tais emissões. O Protocolo GHG é o resultado de mais de uma década de parceria entre World Resources Institute e o World Business Council for Sustainable Development. Vem sendo desenvolvido com o apoio de empresas, governos e 
grupos de proteção ambiental para construção de uma nova geração de programas para defender a mudança climática (www.ghgprotocol.org).

Em maio de 2008, foi lançado o Programa Brasileiro de Inventário Corporativo de Gases de Efeito Estufa que traz ao país a metodologia do GHG Protocol. O Brasil é o terceiro país, depois de México e Filipinas, a desenvolver o programa de emissão de gases baseado no GHG Protocol. O programa no Brasil é uma parceria do Ministério do Meio-Ambiente, o CEBDS (Conselho Empresarial Brasileiro para o Desenvolvimento Sustentável), a Fundação Getúlio Vargas, o World Business Council on Sustainable Development e o World Resources Institute. Empresas como - Banco do Brasil, Bradesco, Natura, Votorantim e Sadia foram algumas das que aderiram de imediato à iniciativa. Logo após seu lançamento, foi deflagrada uma série de encontros com representantes das entidades e das empresas para adequar a ferramenta à realidade brasileira (CEBDS, 2008).

A parceria foi lançada com a adesão de 16 empresas fundadoras e, desde então, mais 5 empresas se juntaram ao programa. A participação das empresas é voluntária e os participantes recebem treinamento e capacitação nos problemas relacionados aos gases do efeito estufa em troca da divulgação dos estoques de GEE de cada uma das empresas. As empresas fundadoras representam diversos setores da economia e estão listadas a seguir (CEBDS, 2008):

- Alcoa (Alumínio)

- Anglo American (Mineração)

- Arcelor Mittal (Aço)

- Banco do Brasil (Financeiro)

- Natura (Cosméticos)

- Nova Petroquímica (Químicos)

- Boticário (Cosméticos)

- Petrobrás (Petróleo)

- Sadia (Alimentos)
- Votorantim (Manufatura)

- Wal-Mart Brasil (Varejo)

- Bradesco (Financeiro)

- CNEC (Engenharia)

- Copel (Eletricidade)

- Ford (Automotivo)

- Grupo Abril (Mídia) 


\section{Ferramentas de Cálculo}

O GHG Protocol possui uma série de ferramentas e metodologias que permitem o cálculo da emissão de carbono em diversas indústrias e negócios existentes pelo mundo. Uma vez que esta é a ferramenta oficialmente utilizada no Brasil para inventariar a emissão de GEE (CEBDS, 2008), os estudos do impacto das emissões de carbono em modelos logísticos desta dissertação estão baseados na metodologia de cálculo existente no site do GHG Protocol (http://www.ghgprotocol.org/calculationtools/all-tools) sob o nome de " $\mathrm{CO}_{2}$ emissions from transport or mobile sources".

A ferramenta disponibilizada pelo GHG Protocol é elaborada em Excel e permite que facilmente seja calculado o total de carbono emitido por uma operação, baseando-se nas variáveis de distância percorrida ou na de consumo de combustível gerado na operação para cada tipo de veículo. A ferramenta possui diversos parâmetros e padrões para calcular os impactos resultantes das emissões de carbono para transporte rodoviário, aéreo, ferroviário e marítimo.

Apesar de ser apontado como uma metodologia mais precisa, as informações necessárias para o cálculo de emissão através do consumo de combustível são mais difíceis de serem obtidas e, portanto, geram um erro potencial maior (para realizar este cálculo seria necessário obter a média de consumo de cada tipo de veículo que compõe na frota). Sendo assim, para a modelagem nesta dissertação, foi adotado o cálculo de emissão de carbono baseado na distância percorrida pelos veículos para realização das transferências e distribuições ao longo dos cenários.

O capítulo seguinte apresenta o detalhamento da modelagem do problema, assim como as melhorias e novidades em relação aos trabalhos citados anteriormente nesta dissertação. 


\section{MODELAGEM DO PROBLEMA}

Este capítulo tem como objetivo caracterizar o contexto do problema, definir as dimensões de custos e volumes, além de estabelecer as premissas de modelagem.

\subsection{DEFINIÇÃO DO PROBLEMA}

O problema analisado é uma rede de distribuição física composta por três elos: Fábrica, Centro de Distribuição e Mercado consumidor, a partir do qual se formulou um modelo que representa o fluxo de distribuição de produtos e que seja capaz de determinar qual configuração da malha logística (quantidade, capacidade e localização de cada elo) gera o menor custo total para a empresa.

O modelo matemático construído toma como ponto de partida o estudo realizado por Silva (2007) e parte do mesmo cenário base para de criação da base comparativa para calibração dos primeiros resultados. No entanto, para atualizar o modelo novos parâmetros foram calculados de acordo com a realidade do mercado brasileiro em 2008. A partir do resultado da comparação e calibração inicial, o modelo foi trabalhado no sentido de aumentar sua flexibilidade e aumentar sua complexidade em termos de variáveis e parâmetros sendo analisados.

O modelo aqui desenvolvido tem como objetivo determinar os fluxos de materiais (na transferência e na distribuição), a abertura de instalações e as regiões atendidas por cada um dos centros de distribuição, considerando simultaneamente o impacto relacionado a emissão de carbono e os benefícios fiscais associados aos Estados brasileiros analisados.

Para efeito de simplificação e agilidade no processamento computacional deste modelo, foram adotadas as seguintes premissas, fruto da discussão no exame de qualificação e da atual realidade de produtos de bens de consumo.

- Cada fábrica tem capacidade de atender sozinha 100\% da demanda do mercado para os 3 produtos analisados; 
- Cada produto deve ser produzido, na sua totalidade, em apenas umas das fabricas devido as restrições das instalações das linhas de produção de cada produto;

- O modelo considera variações de estoque causadas pelas variações na malha em função do número de Centros de Distribuição através do cálculo do estoque em trânsito referente aos arcos da malha;

- O modelo possui uma parcela da função objetivo destinada a análise do impacto do fornecimento de matéria-prima dos fornecedores para as fábricas. Esta parcela da função objetivo será detalhada no próximo capítulo;

- As fábricas possuem diferentes níveis de operação dependentes de suas capacidades e para cada nível foi considerado um custo fixo diferente;

- O modelo não considera o crédito de ICMS gerado pela compra de matériasprimas na fábrica devido ao mesmo ser acrescido pelo fornecedor no momento da venda;

- Permite-se a abertura de múltiplas fábricas e centros de distribuição;

- O modelo considera a existência de três tipos de veículos: carreta, truck e VUC (Veículo Urbano de Carga) para realização do transporte entre os diversos nós representados no estudo:

- Transferência: carreta;

- Distribuição: truck e VUC;

- A frota de veículos utilizada pela empresa é de uso exclusivo, não existindo divisão de cargas com outras empresas;

- Os valores das taxas de emissão de carbono seguem o mesmo padrão adotado pelo Governo Brasileiro, que é baseado no GHG Protocol, detalhado no Capítulo 2;

- O modelo considera somente a emissão de carbono realizada pelo transporte, assumindo-se que as emissões totais de fábricas e centros de distribuição não sofreriam mudança ao longo dos cenários;

Além das premissas descritas anteriormente, algumas premissas consideradas por Silva (2007) foram mantidas, como detalhadas a seguir:

- A demanda considerada corresponde à demanda real, por região, de um único ano de operação da empresa analisada no estudo de caso original;

- O ICMS incidente sobre as transações é 100\% repassado ao mercado; 
- Os mercados podem ser abastecidos por mais de um centro de distribuição;

- Múltiplos pontos de demanda foram agrupados segundo o critério de mesoregiões estabelecido pelo IBGE, somando-se as demandas e aplicando-as à cidade-centro de cada meso-região;

- Os arcos de transporte considerados são: transferência entre fábrica e CD e distribuição entre $\mathrm{CD}$ e mercado;

- Não está contemplada a existência de envios diretos da fábrica para o mercado consumido;

- Os centros de distribuição possuem diferentes níveis de operação dependentes de suas capacidades e para cada nível foi considerado um custo fixo diferente;

- O modal de transporte utilizado para todas as movimentações é o rodoviário;

- A modalidade de frete utilizada pela empresa é CIF (comum no segmento de bens de consumo), ou seja, os custos de transporte devem ser considerados na análise do custo total do modelo em estudo; 


\subsection{MODELO MATEMÁTICO}

O modelo matemático aqui desenvolvido toma como base o modelo de PLIM (Programação Linear Inteira Mista) apresentado por Silva (2007) e insere uma série de mudanças, de modo a aumentar a aderência do modelo a realidade brasileira e torná-lo mais flexível. Comparando-se ao modelo apresentado por Silva (2007), pode se dizer que as principais mudanças realizadas foram:

\begin{tabular}{|c|c|c|}
\hline & Silva (2007) & Modelo Desenvolvido \\
\hline Fábricas & $\begin{array}{l}\text { - Não possui variável de custos } \\
\text { fixos para abertura das fábricas } \\
\text { - As fábricas produzem uma única } \\
\text { classe de produto (especializada) }\end{array}$ & $\begin{array}{l}\text { - Adicionou-se uma variável de custo fixo } \\
\text { para determinar a abertura das fábricas } \\
\text { - As fábricas são capazes de produzir } \\
\text { qualquer um dos produtos } \\
\text { - Criação de fábricas de } n \text { tamanhos } \\
\text { para suportar a existência de fabricação } \\
\text { centralizada }\end{array}$ \\
\hline $\begin{array}{l}\text { Linhas de } \\
\text { Produção }\end{array}$ & $\begin{array}{l}\text { - Não existia a variável de linha de } \\
\text { produção }\end{array}$ & $\begin{array}{l}\text { - Criação da variável de linha de } \\
\text { produção de modo a permitir a abertura } \\
\text { de apenas uma linha por classe de } \\
\text { produto. }\end{array}$ \\
\hline $\begin{array}{l}\text { Centro de } \\
\text { Distribuição }\end{array}$ & $\begin{array}{l}\text { - Custos de transbordo eram } \\
\text { elevados e desproporcionais aos } \\
\text { valores de mercado }\end{array}$ & $\begin{array}{l}\text { - Custos de transbordo dos centros de } \\
\text { distribuição foram revisados de acordo } \\
\text { com os valores de mercado }\end{array}$ \\
\hline $\begin{array}{l}\text { Matéria- } \\
\text { Prima }\end{array}$ & $\begin{array}{l}\text { - Não considera o impacto do custo } \\
\text { de matéria-prima (obs: fábricas } \\
\text { eram fixas) }\end{array}$ & $\begin{array}{l}\text { - Criação de modelagem da matéria- } \\
\text { prima de modo a poder analisar o } \\
\text { impacto no fornecimento da mesma } \\
\text { quando da mudança de localização da } \\
\text { fábrica }\end{array}$ \\
\hline Cenários & $\begin{array}{l}\text { - Não consideravam a existência de } \\
\text { benefícios fiscais simultâneos em } \\
\text { mais de um Estado }\end{array}$ & $\begin{array}{l}\text { - Permite a análise simultânea de } \\
\text { benefícios fiscais nos Estados }\end{array}$ \\
\hline $\begin{array}{l}\text { Emissão de } \\
\text { GEE }\end{array}$ & $\begin{array}{l}\text { - Não considera qualquer impacto } \\
\text { ambiental na operação logística }\end{array}$ & $\begin{array}{l}\text { - Incorpora uma variável de emissão de } \\
\text { carbono para análise do custo de tornar } \\
\text { a operação neutra de emissões de } \\
\text { carbono }\end{array}$ \\
\hline $\begin{array}{l}\text { Distâncias } \\
\text { Percorridas }\end{array}$ & $\begin{array}{l}\text { - Não possui variável de cálculo que } \\
\text { leve em consideração a análise da } \\
\text { distância percorrida pelo transporte }\end{array}$ & $\begin{array}{l}\text { - Possui variável criada para o cálculo da } \\
\text { distância total percorrida pelo transporte } \\
\text { entre os arcos do modelo }\end{array}$ \\
\hline Estoques & $\begin{array}{l}\text { - Não considera os custos dos } \\
\text { estoque }\end{array}$ & $\begin{array}{l}\text { - Considera os custos dos estoques nos } \\
\text { nós e nos arcos do modelo }\end{array}$ \\
\hline
\end{tabular}

Tabela 8: Quadro Comparativo (Modelo de Silva (2007) vs. Modelo Desenvolvido) 
A seguir apresenta-se o modelo matemático desenvolvido:

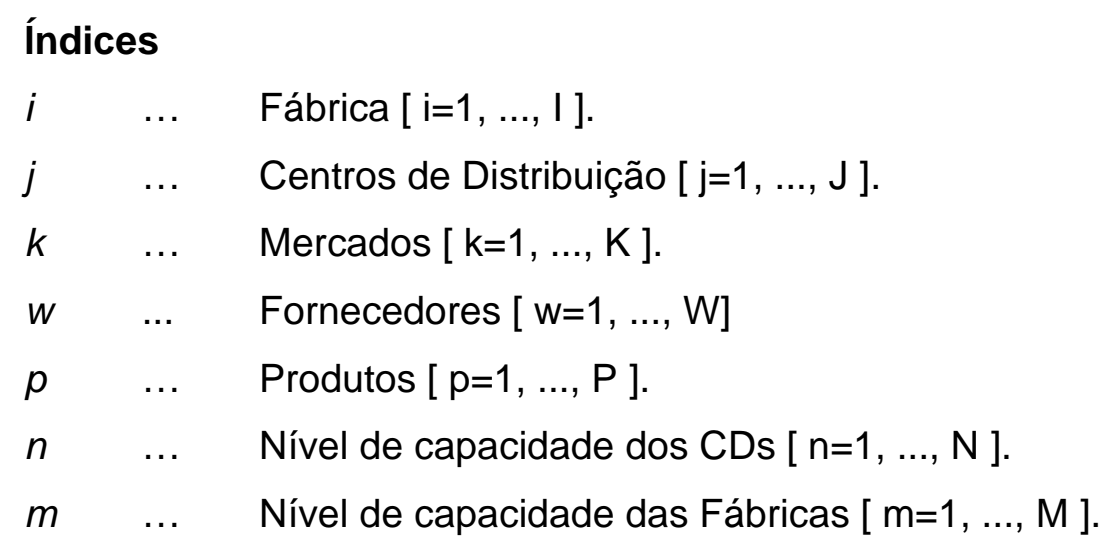

\section{Parâmetros}

$D_{p e} \quad \ldots \quad$ Demanda do produto $p$ no mercado $k$ (t/ano).

CapFabim $_{i m} \quad \ldots \quad$ Capacidade de produção da fábrica $i$ no nível $m$ (t/ano).

CapProdip $\quad . . \quad$ Capacidade de produção na fábrica $i$ do produto $p$ (t/ano).

CapCD $D_{j n} \quad \ldots \quad$ Capacidade do CD $j$ no nível de capacidade $n$ (t/ano).

CTrnsij $\quad \ldots \quad$ Custo do frete de transferência da fábrica i para o $\operatorname{CD} j(\mathrm{R} \$ / \mathrm{t})$.

CDstrjk $\quad \ldots \quad$ Custo do frete de distribuição do CD j para o mercado $k(\mathrm{R} \$ / \mathrm{t})$.

FixFabim $_{i m} \quad \ldots \quad$ Custo fixo da Fábrica $i$ com capacidade $m(\mathrm{R} \$ / \mathrm{ano})$.

Fix $C D_{j n} \quad \ldots \quad$ Custo fixo do CD $j$ com capacidade $n$ (R\$/ano).

$\mathrm{CvF}_{i} \quad \ldots \quad$ Custo variável de transbordo na fábrica $i(\mathrm{R} \$ / \mathrm{t})$.

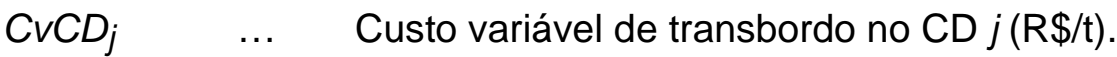

$\mathrm{CTrnsMP}_{w i} \quad \ldots \quad$ Custo de transporte de matéria-prima de $w$ para $i(\mathrm{R} \$ / \mathrm{t})$.

AlíqICMS $S_{i j} \quad \ldots \quad$ Alíquota de ICMS correspondente ao arco com origem na fábrica $i$ e destino no $C D j$.

AlíqICMS jk $\quad \ldots \quad$ Alíquota de ICMS correspondente ao arco com origem no $C D j$ e destino no mercado $k$.

AlíqBef $f_{j} \quad \ldots \quad$ Percentual relativo ao crédito presumido fornecido pelo benefício em relação à base de cálculo, no $C D j$. 

$\begin{array}{lll}P T_{p} & \ldots & \text { Custo de produção do produto } p \text { sem o ICMS, ou seja, o }\end{array}$ valor utilizado na NF de transferência do produto, sobre o qual incide o ICMS $(R \$ / t)$.

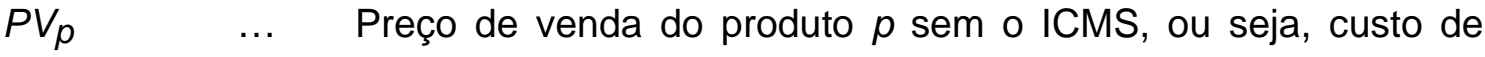 produção + margem, sobre o qual incide o ICMS $(R \$ / t)$.
Dist $_{i j} \quad \ldots \quad$ Distância de $i$ para $j(\mathrm{em} \mathrm{km})$.
DistD $_{j k} \quad \ldots \quad$ Distância de $j$ para $k(\mathrm{em} \mathrm{km})$.
CapTTL $\quad$... Capacidade de transporte de um veículo TL (Truck Load) na transferência de mercadorias (t/viagem).
CapDTL $\quad$... Capacidade de transporte de um veículo TL (Truck Load) na distribuição de mercadorias (t/viagem).
CapDLTL $\quad$... $\quad$ Capacidade de transporte de um veículo LTL (Less Than Truck Load) na distribuição de mercadorias (t/viagem).
FCarbTTL $\quad \ldots \quad$ Custo do $\mathrm{CO}_{2}$ emitido por km percorrido na transferência de mercadorias por um caminhão TL (Truck Load) (em R $\$ / \mathrm{km}$ ).
FCarbDTL $\quad \ldots \quad$ Custo do $\mathrm{CO}_{2}$ emitido por km percorrido na distribuição de mercadorias por um caminhão TL (Truck Load) (em R $\$ / \mathrm{km}$ ).
FCarbDLTL ... Custo do $\mathrm{CO}_{2}$ emitido por km percorrido na distribuição de mercadorias por um caminhão LTL (Less Than Truck Load) (em $\mathrm{R} \$ / \mathrm{km}$ ).
$E_{k} \quad \ldots \quad$ Distância percorrida na distribuição de mercadorias, por um caminhão LTL, dentro da região de entrega $k .(\mathrm{km})$
FForn $_{w p} \quad \ldots \quad$ Percentual do volume de matérias-primas compradas do fornecedor $w$ para produção do produto $p$.
FTL $\quad$... $\quad$ Percentual do volume de transporte realizado em TL (Truck Load).
$D^{D H F a b} b_{i} \quad \ldots \quad$ Dias de estoque na Fabrica $i$ (dias).
$D O H C D_{j} \quad \ldots \quad$ Dias de estoque no Centro de Distribuição $j$ (dias).
CC $\quad$... Taxa de custo de capital (\% ao ano). 


\begin{tabular}{|c|c|c|}
\hline \multicolumn{3}{|l|}{ Variáveis } \\
\hline Trnsijp & $\ldots$ & Quantidade do produto $p$ transferida de i para $j$ (t/ano). \\
\hline$D s t r D_{j k p}$ & $\ldots$ & Quantidade do produto $p$ distribuída de $j$ para $k$ (t/ano). \\
\hline TrnsMP wip & $\ldots$ & $\begin{array}{l}\text { Quantidade de matéria-prima do produto } p \text { transportado de } w \\
\text { para } i(\text { t/ano })\end{array}$ \\
\hline$B F_{j}$ & $\ldots$ & $\begin{array}{l}\text { Ganho auferido com o benefício fiscal na distribuição a } \\
\text { partir do } C D j(\mathrm{R} \$ / \mathrm{ano}) \text {. }\end{array}$ \\
\hline$Z_{\text {im }}$ & $\ldots$ & $\begin{array}{l}\text { Variável binária: assume valor } 1 \text { caso a Fábrica } i \text { de capacidade } \\
m \text { seja aberta; assume } 0 \text { (zero) em caso contrário. }\end{array}$ \\
\hline$Z_{i p}$ & $\ldots$ & $\begin{array}{l}\text { Variável binária: assume valor } 1 \text { caso a Fábrica i produza o } \\
\text { produto p; assume } 0 \text { (zero) em caso contrário. }\end{array}$ \\
\hline$Z_{j n}$ & $\ldots$ & $\begin{array}{l}\text { Variável binária: assume valor } 1 \text { caso o CD } j \text { de capacidade } n \\
\text { esteja aberto; assume } 0 \text { (zero) em caso contrário. }\end{array}$ \\
\hline$C T$ & $\ldots$ & Custo total da operação (R\$/ano). \\
\hline DIST_TTL & $\ldots$ & $\begin{array}{l}\text { Distância total percorrida pelo transporte na transferência da } \\
\text { Fábrica ao Centro de Distribuição. }(\mathrm{km})\end{array}$ \\
\hline DIST_DTL & $\ldots$ & $\begin{array}{l}\text { Distância total percorrida pelo transporte em TL na distribuição } \\
\text { do Centro de Distribuição até o consumidor final }(\mathrm{km}) \text {. }\end{array}$ \\
\hline DIST_DLTL & $\ldots$ & $\begin{array}{l}\text { Distância total percorrida pelo transporte em LTL na distribuição } \\
\text { do Centro de Distribuição até o consumidor final }(\mathrm{km}) \text {. }\end{array}$ \\
\hline EstT & $\ldots$ & Estoque Total (R\$/ano). \\
\hline$E s t F a b_{i}$ & $\ldots$ & Estoque da Fábrica $i(\mathrm{R} \$ / \mathrm{ano})$. \\
\hline$E s t C D_{j}$ & $\cdots$ & Estoque do Centros de Distribuição $j$ ( $\mathrm{R} \$ /$ ano). \\
\hline EstTran $_{i j}$ & $\ldots$ & $\begin{array}{l}\text { Estoque em transito entre a Fábrica i e o Centro de Distribuição } j \\
(\mathrm{R} \$ / \text { ano). }\end{array}$ \\
\hline
\end{tabular}




\section{Função Objetivo}

Minimizar o Custo Total (CT)

$$
\begin{aligned}
& C T=\sum_{i} \sum_{j} \sum_{p}\left(\operatorname{Trns}_{i j p} \times C \operatorname{Trns}_{i j}\right) \quad \text { / (A) Custo do frete de transferência } i-j \\
& +\sum_{j} \sum_{k} \sum_{p}\left(D s t r D_{j k p} \times C D s t r_{j k}\right) \quad \text { / (B) Custo do frete de distribuição } j-k \\
& +\sum_{i} \sum_{m}\left(Z_{i m} \times \text { FixFab }_{i m}\right) \quad \text { / (C) Custo fixo anual da Fábrica } i \\
& +\sum_{j} \sum_{n}\left(Z_{j n} \times F i x C D_{j n}\right) \quad \text { / (D) Custo fixo anual do CD } j \\
& +\sum_{i} \sum_{j} \sum_{p}\left(\operatorname{Trns}_{i j p} \times C V F_{i}\right) \quad \text { / (E) Custo de transbordo na Fábrica } i \\
& +\sum_{j} \sum_{k} \sum_{p}\left(D s t r D_{j k p} \times C V C D_{j}\right) \quad /(\mathrm{F}) \text { Custo de transbordo no CD } j \\
& -\sum_{j} B F_{j} \quad \text { / (G) Ganho fiscal a partir do CD } j \\
& +C E \quad /(\mathrm{H}) \text { Custo ambiental do } \mathrm{CO}_{2} \text { emitido } \\
& + \text { CustoMP } \\
& + \text { EstT } \quad \text { / ( J ) Custo de Estoque Total }
\end{aligned}
$$

\section{Restrições}

- Restrição de atendimento da demanda

$$
\text { Dem }_{p k}=\sum_{j} D_{s t r} D_{j k p} \quad \forall k, \forall p
$$

- Restrição de capacidade de operação da Fábrica $i$

$$
\sum_{j} \sum_{p} \text { Trns }_{i j p} \leq \sum_{m}\left(Z_{i m} \times \text { CapFab }_{i m}\right) \quad \forall i
$$

- Restrição de linhas de operação da Fábrica $i$

$$
\sum_{j} \text { Trns }_{i j p} \leq Z_{i p} \times \text { CapProd }_{i p} \quad \forall i, \forall p
$$

- Restrição de capacidade de operação do CD $j$

$$
\sum_{i} \sum_{p} \operatorname{Trns}_{i j p} \leq \sum_{n}\left(Z_{j n} \times \operatorname{CapCD}_{j n}\right) \quad \forall j
$$


- Restrição para haver uma única capacidade de operação na Fábrica $i$

$$
\sum_{m} Z_{i m}=1 \quad \forall i
$$

- Restrição para haver uma única fábrica i produzindo $100 \%$ de determinado produto $p$

$$
\sum_{i} Z_{i p}=1 \quad \forall p
$$

- Restrição para haver uma única capacidade de operação no CD $j$

$$
\sum_{n} Z_{j n}=1
$$

- Balanço de massa no CD $j$

$$
\sum_{i} \text { Trns }_{i j p}=\sum_{k} D_{s t r D_{j k p}} \quad \forall j, \forall p
$$

- Balanço de massa na fábrica $i$

$$
\sum_{j} \text { Trns }_{i j p}=\sum_{w} \text { TrnsMP }_{w i p} \quad \forall i, \forall p
$$

- Balanço de massa do fornecimento do produto na fábrica $i$

$$
\begin{array}{ll}
\text { TotalMP }_{p}=\sum_{w} \sum_{i} \text { TrnsMP }_{w i p} & \forall p \\
\text { FForn }_{w p} \times \text { TotalMP }_{p}=\sum_{i} \text { TrnsMP }_{w i p} & \forall w, \forall p
\end{array}
$$

- Custo adicional da matéria-prima gerado pela mudança da fábrica

$$
\text { CustoMP }=\sum_{w} \sum_{i} \sum_{p}\left(\text { TrnsMP } P_{w i p} \times C T r n s M P_{w i}\right)
$$

- Saldo de ICMS nulo ou positivo no CD $j$

$$
\begin{aligned}
& \sum_{p} \sum_{k}\left\{D s t r D_{j k p} \times\left[\frac{P V_{p}}{\left(1-A l i q I C M S_{j k}\right.}-P V_{p}\right]\right\}-\sum_{p} \sum_{i}\left\{\operatorname{Trns}_{i j p} \times\left[\frac{P T_{p}}{\left(1-A l i q I C M S_{j}\right)}-P T_{p}\right]\right\}-B F_{j} \geq 0 \\
& \forall j
\end{aligned}
$$


- Cálculo do ganho auferido com o benefício fiscal

$$
B F_{j}=\sum_{p} \sum_{k}\left\{\left[\frac{P V p}{\left(1-\text { AliqICMS }_{j k}\right)}\right] \times \operatorname{DstrD}_{j k p}\right\} \times \text { AliqBef }_{j} \quad \forall j
$$

- Cálculo da distância percorrida pelo transporte de i para j e de j para $k$ (ida e volta)

$$
\begin{aligned}
& \text { DIST_tTL }=\frac{2}{C a p T T L} \times \sum_{i} \sum_{j} \sum_{p}\left(\operatorname{Trns}_{i j p} \times \operatorname{Dist}_{i j}\right) \\
& D I S T_{-} D T L=\frac{2}{C a p D T L} \times F T L \times \sum_{j} \sum_{k} \sum_{p}\left(D_{s t r D} D_{j k p} \times D i s t D_{j k}\right) \\
& D I S T_{-} D L T L=\sum_{j} \sum_{k} \sum_{p}\left(E_{k} \times \frac{D s t r D_{j k p}}{C a p D L T L}\right) \\
& +\frac{2 \times(1-F T L)}{\operatorname{CapDLTL}} \times \sum_{j} \sum_{k} \sum_{p}\left(D s t r D_{j k p} \times D i s t D_{j k}\right)
\end{aligned}
$$

Obs: o nominador dois (2) da parcela de cálculo da distância percorrida refere-se ao trajeto de ida e volta realizado pelos veículos no processo de entrega.

- Cálculo do Estoque Total da Cadeia (nas fábricas, CD’s e em trânsito)

$$
\begin{aligned}
& E s t T=\sum_{i} E s t F a b+\sum_{j} E_{s t C D+\sum_{i} E_{s t T r a n}} \\
& \text { EstFab }_{i}=\sum_{j} \sum_{p} \text { Trns }_{i j p} \times \text { DOHFab }_{i} \times P T_{p} \times \frac{1}{365} \times C C \\
& \text { EstCD }_{j}=\sum_{i} \sum_{p} \text { Trns }_{i j p} \times \text { DOHCD }_{j} \times P T_{p} \times \frac{1}{365} \times C C \\
& \text { EstTran }_{i}=\sum_{j} \sum_{p} \text { Trns }_{i j p} \times\left(\frac{P T_{p}}{1-\text { AliqICMS }_{i j}}\right) \times \frac{\text { Dist }_{i j}}{544} \times \frac{1}{365} \times C C
\end{aligned}
$$

- Cálculo do custo total do carbono emitido no transporte dos produtos

$$
\begin{aligned}
& C E=D I S C_{-} T T L \times F C a r b T T L \\
& +F T L \times\left(D I S T \_D T L \times F C a r b D T L\right) \\
& +(1-F T L) \times\left(D I S T \_D L T L \times F C a r b D L T L\right)
\end{aligned}
$$


- Binárias

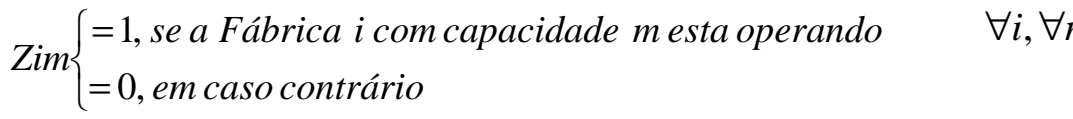

$$
\begin{aligned}
& \operatorname{Zjn}\left\{\begin{array}{l}
=1, \text { se o } C D \text { j com capacidade } n \text { esta operando } \quad \forall j, \forall n \\
=0, \text { em caso contrário }
\end{array}\right.
\end{aligned}
$$

- Não-negatividade

$$
\begin{array}{lc}
\operatorname{Trns}_{i j p} \geq 0 & \forall i, \forall j, \forall p \\
\operatorname{DstrD}_{j k p} \geq 0 & \forall j, \forall k, \forall p \\
\operatorname{TrnsMP}_{w i p} \geq 0 & \forall w, \forall i, \forall p
\end{array}
$$

\subsection{DETALHAMENTO DA MODELAGEM}

A função objetivo é composta por dez somatórias, as quais podem ser agrupadas em sete diferentes parcelas:

- Custo de Transporte

- Custo das Fábricas

- Custo dos Centros de Distribuição

- Benefício Fiscal relativo ao ICMS

- Custo ambiental do $\mathrm{CO}_{2}$ emitido

- Custo de fornecimento de MP

- Custo dos Estoques

$$
\begin{aligned}
& \text { Função Objetivo = Minimizar o Custo (CT) } \\
& \qquad \begin{aligned}
C T= & \text { Custo de Transporte } \\
& + \text { Custo das Fabricas } \\
& + \text { Custo dos Centros de Distribuição } \\
& - \text { Benefício Fiscal } \text { Re lativo ao ICMS } \\
& + \text { Custo ambiental do CO } \mathrm{C}_{2} \text { emitido } \\
& + \text { Custo de fornecimento de MP } \\
& + \text { Custo dos Estoques }
\end{aligned}
\end{aligned}
$$


A primeira parcela refere-se aos custos envolvidos no transporte de mercadorias das fábricas aos centros de distribuição e dos CDs até os mercados.

A segunda parcela refere-se ao custo das fábricas, sendo composta por duas somatórias na função objetivo: custos fixos das e custos variáveis de transbordo das fábricas.

A terceira parcela refere-se aos custos dos centros de distribuição, sendo composta por duas somatórias na função objetivo: custos fixos e custos variáveis de transbordo nos centros de distribuição.

A quarta parcela é formada pelos benefícios fiscais auferidos pela configuração de malha logística para os produtos em análise.

A quinta parcela é formada pelo custo de neutralização da emissão de carbono. Esse custo se deve a realização de compra de crédito de carbono $\left(\mathrm{CO}_{2}\right)$ equivalente á emissão realizada no transporte das fabricas até o mercado consumidor.

A sexta parcela da função objetivo é composta pelo custo adicional de transporte gerado no fornecimento de matéria-prima às fábricas.

A sétima e última parcela diz respeito ao custo de estoque nas fábricas, CD’s e em trânsito.

As restrições desse modelo são determinadas por:

- Atendimento da Demanda: toda a demanda do mercado deve ser atendida; (equação 2)

- Capacidade de Operação da Fábrica $i$ : o fluxo de produtos oriundos de determinada fábrica não pode exceder a capacidade da mesma; (equação 3)

- Linhas de operação da Fábrica $i$ : o fluxo de transferência de determinado produto não pode exceder a capacidade da linha de produção; (equação 4)

- Capacidade de operação do CD $j$ : o fluxo de produtos em determinado centro de distribuição não deve exceder a capacidade do mesmo; (equação 5) 
- Uma única capacidade de operação na Fábrica i: restrição criada de modo a garantir que só exista um único nível de capacidade para uma determinada fábrica em determinada localização; (equação 6)

- Uma única fábrica $i$ produzindo $100 \%$ de determinado produto $p$ : restrição criada de modo a garantir que exista apenas uma linha de produção pra determinado produto; (equação 7)

- Uma única capacidade de operação no CD $j$ : restrição criada de modo a garantir que só exista um único nível de capacidade para um centro de distribuição em determinada localização; (equação 8)

- Balanço de massa no CD j: garante que o volume de entrada de produtos no CD j seja igual ao volume de saída; (equação 9)

- Balanço de massa na fábrica i: garante que o volume de entrada de matéria-prima na fábrica i seja igual ao volume de saída; (equação 10)

- Balanço de massa do fornecimento do produto na fábrica i: garante que o total transferido da matéria-prima utilizada na fabricação do produto $p$ não exceda a capacidade de fornecimento do fornecedor w; (equações 11a e 11b)

- Custo adicional da matéria-prima gerado pela mudança da fábrica: calcula o custo de transporte associado ao envio das matérias-primas até as fábricas; (equação 12)

- Saldo de ICMS nulo ou positivo no CD j: garante que o benefício fiscal obtido não exceda o saldo total de ICMS no centro de distribuição e, ao mesmo tempo, inibe a criação de crédito excessivo de tributos; (equação 13)

- Benefício Fiscal: calcula o montante de benefício auferido pelo crédito de ICMS estabelecido; (equação 14)

- Cálculo da distância percorrida pelo transporte: calcula o total de quilômetros percorridos pelos veículos da fábrica para o centro de distribuição e deste para o mercado consumidor; (equações 15a, 15b e 15c)

- Cálculo do estoque total: calcula o total de estoque existente nos arcos e nos nós do modelo (equações 16a, 16b, 16c e 16d)

- Cálculo do custo total do carbono emitido no transporte dos produtos: calcula o custo da compra do crédito de carbono necessário para zerar o impacto ambiental causado pela operação; (equação 17) 
- Binárias: restrições criadas para garantir a abertura de apenas uma fábrica ou um CD em determinado local e para garantir a existência de apenas uma linha de produção para cada um dos produtos. (equações 18a, 18b e 18c)

- Não-negatividade: garante que as variáveis de decisão do modelo (fluxo de transferência de matéria-prima dos fornecedores para as fábricas, fluxo de transferência entre fábrica e $C D$ e o fluxo de distribuição entre $C D$ e mercado consumidor) sejam maiores ou iguais a zero. (equações 19a, 19b e 19c)

O Capítulo 3 detalhou a modelagem matemática, as premissas e as restrições consideradas na elaboração do modelo matemático desenvolvido. No próximo capítulo, será abordado o estudo de caso utilizado, onde cada um dos parâmetros e variáveis serão detalhados. 


\section{DESCRIÇÃO DO ESTUDO DE CASO}

Este capítulo tem como objetivo a apresentação detalhada do caso para aplicação da formulação matemática desenvolvida. O mesmo tem o intuito de esclarecer o modelo de operação da empresa em estudo e detalhar as premissas e os parâmetros considerados nas análises.

Conforme citado no Capítulo 3 desta dissertação, o estudo de caso em análise toma como base os volumes e localizações utilizados por Silva (2007) e, a partir deles, incorpora uma série de modificações e atualizações:

- Nova estrutura de fabricação (liberdade na abertura e fechamento das fábricas);

- Inclusão do conceito de linha de produção nas fábricas;

- Possibilidade de simulação de benefícios fiscais simultâneos;

- Inclusão de parcela de custo de fornecimento de matéria-prima;

- Inclusão de parcela de custo referente à neutralização da emissão de carbono gerada pelo transporte;

- Inclusão da parcela de custo referente aos estoques nas fábricas, nos centros de distribuição e em trânsito.

\subsection{DESCRIÇÃO FÍSICA DO PROBLEMA}

Para aplicação do modelo matemático elaborado foi utilizado o mesmo problema real apresentado por Silva (2007), representando a operação de produção, transporte e distribuição de uma empresa multinacional de bens de consumo não duráveis com operação no território brasileiro. Os dados de referência para o modelo são referentes à operação em 2003.

Por se tratar de informações estratégicas de operação, o nome da empresa não pode ser divulgado, assim como o nome dos produtos distribuídos. Alguns valores, tais como margem e custo de produção, foram determinados com base em dados típicos, médias e medianas. Os demais parâmetros como frete, custos logísticos e de distribuição são custos reais obtidos junto à empresa e corrigidos de acordo com 
tabelas de correção monetária da FIPE (Fundação Instituto de Pesquisas Econômicas).

Dessa forma, o caso apresentado mantém o sigilo solicitado pela empresa e ao mesmo tempo torna-se um modelo bem próximo da realidade da empresa em análise, mantendo a complexidade necessária e gerando um conjunto de cenários interessantes para ser modelado e analisado.

\section{- Fábricas}

O problema definido apresenta três sugestões de localização de fábrica, cada uma com capacidade para atender sozinha toda a demanda do mercado para todos os produtos. Os locais escolhidos para análise são: São Paulo-SP, por ser o Estado de maior demanda e Belo Horizonte-MG e Goiânia-GO por serem os Estados onde os benefícios fiscais estão sendo analisados. A tabela a seguir mostra a lista de locais candidatos para as fábricas:

\section{LOCAIS CANDIDATOS (Município e Estado)}

\begin{tabular}{l}
\hline (1) São Paulo - SP \\
(2) Belo Horizonte - MG \\
(3) Goiânia - GO \\
9: Relação dos Locais Candidatos para Abertura de Fábricas \\
Fonte: Adaptado de Silva (2007)
\end{tabular}

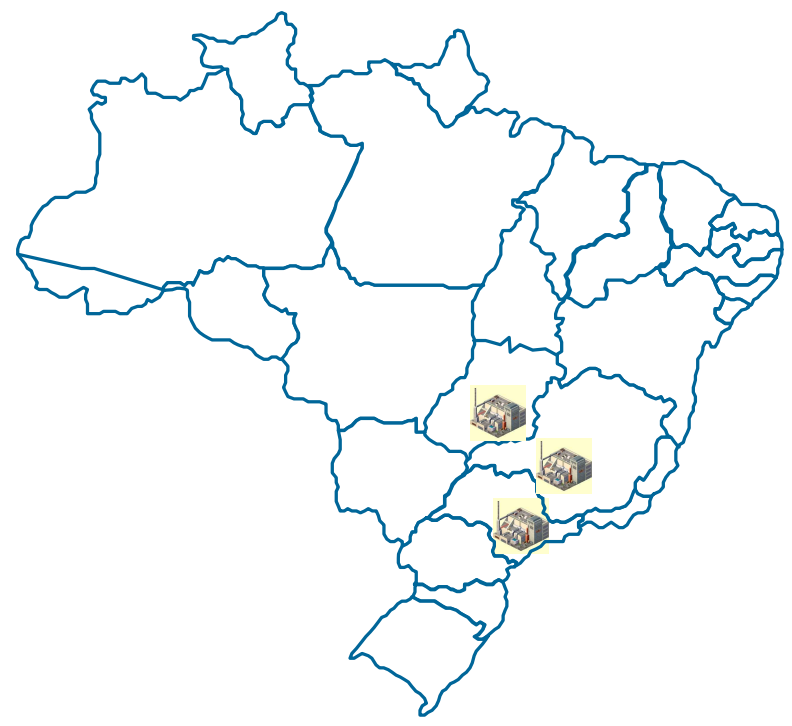

Figura 21: Distribuição dos Locais Candidatos para Abertura de Fábricas 


\section{- Centros de Distribuição}

Para o problema definido foram selecionados sete locais candiudatos: três deles estão localizados nas capitais dos Estados onde estão instaladas as fábricas e os quatro restantes se localizam nas capitais de maior concentração de demanda nas regiões sul e nordeste.

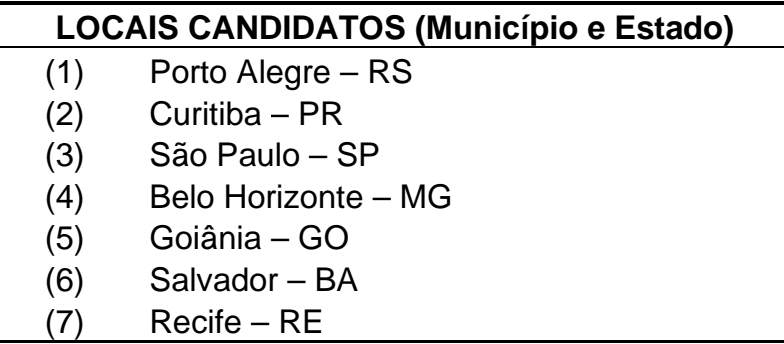

Tabela 10: Relação dos Locais Candidatos para Abertura de CDs Fonte: Adaptado de Silva (2007)

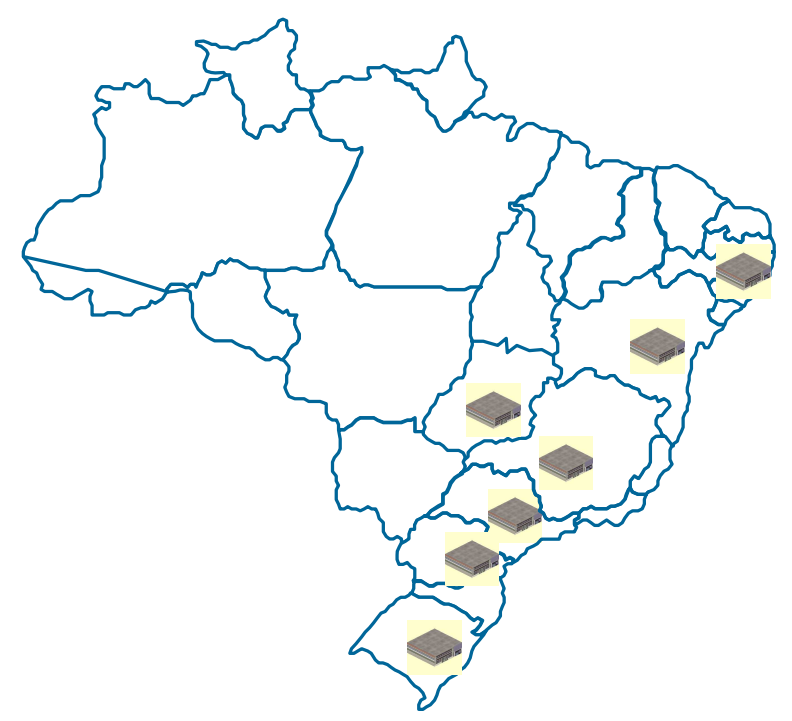

Figura 22: Distribuição dos Locais Candidatos para Abertura de CDs

\section{- Mercado}

Assim como fez Yoshizaki (2002), foi utilizado o critério de agrupamento da demanda por meso-regiões do IBGE (Instituto Brasileiro de Geografia e Estatística), com o intuito de reduzir o tamanho e complexidade do modelo. $O$ agrupamento resultou num total de 137 zonas de demanda, sendo eliminadas apenas as mesoregiões referentes a parte da Amazônia Legal, onde o acesso rodoviário é bastante restrito, gerando altos custos de distribuição e potencial de distorção dos resultados. 
Sendo assim, o mercado final definido para realização desse estudo está representado por 129 zonas, as quais podem ser observadas detalhadamente no Anexo B desta dissertação.

\section{- Fluxos}

Os fluxos adotados para o modelo são orientados da fábrica para os centros de distribuição e depois até o mercado. As fábricas não podem pular elos na cadeia para entregar seus produtos, sendo que, obrigatoriamente, todos os produtos devem passar pelos três elos da cadeia até chegar ao mercado consumidor final.

Isso representa o modelo operacional adotado pela empresa, que utiliza o seu centro de distribuição para preparar os pedidos dos clientes.

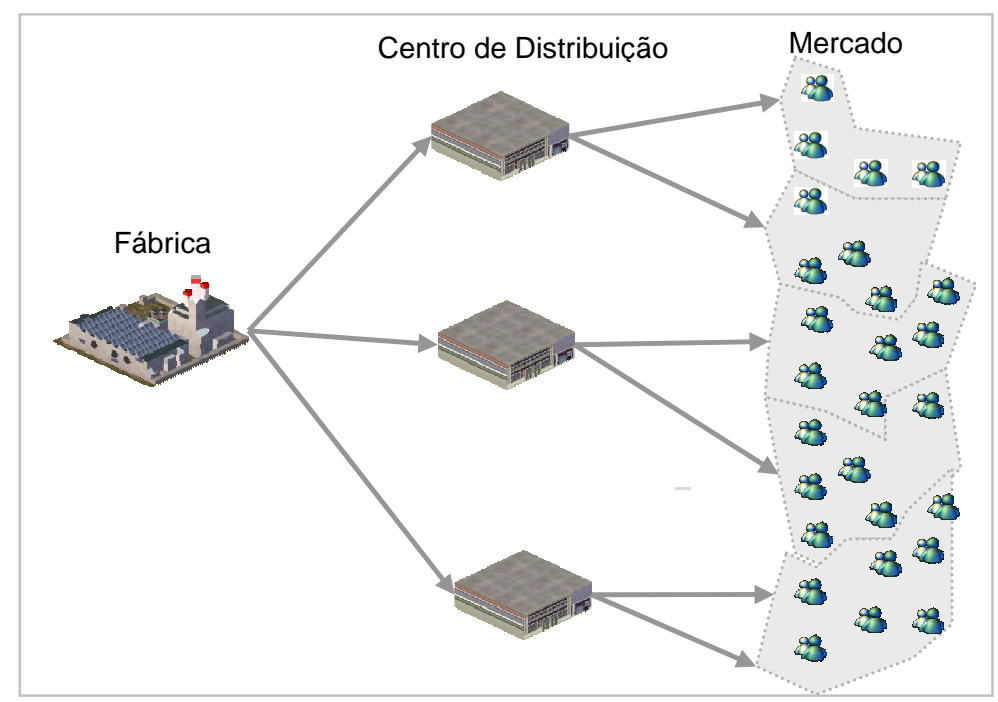

Figura 23: Fluxo de Distribuição

\subsection{CÁLCULO DOS PARÂMETROS}

\section{- Produtos}

Os diversos produtos fabricados e distribuídos foram agrupados em três grandes grupos devido às suas semelhanças nos aspectos produtivos. De modo a manter a mesma nomenclatura do modelo adotado por Silva (2007), os nomes dos produtos não foram alterados apesar de, no novo modelo, os produtos poderem ser produzidos em qualquer uma das fábricas em análise. 


\begin{tabular}{cc}
\hline & LISTA DE PRODUTOS \\
\hline$(1)$ & Produto GO \\
$(2)$ & Produto MG \\
$(3)$ & Produto SP \\
\hline
\end{tabular}

Tabela 11: Lista dos Produtos Agrupados de Acordo com seu Processo Produtivo Fonte: Adaptado de Silva (2007)

\section{- Custo, preço e margem de venda dos produtos}

O cálculo de preço de venda, margem e demais características inerentes ao produto foram feitos de forma ponderada, de modo a respeitar o mix de produtos real da empresa.

Vale ressaltar que os preços de venda nos diversos Estados brasileiros são os mesmos, sendo assim, não existem distorções na base de custos quando analisamos um dos Estados individualmente.

\begin{tabular}{cccc}
\hline Produto & $\begin{array}{c}\text { Preço de } \\
\text { Transferência } \\
(\mathbf{R} \$ \mathbf{t})\end{array}$ & $\begin{array}{c}\text { Preço de Venda } \\
\mathbf{( R \$ / \mathbf { t } )}\end{array}$ & Margem \\
\hline Produto GO & 1.000 & 3.000 & $200 \%$ \\
Produto MG & 1.500 & 4.500 & $200 \%$ \\
Produto SP & 667 & 2.000 & $200 \%$ \\
\hline Tabela 12: Parâmetros de Custo, Preço e Margem de Venda dos Produtos \\
\multicolumn{2}{c}{ Fonte: Adaptado de Silva (2007) }
\end{tabular}

\section{- Demanda}

A demanda por produto utilizada no estudo de caso realizado é descrita na Tabela 13 e pode ser observada no detalhe no Anexo A desta dissertação.

\begin{tabular}{lc}
\hline \multicolumn{1}{c}{ Produto } & Demanda $(\mathbf{t})$ \\
\hline Produto GO & 239.137 \\
Produto MG & 133.848 \\
Produto SP & 28.456 \\
\hline Total & 401.441 \\
\hline
\end{tabular}

A seguir, as Figuras 24, 25 e 26 apresentam os mapas de distribuição das demandas para cada um dos produtos. Pode-se observar que a distribuição dos produtos é semelhante, variando apenas os volumes, como detalhado acima. 


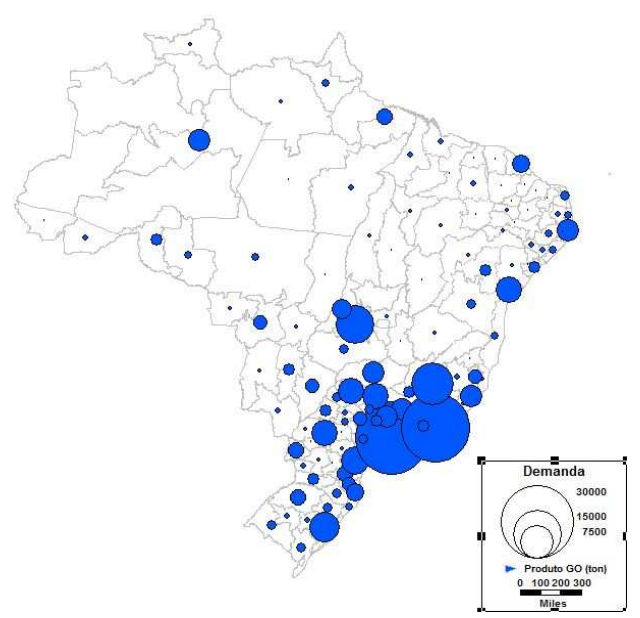

Figura 24: Distribuição da Demanda do Produto GO Fonte: Adaptado de Silva (2007)

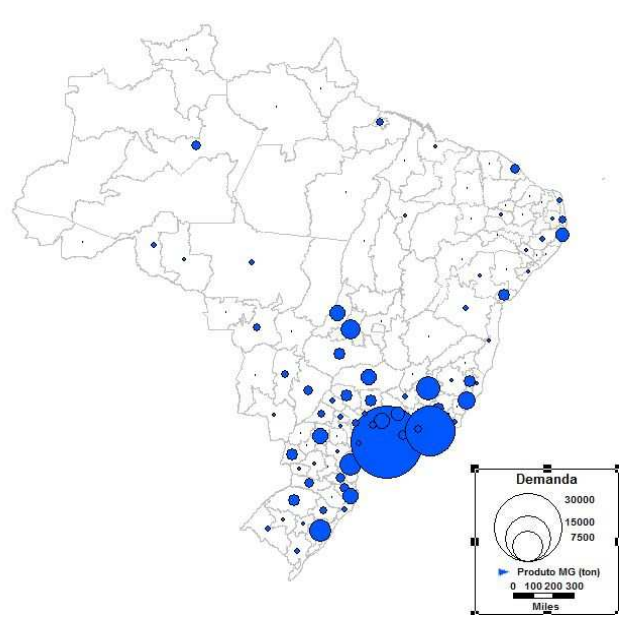

Figura 25: Distribuição da Demanda do Produto MG Fonte: Adaptado de Silva (2007)

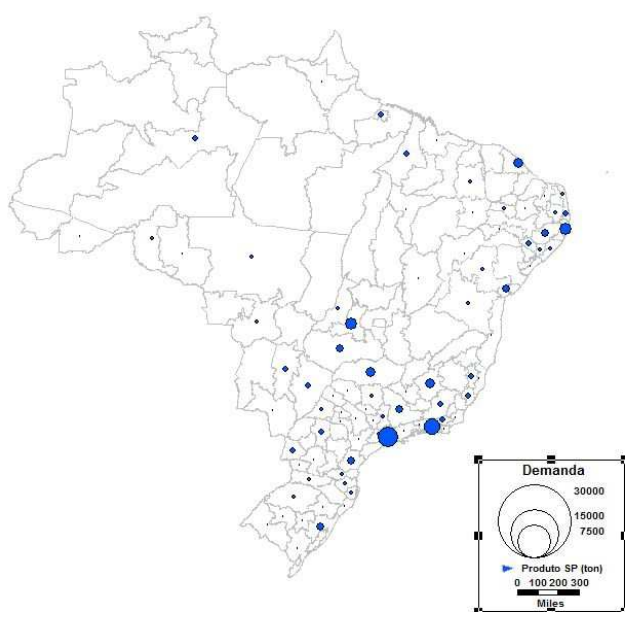

Figura 26: Distribuição da Demanda do Produto SP Fonte: Adaptado de Silva (2007) 


\section{- Capacidades}

Com o intuito de aumentar a flexibilidade do modelo e torná-lo mais próximo da realidade do caso estudado, foram definidos diversos níveis de capacidade para os CDs e para as fábricas.

Para as fábricas, foram definidos sete níveis de acordo com a combinação de linhas de produção possíveis para uma fábrica. Dessa maneira, a fábrica possui sempre capacidade para satisfazer de maneira enxuta, sem excesso de capacidade ociosa, a demanda a ela associada, como pode ser observado na Tabela 14.

\begin{tabular}{cc}
\hline Capacidade & $\begin{array}{c}\text { Capacidade } \\
\text { Máxima Anual } \\
\text { (t/ano) }\end{array}$ \\
\hline Nível 1 & 30.000 \\
Nível 2 & 150.000 \\
Nível 3 & 250.000 \\
Nível 4 & 275.000 \\
Nível 5 & 300.000 \\
Nível 6 & 375.000 \\
Nível 7 & 450.000 \\
\hline 14: Capacidade de Cada um dos Níveis de Fábrica
\end{tabular}

Para os centros de distribuição foram definidos diversos níveis de capacidade que variam entre si em 10.000 t/ano, chegando ao patamar máximo de 410.000 t/ano, capaz de atender sozinho toda a demanda existente, como pode ser observado na Tabela 15.

\begin{tabular}{lc}
\hline Capacidade & $\begin{array}{c}\text { Capacidade Máxima } \\
\text { Anual (t/ano) }\end{array}$ \\
\hline Nível 1 & 10.000 \\
Nível 2 & 20.000 \\
$\ldots$ & $\ldots$ \\
Nível 40 & 400.000 \\
Nível 41 & 410.000 \\
\hline Cacidade de Cada um dos Níveis dos Centros de Distribuição
\end{tabular}

\section{- Custos de fabricação (fixos e variáveis)}

Os custos de fabricação foram separados em duas parcelas, uma de custos fixos e outra de custos variáveis, diferentemente do modelo apresentado por Silva (2007), onde as fábricas só possuíam a parcela de custos variáveis, dado que a abertura das fábricas era obrigatória em todos os cenários. 
Para determinação da parcela de custos fixos da fábrica, adotou-se o mesmo custo fixo utilizado nos CDs por Yoshizaki (2002) e Silva (2007). Isso se deve ao fato de que a parcela de custos referente ao investimento em maquinário não deve afetar a decisão do modelo, visto que, em sua grande maioria, são equipamentos importados e o custo associado é o mesmo, independente do local de instalação.

Além disso, vale ressaltar que, assim como citado por Silva (2007) durante descrição do problema físico em análise, os produtos de cada fábrica original foram agrupados por representarem uma mesma linha de produtos e, conseqüentemente, dividirem boa parte dos maquinários associados em sua produção. Dessa forma, a parcela de custos fixos representa os custos das instalações físicas de galpão, somente excluindo os custos de maquinário e os custos inerentes a depreciação e operação dos mesmos.

A parcela de custos variáveis foi baseada no modelo de Silva (2007), porém, dado que o estudo foi realizado no ano de 2007, houve a necessidade de atualização desses custos. Os custos variáveis foram recalculados com base no INPC (Índice Nacional de Preços ao Consumidor). De acordo com o IBGE (Instituto Brasileiro de Geografia e Estatística), este é o melhor índice para o caso, uma vez que é utilizado para negociação de reajustes salariais e grande parte dos custos variáveis das fábricas são originários de mão de obra direta.

\begin{tabular}{lc}
\hline \multicolumn{1}{c}{ Produto } & $\begin{array}{c}\text { Custo Variável } \\
(\mathbf{R} \mathbf{\$} / \mathbf{t})\end{array}$ \\
\hline São Paulo/SP & 2,90 \\
Belo Horizonte/MG & 3,35 \\
Goiânia/GO & 1,46 \\
\hline Tabela 16: Custo Variável nas Fábricas
\end{tabular}

\section{- Custos de armazenagem}

Os custos de armazenagem de cada um dos centros de distribuição em análise foram divididos em uma parcela de custos fixos e outra de custo variável.

A parcela de custo fixo utilizada no modelo, assim como utilizado por Yoshizaki (2002) e Silva (2007), segue a equação descrita a seguir. Mais uma vez houve a necessidade de atualização dos custos assumidos, porém desta vez os valores 
foram corrigidos pelo IGP-M (Índice Geral de Preços de Mercado). De acordo com a FGV (Fundação Getulio Vargas), o IGP-M é o índice utilizado para balizar os aumentos da energia elétrica e dos contratos de aluguéis, custos estes que representam a maior parte dos custos contidos nos custos fixos dos centros de distribuição.

Custo Fixo $C D=1.700 .000 \times\left[\frac{T}{35.000}\right]^{0,845351}$,

onde "T" é a movimentação anual do CD em toneladas.

Esta curva de ajuste do custo fixo foi elaborada a partir da análise de custos de seis centros de distribuição reais, onde foi identificado que os custos fixos tendem a aumentar em $80 \%$, toda vez que a capacidade do CD dobra de tamanho. De acordo com Yoshizaki (2002), esta curva de ajuste é válida para centros de distribuição de mercadorias secas acondicionadas em caixas de papelão ondulado, como é o caso do problema analisado.

Com relação à parcela de custos variáveis, não foi possível manter os números apresentados por Silva (2007), dado que o custo apresentado pela autora é de $\mathrm{R} \$ 45,60$ / tonelada, ou seja, cerca de vinte vezes mais caro que o custo variável de transbordo citado na fábrica.

Sendo assim, para a determinação desses custos, foram levantadas bases de dados históricas de conhecimento do autor no segmento de bens de consumo duráveis e não duráveis, de modo a se chegar a um valor que traduzisse a realidade da operação. A base de dados em análise contempla três empresas com atuação no mercado brasileiro e que apresentam operações similares à deste estudo. Para tornar o modelo mais aderente a realidade nacional, foi realizada uma análise do custo de arbitragem salarial nos locais candidatos para os centros de distribuição, criando assim uma diferenciação nos custos variáveis de transbordo para cada um dos locais candidatos, como pode ser observado a seguir: 


\begin{tabular}{ccc}
\hline $\begin{array}{c}\text { LOCAIS CANDIDATOS } \\
\text { (Município e Estado) }\end{array}$ & $\begin{array}{c}\text { Custo Variável } \\
\text { (R\$/t) }\end{array}$ \\
\hline (1) & Porto Alegre - RS & 2,52 \\
(2) & Curitiba - PR & 2,48 \\
(3) & São Paulo - SP & 2,69 \\
(4) & Belo Horizonte - MG & 2,57 \\
(5) & Goiânia - GO & 2,49 \\
(6) & Salvador - BA & 2,63 \\
(7) & Recife - RE & 2,60 \\
\hline Tabela 17: Custo Variável nos Centros de Distribuição
\end{tabular}

Observa-se a partir desses custos que as operações em locais como Curitiba-PR e Goiânia-GO apresentam custos cerca de 7\% mais baratos.

\section{- Custo dos Estoques (Nós)}

O custo dos estoques foi calculado com base no custo de capital em estoque presente em cada um dos nós em análise no estudo de caso, podendo sua formulação ser exemplificada como a seguir:

Custo Estoque $=\sum$ Volume $($ em $R \$) \times \frac{\text { Dias de Estoque }}{365} \times 12,75 \%$,

onde o volume é igual ao total de volume transitado pelo nó durante o ano em análise.

Foi adotada a taxa de valor de capital SELIC (12,75\% aa. em janeiro/2009), devido a mesma ser largamente utilizada em análises financeiras.

Para isso, a partir do estoque real da empresa definido para São Paulo, calculou-se os dias de estoque necessários para as demais localidades levando-se em consideração o aumento do estoque de segurança devido ao aumento da distância até o principal centro consumidor (São Paulo).

Vale ressaltar que, apesar dessa abordagem ser largamente utilizada por empresas brasileiras (Avon, Votorantim, etc), a mesma não representa o real aumento de incerteza existente no transporte a partir da mudança do centro de distribuição, além de não considerar os efeitos do estoque de ciclo de cada um dos nós.

Na Tabela 18 e 19 pode-se observar os dias de estoque de cada nó em análise: 


Fábricas Dias de Estoque

\begin{tabular}{cl}
\hline (1) São Paulo - SP & 5 \\
(2) Belo Horizonte - MG & 6 \\
(3) Goiânia - GO & 7 \\
\hline \multicolumn{2}{c}{ Tabela 18: Dias de Estoque presentes nas Fábricas }
\end{tabular}

\begin{tabular}{ll}
\hline Centros de Distribuição $\quad$ Dias de Estoque \\
\hline
\end{tabular}

(1) Porto Alegre - RS 6

(2) Curitiba - PR 5

(3) São Paulo - SP 4

(4) Belo Horizonte - MG 5

(5) Goiânia - GO 6

(6) Salvador - BA 6

(7) Recife - RE 8

Tabela 19: Dias de Estoque presentes nos Centros de Distribuição

\section{- Custo dos Estoques (Arcos)}

Além do estoque nos nós, foi considerado também os estoques em trânsito presente nos arcos do estudo de caso, através do cálculo do número de dias de trânsito de cada arco.

Para determinação desse tempo, assumiu-se que o transportador possui capacidade de locomoção de $544 \mathrm{~km}$ por dia. De acordo com Relatório da CNT (Confederação Nacional do Transporte) de 1999, intitulado "Perfil Sócio-Econômico e as Aspirações dos Caminhoneiros no País", os caminhoneiros costumam rodar 175.384 km por ano em média para 322,4 dias trabalhados no ano.

A formulação pode ser exemplificada através da fórmula apresentada a seguir:

Custo Estoque em Trânsito $=\sum$ Volume $($ em $R \$) \times \frac{\text { Distância entre Nós }}{544 \times 365} \times 12,75 \%$, onde o volume é igual ao total de volume transitado pelo arco durante o ano em análise.

\section{- Fretes}

Os fretes utilizados neste estudo foram calculados com base em análise prévia realizada por Silva (2007), que aplicou uma regressão linear sobre banco de dados disponibilizado pela empresa para obter equações de frete que representavam os 
custos de transferência e distribuição de produtos. Na amostra utilizada, Silva (2007) desconsiderou efeitos de sazonalidade nos dados de 60 pontos de transferência e 1.200 pontos de venda (com distâncias da origem que variavam entre $5 \mathrm{~km}$ e 2.000 $\mathrm{km}$ ) e obteve um fator $R^{2}$ de 0,92 e 0,84 , respectivamente, nas equações a seguir:

$$
\begin{array}{ll}
C_{\text {frete_transferência }}=16,32+0,08 \times \text { Distância } & (\mathrm{R} \$ / \text { tonelada }) \\
C_{\text {frete_distribuição }}=85,06+0,10 \times \text { Distância } & (\mathrm{R} \$ / \text { tonelada })
\end{array}
$$

Para a atualizar os custos utilizados no presente estudo, foi utilizado o Índice de Preços ao Consumidor (IPC-FIPE) calculado para o setor de transportes, que representa o percentual de incremento nos custos com base na análise mensal de variações de mercado. Aplicando o índice de Fundação Instituto de Pesquisas Econômicas (FIPE) sobre os custos de transporte, obteve-se as novas equações para o frete de transferência e de venda:

$$
\begin{array}{ll}
C_{\text {frete_transferência }}=18,07+0,09 \times \text { Distância } & (\mathrm{R} \$ / \text { tonelada }) \\
C_{\text {frete_distribuição }}=94,17+0,11 \times \text { Distância } & (\mathrm{R} \$ / \text { tonelada })
\end{array}
$$

\section{- Distâncias}

Assim como apontado por Ballou (2006), as distâncias entre os centróides de cada meso-região foram calculadas utilizando-se o fator de 1,24 em relação à respectiva distância linear, de modo a estimar distância rodoviária percorrida em cada um dos arcos existentes no modelo.

\section{- Nível de Serviço}

Para o estudo de caso em análise, o nível de serviço corresponde ao cumprimento de prazos pré-estabelecidos entre os centros de distribuição e os clientes. Assim como Yoshizaki (2002), a modelagem do nível de serviço será realizado através da eliminação dos arcos que não atendem ao nível de serviço sendo modelado.

O tema será explorado no Capítulo 6 desta dissertação, onde serão avaliados os impactos do nível de serviço na malha de distribuição e nos custos totais da operação. 


\section{- Incentivos Fiscais}

Os incentivos fiscais relacionados nesse estudo são:

- Goiás (GO): crédito presumido de $3 \%$ sobre a base de cálculo para estabelecimento de comércio atacadista que destine mercadorias para comercialização, produção ou industrialização.

- Minas Gerais (MG): oferta de crédito de 9\% da base de cálculo para mercadorias remetidas por estabelecimentos atacadista ou central de distribuição para comercialização, produção ou industrialização.

Obs: Base de cálculo é o valor da soma das notas fiscais de venda. Sendo a nota fiscal composta do valor de venda do produto mais o ICMS aplicado àquela transação.

\section{- Crédito de Carbono}

O cálculo da emissão de carbono é feito segundo as diretrizes da ferramenta elaborada pelo GHG Protocol e considera um fator de emissão de $\mathrm{CO}_{2}$ por tipo de veículo. O detalhamento da taxa e custo de emissão por tipo de veículo está detalhado no tópico seguinte desta dissertação.

Emissão $\mathrm{CO}_{2}=$ Dis $\tan$ cia Percorrida $\times$ Fator de Emissão

Para efeito de cálculo, assume-se que serão utilizadas somente as emissões provenientes do transporte de mercadorias da fábrica até o mercado consumidor. A emissão relacionada às atividades da fábrica e dos centros de distribuição não serão consideradas porque não se alteraram de um cenário para o outro, ou seja, não tem impacto na rede de distribuição otimizada proposta pelo modelo elaborado.

Estabeleceu-se algumas premissas a serem utilizadas no cálculo da emissão de $\mathrm{CO}_{2}$, como pode ser observado abaixo:

- A distância percorrida pelos veículos para entrega é multiplicada por dois, para representar a viagem completa (ida e volta), dado que os veículos retornam ao ponto de origem para carregamento e realização de nova viagem; 
- Para as entregas de carga fracionada foi acrescido a distância percorrida entre os diversos pontos dentro da zona de entrega (Ek), de acordo com a formulação apresentada por Novaes (1989), que será detalhada a seguir.

\section{- Veículos de Transporte}

Os veículos de transporte são detalhados a seguir pois são fundamentais na determinação da parcela de emissão de carbono, visto que, de acordo com sua capacidade e taxa de emissão de $\mathrm{CO}_{2}$, podem impactar diretamente no resultado final do modelo em análise.

Sendo assim, a frota é composta em por três tipos de veículo de transporte como detalhado na Tabela 20, abaixo:

\begin{tabular}{|c|c|c|c|c|c|}
\hline \multicolumn{2}{|c|}{ Tipo de Veículo } & \multirow{2}{*}{$\begin{array}{c}\begin{array}{c}\text { Utilização do } \\
\text { Transporte }\end{array} \\
\text { Transferência }\end{array}$} & \multirow{2}{*}{$\begin{array}{c}\begin{array}{c}\text { Capacidade } \\
\text { (toneladas) }\end{array} \\
20,0\end{array}$} & \multirow{2}{*}{$\begin{array}{c}\begin{array}{c}\text { Emissão } \mathrm{CO}_{2} \\
\left(\mathrm{tCO}_{\mathbf{2}} \mathrm{e} / 1000\right. \\
\mathbf{k m})\end{array} \\
0,92\end{array}$} & \multirow{2}{*}{$\begin{array}{c}\begin{array}{c}\text { Custo da } \\
\text { Emissão } \\
\text { (R\$/km) }\end{array} \\
4,12\end{array}$} \\
\hline (1) & Veículo 1 & & & & \\
\hline (2) & Veículo 2 & $\begin{array}{l}\text { Distribuição } \\
\text { Carga Cheia }\end{array}$ & 10,0 & 0,43 & 1,92 \\
\hline (3) & Veículo 3 & $\begin{array}{c}\text { Distribuição Carga } \\
\text { Fracionada }\end{array}$ & 3,5 & 0,27 & 1,20 \\
\hline
\end{tabular}

Para determinação dos valores apresentados acima, as seguintes premissas foram consideradas:

- A capacidade de carga dos veículos já apresenta o decréscimo da parcela de ocupação;

- Valor da tonelada de $\mathrm{CO}_{2}$ equivalente $\left(\mathrm{tCO}_{2} \mathrm{e}\right)=\mathrm{U} \$ 1,90(09 / 01 / 2009)$;

- Cotação: U\$ 1,00 = R \$2,35 (09/01/2009);

- Histórico de preço da tonelada de $\mathrm{CO}_{2}$ equivalente $\left(\mathrm{tCO}_{2} \mathrm{e}\right)$ pode ser observada no Anexo $\mathrm{C}$ desta dissertação.

\section{- Fator de Fornecimento}

O fator de fornecimento foi criado para ser possível analisar a sensibilidade do fornecimento de matéria-prima ao se realizar a mudança de localização da fábrica. Devido à complexidade de ser realizar uma análise simultânea de capacidade de fornecimento e preço em cada uma das localizações estudadas e ao fato quetal 
análise depende de diversos fatores externos (mercado, poder de barganha da empresa e recursos naturais da região, estc.), optou-se por trabalhar os fatores de fornecimento como uma análise de sensibilidade, ou seja:

- O impacto da matéria-prima no modelo é calculado pela necessidade adicional de transporte de matéria-prima, como exemplificado a seguir:

- Cenário 1: Fábrica em SP com 100\% do fornecimento de matéria-prima oriundo de SP. Neste cenário o impacto de custo é zero.

- Cenário 2: Fábrica em MG com $30 \%$ do fornecimento de matéria-prima oriundo de SP e 70\% de MG. Neste cenário, o impacto em custo é o equivalente ao transporte de $30 \%$ do volume total distribuído de SP para MG.

- Os preços da matéria-prima não variam de uma localidade para a outra;

- O volume de matéria-prima comprada é o mesmo volume de produto acabado distribuído;

\section{- Fator de Carga Cheia vs. Carga Fracionada (FTL)}

O fator percentual (FTL) da demanda de distribuição realizada em veículo com carga cheia em relação à demanda total distribuída tem como objetivo melhorar a precisão da real distância percorrida pelos veículos de transporte no estudo de caso.

Para determinar esse fator foram levantados dados históricos de duas empresas de bens de consumo com operação similar à da empresa representada no estudo de caso. Esse levantamento foi realizado na segunda quinzena de 2009, através da realização de entrevista com representantes dessas empresas, de modo a se obter um valor bem próximo da realidade brasileira, como pode ser observado a seguir:

$$
F T L=70 \%
$$

\section{- Fator de Acréscimo de Distância}

O fator de acréscimo de distância foi calculado para se aumentar a precisão da distância percorrida pelos veículo de transporte de carga fracionada.

Para a determinação desse fator, utilizou-se a formulação apresentada por Novaes Capítulo 5, 1989), que, a partir de alguns parâmetros como área de atendimento, 
concentração de pontos de entrega e frequência de entrega, é capaz de determinar a distância percorrida na entrega dentro da área de atendimento.

De acordo com Novaes (1989), a distância percorrida dentro da região de entrega é calculada de acordo com a formulação apresentada abaixo:

$$
N_{T}=N \times M
$$

onde:

$$
\begin{aligned}
& N_{T}=\text { Númerode Entregas Diárias } \\
& N=\text { Número Médio de Pontos por Zona } \\
& M=\text { Número de Zonas }
\end{aligned}
$$

A partir desses parâmetros, se calcula o valor da distância média $(\bar{\delta})$ entre pontos de uma determinada zona. Para elaboração dessa formulação, Novaes (1989) partiu da hipótese de que os pontos de entrega são distribuídos espacialmente segundo um processo de Poisson, o que pressupõe densidade média constante em cada zona sendo analisada.

$$
\bar{\delta}=0,765 \times \lambda^{-\frac{1}{2}}
$$

onde:

$$
\lambda=\frac{\text { Número de pontos de entrega }}{\mathrm{km}^{2}}
$$

Dessa maneira, estipula-se a distância euclidiana entre os pontos, que multiplicada por 1,24, assim como adotado por Ballou (2006), permite-se definir a distância rodoviária entre pontos dentro de cada meso-região $k$ em análise. Multiplicando as distâncias pelo número de pontos de entrega, determina-se a distancia percorrida $\left(E_{k}\right)$ entre o primeiro ponto de entrega e o último associado à sua rota.

$$
E=\frac{N_{T}}{M} \times \bar{\delta} \times 1,24
$$


Sendo assim, calcula-se o valor de $E_{k}$ para cada uma das meso-regiões de modo a se definir qual a distância percorrida entre o primeiro e último ponto de entrega dentro de cada uma das 129 meso-regiões. Pode-se, assim, determinar que a distância percorrida pelos veículos na entrega fracionada, que totaliza cerca de 15,7 milhões de quilômetros ao ano, levando-se em consideração a capacidade dos veículos e o número de viagens necessárias para o atendimento da demanda de cada região.

Durante a análise, foi necessário adotar algumas premissas de modo a melhor calibrar o modelo à realidade do estudo de caso em análise, como descrito a seguir:

- Pontos de entrega: levantamento do número de pontos de entrega de empresas com operações similares à analisada e posterior adequação da quantidade de pontos de entrega por meso-região de acordo a distribuição populacional brasileira (Total de 1.721 pontos de entrega distribuídos nas 129 meso regiões)

- Dados populacionais e área de cada meso-região foram conseguidos junto ao IBGE

- Número de pontos de entrega de empresas correlatas: entrevistas com funcionários de duas empresas com operações similares na segunda quinzena de Janeiro de 2009.

No Capítulo 5 são detalhados os cenários e os resultados obtidos em cada uma das análises realizadas. 


\section{RESULTADOS}

Este capítulo tem por objetivo discutir os resultados obtidos no processamento computacional dos cenários, de modo a tornar possível o entendimento dos tradeoffs existentes entre as variáveis, parâmetros e restrições estudadas neste modelo.

Foi elaborada uma árvore de cenários de modo a permitir o entendimento do impacto gerado por uma alteração no modelo ou inclusão de novas variáveis, parâmetros e restrições. A árvore de cenários permite a rastreabilidade das mudanças entre os cenários e, de maneira estruturada, a realização das análises necessárias para as conclusões desta dissertação.

\section{1 ÁRVORE DE CENÁRIOS}

A criação dos cenários tem como objetivo analisar individualmente cada um dos trade-offs em estudo e facilitar o entendimento do comportamento das soluções antes de se chegar ao cenário final, onde todas os trade-offs estão ativos.

Dessa forma, a análise partiu de um cenário onde só são consideradas as variáveis logísticas e a partir dele, de forma gradual, são acrescentadas variáveis, parâmetros e restrições até se chegar ao cenário final, denominado Cenário 4.

Os cenários foram construídos conforme a lógica apresentada na Figura 27 e estão descritos a seguir:

- Cenário 1 - Custo Logístico: Modelo matemático que leva em consideração todos os trade-offs logísticos relacionados a transporte, localização e custos de Fábricas e CDs e estoques.

- Cenário 2 - Carbono: Elaborado a partir do Cenário 1, é acrescentada a variável de custo da neutralização da emissão de carbono pelo transporte de modo a se entender se os efeitos do mesmo são suficientes para causar uma mudança nos fluxos de distribuição e se ocorre alguma mudança relacionada a abertura ou fechamento de alguma fábrica ou $C D$. 
- Cenário 3 - Efeitos Fiscais:

- Cenário 3.1 - Fiscal GO: Modelo matemático usado no Cenário 1 , mas considerando o benefício fiscal associado somente ao Estado de GO.

- Cenário 3.2 - Fiscal MG: Modelo matemático usado no Cenário 1 , mas considerando o benefício fiscal associado somente ao Estado de MG.

- Cenário 3.3 - Fiscal GO e MG: Modelo matemático usado no Cenário 1, mas considerando simultaneamente os benefícios fiscais associados aos Estados de MG e GO.

- Cenário 4: Final: Modelo matemático que incorpora todas as variáveis sendo estudadas, ou seja, a partir do Cenário 1, acrescenta-se o benefício fiscal associado a GO e MG e a parcela de custo referente à neutralização do carbono emitido pelo transporte.

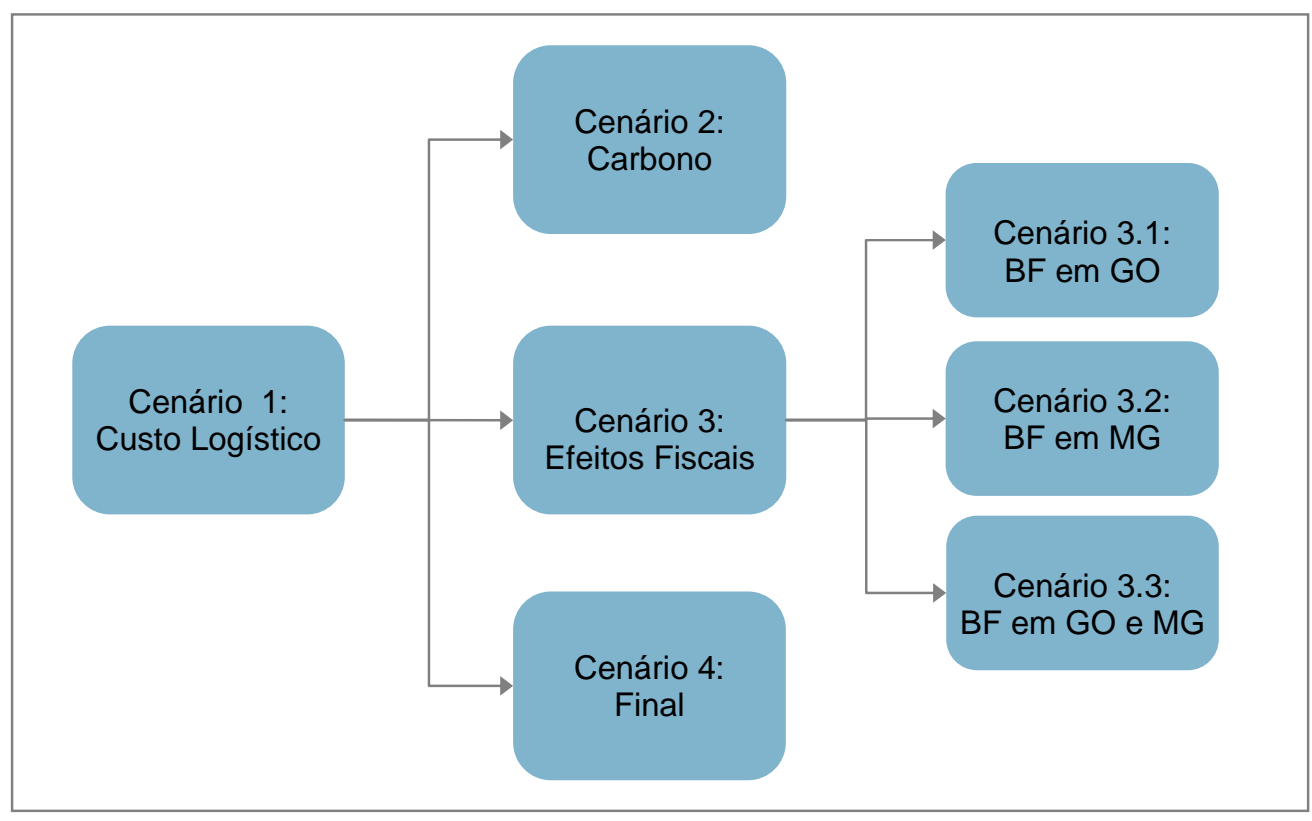

Figura 27: Árvore de Cenários

A partir da análise e entendimento dos resultados desta combinação de cenários, são geradas as primeiras conclusões em relação aos trade-offs existentes no estudo. 


\subsection{PROCESSAMENTO DO MODELO}

Para resolução do problema proposto foi utilizada como linguagem de manipulação algébrica o GAMS e o CPLEX 11.0 como solver, ao contrário do realizado por Silva (2007), que utilizou o solver do What's Best! 8.0, da Lindo Systems Inc., em planilha Excel. Dessa forma, o modelo ganhou maior flexibilidade e proporcionou maior velocidade na simulação de cenários. De acordo com (Godoy; Yoshizaki, 1995; Hino, 1999), o emprego do GAMS facilita demasiadamente a codificação dos modelos e elaboração de cenários.

Vale ressaltar que para validação do modelo elaborado, realizou-se uma calibração anterior ao Cenário 1, utilizando o mesmo modelo, porém em GAMS, e os mesmos dados de entrada adotados por Silva (2007). Nesta calibração inicial chegou-se a um valor de custo logístico total com $99,92 \%$ de precisão em relação aos resultados obtidos anteriormente pela autora, mostrando que o modelo elaborado em GAMS tem total aderência e representa exatamente o modelo formulado anteriormente. A pequena diferença apresentada entre os resultados se deve ao número de casas decimais utilizadas nos valores de frete, sendo que os custos fixos mantiveram-se iguais no novo modelo.

O modelo em GAMS foi processado utilizando uma máquina com processador Intel Pentium Core 2 Duo® de $2.00 \mathrm{GHz}$, com espaço disponível em memória RAM de 2GB, com sistema operacional Windows $\mathrm{Vista} \AA$. O modelo levou aproximadamente 15 segundos (814 interações) para chegar à resposta otimizada de cada cenário, sendo composto por 3333 variáveis (317 variáveis binárias e 3016 variáveis reais) e 3498 restrições, contendo 3917 parâmetros.

O modelo completo elaborado em GAMS encontra-se no Anexo D desta dissertação. 


\subsection{CENÁRIO 1: CUSTO LOGÍSTICO}

O Cenário 1 foi criado para gerar uma base de comparação para os cenários deste modelo, visto que o mesmo reflete exclusivamente os custos logísticos envolvidos.

A Figura 28 representa os custos associados ao Cenário Base:

- Custo de Fabricação: custos fixos e variáveis associado as Fábricas.

- Custo de Armazenagem: custos fixos e variáveis relacionados aos CDs.

- Custo de Transferência: custo do frete de transporte entre Fábrica e CD.

- Custo de Distribuição: custo do frete de transporte entre CDs e mercados.

- Custo do Estoque: custo do estoque nas Fábricas e CDs e em trânsito.

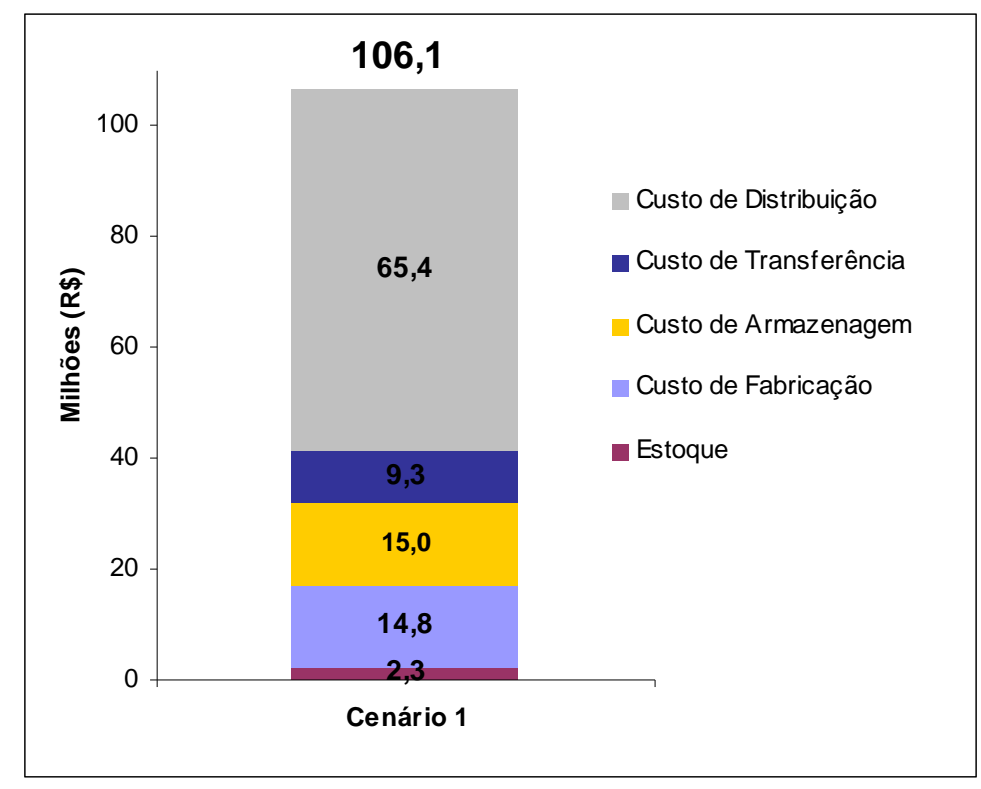

Figura 28: Custo Total do Cenário Base

Na Tabela 21, é apresentado a configuração logística associada a este cenário, onde apenas uma Fábrica é aberta para abastecimento de dois centros de distribuição: São Paulo e Recife.

\begin{tabular}{ccccc}
\hline Fábrica & CD & Produto BH & Produto GO & Produto SP \\
\hline São Paulo/SP & Recife/PE & 2.634 & 5.367 & 1.999 \\
São Paulo/SP & São Paulo/SP & 131.214 & 233.770 & 26.457 \\
\hline
\end{tabular}

Tabela 21: Fluxo de Transferência no Cenário 1 (em toneladas) 
Comparando o resultado do Cenário 1 com o cenário logístico apresentado por Silva (2007), pode-se observar que aconteceram diversas mudanças, tanto nos volumes das Fábricas e CDs (Tabela 22), quanto na distribuição dos custos totais, observado na Figura 29, a seguir:

\begin{tabular}{|c|c|c|c|c|}
\hline Fábrica & CD & Produto $\mathrm{BH}$ & Produto GO & Produto SP \\
\hline Goiânia/GO & Goiânia/GO & & 225.000 & \\
\hline Goiânia/GO & Belo Horizonte/MG & & 7.292 & \\
\hline Goiânia/GO & São Paulo/SP & & 6.845 & \\
\hline Belo Horizonte/MG & Belo Horizonte/MG & 133.848 & & \\
\hline São Paulo/SP & Belo Horizonte/MG & & & 5.301 \\
\hline São Paulo/SP & São Paulo/SP & & & 23.155 \\
\hline
\end{tabular}

Tabela 22: Fluxo de Transferência no Modelo de Silva (2007) (em toneladas)

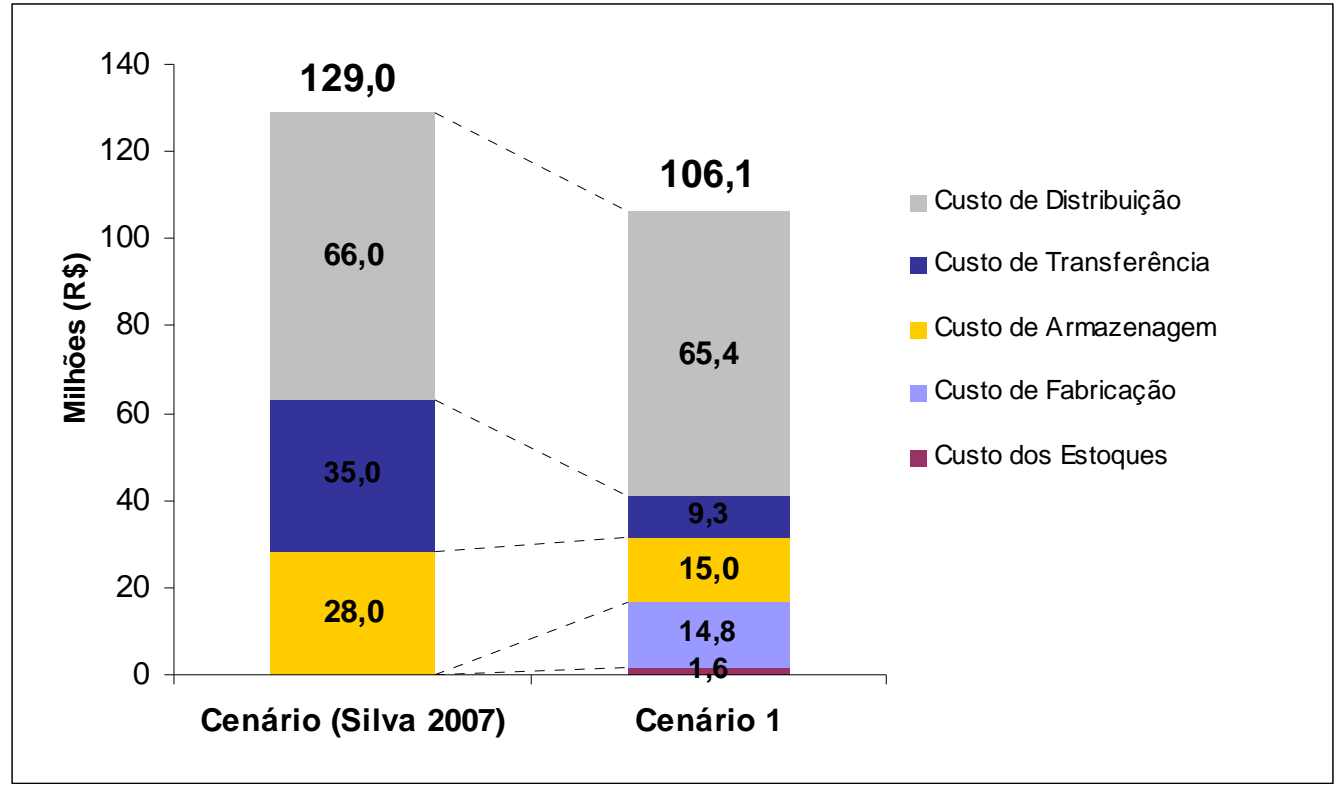

Figura 29: Comparação de Custos entre Cenários 1 e Cenário Silva (2007)

Essa mudança se deve principalmente a inclusão de novas parcelas de custos e as flexibilizações feitas ao modelo que permitem a abertura e fechamento de fábricas. Pode-se observar claramente na Figura 28 que o custo de fabricação e o de estoque partem de zero para cerca de $\mathrm{R} \$ 16,4$ milhões. Em contrapartida, os custos de transportes diminuem significativamente, uma vez que existe flexibilidade para abertura e fechamento de fábricas no novo modelo. 
O mapa com a distribuição dos produtos é interessante pelo ponto de vista do entendimento das distâncias percorridas entre CD e mercado consumidor, uma vez que, no próximo capítulo, serão analisados os impactos da inserção de restrição de nível de serviço para alguns mercados.

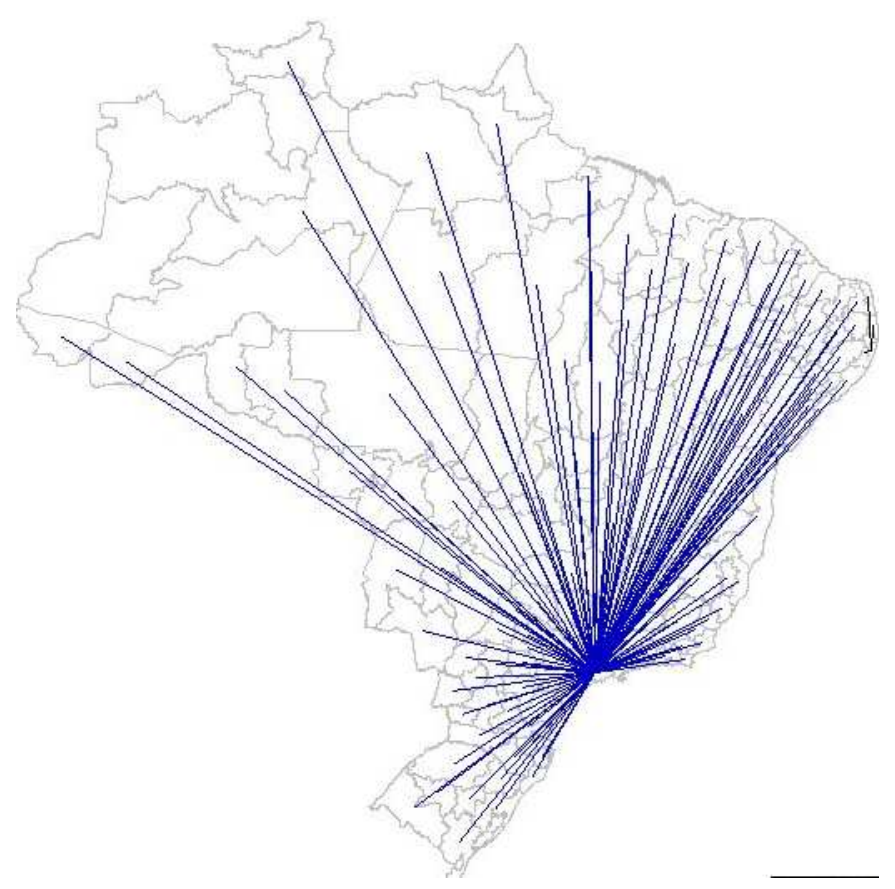

Figura 30: Fluxo de Distribuição do Cenário 1

Finalizada a análise do cenário logístico, passa-se a explorar a árvore de cenários de modo a permitir o entendimento dos trade-offs existentes entre os custos logísticos, fiscais e ambientais.

\subsection{CENÁRIO 2: CARBONO}

O cenário com os custos do carbono da neutralização da emissão de $\mathrm{CO}_{2}$ oriundos do transporte de transferência e distribuição é baseado na estrutura do Cenário 1 , com a inclusão do parâmetro de custo/km relativo a cada um dos veículos utilizados no estudo de caso.

Ao analisar os resultados deste cenário, observa-se que a configuração logística das Fábricas e Centros de Distribuição não sofre nenhuma alteração, sendo 
acrescentado apenas uma parcela de $R \$ 0,16$ milhões referente à aquisição de crédito de carbono necessário para se manter uma operação com zero emissão.

De maneira preliminar, pode-se concluir então que o carbono, por si só, não é capaz de alterar a malha logística do estudo de caso em análise, mesmo resultando numa emissão de 36 mil toneladas de $\mathrm{CO}_{2}$, como pode ser observado na Tabela 23.

\begin{tabular}{|c|c|c|c|c|c|}
\hline \multicolumn{2}{|c|}{ Tipo de Veículo } & \multirow{2}{*}{$\begin{array}{c}\begin{array}{c}\text { Utilização do } \\
\text { Transporte }\end{array} \\
\text { Transferência }\end{array}$} & \multirow{2}{*}{$\begin{array}{c}\begin{array}{c}\text { Distância } \\
\text { (milhões de } \\
\text { km) }\end{array} \\
4,2\end{array}$} & \multirow{2}{*}{$\begin{array}{c}\begin{array}{c}\text { Emissão } \mathrm{CO}_{2} \\
\left(\mathrm{tCO}_{\mathbf{2}} \mathrm{e} / 1000\right. \\
\mathbf{k m})\end{array} \\
0,92\end{array}$} & \multirow{2}{*}{$\begin{array}{c}\begin{array}{c}\text { Total de CO2 } \\
\text { Emitido } \\
\text { (toneladas) }\end{array} \\
3.899\end{array}$} \\
\hline (1) & Veículo 1 & & & & \\
\hline (2) & Veículo 2 & $\begin{array}{l}\text { Distribuição } \\
\text { Carga Cheia }\end{array}$ & 35,2 & 0,43 & 15.140 \\
\hline \multirow[t]{2}{*}{ (3) } & Veículo 3 & $\begin{array}{c}\text { Distribuição Carga } \\
\text { Fracionada }\end{array}$ & 60,9 & 0,27 & 15.812 \\
\hline & & & & TOTAL & 34.851 \\
\hline
\end{tabular}

Tabela 23: Emissão de Carbono no Cenário 2

No Capítulo 6, será realizada analise de sensibilidade do valor da tonelada de $\mathrm{CO}_{2}$ equivalente $\left(\mathrm{tCO}_{2} \mathrm{e}\right)$, de modo a se entender o impacto potencial que essa variável pode causar na configuração logística do estudo de caso em análise.

\subsection{CENÁRIO 3.1: BENEFÍCIO FISCAL SOMENTE EM GO}

O cenário com benefício fiscal aplicado apenas no Estado de Goiás é baseado na estrutura otimizada do Cenário 1, com a inclusão de um fator benefício fiscal nas operações do CD em Goiânia de 3\% sobre o saldo de ICMS acumulado.

Ao analisar os resultados deste cenário, constata-se que o benefício fiscal inserido altera a configuração logística ótima da empresa, ainda que apresente um custo logístico de $R \$ 116,5$ milhões, que é $9,7 \%$ maior do que o custo logístico do Cenário 1. A análise detalhada dos custos deste cenário mostra que o incremento se concentrou nas parcelas de transporte de transferência.

Nota-se também, que o potencial de benefício fiscal tem um valor tão significativo ( $R \$ 47,1$ milhões) que compensa o aumento de custo do transporte e ainda gera 
redução no custo total. O custo total do Cenário 3.1 soma apenas $\mathrm{R} \$ 69,4$ milhões, ficando $35 \%$ menor do que o custo total do Cenário 1 (otimização do custo logístico), como pode ser observado na Figura 31.

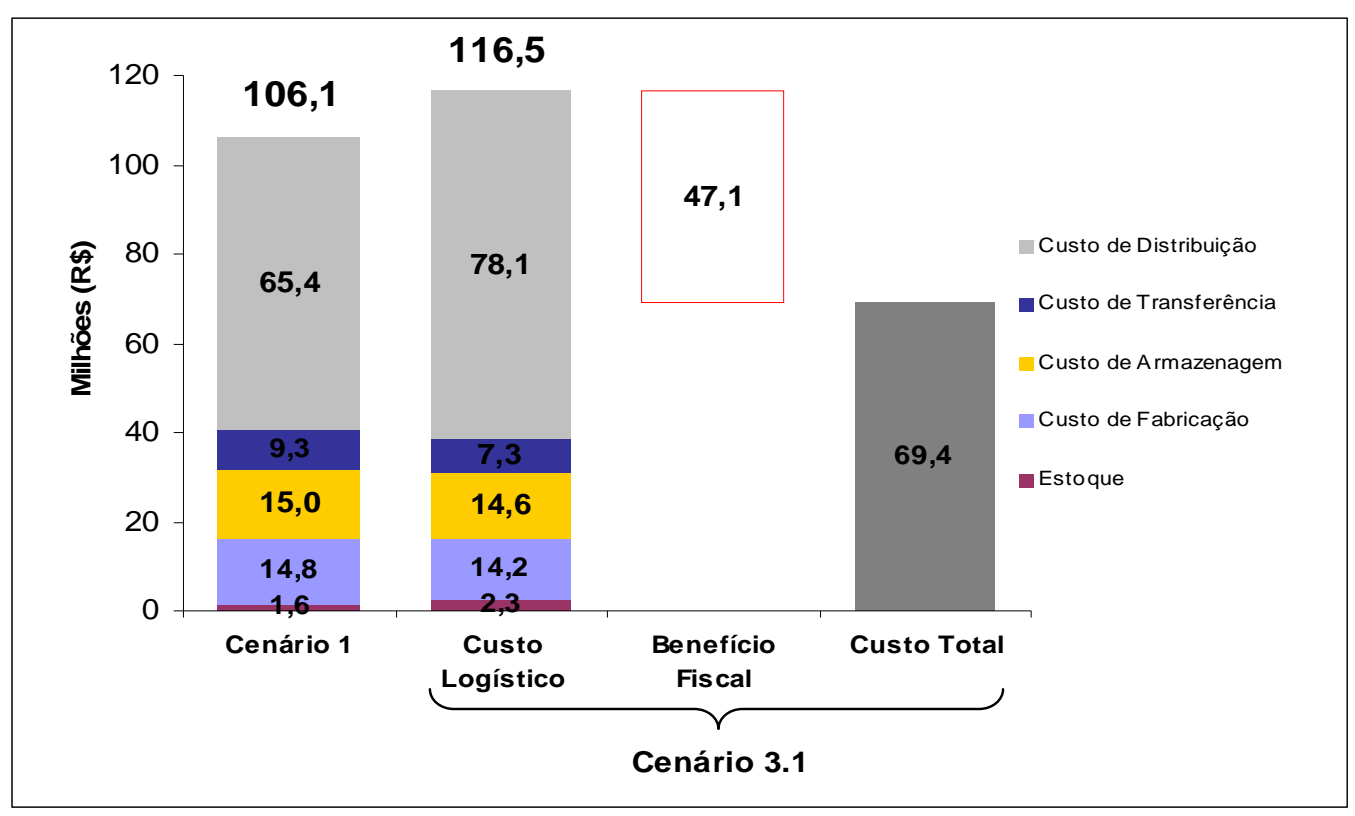

Figura 31: Custo Total do Cenário 1 vs. Cenário Fiscal GO

Os benefícios de ICMS em Goiás alteram os fluxos naturais de transporte, aumentando o volume de produtos que passam pelo CD de Goiânia de maneira a gerar maiores descontos e, com isso, altera o restante das decisões logísticas.

Na Figura 32 é apresentado o mapa de distribuição deste cenário, para a permitir a melhor visualização dos fluxos. 


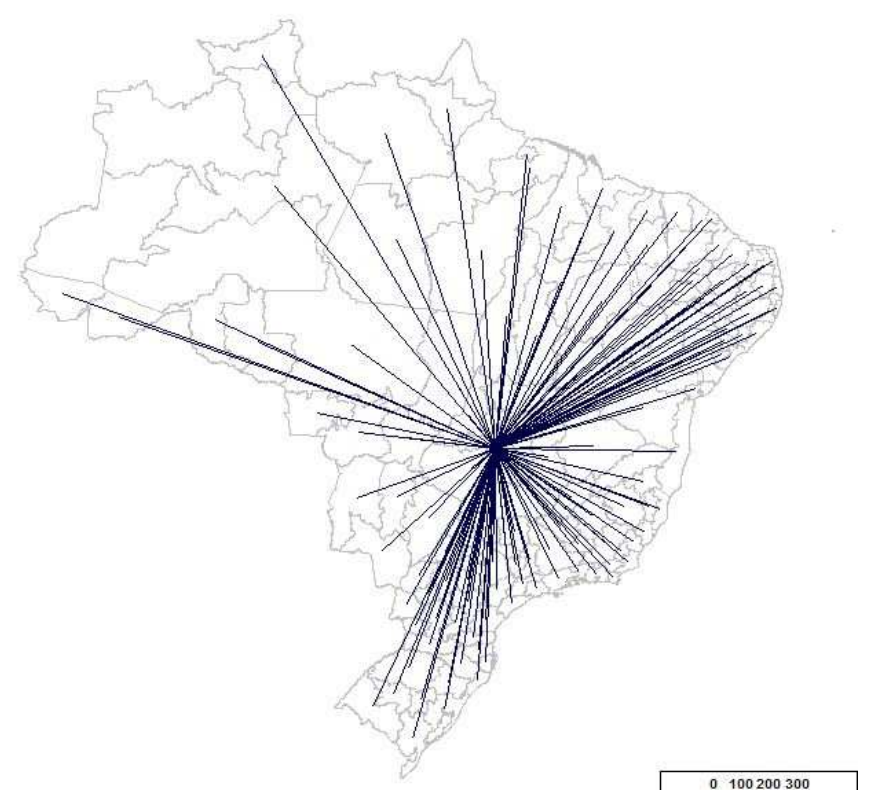

Figura 32: Fluxo de Distribuição do Cenário Fiscal GO

Observa-se na Tabela 21 que tanto o CD quanto a Fábrica passam a ser instalados em Goiânia/GO, sendo responsáveis por $100 \%$ da produção e distribuição dos produtos.

\begin{tabular}{|c|c|c|c|c|}
\hline Fábrica & CD & Produto BH & Produto GO & Produto SP \\
\hline Goiânia/GO & Goiânia/GO & 133.848 & 239.137 & 28.456 \\
\hline
\end{tabular}

Tabela 24: Fluxo de Transferência no Cenário Fiscal MG (em toneladas)

\subsection{CENÁRIO 3.2: BENEFÍCIO FISCAL SOMENTE EM MG}

O cenário com benefício fiscal aplicado apenas no Estado de Minas Gerais é baseado na estrutura otimizada do Cenário 1 , com a inclusão de um fator benefício fiscal nas operações do CD em Belo Horizonte/MG de $9 \%$ sobre o saldo de ICMS acumulado.

Em linha com os resultados obtidos no cenário de benefício fiscal em GO, observase, na Figura 33, que o cenário apresenta um aumento dos custos logísticos em $\mathrm{R} \$ 19,0$ milhões (17,8\% acima dos custos do Cenário 1) e a geração de benefício fiscal de $\mathrm{R} \$ 96,2$ milhões. Neste cenário, o custo total acaba tendo um abatimento de cerca de $73 \%$ do custo logístico total. 


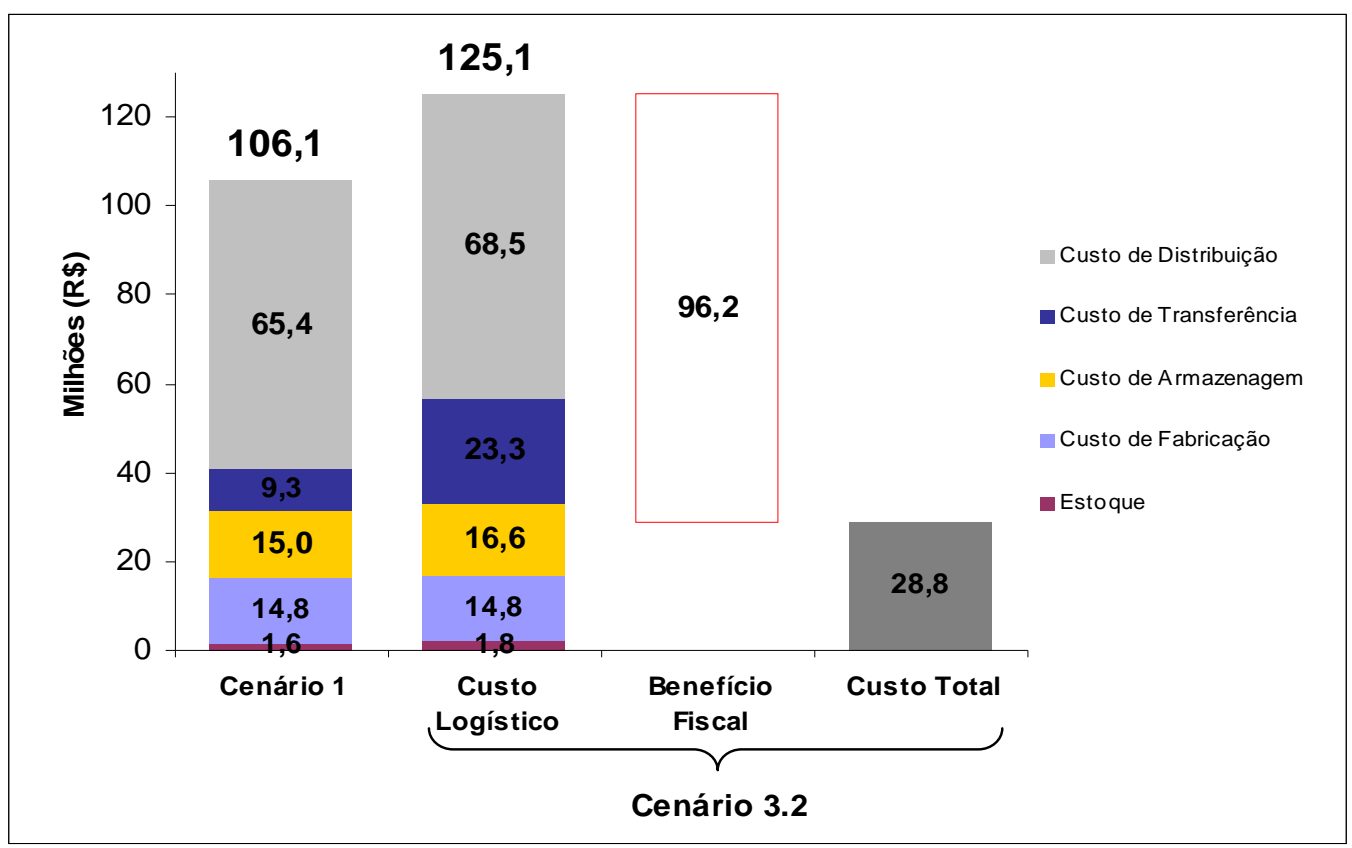

Figura 33: Custo Total do Cenário 1 vs. Cenário Fiscal MG

O aumento de custo observado é, em grande parte, resultante do aumento dos custos de transportes resultantes da abertura de dois novos CDs, um em Belo Horizonte/MG e outro em Salvador/BA, e o fechamento do CD do Recife/PE, como pode ser observado na Tabela 25. O CD de Belo Horizonte concentra, neste caso, $65 \%$ de todo o volume de produtos distribuídos.

\begin{tabular}{ccccc}
\hline Fábrica & CD & Produto BH & Produto GO & Produto SP \\
\hline São Paulo/SP & Belo Horizonte/MG & 104.354 & 149.722 & 5.924 \\
São Paulo/SP & Salvador/BA & 6.817 & 17.276 & 5.907 \\
São Paulo/SP & São Paulo/SP & 22.677 & 72.139 & 16.625 \\
\hline
\end{tabular}

Tabela 25: Fluxo de Transferência no Cenário Fiscal GO (em toneladas)

O fato de, no cenário 3.2, a Fábrica e o CD de São Paulo/SP continuarem abertos, ao contrário do cenário 3.1 , se deve ao fato do modelo ter conseguido zerar o saldo de ICMS no CD de Minas Gerais. Qualquer volume a mais que fosse atribuído a esse $C D$, faria com que fossem gerados créditos de ICMS. Os créditos de ICMS são inibidos por uma restrição do modelo que faz com que não seja possível a obtenção de benefício fiscal maior que saldo devedor de ICMS nos CDs. 
$\mathrm{Na}$ Figura 34, são apresentados os fluxos de distribuição deste novo cenário, onde estão destacados em azul, preto e vermelho os fluxos dos CDs de São Paulo, Minas Gerais e Salvador, respectivamente.

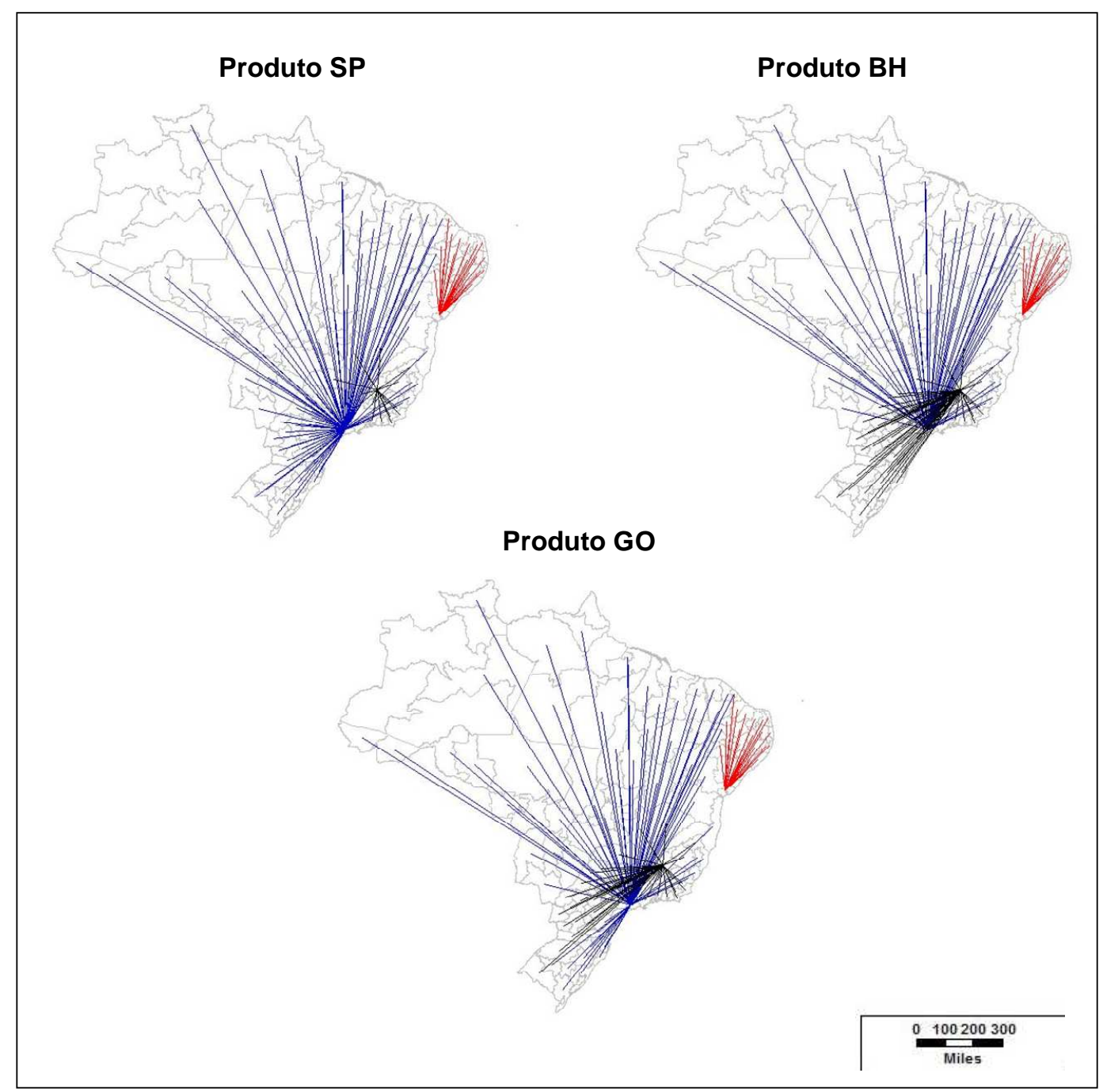

Figura 34: Fluxo de Distribuição do Cenário Fiscal MG

\subsection{CENÁRIO 3.3: BENEFÍCIO FISCAL SIMULTÂNEO EM GO E MG}

O cenário com benefício fiscal aplicado simultaneamente nos Estados de Minas Gerais e Goiás é baseado na estrutura otimizada do Cenário 1, com a inclusão de dois fatores de benefício fiscal sobre o saldo de ICMS acumulado: nas operações do CD em Belo Horizonte/MG, de 9\%, e nas operações do CD em Goiânia/GO, de 3\%. 
Observa-se, na Figura 35, que este cenário apresenta custos logísticos cerca de 21\% maiores do que o Cenário 1 , mas que gera $R \$ 111,6$ milhões de benefício fiscal somando as taxas aplicadas nas operações em Goiás e Minas.

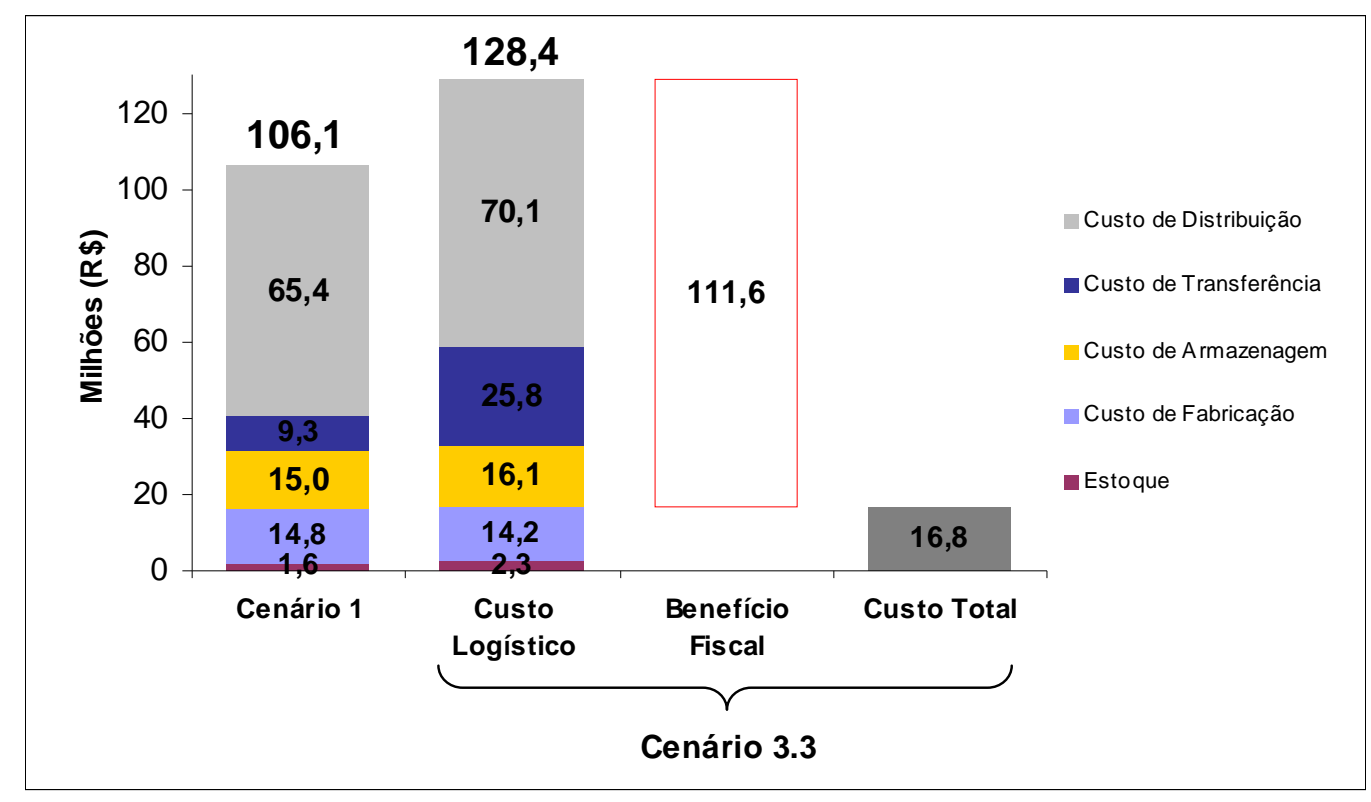

Figura 35: Custo Total do Cenário 1 vs. Cenário Fiscal GO e MG

Este cenário apresenta o menor custo total de todos os cenários estudados. Comparando-o com o cenário de menor custo até o momento (benefício em MG), esta configuração de malha gerou uma redução adicional de $\mathrm{R} \$ 12$ milhões no custo total. Desta redução adicional, verifica-se que grande parte é oriunda do aumento do benefício fiscal auferido na malha.

Os fluxos deste cenário estão $100 \%$ concentrados nos CDs localizados em ambos os Estados com oferta de incentivo fiscal, tal como era esperado. Verificamos $65 \%$ do volume passando pelo $C D$ de Belo Horizonte/MG e outros $35 \%$ passam pelo $C D$ de Goiânia/GO. Comparado com o Cenário 1, tem-se o mesmo número de fábricas abertas (uma), porém a mesma é transferida para o Estado de GO.

\begin{tabular}{ccccc}
\hline Fábrica & CD & Produto BH & Produto GO & Produto SP \\
\hline Goiânia/GO & Belo Horizonte/MG & 103.931 & 147.883 & 9.627 \\
Goiânia/GO & Goiânia/GO & 29.917 & 91.254 & 18.829 \\
\hline
\end{tabular}

Tabela 26: Fluxo de Transferência no Cenário Fiscal MG e GO (em toneladas) 
A Figura 36 mostra os mapas que detalham os fluxos de distribuição dos produtos.

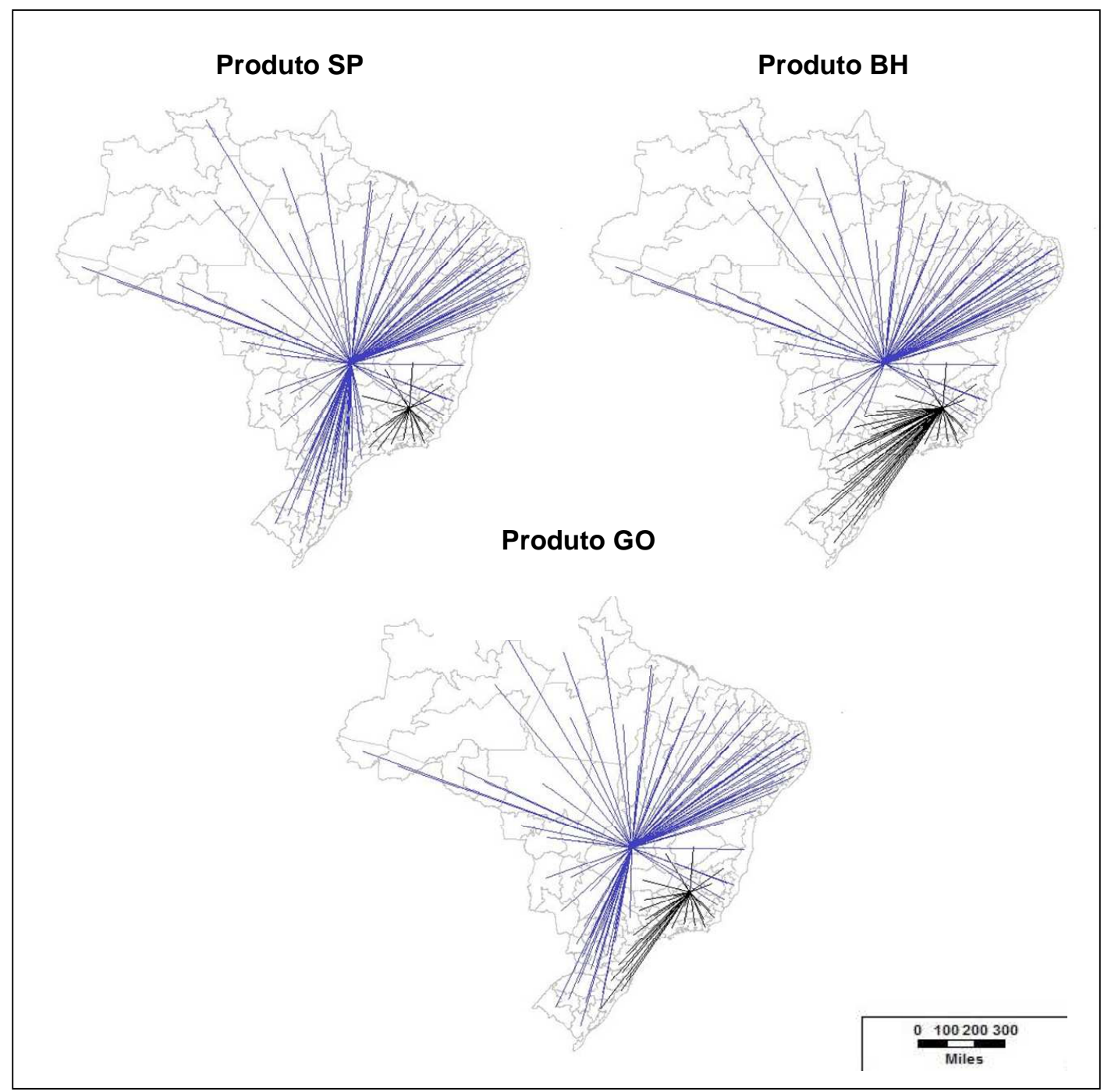

Figura 36: Fluxo de Distribuição do Cenário Fiscal Simultâneo

Observa-se que, no cenário com benefício simultâneo nos Estados de Minas Gerais e Goiás, o benefício resultante da cadeia de distribuição é $R \$ 15,4$ milhões maior que o cenário com benefício somente em Minas Gerais, valor que faz com que seja compensado o aumento dos custos logísticos.

A análise dos cenários $3.1,3.2$ e 3.3 mostra que o principal responsável pelos aumentos dos custos logísticos é o custo do frete de transferência, que passa de $\mathrm{R} \$ 7,3$ milhões para $\mathrm{R} \$ 25,8$ milhões no cenário com benefício fiscal simultâneo. 


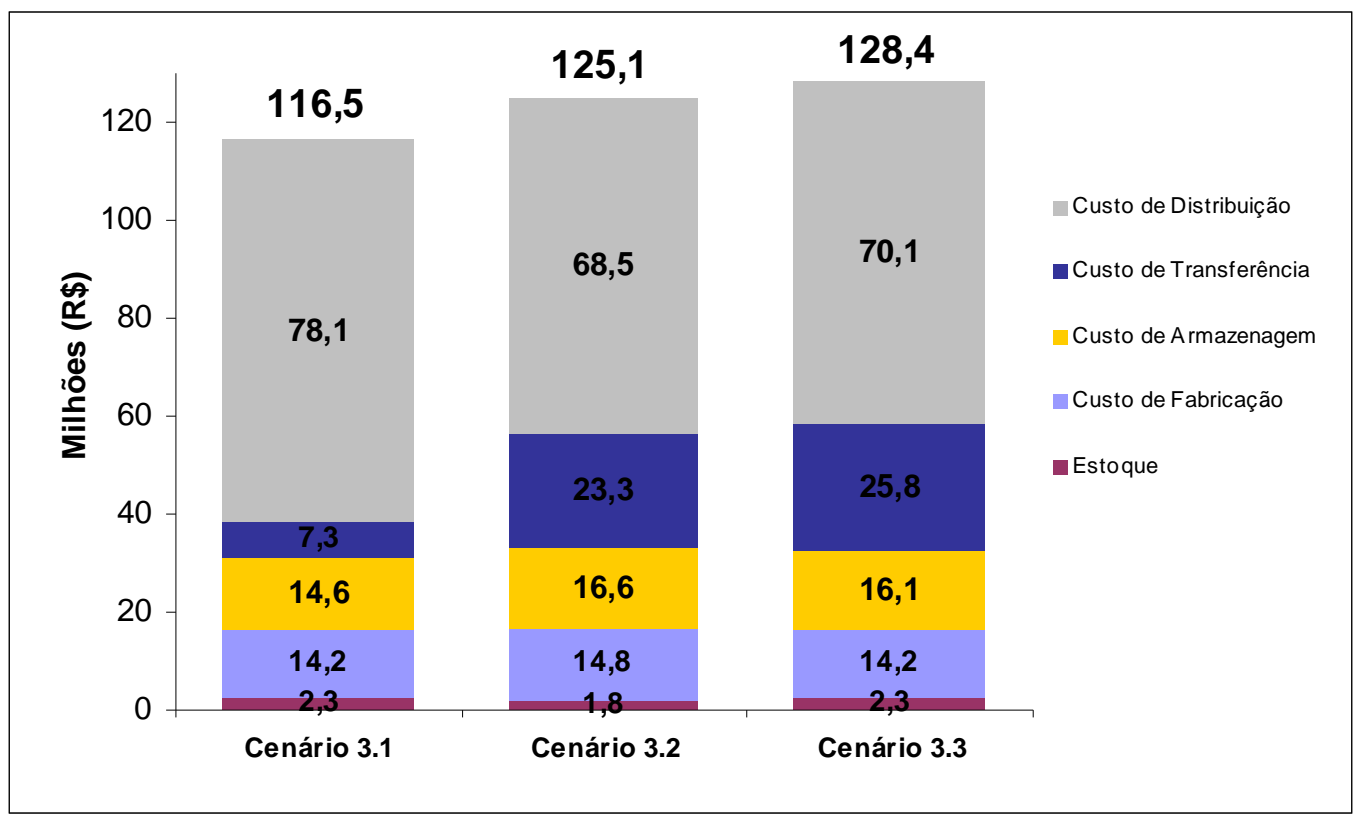

Figura 37: Custo Total dos Cenários com Benefício Fiscal

No entanto, observa-se claramente na Figura 38 que o aumento dos custos logísticos são amplamente compensados pelo benefício fiscal em todos os cenários.

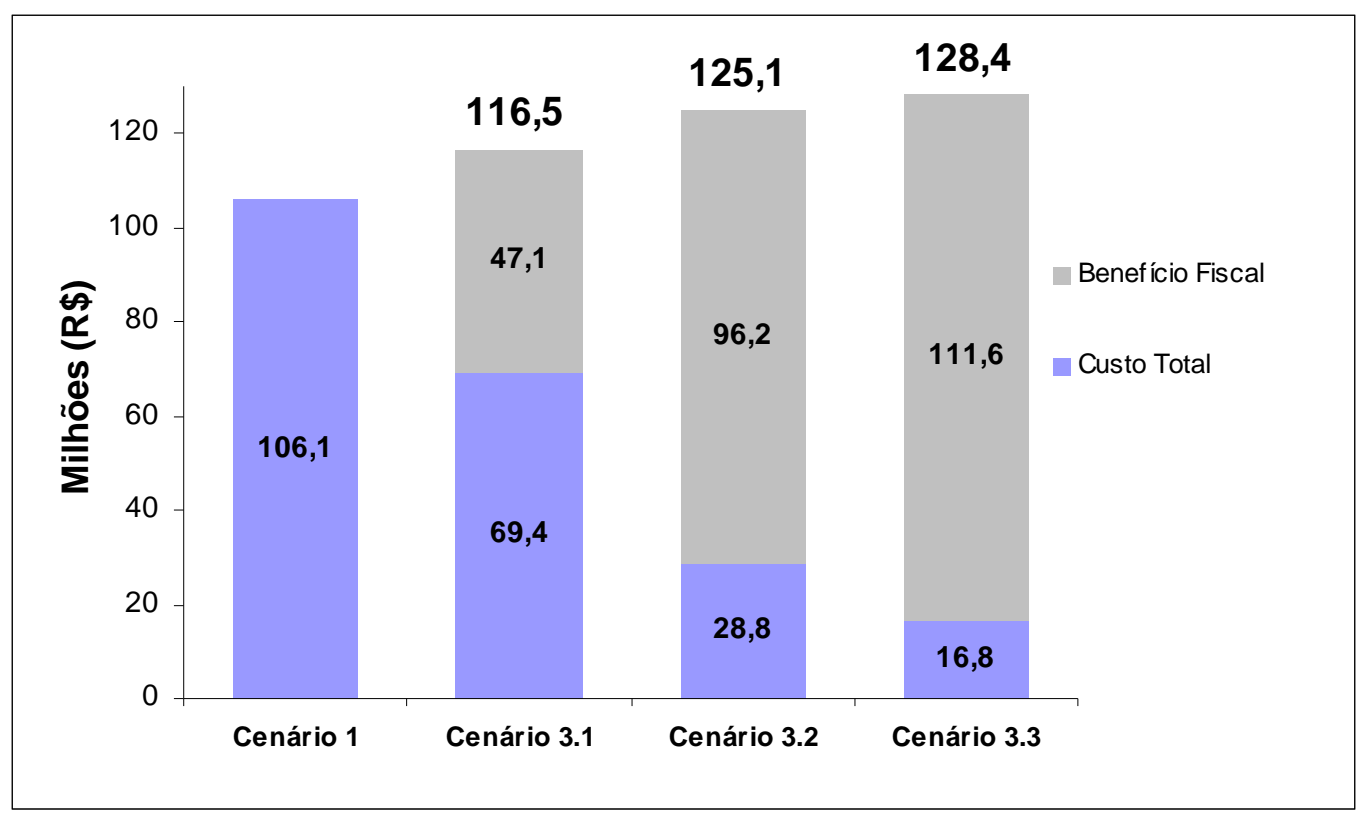

Figura 38: Comparativo de Custo Total dos Cenários com Benefício Fiscal 


\subsection{CENÁRIO 4: FINAL}

O cenário final também é baseado no Cenário 1 , com a inclusão do benefício fiscal dos estados de Minas Gerais e Goiás, além de acrescentar também o parâmetro de custo de neutralização das emissões de carbono.

A partir da análise dos resultados, pode-se observar que o Cenário 4 é idêntico ao Cenário 3.3, mostrando mais uma vez que o custo proveniente da parcela de carbono não é capaz de alterar um cenário. A única diferença entre os dois cenários se encontra na parcela de custo do carbono, que é de $\mathrm{R} \$ 0,24$ milhões no Cenário 4 .

Ao se comparar o Cenário 4 com o Cenário 1, observa-se novamente que os fluxos estão 100\% concentrados nos CDs localizados nos Estados com oferta de incentivo fiscal, sendo que $65 \%$ do volume passa pelo CD de Belo Horizonte/MG, e os outros $35 \%$ ficam no $C D$ de Goiânia/GO. Além disso, a fábrica, que inicialmente estava localizada em São Paulo, é transferida para o Estado de GO.

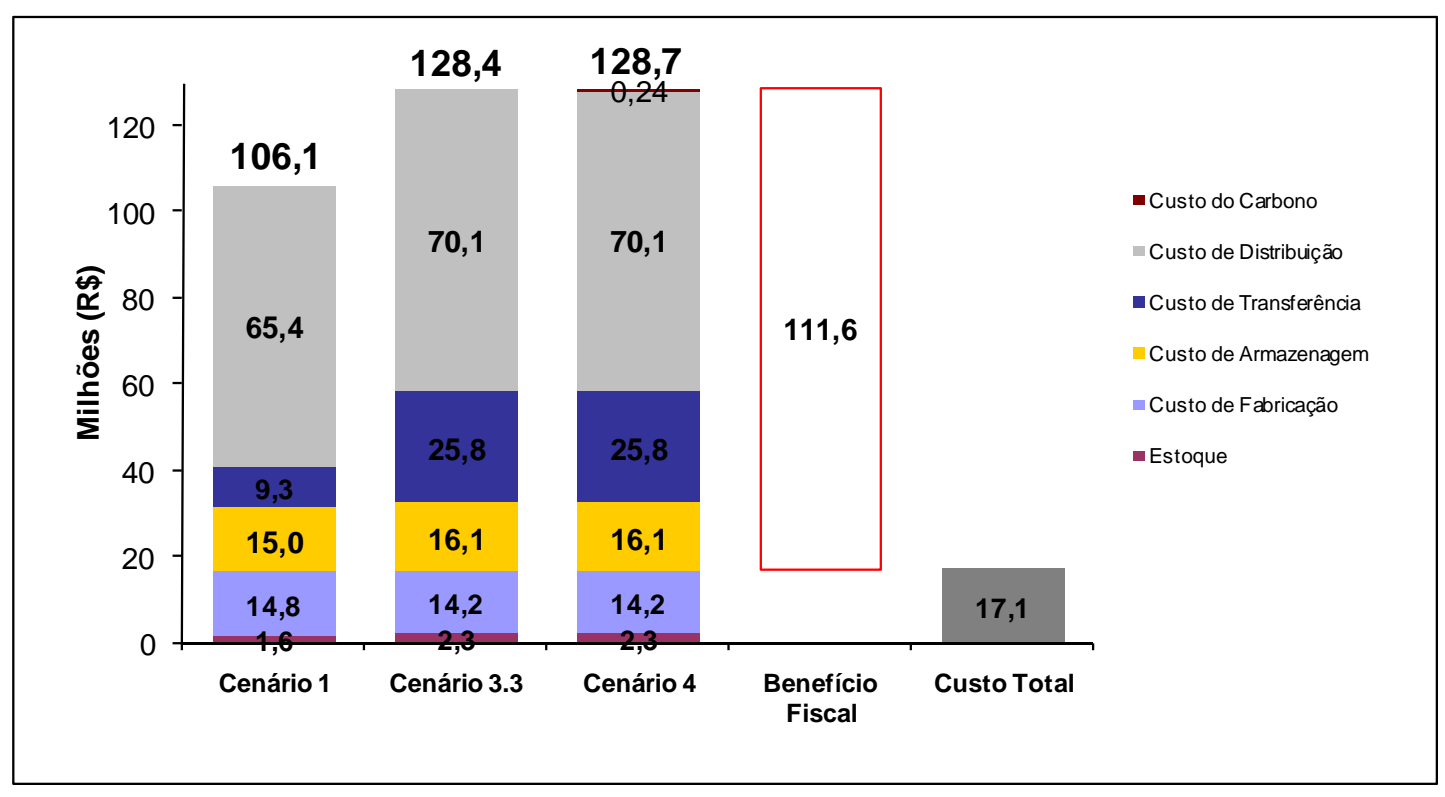

Figura 39: Comparativo de Custo Logístico dos Cenários com Benefício Fiscal 


\subsection{COMPARAÇÃO DOS CENÁRIOS}

A partir da análise dos seis cenários, foi possível o entendimento dos trade-offs existentes entre os diversos custos logísticos em análise e os impactos fiscais e ambientais do problema de localização de instalações.

O resumo dos cenários, apresentados na Tabela 27, explicita cada parcela de custo da função objetivo e mostra claramente onde estão os trade-offs do modelo.

\begin{tabular}{|c|c|c|c|c|c|c|}
\hline & Cenário 1 & Cenário 2 & Cenário 3.1 & Cenário 3.2 & Cenário 3.3 & Cenário 4 \\
\hline & Logístico & Carbono & \begin{tabular}{|c|} 
Benefício em \\
GO
\end{tabular} & $\begin{array}{c}\text { Benefício em } \\
\text { MG }\end{array}$ & $\begin{array}{c}\text { Benefício em } \\
\text { GO e MG }\end{array}$ & Final \\
\hline Custo Total & 106.133 .530 & 106.291 .580 & 69.370 .600 & 28.835 .062 & 16.808 .015 & 17.057 .041 \\
\hline \multirow{2}{*}{$\begin{array}{l}\text { Benefício Fiscal } \\
\text { Custo Logístico Total }\end{array}$} & 0 & 0 & 47.099 .936 & 96.221 .595 & 111.595 .294 & 111.595 .294 \\
\hline & 106.133 .530 & 106.289.141 & 116.470 .536 & 125.056 .657 & 128.403 .309 & 128.646 .303 \\
\hline Frete Transferência & 9.296 .139 & 9.296 .139 & 7.254 .039 & 23.331 .939 & 25.766 .676 & 25.766 .676 \\
\hline Frete de Distribuição & 65.432 .413 & 65.432 .413 & 78.128 .025 & 68.490 .682 & 70.078 .438 & 70.078 .438 \\
\hline Custo Fixo CD & 13.919 .345 & 13.919 .345 & 13.610 .965 & 15.570 .888 & 15.049 .316 & 15.049 .316 \\
\hline Custo Fixo Fabrica & 13.610 .965 & 13.610 .965 & 13.610 .965 & 13.610 .965 & 13.610 .965 & 13.610 .965 \\
\hline Transbordo no CD & 1.078 .976 & 1.078 .976 & 999.588 & 1.046 .876 & 1.020 .503 & 1.020 .503 \\
\hline Transbordo na Fabrica & 1.164 .179 & 1.164 .179 & 586.104 & 1.164 .179 & 586.104 & 586.104 \\
\hline Estoques & 1.631 .514 & 1.631 .514 & 2.280 .851 & 1.841 .128 & 2.291 .307 & 2.291 .307 \\
\hline Carbono & 0 & 155.611 & 0 & 0 & 0 & 242.994 \\
\hline
\end{tabular}

Tabela 27: Quadro resumo dos cenários analisados

Os Cenários 1 e 2, sem incidência de benefício fiscal, mostraram uma logística bastante eficiente, com custos de transporte reduzidos e fluxos de distribuição enxutos. Os cenários com benefícios fiscais penalizaram a parcela de custos de transporte em função do benefício fiscal potencial de cada um. Em todos os cenários de avaliação fiscal, nota-se a distorção das rotas para que o fluxo de mercadorias seja concentrado no(s) estado(s) que oferta(m) benefício.

Além disso, pode-se também verificar que, ao considerar os benefícios fiscais simultaneamente, criou-se um cenário de custo total ainda menor pois, além do aumento do benefício fiscal total, ocorreu uma diminuição nos fretes de distribuição devido a abertura de mais um CD. 
Conclui-se então que os benefícios fiscais incidentes impactam a decisão de localização das instalações, sejam elas fábricas ou centros de distribuição, e que os custos de carbono, por si só, não são suficientes para alterar a solução do cenário.

Porém, um ponto importante a se observar é que, ao compararmos a emissão de $\mathrm{CO}_{2}$ resultante do Cenário $1 \mathrm{com}$ a emissão do Cenário 4, a mesmo sofreu um aumento de $56,1 \%$, ou cerca de 19,6 mil toneladas.

Mesmo sem possuir impacto financeiro significativo capaz de mudar a configuração logística, o aumento da emissão de $\mathrm{CO}_{2}$ pode afetar a imagem da empresa frente aos seus clientes, além de causar maior degradação do meio ambiente.

A partir do entendimento dos cenários, foram elaboradas uma série de análises de sensibilidade de modo a entender mais detalhadamente a influência de algumas variáveis e parâmetros nos resultados e chegar a uma conclusão mais precisa sobre os trade-offs existentes. $O$ detalhamento destas análises pode ser observado no Capítulo 6 dessa dissertação. 


\section{ANÁLISE DE SENSIBILIDADE}

Este capítulo tem como objetivo apresentar as análises de sensibilidade realizadas, de modo a mostrar o real impacto das variáveis, assim como testar a robustez dos parâmetros e do cenário de menor custo total.

A partir do Cenário 4, foram elaboradas seis análises de sensibilidade com o objetivo de aprofundar as análises já conduzidas e chegar a uma conclusão final sobre os trade-offs existentes entre os custos logísticos, os benefícios fiscais e os custos ambientais.

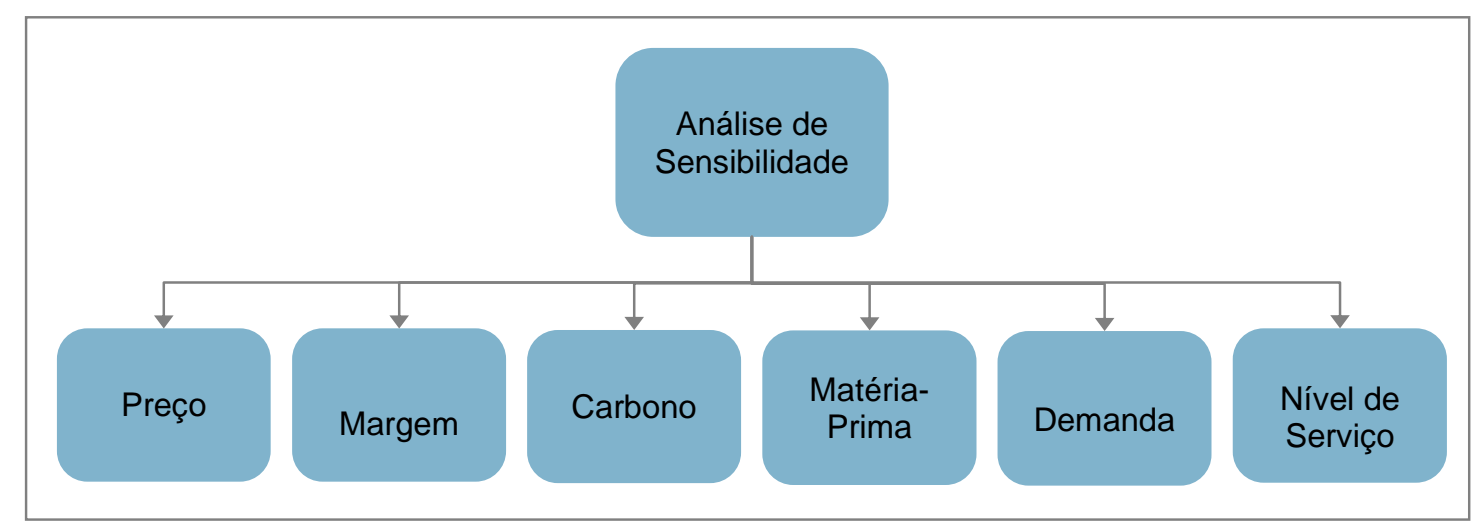

Figura 40: Análises de Sensibilidade

As análises foram construídas conforme apresentado na Figura 40 e estão descritas a seguir:

- Preço: Analisa a sensibilidade do modelo em relação ao preço de transferência e de venda dos produtos. Tem-se como objetivo verificar o impacto da parcela de benefício fiscal no custo total. Essa análise é interessante para entender quais os tipos de produto (commodities, alto valor, etc) a que se pode atribuir os resultados analisados.

- Margem: Analisa a sensibilidade do modelo a alterações de margem dos produtos de modo a entender como a parcela de benefício fiscal se comporta nessas situações. Essa análise, assim como a de preço, possibilita o entendimento sobre para quais produtos pode-se atribuir os resultados encontrados. 
- Carbono: Analisa a sensibilidade do preço do carbono no modelo, visto que, quando avaliado com o preço atual, não gerou mudança na solução.

- Fornecimento de Matéria-Prima: Analisa a sensibilidade do estudo em relação ao fornecimento de matéria-prima para as fábricas. O objetivo é testar até onde o cenário continua válido e em que momento o fornecimento de matéria-prima passa a alterar o resultado.

- Demanda: Analisa a variação da demanda total no modelo de modo a entender as variações decorrentes da mudança da proporção entre os custos fixos e variáveis do estudo.

- Nível de Serviço: Analisa o impacto no resultado da utilização de restrições de nível de serviço para atendimento de alguns mercados.

\subsection{PREÇO}

A análise de sensibilidade sobre o preço de transferência dos produtos foi realizada variando-se os preços de transferência e distribuição dos produtos em escala de 10 pontos percentuais para cima e para baixo, mantendo-se a margem estabelecida no modelo, como pode ser observado nas Tabelas 28 e 29:

\begin{tabular}{cccccccccccc}
\hline Produto & $\mathbf{- 5 0 \%}$ & $\mathbf{- 4 0 \%}$ & $\mathbf{- 3 0 \%}$ & $\mathbf{- 2 0 \%}$ & $\mathbf{- 1 0 \%}$ & $\mathbf{0 \%}$ & $\mathbf{1 0 \%}$ & $\mathbf{2 0 \%}$ & $\mathbf{3 0 \%}$ & $\mathbf{4 0 \%}$ & $\mathbf{5 0 \%}$ \\
\hline Produto SP & 333 & 400 & 467 & 533 & 600 & 667 & 733 & 800 & 867 & 933 & 1.000 \\
Produto MG & 750 & 900 & 1.050 & 1.200 & 1.350 & 1.500 & 1.650 & 1.800 & 1.950 & 2.100 & 2.250 \\
Produto GO & 500 & 600 & 700 & 800 & 900 & 1.000 & 1.100 & 1.200 & 1.300 & 1.400 & 1.500 \\
\hline
\end{tabular}

Tabela 28: Quadro Resumo dos Preços de Transferência Utilizados na Análise

\begin{tabular}{cccccccccccc}
\hline Produto & $\mathbf{- 5 0 \%}$ & $\mathbf{- 4 0 \%}$ & $\mathbf{- 3 0 \%}$ & $\mathbf{- 2 0 \%}$ & $\mathbf{- 1 0 \%}$ & $\mathbf{0 \%}$ & $\mathbf{1 0 \%}$ & $\mathbf{2 0 \%}$ & $\mathbf{3 0 \%}$ & $\mathbf{4 0 \%}$ & $\mathbf{5 0 \%}$ \\
\hline Produto SP & 1.000 & 1.200 & 1.400 & 1.600 & 1.800 & 2.000 & 2.200 & 2.400 & 2.600 & 2.800 & 3.000 \\
Produto MG & 2.250 & 2.700 & 3.150 & 3.600 & 4.050 & 4.500 & 4.950 & 5.400 & 5.850 & 6.300 & 6.750 \\
Produto GO & 1.500 & 1.800 & 2.100 & 2.400 & 2.700 & 3.000 & 3.300 & 3.600 & 3.900 & 4.200 & 4.500 \\
\hline
\end{tabular}

Tabela 29: Quadro Resumo dos Preços de Venda Utilizados na Análise 
A partir da variação dos preços no modelo elaborado em GAMS, pode-se observar que a solução do modelo é estável em relação à variação dos preços, visto que a configuração logística somente sofreu alteração após redução de 50\% no preço, enquanto o aumento dos preços em nada mudou a configuração logística.

Essa diferença encontrada na análise com redução de $50 \%$ do preço dos produtos se dá no mix entre o CD de Belo Horizonte e o Goiânia, que passa de um mix de 65\% em Belo horizonte e 35\% em Goiânia para um mix de 62,5\% e 37,5\%, respectivamente.

A mudança no mix entre os CDs acontece pois, com a redução dos preços dos produtos, a parcela de benefício fiscal passa a perder importância no custo total fazendo com que as parcelas de fretes de transferência e distribuição comecem a atuar no direcionamento dos resultados.

Por outro lado, ao avaliar o benefício fiscal e o custo total da operação, observa-se que o benefício aumenta a medida que os preços vão aumentando, podendo chegar a valores onde a operação logística é totalmente compensada pelo benefício auferido, como pode ser observado na Tabela 30.

\begin{tabular}{|c|c|c|c|c|c|c|c|c|c|c|c|}
\hline & \multicolumn{11}{|c|}{ Variação do Preço } \\
\hline & $-50 \%$ & $-40 \%$ & $-30 \%$ & $-20 \%$ & $-10 \%$ & $0 \%$ & $10 \%$ & $20 \%$ & $30 \%$ & $40 \%$ & $50 \%$ \\
\hline Custo Total & 71,7 & 60,8 & 49,8 & 38,9 & 28,0 & 17,1 & 6,1 & $-4,8$ & $-15,7$ & $-26,7$ & $-37,6$ \\
\hline Benefício Fiscal & 54,7 & 67,0 & 78,1 & 89,3 & $\overline{100,4}$ & 111,6 & 122,8 & 133,9 & 145,1 & 156,2 & 167,4 \\
\hline Custo Logístico Total & 126,4 & 127,7 & 128,0 & 128,2 & 128,4 & 128,7 & 128,9 & 129,1 & 129,3 & 129,6 & 129,8 \\
\hline Frete Transferência & 25,1 & 25,8 & 25,8 & 25,8 & 25,8 & 25,8 & 25,8 & 25,8 & 25,8 & 25,8 & 25,8 \\
\hline Frete de Distribuição & 69,7 & 70,1 & 70,1 & 70,1 & 70,1 & 70,1 & 70,1 & 70,1 & 70,1 & 70,1 & 70,1 \\
\hline Custo Fixo CD & 15,1 & 15,0 & 15,0 & 15,0 & 15,0 & 15,0 & 15,0 & 15,0 & 15,0 & 15,0 & 15,0 \\
\hline Custo Fixo Fabrica & 13,6 & 13,6 & 13,6 & 13,6 & 13,6 & 13,6 & 13,6 & 13,6 & 13,6 & 13,6 & 13,6 \\
\hline Transbordo no CD & 1,0 & 1,0 & 1,0 & 1,0 & 1,0 & 1,0 & 1,0 & 1,0 & 1,0 & 1,0 & 1,0 \\
\hline Transbordo na Fabrica & 0,6 & 0,6 & 0,6 & 0,6 & 0,6 & 0,6 & 0,6 & 0,6 & 0,6 & 0,6 & 0,6 \\
\hline Estoques & 1,1 & 1,4 & 1,6 & 1,8 & 2,1 & 2,3 & 2,5 & 2,7 & 3,0 & 3,2 & 3,4 \\
\hline Carbono & 0,2 & 0,2 & 0,2 & 0,2 & 0,2 & 0,2 & 0,2 & 0,2 & 0,2 & 0,2 & 0,2 \\
\hline
\end{tabular}

Tabela 30: Resumo da Análise de Sensibilidade dos Preços. (em R \$ milhões)

Além do benefício fiscal, podemos observar uma variação no capital em estoque, visto que o mesmo é diretamente proporcional aos preços dos produtos. 
Sendo assim, podemos concluir que o preço em pouco influencia a configuração logística, porém tem impacto considerável nos benefícios fiscais.

\subsection{MARGEM}

A análise de sensibilidade sobre a margem dos produtos foi realizada variando-se o preço de venda e mantendo-se preço de transferência fixo, como pode ser observado na Tabela 31:

\begin{tabular}{ccccccccccccc}
\hline $\begin{array}{c}\text { Produto / } \\
\text { Margem }\end{array}$ & $\mathbf{1 5 0} \%$ & $\mathbf{1 6 0 \%}$ & $\mathbf{1 7 0} \%$ & $\mathbf{1 8 0} \%$ & $\mathbf{1 9 0} \%$ & $\mathbf{2 0 0} \%$ & $\mathbf{2 1 0} \%$ & $\mathbf{2 2 0} \%$ & $\mathbf{2 3 0} \%$ & $\mathbf{2 4 0} \%$ & $\mathbf{2 5 0} \%$ \\
\hline Produto SP & 1.668 & 1.734 & 1.801 & 1.868 & 1.934 & 2.001 & 2.068 & 2.134 & 2.201 & 2.268 & 1.668 \\
Produto MG & 3.750 & 3.900 & 4.050 & 4.200 & 4.350 & 4.500 & 4.650 & 4.800 & 4.950 & 5.100 & 5.250 \\
Produto GO & 2.600 & 2.700 & 2.800 & 2.900 & 3.000 & 3.100 & 3.200 & 3.300 & 3.400 & 3.500 & 2.600 \\
\hline
\end{tabular}

Tabela 31: Resumo dos Preços de Venda Utilizados na Análise de Margem

Um fato interessante que pode ser observado nessa análise é que existe um ponto máximo de custo logístico. Isso se deve ao modelo não permitir benefício fiscal maior que o saldo devedor de determinado Estado. Ao aumentar as margens, aumenta-se o valor do benefício fiscal, fazendo com que seja necessário um menor volume de mercadorias para que o benefício fiscal compense o saldo devedor de ICMS.

Ao diminuir a margem, ocorre um efeito contrário. O benefício fiscal força a centralização do volume nos Estados onde exista tal benefício até o ponto onde este passa a ter menor importância frente aos custos logísticos, fazendo com que a sua importância no custo total diminua e torne os custos logísticos novamente significativos.

Nota-se também que o aumento da margem aumenta em muito o benefício fiscal auferido, de maneira que o mesmo mais do que compensa os custos logísticos. $\mathrm{O}$ benefício chega a zerar o custo total em casos com margens superiores a $230 \%$ entre preço de transferência e de venda, como pode ser observado na Tabela 32. 


\begin{tabular}{|c|c|c|c|c|c|c|c|c|c|c|c|}
\hline \multirow[b]{2}{*}{ Margem } & \multicolumn{11}{|c|}{ Variação da Margem } \\
\hline & $150 \%$ & $160 \%$ & $170 \%$ & $180 \%$ & $190 \%$ & $200 \%$ & $210 \%$ & $220 \%$ & $230 \%$ & $240 \%$ & $250 \%$ \\
\hline Custo Total & 50,8 & 45,4 & 39,4 & 32,6 & 25,1 & 17,1 & 9,3 & 3,1 & $-3,0$ & $-9,0$ & $-15,1$ \\
\hline \multirow{2}{*}{$\begin{array}{l}\text { Benefício Fiscal } \\
\text { Custo Logístico Total }\end{array}$} & 69,5 & 75,8 & 82,9 & 91,0 & 100,4 & 111,6 & 122,5 & 127,9 & 133,4 & 138,9 & 144,5 \\
\hline & 120,3 & 121,2 & 122,2 & 123,6 & 125,6 & 128,7 & 131,8 & 131,0 & 130,4 & 129,9 & 129,4 \\
\hline \multirow{2}{*}{$\begin{array}{l}\text { Frete Transferência } \\
\text { Frete de Distribuição }\end{array}$} & 17,0 & 18,4 & 20,0 & 21,5 & 23,4 & 25,8 & 27,7 & 27,5 & 27,4 & 27,3 & 27,1 \\
\hline & 70,5 & 70,0 & 69,4 & 69,2 & 69,3 & 70,1 & 71,2 & 70,6 & 70,2 & 69,9 & 69,6 \\
\hline \multirow{5}{*}{$\begin{array}{l}\text { Custo Fixo CD } \\
\text { Custo Fixo Fabrica } \\
\text { Transbordo no CD } \\
\text { Transbordo na Fabrica }\end{array}$} & 15,0 & 15,1 & 15,1 & 15,2 & 15,1 & 15,0 & 14,9 & 14,9 & 14,8 & 14,8 & 14,7 \\
\hline & 13,6 & 13,6 & 13,6 & 13,6 & 13,6 & 13,6 & 13,6 & 13,6 & 13,6 & 13,6 & 13,6 \\
\hline & 1,0 & 1,0 & 1,0 & 1,0 & 1,0 & 1,0 & 1,0 & 1,0 & 1,0 & 1,0 & 1,0 \\
\hline & 0,6 & 0,6 & 0,6 & 0,6 & 0,6 & 0,6 & 1,2 & 1,2 & 1,2 & 1,2 & 1,2 \\
\hline & 2,3 & 2,3 & 2,3 & 2,3 & 2,3 & 2,3 & 1,9 & 1,9 & 1,9 & 1,9 & 1,9 \\
\hline $\begin{array}{l}\text { Estoques } \\
\text { Carbono }\end{array}$ & 0,2 & 0,2 & 0,2 & 0,2 & 0,2 & 0,2 & 0,3 & 0,3 & 0,3 & 0,3 & 0,3 \\
\hline
\end{tabular}

Tabela 32: Resumo dos Custos Totais - Análise de Margem. (em R $\$$ milhões)

Além disso, ao aumentar as margens dos produtos, a parcela de benefício aumenta cada vez mais o seu valor, fazendo com que a configuração logística se altere significativamente.

Na Figura 41, pode-se observar as variações na configuração logística dos cenários com margens de $210 \%$ e $250 \%$, onde parte da demanda do nordeste brasileiro passa a ser suprida pelo $C D$ de MG, mesmo com 0 aumento das distâncias percorridas pelo transporte.

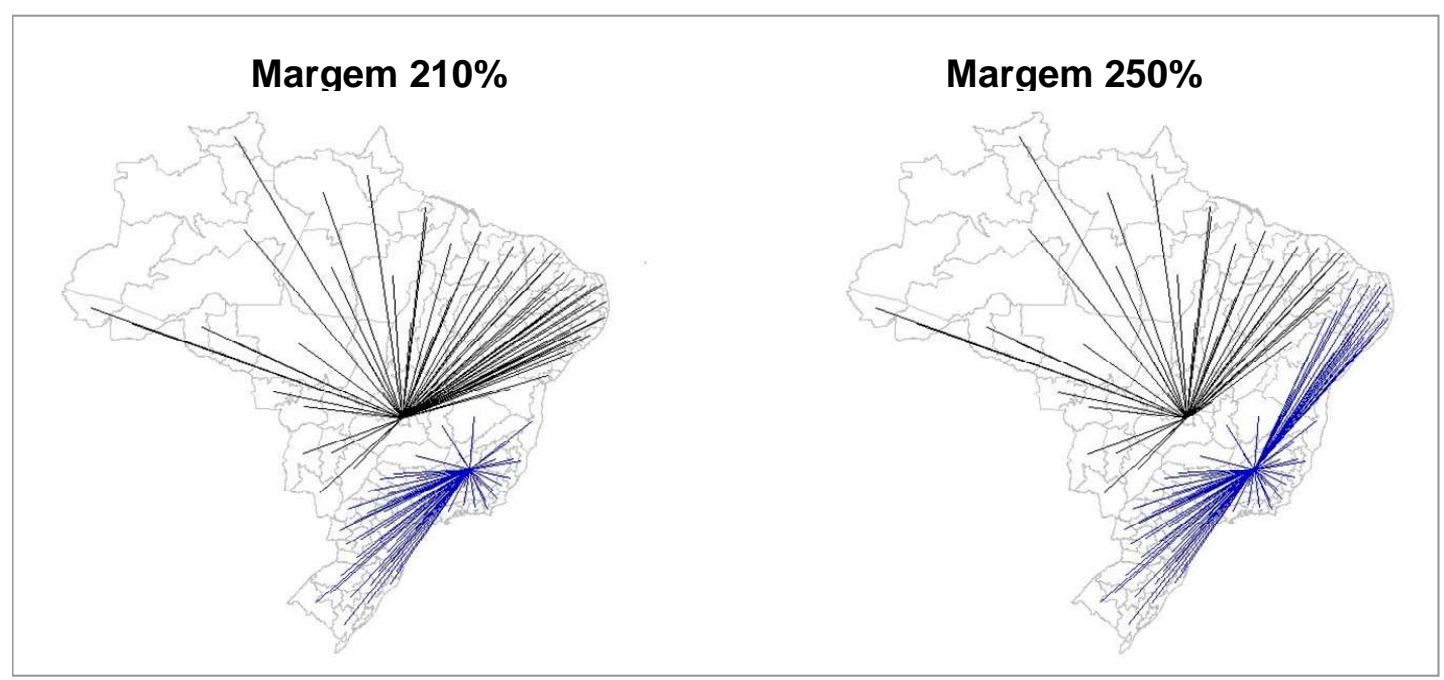

Figura 41: Variação do Fluxo de Distribuição - Análise de Variação na Margem

$\mathrm{Na}$ Tabela 33, pode-se observar a variação da configuração logística resultante da variação da margem dos produtos. 


\begin{tabular}{cccc}
\hline Margem & Fábrica & $\%$ MG & $\%$ GO \\
\hline $150 \%$ & Goiânia/GO & $34 \%$ & $66 \%$ \\
$160 \%$ & Goiânia/GO & $39 \%$ & $61 \%$ \\
$170 \%$ & Goiânia/GO & $45 \%$ & $55 \%$ \\
$180 \%$ & Goiânia/GO & $50 \%$ & $50 \%$ \\
$190 \%$ & Goiânia/GO & $57 \%$ & $43 \%$ \\
$200 \%$ & Goiânia/GO & $65 \%$ & $35 \%$ \\
$210 \%$ & São Paulo/SP & $74 \%$ & $26 \%$ \\
$220 \%$ & São Paulo/SP & $76 \%$ & $24 \%$ \\
$230 \%$ & São Paulo/SP & $78 \%$ & $22 \%$ \\
$240 \%$ & São Paulo/SP & $79 \%$ & $21 \%$ \\
$250 \%$ & São Paulo/SP & $81 \%$ & $19 \%$ \\
\hline
\end{tabular}

Tabela 33: Resumo das Configurações Logísticas - Análise de Margem

Pode-se concluir, a partir dos resultados apresentados, que a margem dos produtos é extremamente sensível na definição da melhor configuração logística para determinada empresa. Pode-se concluir, também, que o benefício fiscal atuará de maneira diferente para cada indústria, sendo que uma indústria de bens de consumo duráveis, com maiores margens de venda, será bem mais afetada pelo benefício fiscal do que uma indústria de bens de consumo não duráveis, caracterizada por baixas margens e competitividade acirrada.

\subsection{CARBONO}

A análise de sensibilidade realizada para melhor entendimento do parâmetro de carbono no modelo foi elaborada com o objetivo de identificar se variações de preço do carbono podem torná-lo uma parcela de custo capaz de mudar a configuração logística do cenário.

O cenário escolhido como base para esta análise, diferentemente dos demais, foi o Cenário 2, sem benefício fiscal, pois, assim como apresentado no capítulo anterior, o benefício fiscal possui um peso muito grande no resultado final da análise e poderia dificultar o entendimento dos resultados dessa análise de sensibilidade.

Pode-se observar, na Tabela 34, que o preço do carbono somente começa a modificar o cenário logístico após um aumento de cerca de $400 \%$ em seu valor orignal e que o mesmo mantém-se estável até um aumento de $3200 \%$ no preço praticado para o carbono equivalente. 


\begin{tabular}{|l|c|c|c|c|c|c|c|}
\hline \multicolumn{1}{c|}{} & \multicolumn{7}{c|}{ Variação do Custo do Carbono } \\
\cline { 2 - 8 } & $\mathbf{+ 5 0}$ & $\mathbf{+ 1 0 0 \%}$ & $\mathbf{+ 2 0 0 \%}$ & $\mathbf{+ 4 0 0 \%}$ & $\mathbf{+ 8 0 0 \%}$ & $\mathbf{+ 1 6 0 0 \%}$ & $\mathbf{+ 3 2 0 0 \%}$ \\
\hline Custo Total & 106,4 & 106,4 & 106,6 & 106,9 & 107,5 & 108,8 & 111,3 \\
\hline
\end{tabular}

\begin{tabular}{|c|c|c|c|c|c|c|c|}
\hline \multirow{2}{*}{$\begin{array}{l}\text { Benefício Fiscal } \\
\text { Custo Logístico Total }\end{array}$} & 0,0 & 0,0 & 0,0 & 0,0 & 0,0 & 0,0 & 0,0 \\
\hline & 106,4 & 106,4 & 106,6 & 106,9 & 107,5 & 108,8 & 111,3 \\
\hline \multirow{8}{*}{$\begin{array}{l}\text { Frete Transferência } \\
\text { Frete de Distribuição } \\
\text { Custo Fixo CD } \\
\text { Custo Fixo Fabrica } \\
\text { Transbordo no CD } \\
\text { Transbordo na Fabrica } \\
\text { Estoques } \\
\text { Carbono }\end{array}$} & 9,3 & 9,3 & 9,3 & 11,4 & 11,4 & 11,4 & 11,4 \\
\hline & 65,4 & 65,4 & 65,4 & 63,0 & 63,0 & 63,0 & 63,0 \\
\hline & 13,9 & 13,9 & 13,9 & 14,3 & 14,3 & 14,3 & 14,3 \\
\hline & 13,6 & 13,6 & 13,6 & 13,6 & 13,6 & 13,6 & 13,6 \\
\hline & 1,1 & 1,1 & 1,1 & 1,1 & 1,1 & 1,1 & 1,1 \\
\hline & 1,2 & 1,2 & 1,2 & 1,2 & 1,2 & 1,2 & 1,2 \\
\hline & 1,6 & 1,6 & 1,6 & 1,7 & 1,7 & 1,7 & 1,7 \\
\hline & 0,2 & 0,3 & 0,5 & 0,8 & 1,4 & 2,6 & 5,1 \\
\hline
\end{tabular}

Tabela 34: Resumo da Análise dos Preços do Carbono. (em $\mathrm{R} \$$ milhões)

Ao aumentar o preço do carbono em $400 \%$, a configuração logística sofre uma variação significativa em relação ao Cenário 1. Ocasiona o fechamento do $C D$ do Recife e abertura de um CD na Bahia para atendimento de 7,5\% da demanda, como pode ser observado na Tabela 35.

\begin{tabular}{ccrrrr}
\hline Fábrica & CD & Produto BH & Produto Go & Produto SP & \multicolumn{1}{c}{ Total } \\
\hline São Paulo/SP & Salvador/BA & 6.817 & 17.276 & 5.907 & 30.000 \\
São Paulo/SP & São Paulo/SP & 127.031 & 221.861 & 22.549 & 371.441 \\
\hline
\end{tabular}

Tabela 35: Fluxo de Transferência no Cenário 1 - Análise de Preço do Carbono

Observa-se claramente na Figura 42 que o aumento do preço do carbono faz com que o modelo diminua as distâncias percorridas pelo transporte de modo a reduzir a emissão de carbono e, consequentemente, minimizar os custos associados a esta parcela da função objetivo. 


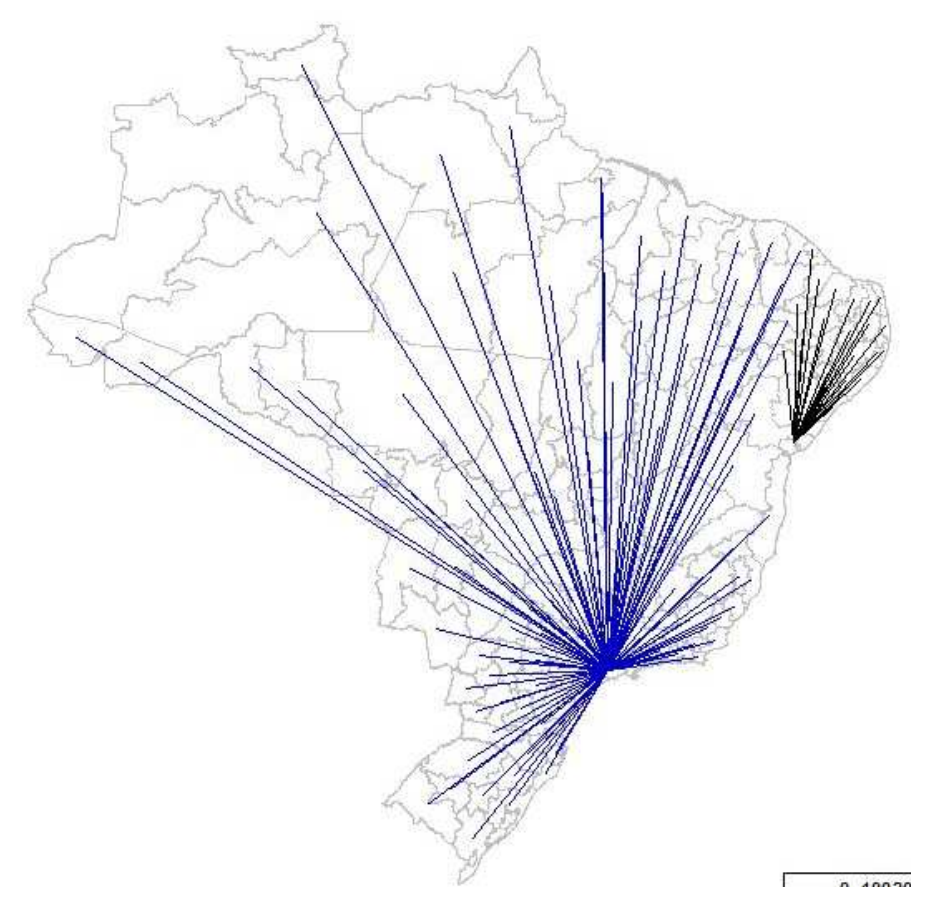

Figura 42: Variação do Fluxo de Distribuição - Análise do Preço do Carbono

Conclui-se também que o aumento do preço do carbono não faz com que a configuração logística se altere a cada ponto percentual de aumento, mas que apresenta pontos de inflexão, onde o custo de neutralização das emissões de carbono tornam-se uma parcela com valor suficiente para permitir abertura ou fechamento de CDs e Fábricas. Na análise de sensibilidade apresentada, a configuração manteve-se inalterada até o custo ser aumentado em 400\% e depois disso, manteve a mesma solução até o final da análise.

\subsection{FORNECIMENTO DE MATÉRIA-PRIMA}

A análise de sensibilidade relacionada ao fornecimento de matéria-prima se deve a necessidade de entender o impacto nos cenários para o caso em que ocorra uma mudança de localização de uma fábrica, mas não seja possível alterar o centro fornecedor.

Nos cenários analisados no capítulo anterior, a parcela de custos de matéria-prima tem custo zero devido a falta de informações mais detalhadas sobre os componentes que formam os produtos, mercados fornecedores e os impactos em preço que podem sofrer em cada uma das regiões. 
Sendo assim, essa análise tem como objetivo a identificação dos impactos que o fornecimento de matéria-prima pode causar e em qual ponto a mesma começa a modificar o Cenário 4, tido como final dessa tese. Em nenhum momento tem-se como objetivo o detalhamento dos custos de matéria-prima e análise dos mercados fornecedores nacionais ou internacionais.

Uma vez detalhados os objetivos e estabelecidas as premissas para esta análise, foram montados cenários onde se varia o percentual do volume fornecido pelo local original dos produtos, como por exemplo o Produto $\mathrm{BH}$ tem suas matérias-primas oriundas de Belo Horizonte. Dessa forma pode-se analisar o comportamento do modelo ao se alterar essa taxa de fornecimento .

$\mathrm{Na}$ Tabela 36, pode-se observar o detalhamento dos custos e como a parcela de custo de matéria-prima impacta o custo total, ao aumentar a taxa da matéria-prima fornecida pelo Estado de origem, de $0 \%$ até $100 \%$

\begin{tabular}{|c|c|c|c|c|c|c|c|c|c|c|c|}
\hline \multirow{3}{*}{$\begin{array}{l}\text { Percentual de Fornecimento } \\
\text { Custo Total }\end{array}$} & \multicolumn{11}{|c|}{ Variação do Percentual de Fornecimento do Local de Origem dos Produtos } \\
\hline & $0 \%$ & $10 \%$ & $20 \%$ & $30 \%$ & $40 \%$ & $50 \%$ & $60 \%$ & $70 \%$ & $80 \%$ & $90 \%$ & $100 \%$ \\
\hline & 17,1 & 20,0 & 22,7 & 24,7 & 26,7 & 28,7 & 30,7 & 32,7 & 34,7 & 36,8 & 38,8 \\
\hline \multirow{2}{*}{$\begin{array}{l}\text { Benefício Fiscal } \\
\text { Custo Logístico Total }\end{array}$} & 111,6 & 111,6 & 111,6 & 111,6 & 111,6 & 111,6 & 111,6 & 111,6 & 111,6 & 111,6 & 111,6 \\
\hline & 128,7 & 131,6 & 134,3 & 136,3 & 138,3 & 140,3 & 142,3 & 144,3 & 146,3 & 148,4 & 150,4 \\
\hline \multirow{9}{*}{$\begin{array}{l}\text { Frete Transferência } \\
\text { Frete de Distribuição } \\
\text { Custo Fixo CD } \\
\text { Custo Fixo Fabrica } \\
\text { Transbordo no CD } \\
\text { Transbordo na Fabrica } \\
\text { Estoques } \\
\text { Carbono } \\
\text { Matéria-Prima }\end{array}$} & 25,8 & 25,8 & 25,7 & 25,7 & 25,7 & 25,7 & 25,7 & 25,7 & 25,7 & 25,7 & 25,7 \\
\hline & 70,1 & 70,1 & 70,2 & 70,2 & 70,2 & 70,2 & 70,2 & 70,2 & 70,2 & 70,2 & 70,2 \\
\hline & 15,0 & 15,0 & 15,0 & 15,0 & 15,0 & 15,0 & 15,0 & 15,0 & 15,0 & 15,0 & 15,0 \\
\hline & 13,6 & 13,6 & 15,1 & 15,1 & 15,1 & 15,1 & 15,1 & 15,1 & 15,1 & 15,1 & 15,1 \\
\hline & 1,0 & 1,0 & 1,0 & 1,0 & 1,0 & 1,0 & 1,0 & 1,0 & 1,0 & 1,0 & 1,0 \\
\hline & 0,6 & 0,6 & 0,8 & 0,8 & 0,8 & 0,8 & 0,8 & 0,8 & 0,8 & 0,8 & 0,8 \\
\hline & 2,3 & 2,3 & 2,1 & 2,1 & 2,1 & 2,1 & 2,1 & 2,1 & 2,1 & 2,1 & 2,1 \\
\hline & 0,2 & 0,2 & 0,2 & 0,2 & 0,2 & 0,2 & 0,2 & 0,2 & 0,2 & 0,2 & 0,2 \\
\hline & 0,0 & 2,9 & 4,0 & 6,0 & 8,0 & 10,1 & 12,1 & 14,1 & 16,1 & 18,1 & 20,1 \\
\hline
\end{tabular}

Tabela 36: Resumo dos Custos (Variação do Percentual de Fornecimento)

Pode-se observar claramente que, com fornecimentos até $10 \%$ do local de origem dos produtos, o modelo não sofre alteração, mantendo a mesma configuração do Cenário 4, que serviu de base para as análises de sensibilidade. Porém, a partir dos $20 \%$ e até chegar aos $100 \%$ fornecido do local de origem, a configuração logística muda, com a abertura de uma nova Fábrica em SP, e manutenção dos CDs de Belo Horizonte e Goiânia.

Mesmo sendo o Produto SP o de menor demanda e o que menos afetaria a parcela de custos de matéria-prima, a Fábrica de SP é aberta para atender $40 \%$ do volume 
total, ou seja, $100 \%$ do volume do Produto $\mathrm{BH}$ e do Produto SP, como pode ser observado na Tabela 37.

\begin{tabular}{ccccc}
\hline Fábrica & CD & Produto BH & Produto GO & Produto SP \\
\hline Goiânia/GO & Belo Horizonte/MG & \multicolumn{3}{c}{143.757} \\
Goiânia/GO & Goiânia/GO & & 95.380 & \\
São Paulo/SP & Belo Horizonte/MG & 104.354 & & 14.853 \\
São Paulo/SP & Goiânia/GO & 29.494 & & 13.603 \\
\hline
\end{tabular}

Tabela 37: Fluxo de Transferência (Variação do Percentual de Fornecimento)

A razão pela qual o modelo mantém a fábrica de $\mathrm{GO}$, mas abre uma adicional em SP, se deve novamente aos impactos dos benefícios fiscais associados. Ao inserir a variável de matéria-prima, o Estado de Goiás, já escolhido para sediar a fábrica no Cenário 4, ganha ainda mais força, pois o produto de origem GO representa $60 \%$ do volume total fabricado e a manutenção da fábrica faz com que a parcela de matériaprima tenha seu custo igual a zero. A segunda escolha mais provável seria a abertura da fábrica no Estado de origem do produto com o segundo maior volume, que seria o Produto $\mathrm{BH}$ (33,5\% do volume). Porém a abertura da fábrica em $\mathrm{BH}$ faria com que o potencial de benefício fiscal diminuísse, uma vez que o ICMS cobrado de um envio de fora do Estado é menor que o ICMS intra-estadual de MG, o que faria com que o saldo de ICMS diminuísse e, consequentemente, também o benefício fiscal auferido.

Dessa maneira, pode-se dizer que a abertura da fábrica em GO e SP é um cenário mais robusto se comparado ao Cenário 4, pois mantém o benefício fiscal com apenas um pequeno aumento nas parcelas de custo logístico. Isso torna este cenário mais seguro, caso não seja possível o estabelecimento de fontes fornecedoras nos Estados onde as fábricas estão localizadas.

A seguir, na Figura 43, é apresentado o mapa de distribuição da nova configuração para cada um dos produtos analisados. 


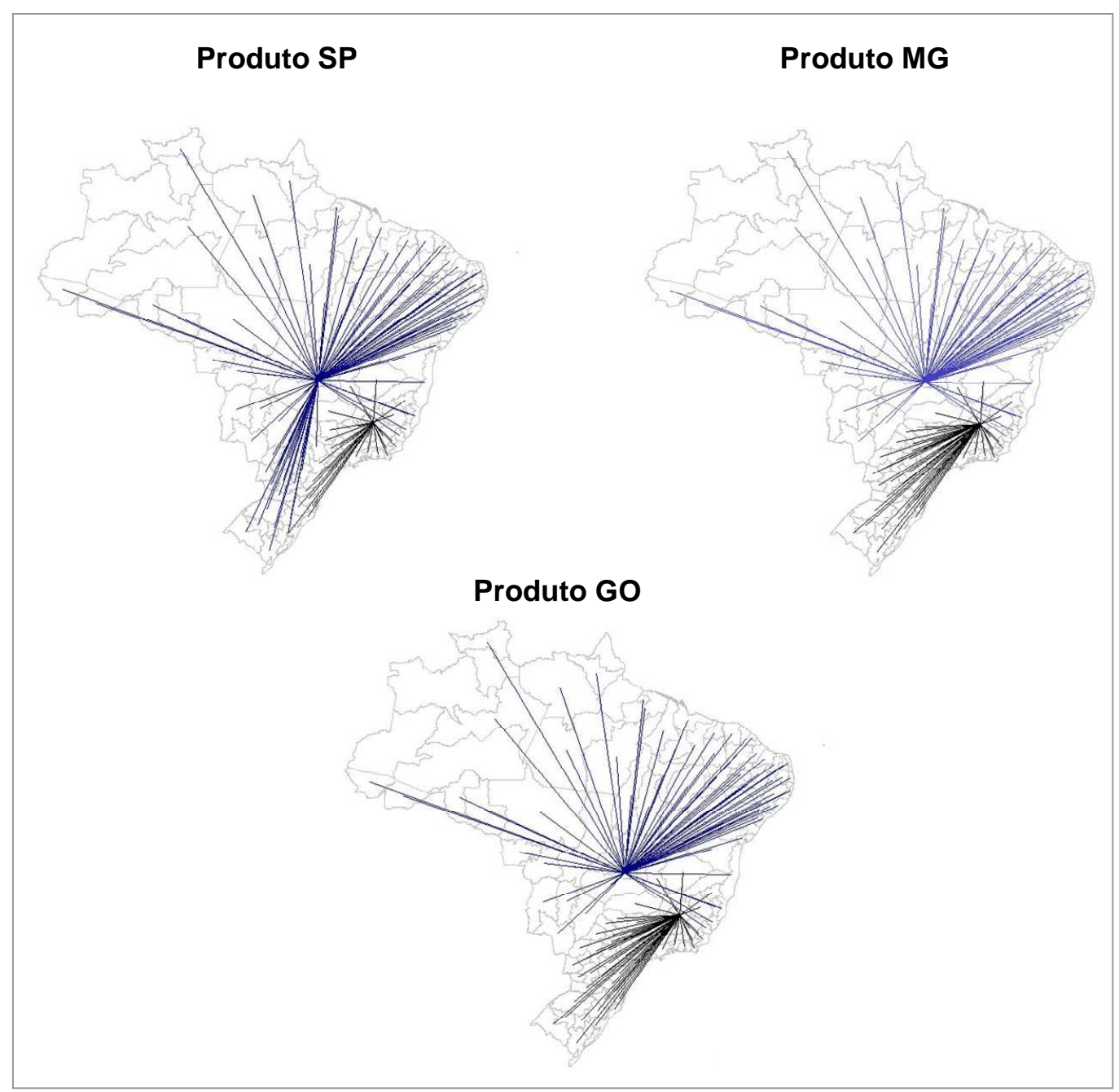

Figura 43: Fluxo de Distribuição do Cenário com Matéria-Prima maior que 20\%

\subsection{DEMANDA}

A análise de sensibilidade referente a variação da demanda foi realizada com o objetivo de entender qual o comportamento da solução ao se aplicar volumes maiores ou menores ao volume do estudo de caso analisado. Essa análise partiu do Cenário 4, a partir do qual se variou única e exclusivamente a demanda total, respeitando-se o mix de distribuição para cada uma das meso-regiões.

A variação da demanda atua principalmente nos percentuais de custo referentes as parcelas de custos fixos e variáveis das instalações, devido à incorporação ao modelo do ganho de escala nos custos das fábricas e centros de distribuição. 
Vale ressaltar que, para a análise realizada, variou-se a demanda numa amostra de $50 \%$ para a menos até $50 \%$ a mais. Para tanto, criaram-se as fábricas e os CDs dos tamanhos necessários para ser possível a abertura de uma única instalação, caso esse seja a melhor solução possível.

É importante notar que, ao analisar os custos por tonelada movimentada, a parcela de benefício fiscal não se altera ao longo da análise, enquanto a parcela de custos logísticos apresenta um ganho de escala, como detalhada na Tabela 38.

\begin{tabular}{|c|c|c|c|c|c|}
\hline \multirow[b]{2}{*}{ Variação da Demanda (\%) } & \multicolumn{5}{|c|}{ Variação da Demanda (Custos em $\mathbf{R} \$ /$ tonelada) } \\
\hline & $-50 \%$ & $-25 \%$ & $0 \%$ & $25 \%$ & $50 \%$ \\
\hline Demanda (em toneladas) & 200.721 & 301.081 & 401.441 & 501.801 & 602.162 \\
\hline Custo Total & 50,9 & 45,6 & 42,5 & 39,5 & 37,4 \\
\hline \multirow{2}{*}{$\begin{array}{l}\text { Benefício Fiscal } \\
\text { Custo Logístico Total }\end{array}$} & 278,0 & 278,0 & 278,0 & 278,0 & 278,0 \\
\hline & 328,9 & 323,6 & 320,5 & 317,5 & 315,4 \\
\hline \multirow{8}{*}{$\begin{array}{l}\text { Frete Transferência } \\
\text { Frete de Distribuição } \\
\text { Custo Fixo CD } \\
\text { Custo Fixo Fabrica } \\
\text { Transbordo no CD } \\
\text { Transbordo na Fabrica } \\
\text { Estoques } \\
\text { Carbono }\end{array}$} & 64,2 & 64,2 & 64,2 & 64,2 & 64,2 \\
\hline & 174,6 & 174,6 & 174,6 & 174,6 & 174,6 \\
\hline & 42,6 & 39,5 & 37,5 & 36,1 & 35,0 \\
\hline & 37,3 & 35,0 & 33,9 & 32,2 & 31,3 \\
\hline & 2,5 & 2,5 & 2,5 & 2,5 & 2,5 \\
\hline & 1,5 & 1,5 & 1,5 & 1,5 & 1,5 \\
\hline & 5,7 & 5,7 & 5,7 & 5,7 & 5,7 \\
\hline & 0,6 & 0,6 & 0,6 & 0,6 & 0,6 \\
\hline
\end{tabular}

Tabela 38: Quadro Resumo dos Custos (Variação da Demanda)

Outro dado interessante, já esperado após verificar que a parcela de benefício fiscal não se alterava, é que a configuração logística mantém-se a mesma. Tem-se a abertura de uma fábrica em Goiás e dois CDs, sendo um em Goiânia e o outro em Belo Horizonte, com $35 \%$ e $65 \%$ do volume respectivamente, assim como apresentado na análise do Cenário 4 a na Tabela 39.

\begin{tabular}{cccccc}
\hline Fábrica & CD & Produto BH & Produto GO & Produto SP & Total \\
\hline Goiânia/GO & Belo Horizonte/MG & $78 \%$ & $62 \%$ & $34 \%$ & $65 \%$ \\
Goiânia/GO & Goiânia/GO & $22 \%$ & $38 \%$ & $66 \%$ & $35 \%$ \\
\hline
\end{tabular}

Tabela 39: Fluxo de Transferência (Variação da Demanda)

\subsection{NÍVEL DE SERVIÇO}

A análise de sensibilidade referente a aplicação, ou não, de restrições de nível de serviço foi realizada com o objetivo de melhor entender o comportamento do modelo 
ao se aplicar tal restrição. Porém, dado que no estudo de caso analisado, os clientes finais são, em sua maioria, grandes atacadistas e varejistas, já existe uma programação de entregas semanais pré-estabelecida. Isso faz com que a análise sirva como parte do estudo, porém não seja totalmente aplicável na prática, devido ao planejamento de transportes realizado pela empresa.

Essa análise partiu do Cenário 4, a partir do qual criaram-se dois cenários adicionais utilizando critérios de nível de serviço usualmente encontrados na indústria e de conhecimento prévio do autor com sua experiência em empresas como Sadia, Pernambucanas, C\&A e Avon.

O primeiro cenário apresenta restrição de nível de serviço de entrega de 1 dia para todas as meso-regiões consideradas "AAA", que representam cerca de $50 \%$ do volume total.

O segundo cenário apresenta além da restrição de 1 dia para as meso-regiões "AAA", uma restrição de entrega em 2 dias para as meso-regiões "AA", abrangendo, juntos, $70 \%$ do volume total distribuído.

Para realização destas análises, foram retirados os arcos do modelo elaborado em GAMS onde não era possível o atendimento dentro do nível de serviço esperado. Então, os cenários foram simulados novamente para a análise dos resultados.

Como já era esperado, a partir de outras análises de sensibilidade realizadas por outros autores, tal como Silva (2007), a inserção desta restrição fez com que ocorresse a abertura de mais centros de distribuição; como pode ser observado na Figura 44 e na Tabela 40, onde é apresentado o fluxo de distribuição do cenário com nível de serviço "AAA".

\begin{tabular}{ccccc}
\hline Fábrica & CD & Produto BH & Produto GO & Produto SP \\
\hline São Paulo/SP & Belo Horizonte/MG & $70 \%$ & $66 \%$ & $50 \%$ \\
São Paulo/SP & Curitiba/PR & $6 \%$ & $8 \%$ & $6 \%$ \\
São Paulo/SP & Goiânia/GO & $22 \%$ & $24 \%$ & $40 \%$ \\
São Paulo/SP & São Paulo/SP & $2 \%$ & $3 \%$ & $4 \%$ \\
\hline
\end{tabular}

Tabela 40: Fluxo de Transferência (Nível de Serviço "AAA") 


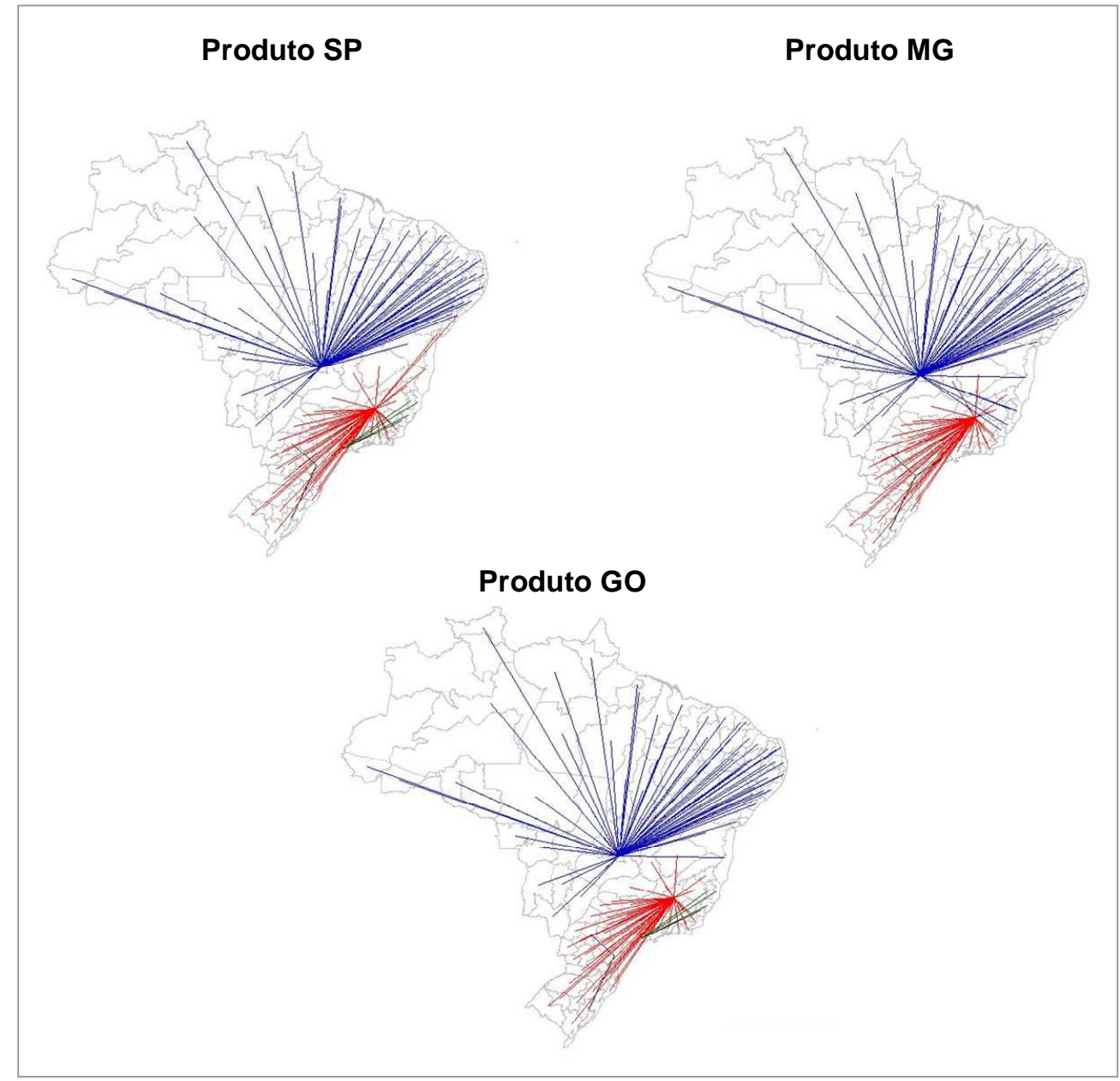

Figura 44: Fluxo de Distribuição do Cenário com Nível de Serviço "AAA"

Ao aumentar o nível de serviço, pode-se observar a abertura de ainda mais CDs, como pode ser observado na Figura 45 e na Tabela 41.

\begin{tabular}{ccccc}
\hline Fábrica & CD & Produto BH & Produto GO & Produto SP \\
\hline São Paulo/SP & Belo Horizonte/MG & $70 \%$ & $66 \%$ & $50 \%$ \\
São Paulo/SP & Curitiba/PR & $7 \%$ & $8 \%$ & $6 \%$ \\
São Paulo/SP & Goiânia/GO & $17 \%$ & $21 \%$ & $29 \%$ \\
São Paulo/SP & Salvador/BA & $3 \%$ & $4 \%$ & $13 \%$ \\
São Paulo/SP & São Paulo/SP & $3 \%$ & $2 \%$ & $2 \%$ \\
\hline
\end{tabular}

Tabela 41: Fluxo de Transferência (Nível de Serviço "AAA" + "AA") 


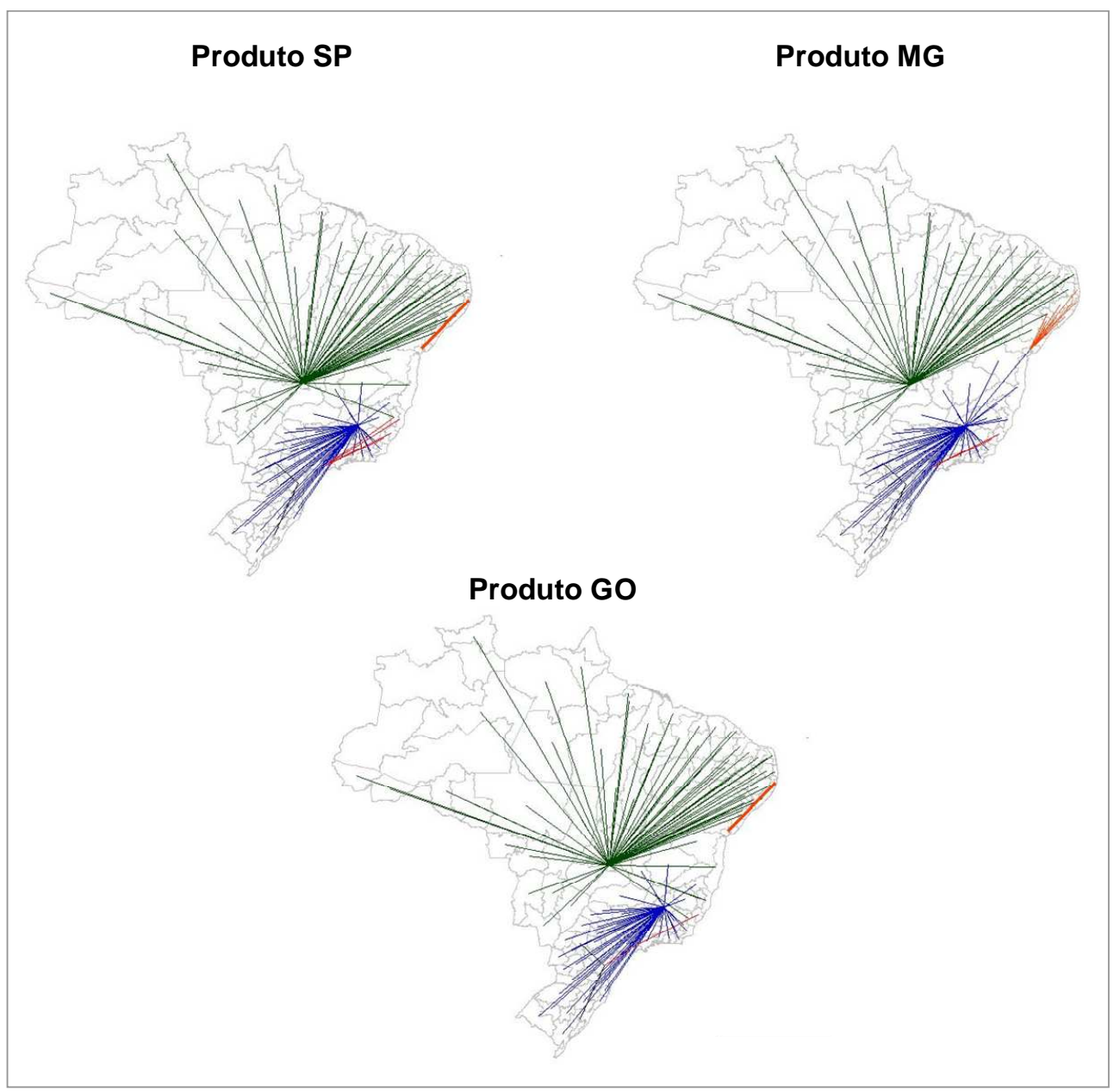

Figura 45: Fluxo de Distribuição do Cenário com Nível de Serviço "AAA" + "AA"

No entanto, um fato interessante é que em ambos os cenários o benefício fiscal continua a direcionar a solução, sendo que a abertura de CDs adicionais se dá única e exclusivamente para o atendimento de determinada meso-região, continuando mais de $90 \%$ do volume nos CDs de Goiânia e Belo Horizonte, como no Cenário 4.

É interessante observar também que os custos logísticos quase se igualam ao cenário de menor custo total (Cenário 4). Mesmo com a abertura de mais centros de distribuição e da mudança da fábrica para São Paulo, os custos totais pouco se alteram, sendo que $\mathrm{o}$ aumento dos custos fixos e de transferências são compensados pela diminuição da parcela de custo de distribuição, como pode ser observado na Figura 46. 


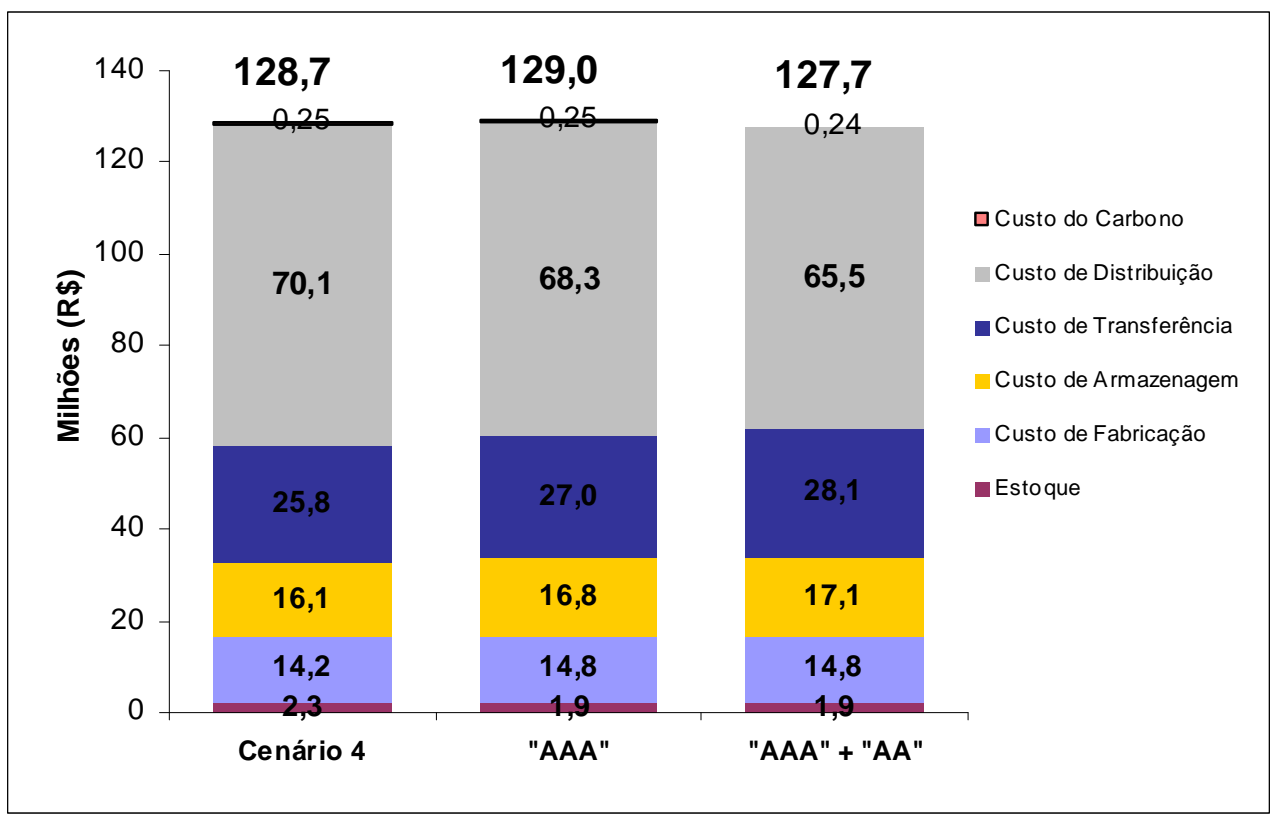

Figura 46: Custo Total dos Cenários com Restrição de Nível de Serviço

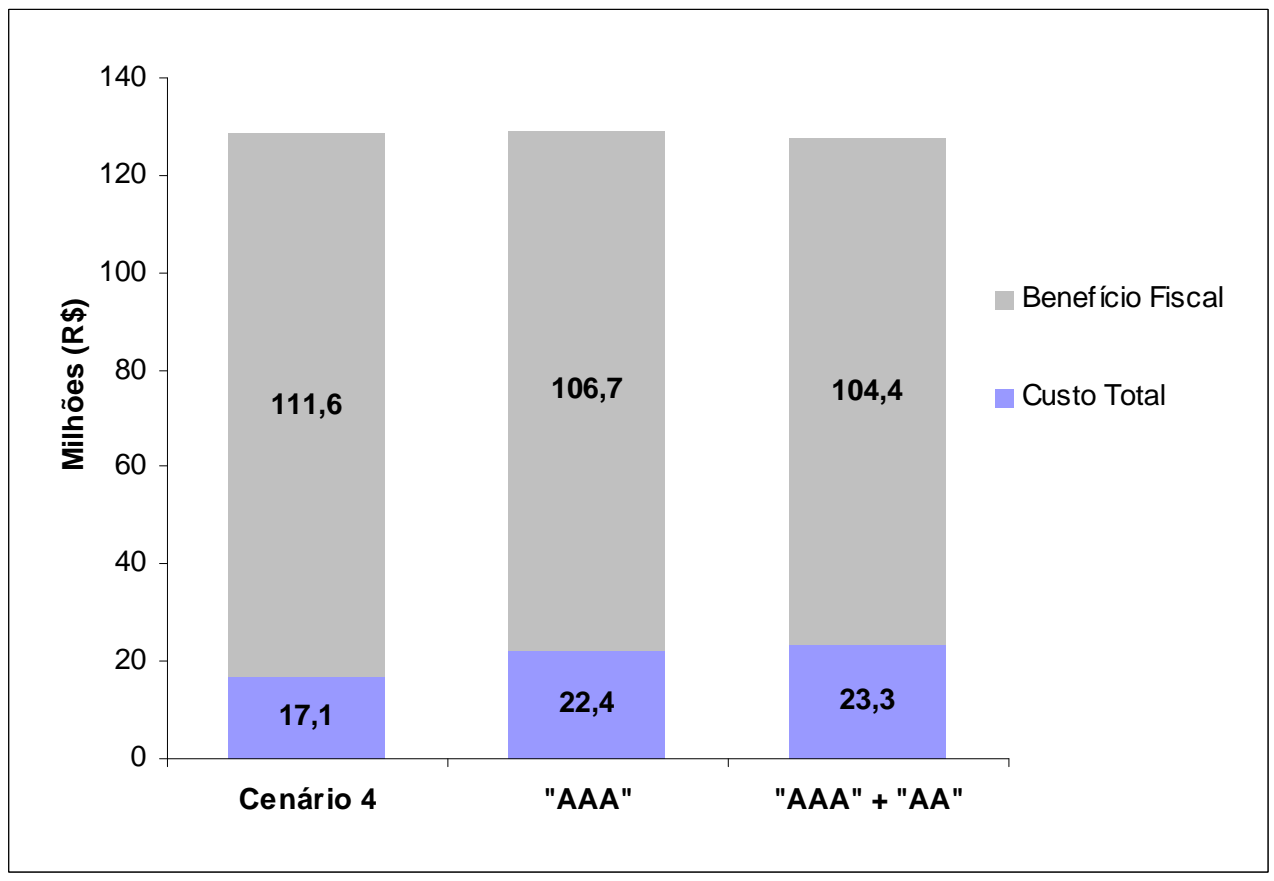

Figura 47: Custo Total e Benefício Fiscal com Restrição de Nível de Serviço

Outro fato interessante e que comprova a relevância do benefício fiscal na decisão de localização é que o benefício fiscal auferido aos três cenários é muito próximo. Mais de $85 \%$ do volume continua nos CDs localizados nos Estados com benefício fiscal e que o volume do CD de Minas Gerais, maior gerador de benefício, continua praticamente igual. 
Esses resultados reforçam a importância da análise dos trade-offs existentes entre os benefícios fiscais e a configuração logística das empresas, pois mesmo em empresas onde o nível de serviço é fator diferenciador e importante para o sucesso da mesma, a política fiscal continua atuante de forma a alterar o resultado logístico ótimo.

Uma vez finalizada as diversas análises de sensibilidade, o próximo capítulo apresenta as conclusões finais. 


\section{CONCLUSÕES}

Esta parte da dissertação tem como objetivo a apresentação das principais conclusões e recomendações obtidas através do modelo elaborado para análise dos trade-offs existentes entre os custos logísticos e os benefícios fiscais envolvidos no modelo de decisão.

Após a conclusão das análises dos cenários e das análises de sensibilidade, podese dizer que a dissertação contribui em diversos aspectos aos estudos já realizados sobre o tema, pois, além da criação de um modelo matemático elaborado em GAMS (Anexo D), flexível e aderente a realidade brasileira de modo a possibilitar a simulação de uma série de cenários, insere de forma pioneira a parcela de custos da emissão de carbono na função objetivo de modo a se obter o completo entendimento dos trade-offs existentes entre os custos logísticos, os benefícios fiscais e os custos ambientais oriundos da emissão de carbono pelo transporte.

Pode-se dizer então que, a partir dos resultados analisados, os benefícios fiscais impactam fortemente na localização das fábricas e centros de distribuição e que o aumento nos custos logísticos são facilmente sobrepujados pelos benefícios fiscais incidentes em cada um dos cenários, como pode ser observado na Figura 48.

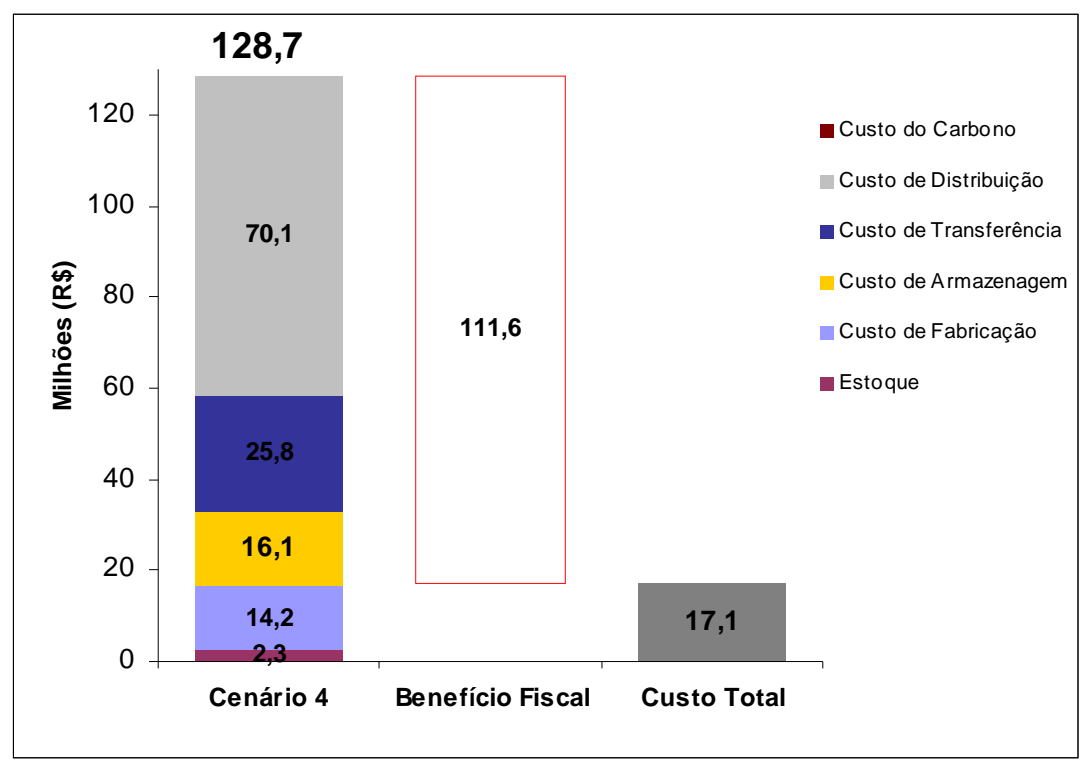

Figura 48: Custo Total e Benefício Fiscal do Cenário 4: Final 
Além disso, constata-se que o valor da parcela referente ao carbono em nada afeta o resultado do modelo, mesmo existindo um aumento de $56,1 \%$ da emissão realizada entre o cenário puramente logístico e o cenário com existência de benefício fiscal, como pode ser observado na Tabela 42.

\begin{tabular}{|c|c|c|c|c|c|c|}
\hline & \multicolumn{2}{|c|}{ Cenário 1} & \multicolumn{2}{|c|}{ Cenário 4} \\
\hline \multicolumn{2}{|c|}{ Tipo de Veículo } & $\begin{array}{l}\text { Utilização do } \\
\text { Transporte }\end{array}$ & $\begin{array}{c}\text { Distância } \\
\text { Percorrida } \\
\text { (milhões km) }\end{array}$ & $\begin{array}{c}\text { Emissão } \\
\mathrm{CO}_{2} \\
\left(\mathrm{tCO}_{2} \mathrm{e}\right)\end{array}$ & $\begin{array}{c}\text { Distância } \\
\text { Percorrida } \\
\text { (milhões km) }\end{array}$ & $\begin{array}{c}\text { Emissão } \\
\mathrm{CO}_{2} \\
\left(\mathrm{tCO}_{2} \mathrm{e}\right)\end{array}$ \\
\hline (1) & Veículo 1 & Transferência & 4,2 & 3,9 & 20,6 & 19,0 \\
\hline (2) & Veículo 2 & $\begin{array}{l}\text { Distribuição } \\
\text { Carga Cheia }\end{array}$ & 35,2 & 15,1 & 41,1 & 17,7 \\
\hline \multirow[t]{2}{*}{ (3) } & Veículo 3 & $\begin{array}{c}\text { Distribuição Carga } \\
\text { Fracionada }\end{array}$ & 58,8 & 15,8 & 66,0 & 17,8 \\
\hline & & TOTAL & 100,3 & 35,8 & 127,6 & 54,5 \\
\hline
\end{tabular}

Tabela 42: Comparativo das Emissão de $\mathrm{CO}_{2}$ entre Cenário 1 e 4

Dessa maneira, conclui-se que a política fiscal existente afeta demasiadamente o meio-ambiente, gerando o aumento as emissões de carbono na atmosfera e o aumento do fluxo de veículos nas rodovias do País.

Pode-se dizer ainda que a análise de sensibilidade aplicada ao modelo mostrou que o mesmo é bem estável, apresentando mudanças significativas na malha somente no cenário onde foi variada a margem de contribuição dos produtos.

- Preço: o aumento ou diminuição dos preços de transferência e distribuição não geram mudanças na configuração logística do modelo em análise.

- Margem: as variações de margem apresentam grande impacto na configuração logística uma vez que afetam diretamente o benefício fiscal.

- Carbono: a variação nos preços do carbono somente começam a afetar a configuração logística do modelo em estudo após elevação significativa dos preços.

- Matéria-prima: o impacto no fornecimento de matéria-prima muda a configuração logística porém sem alterar significativamente o benefício fiscal auferido.

- Demanda: a variação da demanda não afeta o resultado do modelo, uma vez que mantém o benefício fiscal por tonelada inalterado e simplesmente altera a parcela de custo fixo por tonelada devido ao ganho de escala existente. 
- Nível de Serviço: o nível de serviço tem pouco impacto na configuração logística, uma vez que com a inserção das restrições de nível de serviço, a única mudança sofrida foi a abertura de CDs para atendimento único e exclusivo dos pontos de entrega onde não era possível atendimento dos CDs abertos no Cenário 4.

Como sugestão de trabalhos futuros relacionados ao tema que possam vir a serem realizados de modo a aprofundar ainda mais o entendimento, pode-se destacar:

- Emissão de $\mathrm{CO}_{2} \times$ Alternativas de Transporte: análise de cenários com diferentes modais associados de modo a entender se, por exemplo, o uso de cabotagem gera redução de emissão suficiente para compensar o aumento dos estoques proveniente do maior lead time de entrega.

- Inclusão de outros incentivos fiscais: análise de outros benefícios fiscais existentes e seus impactos na configuração logística das empresas.

- Variação da Função Objetivo: Variar o modelo de modo a mudar a função objetivo para minimização do $\mathrm{CO}_{2}$ emitido ao invés de minimização dos custos. Esse estudo poderia incluir ainda as parcelas de emissão proveniente das fábricas, CDs e fornecimento de matéria-prima. 


\section{ANEXO A. TABELA DE ICMS}

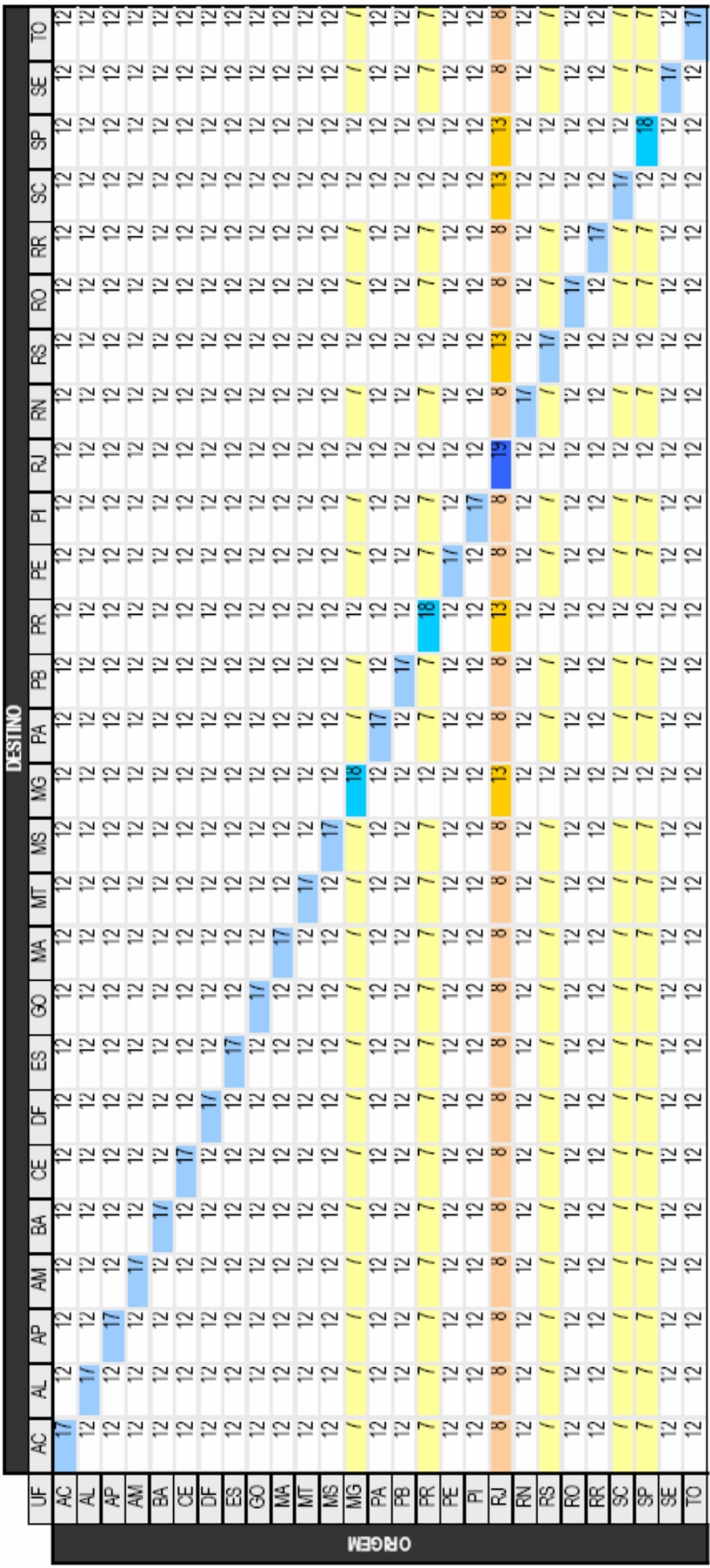




\section{ANEXO B. TABELA DE DEMANDA POR MESO-REGIÃO}

\begin{tabular}{|c|c|c|c|c|c|c|}
\hline UF & $\begin{array}{l}\text { Mercado } \\
\text { Descrição }\end{array}$ & MESO-REGIAO & PD_GO & PD_MG & PD_SP & TOTAL \\
\hline $\mathrm{AC}$ & ME_AC01 & VALE DO JURUA & 40 & 6 & 4 & 50 \\
\hline $\mathrm{AC}$ & ME_AC02 & VALE DO ACRE & 545 & 139 & 56 & 740 \\
\hline $\mathrm{AL}$ & ME_AL01 & SERTAO ALAGOANO & 456 & 195 & 426 & 1,077 \\
\hline $\mathrm{AL}$ & ME_AL02 & AGRESTE ALAGOANO & 464 & 61 & 183 & 708 \\
\hline $\mathrm{AL}$ & ME_AL03 & LESTE ALAGOANO & 746 & 155 & 314 & 1,215 \\
\hline AM & ME_AM03 & CENTRO AMAZONENSE & 3,943 & 1,001 & 336 & 5,280 \\
\hline $\mathrm{AP}$ & ME_AP02 & SUL DO AMAPA & 698 & 111 & 64 & 873 \\
\hline $\mathrm{BA}$ & ME_BA01 & EXTREMO OESTE BAIANO & 123 & 30 & 43 & 196 \\
\hline $\mathrm{BA}$ & ME_BA02 & VALE SAO-FRANCISCANO DA BAHIA & 198 & 94 & 120 & 412 \\
\hline $\mathrm{BA}$ & ME_BA03 & CENTRO NORTE BAIANO & 1,212 & 194 & 227 & 1,633 \\
\hline $\mathrm{BA}$ & ME_BA04 & NORDESTE BAIANO & 151 & 49 & 13 & 213 \\
\hline $\mathrm{BA}$ & ME_BA05 & METROPOLITANA DE SALVADOR & 5,466 & 1,722 & 835 & 8,023 \\
\hline $\mathrm{BA}$ & ME_BA06 & CENTRO SUL BAIANO & 923 & 479 & 224 & 1,626 \\
\hline $\mathrm{BA}$ & ME_BA07 & SUL BAIANO & 716 & 237 & 122 & 1,075 \\
\hline $\mathrm{CE}$ & ME_CE01 & NOROESTE CEARENSE & 148 & 56 & 26 & 230 \\
\hline $\mathrm{CE}$ & ME_CE02 & NORTE CEARENSE & 22 & 7 & 4 & 33 \\
\hline $\mathrm{CE}$ & ME_CE03 & METROPOLITANA DE FORTALEZA & 2,792 & 1,152 & 867 & 4,811 \\
\hline $\mathrm{CE}$ & ME_CE04 & SERTOES CEARENSES & 70 & 22 & 12 & 104 \\
\hline $\mathrm{CE}$ & ME_CE05 & JAGUARIBE & 39 & 14 & 3 & 56 \\
\hline $\mathrm{CE}$ & ME_CE06 & CENTRO-SUL CEARENSE & 44 & 44 & 23 & 111 \\
\hline $\mathrm{CE}$ & ME_CE07 & SUL CEARENSE & 243 & 240 & 258 & 741 \\
\hline ES & ME_ES01 & NOROESTE ESPIRITO-SANTENSE & 1,646 & 1,334 & 544 & 3,524 \\
\hline ES & ME_ES02 & LITORAL NORTE ESPIRITO-SANTENSE & 315 & 235 & 50 & 600 \\
\hline ES & ME_ES03 & CENTRAL ESPIRITO-SANTENSE & 4,104 & 3,164 & 566 & 7,834 \\
\hline ES & ME_ES04 & SUL ESPIRITO-SANTENSE & 164 & 122 & 22 & 308 \\
\hline GO & ME_G001 & NOROESTE GOIANO & 3,426 & 2,381 & 251 & 6,058 \\
\hline GO & ME_GO02 & NORTE GOIANO & 12 & 4 & 1 & 17 \\
\hline GO & ME_G003 & CENTRO GOIANO & 10,191 & 3,472 & 1,244 & 14,907 \\
\hline GO & ME_GO04 & LESTE GOIANO & 205 & 43 & 9 & 257 \\
\hline GO & ME_GO05 & SUL GOIANO & 1,078 & 1,507 & 622 & 3,207 \\
\hline MA & ME_MA01 & NORTE MARANHENSE & 510 & 175 & 81 & 766 \\
\hline MA & ME_MA02 & OESTE MARANHENSE & 557 & 164 & 444 & 1,165 \\
\hline MA & ME_MA03 & CENTRO MARANHENSE & 21 & 2 & 2 & 25 \\
\hline MA & ME_MA04 & LESTE MARANHENSE & 67 & 8 & 4 & 79 \\
\hline MA & ME_MA05 & SUL MARANHENSE & 272 & 185 & 122 & 579 \\
\hline MG & ME_MG01 & NOROESTE DE MINAS & 134 & 39 & 6 & 179 \\
\hline MG & ME_MG02 & NORTE DE MINAS & 168 & 100 & 16 & 284 \\
\hline MG & ME_MG04 & VALE DO MUCURI & 76 & 48 & 9 & 133 \\
\hline$M G$ & ME_MG05 & TRIANGULO MINEIRO/ALTO PARANAI & 3,998 & 2,256 & 874 & 7,128 \\
\hline MG & ME_MG06 & CENTRAL MINEIRA & 150 & 53 & 7 & 210 \\
\hline MG & ME_MG07 & METROPOLITANA DE BELO HORIZONTE & 12,013 & 5,357 & 894 & 18,264 \\
\hline MG & ME_MG08 & VALE DO RIO DOCE & 552 & 283 & 32 & 867 \\
\hline MG & ME_MG09 & OESTE DE MINAS & 1,265 & 380 & 45 & 1,690 \\
\hline$M G$ & ME_MG10 & SUL/SUDOESTE DE MINAS & 4,176 & 2,184 & 832 & 7,192 \\
\hline MG & ME_MG11 & CAMPO DAS VERTENTES & 385 & 152 & 32 & 569 \\
\hline$M G$ & ME_MG12 & ZONA DA MATA & 3,060 & 1,480 & 423 & 4,963 \\
\hline MS & ME_MS01 & PANTANAL SUL MATO-GROSSENSE & 211 & 69 & 26 & 306 \\
\hline MS & ME_MS02 & CENTRO NORTE DE MATO GROSSO DO & 1,480 & 781 & 350 & 2,611 \\
\hline MS & ME_MS03 & LESTE DE MATO GROSSO DO SUL & 1,684 & 1,330 & 396 & 3,410 \\
\hline MS & ME_MS04 & SUDOESTE DE MATO GROSSO DO SUL & 445 & 215 & 71 & 731 \\
\hline MT & ME_MT01 & NORTE MATO-GROSSENSE & 700 & 489 & 154 & 1,343 \\
\hline MT & ME_MT02 & NORDESTE MATO-GROSSENSE & 79 & 19 & 6 & 104 \\
\hline MT & ME_MT03 & SUDOESTE MATO-GROSSENSE & 205 & 70 & 26 & 301 \\
\hline MT & ME_MT04 & CENTRO-SUL MATO-GROSSENSE & 1,892 & 855 & 190 & 2,937 \\
\hline MT & ME_MT05 & SUDESTE MATO-GROSSENSE & 321 & 106 & 26 & 453 \\
\hline $\mathrm{PA}$ & ME_PA01 & BAIXO AMAZONAS & 170 & 55 & 38 & 263 \\
\hline $\mathrm{PA}$ & ME_PA03 & METROPOLITANA DE BELEM & 2,194 & 767 & 345 & 3,306 \\
\hline $\mathrm{PA}$ & ME_PA04 & NORDESTE PARAENSE & 22 & 8 & 3 & 33 \\
\hline $\mathrm{PA}$ & ME_PA05 & SUDOESTE PARAENSE & 67 & 28 & 8 & 103 \\
\hline $\mathrm{PA}$ & ME_PA06 & SUDESTE PARAENSE & 389 & 101 & 30 & 520 \\
\hline
\end{tabular}




\begin{tabular}{|c|c|c|c|c|c|c|}
\hline PB & ME_PB01 & SERTAO PARAIBANO & 128 & 99 & 58 & 285 \\
\hline PB & ME_PB02 & BORBOREMA & 9 & 16 & 1 & 26 \\
\hline PB & ME_PB03 & AGRESTE PARAIBANO & 400 & 315 & 238 & 953 \\
\hline PB & ME_PB04 & MATA PARAIBANA & 692 & 668 & 366 & 1,726 \\
\hline $\mathrm{PE}$ & ME_PE01 & SERTAO PERNAIMBUCANO & 43 & 30 & 9 & 82 \\
\hline $\mathrm{PE}$ & ME_PE02 & SAO FRANCISCO PERNAMBUCANO & 229 & 128 & 112 & 469 \\
\hline $\mathrm{PE}$ & ME_PE03 & AGRESTE PERNAIMBUCANO & 593 & 515 & 581 & 1,689 \\
\hline $\mathrm{PE}$ & ME_PE04 & MATA PERNAMBUCANA & 46 & 23 & 24 & 93 \\
\hline $\mathrm{PE}$ & ME_PE05 & METROPOLITANA DE RECIFE & 3,862 & 1,943 & 1,379 & 7,184 \\
\hline $\mathrm{PI}$ & ME_PI01 & NORTE PIAUIENSE & 87 & 13 & 31 & 131 \\
\hline $\mathrm{PI}$ & ME_PI02 & CENTRO-NORTE PIAUIENSE & 546 & 147 & 156 & 849 \\
\hline $\mathrm{PI}$ & ME_PI03 & SUDOESTE PIAUIENSE & 175 & 34 & 30 & 239 \\
\hline $\mathrm{PI}$ & ME_PI04 & SUDESTE PIAUIENSE & 89 & 63 & 39 & 191 \\
\hline PR & ME_PR01 & NOROESTE PARANAENSE & 185 & 81 & 30 & 296 \\
\hline PR & ME_PR02 & CENTRO OCIDENTAL PARANAENSE & 61 & 45 & 5 & 111 \\
\hline PR & ME_PR03 & NORTE CENTRAL PARANAENSE & 5,463 & 2,356 & 488 & 8,307 \\
\hline PR & ME_PR04 & NORTE PIONEIRO PARANAENSE & 122 & 45 & 9 & 176 \\
\hline PR & ME_PR05 & CENTRO ORIENTAL PARANAENSE & 273 & 166 & 29 & 468 \\
\hline PR & ME_PR06 & OESTE PARANAENSE & 2,314 & 1,759 & 386 & 4,459 \\
\hline PR & ME_PR07 & SUDOESTE PARANAENSE & 523 & 231 & 120 & 874 \\
\hline PR & ME_PR08 & CENTRO-SUL PARANAENSE & 324 & 205 & 45 & 574 \\
\hline PR & ME_PR09 & SUDESTE PARANAENSE & 84 & 70 & 20 & 174 \\
\hline PR & ME_PR10 & METROPOLITANA DE CURITIBA & 6,061 & 4,129 & 631 & 10,821 \\
\hline $\mathrm{RJ}$ & ME_RJ01 & NOROESTE FLUMINENSE & 241 & 139 & 35 & 415 \\
\hline RJ & ME_RJ02 & NORTE FLUMINENSE & 867 & 545 & 95 & 1,507 \\
\hline RJ & ME_RJ03 & CENTRO FLUMINENSE & 2,563 & 1,285 & 336 & 4,184 \\
\hline RJ & ME_RJ04 & BAIXADAS & 437 & 387 & 44 & 868 \\
\hline RJ & ME_RJ05 & SUL FLUMINENSE & 1,430 & 689 & 117 & 2,236 \\
\hline RJ & ME_RJ06 & METROPOLITANA DO RIO DE JANEIRO & 27,065 & 17,869 & 2,151 & 47,085 \\
\hline $\mathrm{RN}$ & ME_RN01 & OESTE POTIGUAR & 134 & 77 & 14 & 225 \\
\hline RN & ME_RN02 & CENTRAL POTIGUAR & 81 & 86 & 61 & 228 \\
\hline RN & ME_RN03 & AGRESTE POTIGUAR & 5 & 3 & 2 & 10 \\
\hline $\mathrm{RN}$ & ME_RN04 & LESTE POTIGUAR & 915 & 444 & 230 & 1,589 \\
\hline RO & ME_R001 & MADEIRA-GUAPORE & 1,270 & 425 & 225 & 1,920 \\
\hline $\mathrm{RO}$ & ME_RO02 & LESTE RONDONIENSE & 632 & 195 & 57 & 884 \\
\hline RR & ME_RR01 & NORTE DE RORAIMA & 231 & 72 & 10 & 313 \\
\hline RS & ME_RS01 & NOROESTE RIO-GRANDENSE & 2,221 & 1,352 & 323 & 3,896 \\
\hline RS & ME_RS02 & NORDESTE RIO-GRANDENSE & 936 & 786 & 131 & 1,853 \\
\hline RS & ME_RS03 & CENTRO OCIDENTAL RIO-GRANDENSE & 499 & 315 & 70 & 884 \\
\hline RS & ME_RS04 & CENTRO ORIENTAL RIO-GRANDENSE & 421 & 247 & 73 & 741 \\
\hline RS & ME_RS05 & METROPOLITANA DE PORTO ALEGRE & 6,973 & 4,402 & 605 & 11,980 \\
\hline RS & ME_RS06 & SUDOESTE RIO-GRANDENSE & 1,036 & 399 & 94 & 1,529 \\
\hline RS & ME_RS07 & SUDESTE RIO-GRANDENSE & 943 & 512 & 116 & 1,571 \\
\hline $\mathrm{SC}$ & ME_SC01 & OESTE CATARINENSE & 1,532 & 1,200 & 218 & 2,950 \\
\hline $\mathrm{SC}$ & ME_SC02 & NORTE CATARINENSE & 2,052 & 998 & 202 & 3,252 \\
\hline $\mathrm{SC}$ & ME_SC03 & SERRANA & 1,062 & 71 & 10 & 1,143 \\
\hline SC & ME_SC04 & VALE DO ITAJAI & 1,949 & 1,210 & 226 & 3,385 \\
\hline SC & ME_SC05 & GRANDE FLORIANOPOLIS & 2,573 & 2,585 & 203 & 5,361 \\
\hline $\mathrm{SC}$ & ME_SC06 & SUL CATARINENSE & 809 & 526 & 76 & 1,411 \\
\hline $\mathrm{SE}$ & ME_SE01 & SERTAO SERGIPANO & 8 & 3 & 3 & 14 \\
\hline $\mathrm{SE}$ & ME_SE02 & AGRESTE SERGIPANO & 102 & 23 & 26 & 151 \\
\hline $\mathrm{SE}$ & ME_SE03 & LESTE SERGIPANO & 1,459 & 332 & 139 & 1,930 \\
\hline $\mathrm{SP}$ & ME_SP01 & SAO JOSE DO RIO PRETO & 5,187 & 1,687 & 93 & 6,967 \\
\hline $\mathrm{SP}$ & ME_SP02 & RIBEIRAO PRETO & 4,924 & 1,364 & 249 & 6,537 \\
\hline $\mathrm{SP}$ & ME_SP03 & ARACATUBA & 946 & 549 & 115 & 1,610 \\
\hline $\mathrm{SP}$ & ME_SP04 & BAURU & 1,851 & 895 & 140 & 2,886 \\
\hline $\mathrm{SP}$ & ME_SP05 & ARARAQUARA & 1,075 & 498 & 68 & 1,641 \\
\hline $\mathrm{SP}$ & ME_SP06 & PIRACICABA & 1,580 & 947 & 110 & 2,637 \\
\hline $\mathrm{SP}$ & ME_SP07 & CAMPINAS & 4,032 & 2,612 & 225 & 6,869 \\
\hline $\mathrm{SP}$ & ME_SP08 & PRESIDENTE PRUDENTE & 1,321 & 699 & 163 & 2,183 \\
\hline $\mathrm{SP}$ & ME_SP09 & MARILIA & 507 & 376 & 46 & 929 \\
\hline $\mathrm{SP}$ & ME_SP10 & ASSIS & 694 & 263 & 58 & 1,015 \\
\hline $\mathrm{SP}$ & ME_SP11 & ITAPETININGA & 916 & 418 & 53 & 1,387 \\
\hline $\mathrm{SP}$ & ME_SP12 & MACRO METROPOLITANA PAULISTA & 3,729 & 2,831 & 236 & 6,796 \\
\hline $\mathrm{SP}$ & ME_SP13 & VALE DO PARAIBA PAULISTA & 1,464 & 1,046 & 100 & 2,610 \\
\hline $\mathrm{SP}$ & ME_SP14 & LITORAL SUL PAULISTA & 235 & 119 & 21 & 375 \\
\hline $\mathrm{SP}$ & ME_SP15 & METROPOLITANA DE SAO PAULO & 50,100 & 33,114 & 3,118 & 86,332 \\
\hline TO & ME_TO01 & OCIDENTAL DO TOCANTINS & 235 & 102 & 13 & 350 \\
\hline TO & ME_TO02 & ORIENTAL DO TOCANTINS & 143 & 41 & 8 & 192 \\
\hline
\end{tabular}




\section{ANEXO C. HISTÓRICO DE PREÇO DA TONELADA DE $\mathrm{tCO}_{2} \mathrm{e}$}

\begin{tabular}{|c|c|c|c|c|c|c|c|c|c|}
\hline Ano & Mês & 2003 & 2004 & 2005 & 2006 & 2007 & 2008 & 2009 & 2010 \\
\hline \multirow{12}{*}{2004} & Jan & 0,98 & 0,94 & 0,97 & & & & & \\
\hline & Fev & 0,92 & 0,91 & 0,89 & 0,91 & & & & \\
\hline & Mar & 0,83 & 0,89 & 0,79 & 0,91 & & & & \\
\hline & $\mathrm{Abr}$ & 0,86 & 0,80 & 0,81 & 0,85 & & & & \\
\hline & Mai & 0,84 & 0,82 & 0,79 & 0,80 & & & & \\
\hline & Jun & 0,92 & 0,91 & 0,91 & 0,93 & & & & \\
\hline & Jul & 0,96 & 0,95 & 0,95 & 0,95 & & & & \\
\hline & Ago & 0,96 & 0,96 & 0,96 & 0,96 & & & & \\
\hline & Set & 0,96 & 0,96 & 0,97 & 0,96 & & & & \\
\hline & Out & 1,30 & 1,31 & 1,31 & 1,30 & & & & \\
\hline & Nov & 1,56 & 1,67 & 1,66 & 1,66 & & & & \\
\hline & Dez & 1,69 & 1,68 & 1,74 & 1,68 & & & & \\
\hline \multirow{12}{*}{2005} & Jan & 1,87 & 1,90 & 1,88 & 1,80 & & & & \\
\hline & Fev & 1,75 & 1,73 & 1,73 & 1,73 & & & & \\
\hline & Mar & 1,57 & 1,58 & 1,54 & 1,65 & & & & \\
\hline & Abr & 1,26 & 1,24 & 1,21 & 1,25 & & & & \\
\hline & Mai & 1,31 & 1,32 & 1,30 & 1,30 & & & & \\
\hline & Jun & 1,52 & 1,52 & 1,50 & 1,45 & & & & \\
\hline & Jul & 2,24 & 2,04 & 1,96 & 1,94 & & & & \\
\hline & Ago & 2,04 & 2,06 & 1,95 & 1,91 & & & & \\
\hline & Set & 2,79 & 2,78 & 2,32 & 2,21 & & & & \\
\hline & Out & 2,61 & 2,43 & 2,21 & 2,15 & & & & \\
\hline & Nov & 2,13 & 2,03 & 2,00 & 1,95 & & & & \\
\hline & Dez & 1,66 & 1,65 & 1,68 & 1,68 & & & & \\
\hline \multirow{12}{*}{2006} & Jan & 1,70 & 1,67 & 1,68 & 1,69 & & & & \\
\hline & Fev & 2,13 & 2,09 & 2,08 & 2,08 & & & & \\
\hline & Mar & 2,25 & 2,25 & 2,23 & 2,23 & & & & \\
\hline & Abr & 3,94 & 3,89 & 3,88 & 3,88 & 4,38 & 4,34 & 4,32 & 4,33 \\
\hline & Mai & 3,55 & 3,53 & 3,52 & 3,50 & 3,53 & 3,53 & 3,53 & 3,55 \\
\hline & Jun & 4,32 & 4,30 & 4,27 & 4,29 & 4,31 & 4,31 & 4,31 & 4,31 \\
\hline & Jul & 4,52 & 4,52 & 4,52 & 4,51 & 4,50 & 4,52 & 4,53 & 4,55 \\
\hline & Ago & 4,24 & 4,18 & 4,18 & 4,17 & 4,18 & 4,19 & 4,18 & 4,20 \\
\hline & Set & 4,12 & 4,04 & 4,06 & 4,08 & 4,08 & 4,08 & 4,04 & 4,07 \\
\hline & Out & 4,04 & 4,00 & 3,99 & 3,98 & 3,97 & 3,97 & 3,97 & 3,99 \\
\hline & Nov & 4,29 & 4,26 & 4,26 & 4,28 & 4,26 & 4,26 & 4,25 & 4,26 \\
\hline & Dez & 4,05 & 4,09 & 4,07 & 4,07 & 3,99 & 3,95 & 3,94 & 3,97 \\
\hline \multirow{12}{*}{2007} & Jan & 3,91 & 3,90 & 3,89 & 3,90 & 3,90 & 3,91 & 3,91 & 3,92 \\
\hline & Fev & 3,73 & 3,72 & 3,73 & 3,70 & 3,75 & 3,73 & 3,73 & 3,74 \\
\hline & Mar & 3,79 & 3,78 & 3,75 & 3,75 & 3,78 & 3,77 & 3,76 & 3,75 \\
\hline & Abr & 3,63 & 3,62 & 3,62 & 3,62 & 3,62 & 3,62 & 3,62 & 3,63 \\
\hline & Mai & 3,69 & 3,68 & 3,66 & 3,66 & 3,68 & 3,70 & 3,68 & 3,70 \\
\hline & Jun & 3,34 & 3,33 & 3,32 & 3,32 & 3,33 & 3,35 & 3,34 & 3,35 \\
\hline & Jul & 3,49 & 3,48 & 3,48 & 3,47 & 3,49 & 3,48 & 3,49 & 3,48 \\
\hline & Ago & 3,42 & 3,41 & 3,41 & 3,41 & 3,42 & 3,42 & 3,42 & 3,42 \\
\hline & Set & 3,04 & 3,03 & 3,02 & 3,03 & 3,03 & 3,03 & 3,02 & 3,03 \\
\hline & Out & 2,31 & 2,31 & 2,30 & 2,31 & 2,31 & 2,31 & 2,31 & 2,31 \\
\hline & Nov & 1,92 & 1,91 & 1,91 & 1,92 & 1,91 & 1,92 & 1,91 & 1,92 \\
\hline & Dez & 2,01 & 2,00 & 1,99 & 2,02 & 2,02 & 2,00 & 2,00 & 2,00 \\
\hline \multirow{12}{*}{2008} & Jan & 2,17 & 2,15 & 2,15 & 2,17 & 2,17 & 2,17 & 2,17 & 2,17 \\
\hline & Fev & 4,15 & 4,14 & 4,14 & 4,14 & 4,15 & 4,15 & 4,15 & 4,16 \\
\hline & Mar & 5,41 & 5,40 & 5,41 & 5,39 & 5,39 & 5,44 & 5,44 & 5,41 \\
\hline & Abr & 6,06 & 6,06 & 6,04 & 6,05 & 6,05 & 6,06 & 6,05 & 6,04 \\
\hline & Mai & 6,81 & 6,80 & 6,81 & 6,82 & 6,81 & 6,81 & 6,80 & 6,80 \\
\hline & Jun & 5,75 & 5,76 & 5,75 & 5,75 & 5,74 & 5,73 & 5,74 & 5,75 \\
\hline & Jul & 4,09 & 4,06 & 4,08 & 4,05 & 4,05 & 4,05 & 4,06 & 4,06 \\
\hline & Ago & 3,79 & 3,78 & 3,77 & 3,78 & 3,77 & 3,79 & 3,79 & 3,79 \\
\hline & Set & 2,33 & 2,30 & 2,34 & 2,33 & 2,34 & 2,29 & 2,31 & 2,33 \\
\hline & Out & 1,64 & 1,64 & 1,63 & 1,60 & 1,61 & 1,58 & 1,62 & 1,60 \\
\hline & Nov & 1,22 & 1,23 & 1,20 & 1,21 & 1,23 & 1,21 & 1,22 & 1,21 \\
\hline & Dez & 1,55 & 1,55 & 1,57 & 1,56 & 1,57 & 1,62 & 1,56 & 1,60 \\
\hline
\end{tabular}

Nota: Preço da Tonelada de tCO2e (em US\$)

Observação: Preço Médio da Tonelada de tCO2e comercializada durante o período. 


\section{ANEXO D. MODELO EM GAMS}

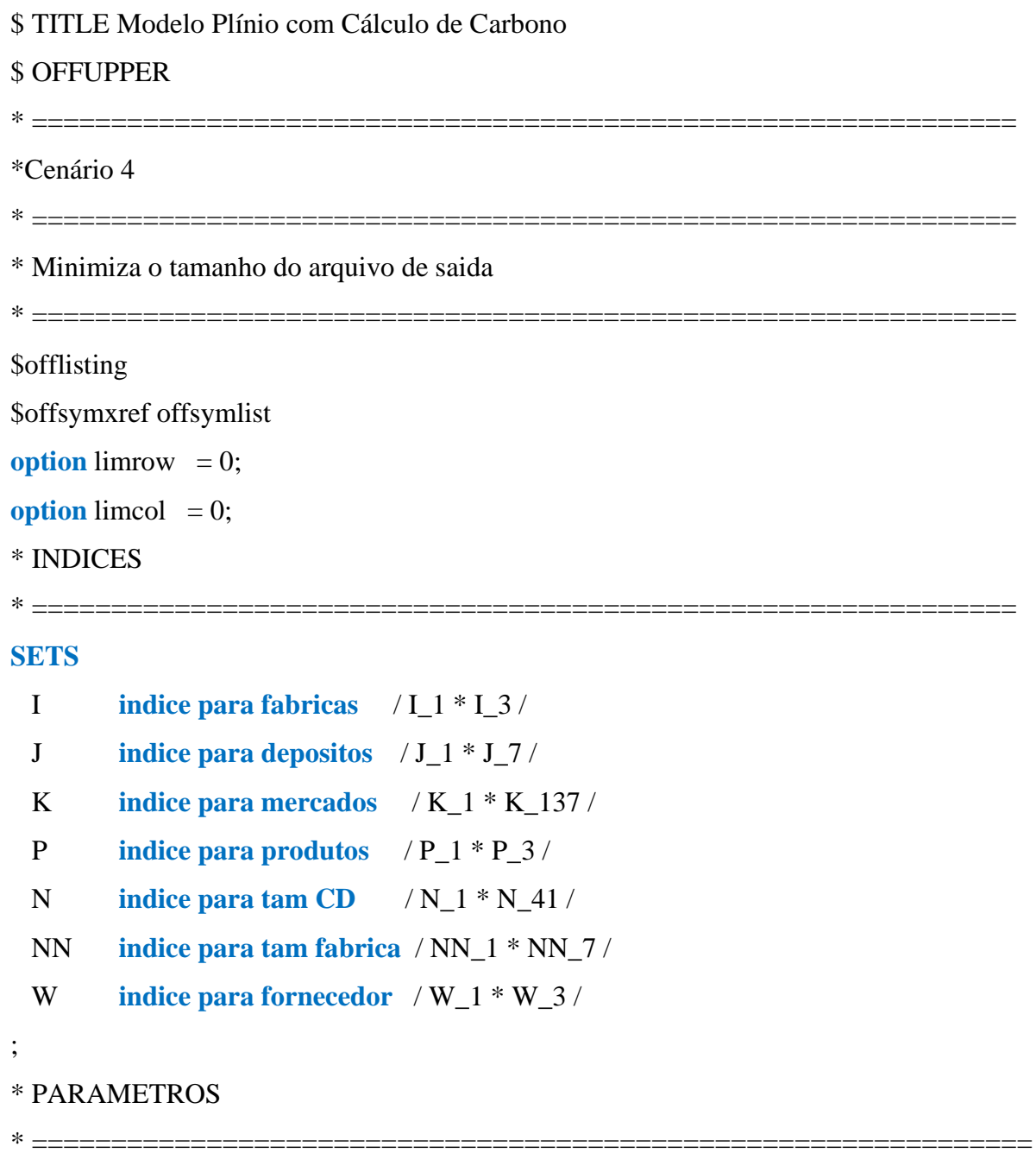

PARAMETER Dem $(\mathrm{P}, \mathrm{K})$ demanda do produto $\mathbf{P}$ no mercado $\mathrm{K}$;

\$include "C:\Users\Plinio Carraro\Documents\TeselCenario_4\Dem.prn"

PARAMETER CapFab(NN,I) capacidade de fabrica ;

\$include "C:\Users\Plinio Carraro\Documents\TeselCenario_4\CapFab.prn"

PARAMETER CapFab_Prod(P,I) capacidade produto_fabrica ;

CapFab_Prod('P_1','I_1') $=28456$;

CapFab_Prod('P_2','I_1') = 133848 ;

CapFab_Prod('P_3','I_1') = 239137 ;

CapFab_Prod('P_1','I_2') $=28456$;

CapFab_Prod('P_2','I_2') = 133848 ;

CapFab_Prod('P_3','I_2') = 239137 ;

CapFab_Prod('P_1','I_3') $=28456$;

CapFab_Prod('P_2','I_3') $=133848$;

CapFab_Prod('P_3','I_3') = 239137 ; 
PARAMETER CapCD(N,J) capacidade do deposito J ;

\$include "C:IUsers\Plinio Carraro\Documents\TeselCenario_4\CapCD.prn"

PARAMETER CTrns $(I, J)$ custos de transferencia da fabrica i para o $\mathrm{CD} \mathbf{j}$;

\$include "C:IUsers\Plinio Carraro\Documents\TeselCenario_4ICTrns.prn"

PARAMETER CDstr(J,K) custos de distribuicao do CD j para o mercado $\mathbf{k}$;

\$include "C:IUsers\Plinio Carraro\Documents\TeselCenario_4ICDstr.prn"

PARAMETER FixCD(N,J) custo fixo de deposito ;

\$include "C:\Users\Plinio Carraro\Documents\TeselCenario_4\FixCD.prn"

PARAMETER FixFab(NN,I) custo fixo de deposito ;

\$include "C:\Users\Plinio Carraro\Documents\TeselCenario_4\FixFab.prn"

PARAMETER CvCD $(\mathrm{J})$ custo de transbordo no $\mathrm{CD} \mathbf{j}$;

\$include "C:IUsers\Plinio Carraro\Documents\TeselCenario_4ICvCD.prn"

PARAMETER CvF(I) custo de transbordo na fabrica i ;

\$include "C:\Users\Plinio Carraro\Documents\TeselCenario_4\CvF.prn"

PARAMETER AliqICMS_F(I,J) aliq de ICMS origem na fab i e destino no CD j ;

\$include "C:IUsers\Plinio Carraro\Documents\TeselCenario_4\AliqICMS_F.prn"

PARAMETER AliqICMS_CD $(J, K)$ aliq de ICMS origem no CD j e destino em k ;

\$include "C:IUsers\Plinio Carraro\Documents\TeselCenario_4\AliqICMS_CD.prn"

PARAMETER AliqBef(J) percentual relativo ao credito presumido no $\mathrm{CD} \mathbf{j}$;

\$include "C:\Users\Plinio Carraro\Documents\TeselCenario_4\AliqBef.prn"

PARAMETER PT(P) custo de produçao do produto $\mathbf{p}$;

\$include "C:IUsers\Plinio Carraro\Documents\TeselCenario_4\PT.prn"

PARAMETER PV(P) preço de venda do produto $\mathrm{p}$;

\$include "C:\Users\Plinio Carraro\Documents\TeselCenario_4\PV.prn"

PARAMETER CTrnsMP(W,I) custos de transp mp do fornecedor w para a fabrica i ;

\$include "C:IUsers\Plinio Carraro\Documents\TeselCenario_4\CTrnsMP.prn"

*PARAMETER FForn(W,P) fator de mp;

*\$include "C:IUsers\Plinio Carraro\Documents\TeselCenario_4lFForn.prn"

PARAMETER FForn(W,I,P) fator de mp;

FForn $(\mathrm{W}, \mathrm{I}, \mathrm{P})=0.0$;

FForn('W_1','I_1','P_1') = 1.0 ;

FForn('W_2','I_2','P_2') $=1.0$;

FForn('W_3','I_3','P_3') $=1.0$;

*0.6 OU $1.0 *$

FForn('W_1','I_2','P_1') $=0.0$;

FForn ('W_1','I_3','P_1') $=0.0$;

FForn ('W_2','I_1','P_2') $=0.0$;

FForn('W_2','I_3','P_2') $=0.0$;

FForn ('W_3','I_1','P_3') $=0.0$;

FForn ('W_3','I_2','P_3') $=0.0$; 
*0.4 OU $0.0 *$

FForn ('W_1','I_1','P_2') = 1.0 ;

FForn $\left(' \mathrm{~W} \_1\right.$ ','I_1','P_3') $=1.0$;

FForn ('W_2','I_2','P_1') $=1.0$;

FForn('W_2','I_2','P_3') $=1.0$;

FForn('W_3','I_3','P_1') $=1.0$;

FForn $\left(' \mathrm{~W} \_3{ }^{\prime}, ' \mathrm{I} \_3\right.$ ','P_2') $=1.0$;

PARAMETER Dist_F(I,J) distancia da fabrica i para o CD j ;

\$include "C:IUsers\Plinio Carraro\Documents\TeselCenario_4\Dist_F.prn"

PARAMETER Dist_CD $(\mathrm{J}, \mathrm{K})$ distancia do CD j para o mercado $\mathrm{k}$;

\$include "C:\Users\Plinio Carraro\Documents\TeselCenario_4\Dist_CD.prn"

PARAMETER DEFab(I) dias de estoque na fabrica i ;

DEFab('I_1') $=5$;

DEFab('I_2') $=6$;

DEFab('I_3') $=7$;

PARAMETER LT(I,J) tempo de viagem entre a fabrica i e o cd j ;

\$include ""C:\Users\Plinio Carraro\Documents\TeselCenario_4\LT.prn"

PARAMETER E(K) Distancia percorrida entre o primeiro e ultimo ponto de entrega ;

\$include ""C:IUsers\Plinio Carraro\Documents\TeselCenario_4lE_Dist.prn"

PARAMETER DECD $(\mathrm{J})$ dias de estoque no $\mathrm{cd} \mathbf{j}$;

$\operatorname{DECD}\left(' \mathrm{~J} \_1\right.$ ') $=6$;

$\operatorname{DECD}\left(' \mathrm{~J} \_2 '\right)=5$;

$\operatorname{DECD}\left(' \mathrm{~J} \_3 '\right)=4$;

$\operatorname{DECD}\left({ }^{\prime} \mathrm{J} 4\right.$ ') $=5$;

$\operatorname{DECD}\left(' \mathrm{~J} \_5 '\right)=6$;

$\operatorname{DECD}\left(' \mathrm{~J} \_6\right.$ ') $=6$;

$\operatorname{DECD}\left({ }^{\prime} \mathrm{J}_{-} 7^{\prime}\right)=8$;

SCALAR CC custo do capital imobilizado da empresa /0.1275/ ;

*******************************************************************

SCALAR FTL /0.7/ ;

SCALAR FCarb_TTL fator de carbono referente a conversão R\$-Km /0.00412/ ;

SCALAR FCarb_DTL fator de carbono referente a conversão R\$-Km /0.00192/ ;

SCALAR FCarb_DLTL fator de carbono referente a conversão R\$-Km /0.00120/ ;

SCALAR CapTTL capacidade caminhão em ton /20/ ;

SCALAR CapDTL capacidade caminhão em ton /10/ ;

SCALAR CapDLTL capacidade caminhão em ton /3.5/ ;

* VARIAVEIS 


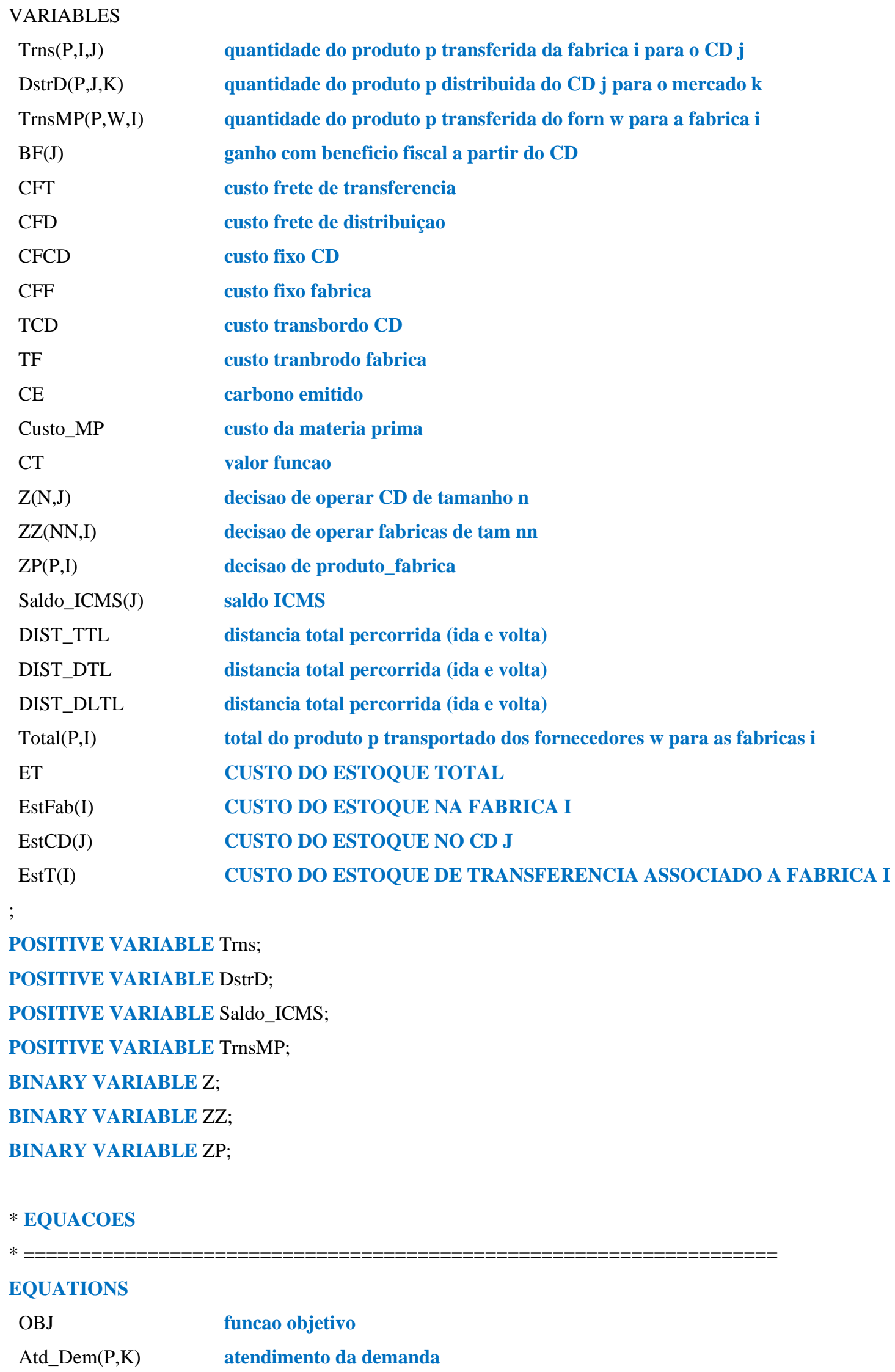




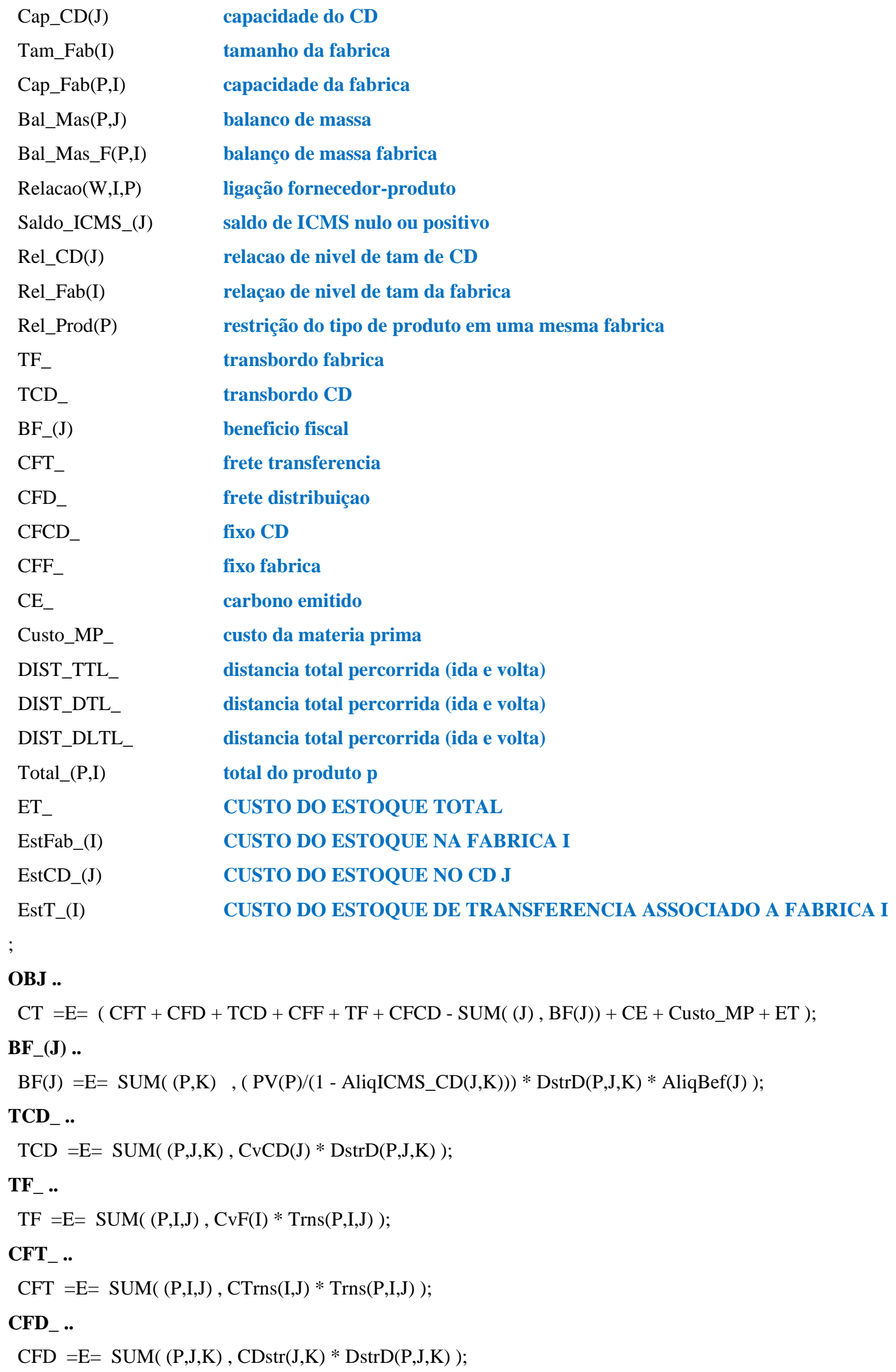




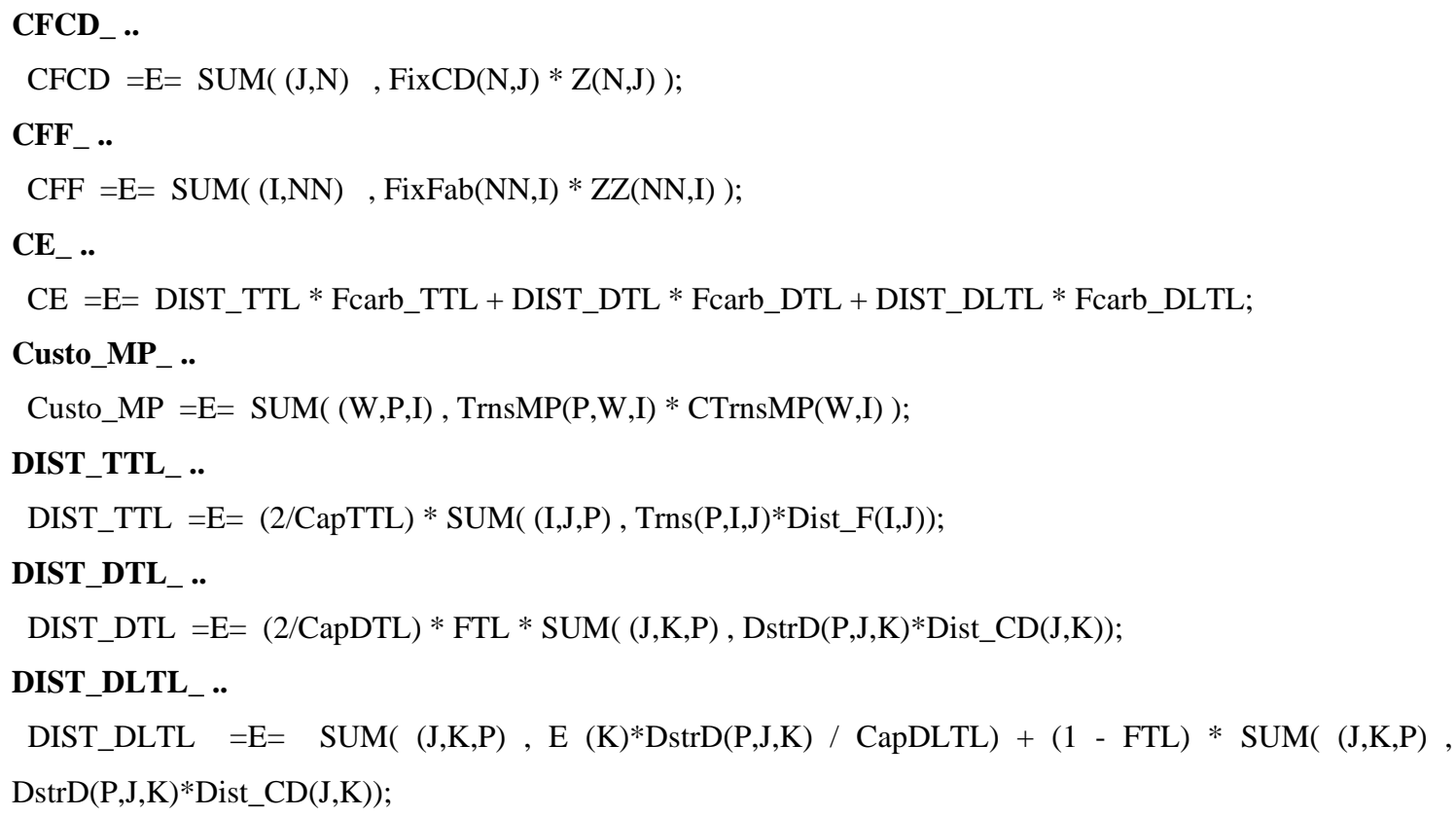


ET_.

$\mathrm{ET}=\mathrm{E}=\operatorname{SUM}((\mathrm{I}), \operatorname{EstFab}(\mathrm{I}))+\operatorname{SUM}((\mathrm{J}), \operatorname{EstCD}(\mathrm{J}))+\operatorname{SUM}((\mathrm{I}), \operatorname{EstT}(\mathrm{I}))$;

EstFab_(I) ..

$\operatorname{EstFab}(\mathrm{I})=\mathrm{E}=\operatorname{SUM}((\mathrm{J}, \mathrm{P}), \operatorname{Trns}(\mathrm{P}, \mathrm{I}, \mathrm{J}) * \mathrm{PT}(\mathrm{P}) * \operatorname{DEFab}(\mathrm{I}) *(1 / 365) * \mathrm{CC})$;

EstT_(I) ..

$\operatorname{EstT}(\mathrm{I})=\mathrm{E}=\operatorname{SUM}((\mathrm{J}, \mathrm{P}), \operatorname{Trns}(\mathrm{P}, \mathrm{I}, \mathrm{J}) *(\mathrm{PT}(\mathrm{P}) /(1$ - AliqICMS_F(I,J)) $) *($ Dist_F(I,J)/544)*(1/365) * CC $)$;

EstCD_(J) ..

$\operatorname{EstCD}(\mathrm{J})=\mathrm{E}=\operatorname{SUM}((\mathrm{I}, \mathrm{P}), \operatorname{Trns}(\mathrm{P}, \mathrm{I}, \mathrm{J}) *(\mathrm{PT}(\mathrm{P}) /(1-\operatorname{AliqICMS} \mathrm{F}(\mathrm{I}, \mathrm{J}))) * \operatorname{DECD}(\mathrm{J}) *(1 / 365) * \mathrm{CC}) ;$

************************************************************

* MODEL E SOLVER

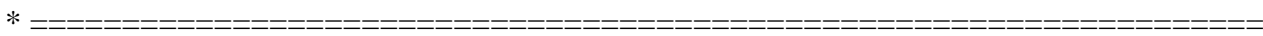

MODEL SUPPLY /ALL/ ;

OPTION MIP = CPLEX ;

OPTION OPTCR $=0.00000001 ;$

OPTION ITERLIM = 9000000 ;

OPTION RESLIM $=9000000$;

SOLVE SUPPLY USING MIP MINIMIZING CT ;

FILE Sd_4lo00Trns ;

PUT Sd_4lo00Trns ;

PUT 'Trns' //;

LOOP $(\mathrm{P}$,

LOOP (I,

$\operatorname{LOOP}(\mathrm{J}$,

IF ( Trns.L(P,I,J) NE 0,

PUT P.TL ;

PUT @10,I.TL;

PUT @20, J.TL;

PUT @30,Trns.L(P,I,J) :0:2 ;

PUT @ 40, CTrns(I,J) : :0:2 ;

PUT @ $50, \operatorname{CvF}(\mathrm{I}) \quad: 0: 2$;

PUT @60, AliqICMS_F(I,J) :0:2 /;

);

);

)

)

FILE Sd_4lo00TrnsMP ;

PUT Sd_4lo00TrnsMP ; 


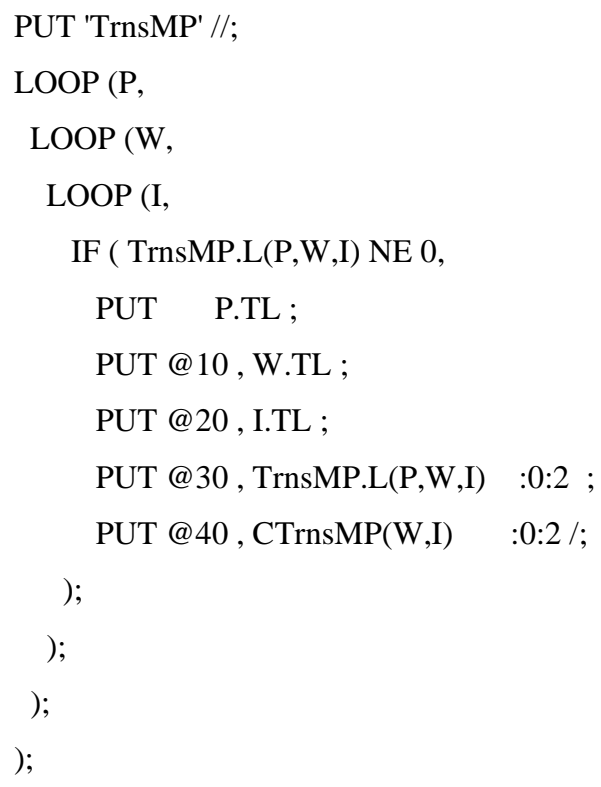


PUT @ 12, CT.L :0:2 //;

PUT 'BF';

aux $=\operatorname{SUM}((\mathrm{J})$, BF.L(J));

put@12, aux:0:2;

PUT @24 , 'DIST_TTL';

PUT @36,DIST_TTL.L :0:2 /;

PUT 'CFT';

PUT @ 12, CFT.L :0:2 ;

PUT @24 , 'DIST_DTL';

PUT @36, DIST_DTL.L :0:2 /;

PUT 'CFD';

PUT @ 12 , CFD.L :0:2 ;

PUT @24 , 'DIST_DLTL';

PUT @36,DIST_DLTL.L :0:2 /;

PUT 'CFCD';

PUT @ 12, CFCD.L :0:2 ;

PUT @24, 'ET';

PUT @36,ET.L :0:2 /;

PUT 'CFF';

PUT @ 12, CFF.L :0:2 /;

PUT 'CE';

PUT @ 12, CE.L :0:2 /;

PUT 'Custo_MP';

PUT @ 12 ,Custo_MP.L :0:2 /;

PUT 'TCD';

PUT @ 12, TCD.L :0:2 /;

PUT 'TF'; 


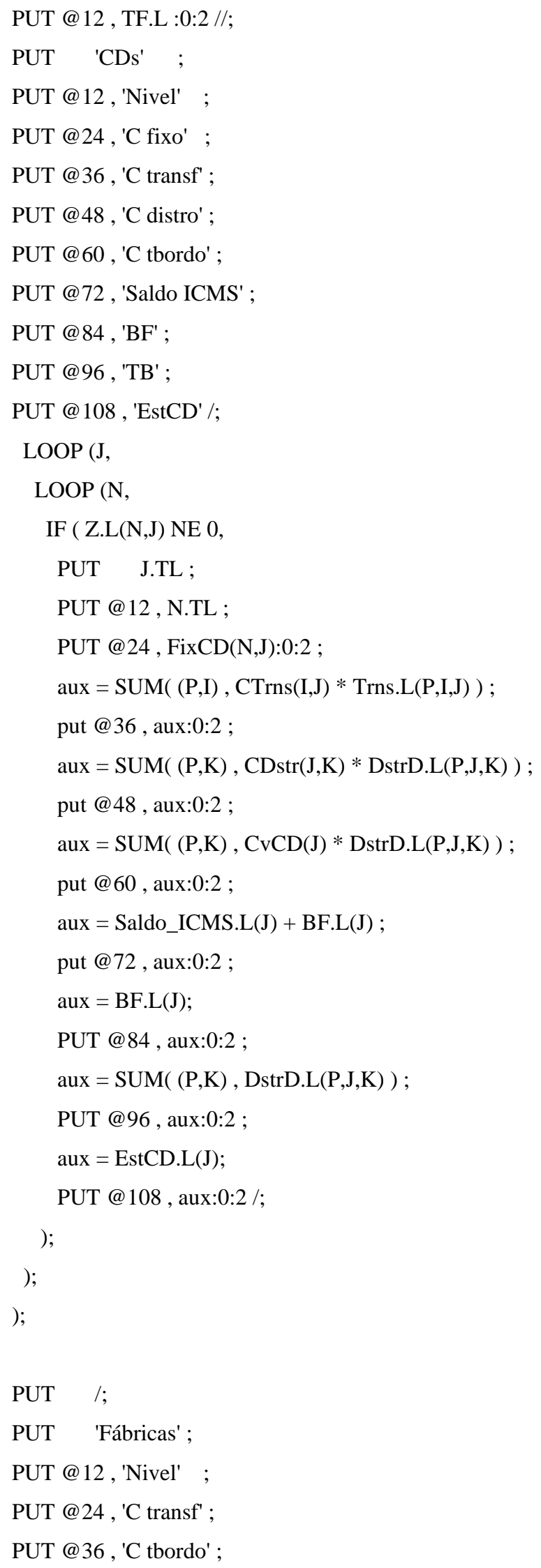




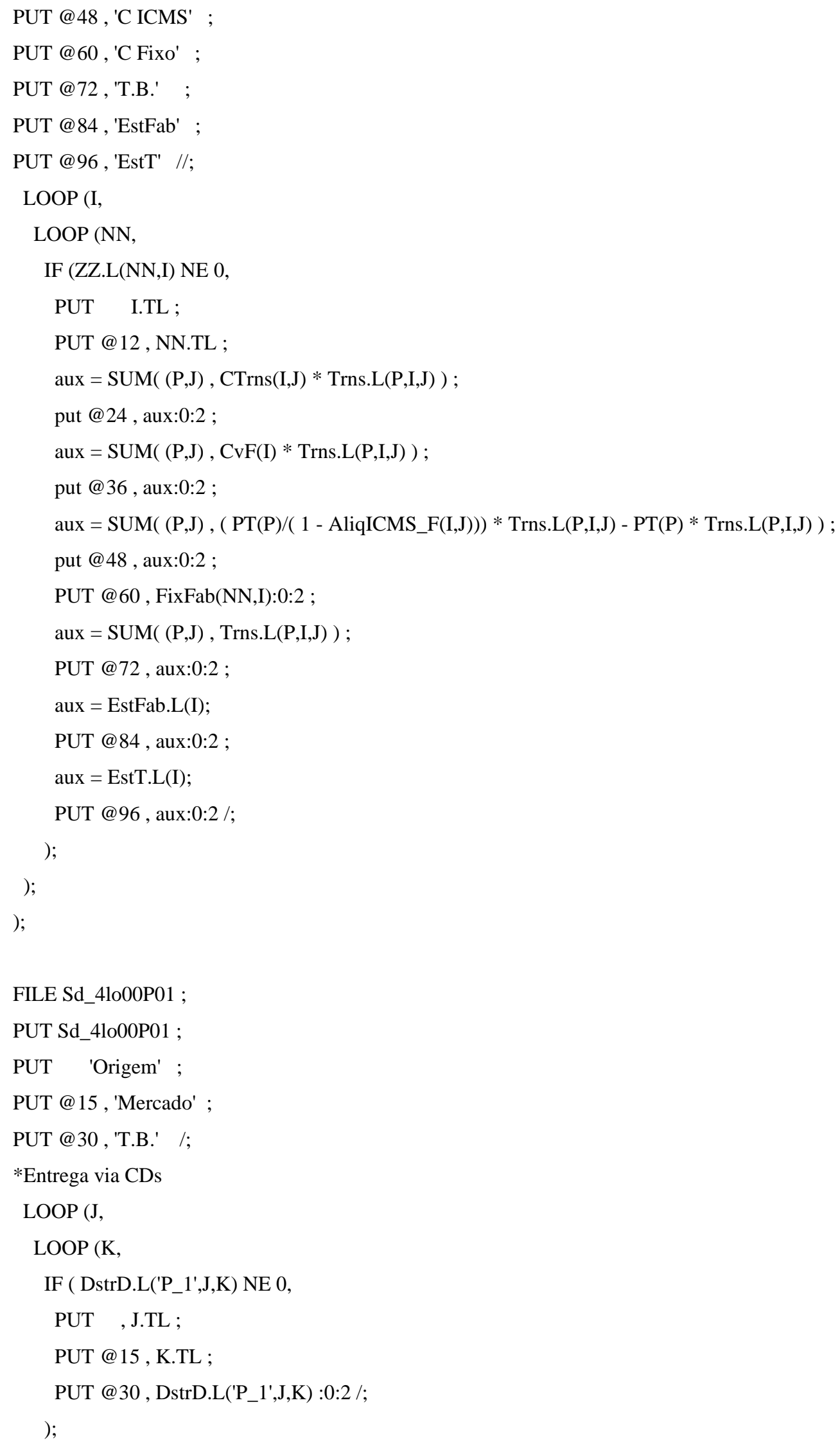




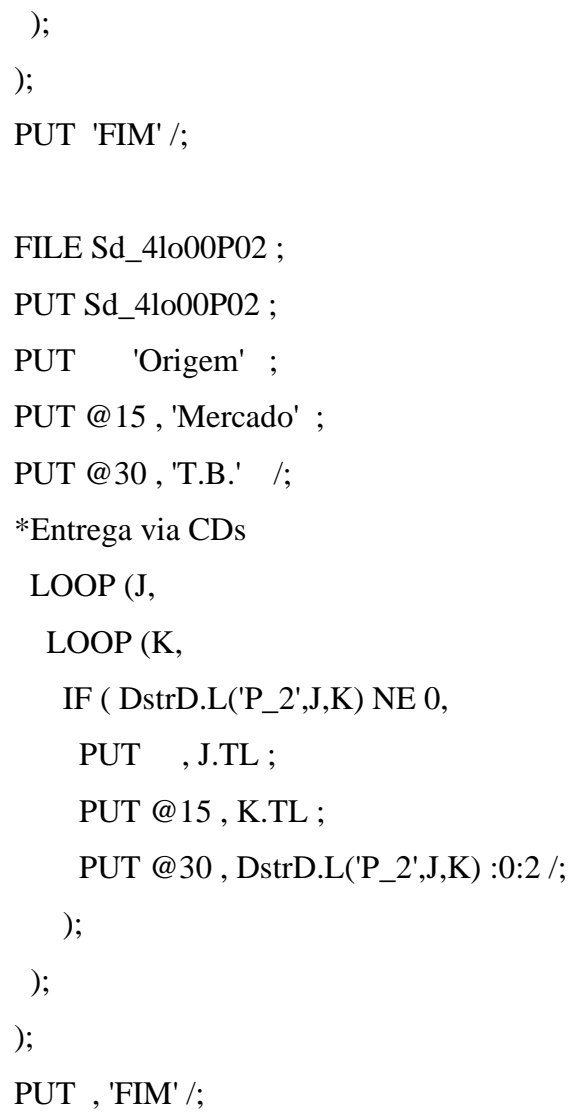




\section{GLOSSÁRIO}

$\begin{array}{lll}\text { CD } & \ldots & \text { Centro de Distribuição } \\ \text { CE } & \ldots & \text { Comércio de Emissões } \\ \text { CCX } & \ldots & \text { Bolsa do Clima de Chicago } \\ \mathbf{C O}_{2} \text { e } & \ldots & \text { CO2 Equivalente } \\ \text { CSR } & \ldots & \text { Créditos de Responsabilidade Social } \\ \text { ECX } & \ldots & \text { Bolsa do Clima Européia } \\ \text { EU } & \ldots & \text { União Européia } \\ \text { EU ETS } & \ldots & \text { Emission Trading Scheme (Mercado Europeu de Emissões) } \\ \text { ERU } & \ldots & \text { Emission Reduction Unit (Unidade de Redução de Emissões) } \\ \text { FIPE } & \ldots & \text { Fundação Instituto de Pesquisas Econômicas } \\ \text { GEE } & \ldots & \text { Gases do Efeito Estufa } \\ \text { IBGE } & \ldots & \text { Instituto Brasileiro de Geografia e Estatística } \\ \text { HFC } & \ldots & \text { Hidrofluorocarbonetos } \\ \text { IC } & \ldots & \text { Implementação Conjunta } \\ \text { ICMS } & \ldots & \text { Imposto sobre Circulação de Materiais e Serviços } \\ \text { IETA } & \ldots & \text { Associação Comercial Internacional das Emissões } \\ \text { IPCC } & \ldots & \text { Intergovernmental Panel on Climate Change - Painel } \\ & & \text { Intergovernamental sobre Mudança Climática } \\ \text { MceX } & \ldots & \text { Bolsa do Clima de Montreal } \\ \text { MDL } & \ldots & \text { Mecanismo de Desenvolvimento Limpo } \\ \text { RCE } & \ldots & \text { Reduçães Certificadas de Emissão } \\ \text { UNFCCC } & \ldots & \text { United Nations Framework Convention on Climate Change } \\ \text { VER } & \ldots & \text { Voluntary Emission Reductions (redução de emissão voluntária) }\end{array}$




\section{BIBLIOGRAFIA}

AMARAL, G.L. OLENIKE, J.E. A insuportável carga tributária empresarial brasileira. Instituto Brasileiro de Planejamento Tributário - IBPT. Curitiba, 2004.

ARAUJO, Antônio Carlos Porto de. Como comercializar créditos de carbono. São Paulo - Trevisan Editora Universitária, 2006

BALLOU, Ronald H.; tradução Raul Rubenich. Gerenciamento da Cadeia de Suprimentos/Logística Empresarial. 5ํㅡ edição - Porto Alegre: Bookmann, 2006

BRANDEAU, M.L.; CHIU, S.S. An overview of representative problems in location research. Management Science V. 35, no 6, p. 645-674. Junho, 1989.

CAPOOR, K.; AMBROSI, P. State and Trends of the Carbon Market 2008 Washington DC: World Bank, 2008

CENTRO DE GESTÃO E ESTUDOS ESTRATÉGICOS. Manual de Capacitação sobre Mudança do Clima e Projetos de Mecanismo de Desenvolvimento Limpo (MDL) - 1ª edição - Brasília, DF, 2008

CENTRO DE ESTUDOS LOGÍSTICOS (CEL) - COPPEAD. Panorama Logístico: Custos Logísticos do Brasil 2006-2008. Rio de Janeiro, 2008

CHICAGO CLIMATE EXCHANGE, CCX® MARKET REPORT, V. 5, Número 7, Julho 2008 Disponível em <http://www.chicagoclimatex.com/content.jsf?id=245> Acesso em 17/08/2008.

CHOPRA, Sunil; MEINDL, Peter Gere; tradução Cláudia Freie. Gerenciamento da Cadeia de Suprimentos - São Paulo: Prentice Hall, 2003, p. 3 - 64, 263 - 338

CONSELHO EMPRESARIAL BRASILEIRO PARA O DESENVOLVIMENTO SUSTENTÁVEL (CEBDS). Empresas terão como medir gases de efeito estufa -Energia e Mudança do Clima, 02/05/2008 Disponível em: <http://www.cebds.org.br/cebds/noticias.asp?ID=296> Acesso em 25/08/2008

DAVIS, S.; DIEGEL, S.; BOUNDY, R. Transportation Energy Data Book Washington, DC: U.S. Department of Energy, 2008, $27^{\mathrm{a}}$ edição, capítulo 11

EUROPEAN COMMISSION. EU emissions trading: an open system promoting global innovation - Bélgica, 2007

GODOY, G.K.; YOSHIZAKI, H.T.Y. Estudo comparativo de softwares de Programação matemática para uso didático. In: ENCONTRO NACIONAL DE ENGENHARIA DE PRODUÇÂO - XV ENEGEP, 15. São Carlos, 1995. Anais. São Carlos: UFSCar, 1995.

HAMAD, R. Modelo para localização de instalações em escala global envolvendo vários elos da cadeia logística, Dissertação (Mestrado), Escola Politécnica da USP, São Paulo, 2006. 
HINO, C.M. Desenvolvimento de métodos para elaboração de modelos heurísticos de designação e seqüenciamento de planos de estivagem de navios porta-conteineres. Dissertação (Mestrado), Depto. De Engenharia Naval, EPUUSP, 1999.

JONES, C. Supply Chain management: the key issues, BPICS Control, Oct. No. 1989

KLOSE, A; DREXL, A. Facility location models for distribution system design. European Journal of Operational Research, 2005 V.162, p.4-29.

LAPORTE, Gilbert; CRAINIC, Teodor G. Planning models for freight transportation. Artigo periódico. European Journal of Operational Research, 1997, V. 97 p. 409-438.

LECOCQ, F.; CAPOOR, K. State and Trends of the Carbon Market 2003Washington DC: World Bank, 2003

LECOCQ, F.; CAPOOR, K. State and Trends of the Carbon Market 2004 Washington DC: World Bank, 2004

LIMA, Mauricio Pimenta. Custos logísticos na economia brasileira. Artigo de periódico. Revista Tecnologística, 2006, V.1

LOVE, R.F.; J.G. MORRIS; G.O. WESOLOWSKY. Facilities location: models \& methods. New York: North-Holland, 1988.

MAGNOLI, Demetrio et al. História da paz. $1^{\text {a }}$ ed. - São Paulo: Contexto, 2008.

MARTOS, Antônio Carlos. Projeto de redes logísticas com consideração de estoques e modais: aplicação de programação linear inteira mista à indústria petroquímica. 2000. 98 p. Dissertação (Mestrado) - ESCOLA POLITÉCNICA, Universidade de São Paulo, São Paulo, 2000.

MEIRIM, Hélio. A importância da logística para as empresas brasileiras. Publicação disponível em: <www.guialog.com.br>. V.5 2006 (em agosto de 2008)

MELO, José Eduardo Soares. ICMS: Teoria e Prática. 9a ed. - São Paulo: Dialética, 2006.

NETTO, J.S.M. Guerra fiscal entre os estados. Consultoria Legislativa da câmara dos deputados de Brasília, 2003.

NOVAES, Antônio Galvão. Logística e Gerenciamento da Cadeia de Distribuição. 3a edição - Rio de Janeiro: Elsevier, 2004 p. 31-58; 189-210.

NOVAES, Antônio Galvão. Sistemas Logísticos: Transportes, Armazenagem e Distribuição Física de Produtos. Ed. Edgard Blücher Ltda. São Paulo, 1989.

OWEN, S. H. DASKIN; M. S. Strategic facility location: A review. Artigo de periódico. European Journal of Operational Research, 1998, V. 111 p. 423-447. 
PANTALENA, B.G. Otimização da malha logística de uma indústria química. Trabalho de Formatura (Graduação) - Escola Politécnica, Universidade de São Paulo. São Paulo, 2004.

RIBEIRO, N.V. Contribuição ao aperfeiçoamento de sistemas logísticos de distribuição no contexto tributário brasileiro : estudo de caso em indústria de bens de consumo. Dissertação (Mestrado) - Faculdade de Economia, Administração e Contabilidade, Universidade de São Paulo. São Paulo, 1999.

ROCHA, Pedro C.; Mello, Marcelo T. A utilização de MDL e as oportunidades na área de comercialização de créditos de carbono em TEIXEIRA, Antônio Carlos et al. A Questão Ambiental Desenvolvimento e Sustentabilidade Fundação Escola Nacional de Seguros, Rio de Janeiro: FUNENSEG, 2004 cap. 6

SENSUS para CNT - Confederação Nacional dos Transportes - O Perfil SócioEconômico e as Aspirações dos Caminhoneiros no País. - Minas Gerais: SEST / SENAT, 1999.

SHAPIRO, J.F. Modeling the supply chain. Pacific Grove: Duxbury, 2001 p.2-28

SILVA, Mariana Bergmann da. Otimização de redes de distribuição física considerando incentivo fiscal baseado no crédito presumido de ICMS. 2007. 107 p. Dissertação (Mestrado), Escola Politécnica, Universidade de São Paulo, São Paulo, 2007.

SLACK, Nigel; STUART, Chambers; HARLAND, Christine; HARISSON, Alan; JOHNSTON, Robert. Administração da Produção. 1aㅡ ed. - São Paulo: Atlas, 1996.

UNITED NATIONS FRAMEWORK CONVENTION ON CLIMATE CHANGE UNFCCC- Convenção sobre Mudança do Clima. $2^{\mathrm{a}}$ ed. - Brasília: MCT, 2001a

UNITED NATIONS FRAMEWORK CONVENTION ON CLIMATE CHANGE UNFCCC- Protocolo de Quioto. 2a edição - Brasília: MCT, 2001b

UNITED STATES ENVIRONMENTAL PROTECTION AGENCY (EPA - OFFICE OF TRANSPORTATION AND AIR QUALITY). Calculating Emissions of Greenhouse Gases: Key Facts and Figures - 2005 Disponível em $<$ www.epa.gov/otaq/greenhousegases.htm> Acesso em 15/08/2008

VALLIM Filho A.R.A (2004), Localização de Centros de Transporte e Carga Uma Contribuição para modelos de otimização, Tese (Doutorado), Escola Politécnica da USP, São Paulo

YOSHIZAKI, H.T.Y. Projeto de redes de distribuição física considerando a influência do imposto de circulação de mercadorias e serviços. 144P. Tese (Livre Docência), Escola Politécnica, Universidade de São Paulo. São Paulo, 2002. 


\section{SITES CONSULTADOS NA INTERNET:}

ICMS - Disponível em <http://www.portaltributario.com.br/tributos/icms.html> Acesso em 05/08/08.

Tabela de Incidência de ICMS sobre o Preço Final ao Consumidor Disponível em <http://www.deltatranslator.com/taxes.htm> Acesso em 05/08/08.

Acompanhamento diário das cotações de créditos de carbono CFI Disponível em <http://www.chicagoclimatex.com/market/data/summary.jsf> Acesso em 25/01/09.

Ferramenta de cálculo de emissões de carbono para o setor de transportes: $\mathrm{CO}_{2}$ emissions from transport or mobile sources Disponível em <http://www.ghgprotocol.org/calculation-tools/all-tools> Acesso em 12/08/08. 